\title{
UTILIZATION OF DESIGN ELEMENTS OF PERSONALIZED CANCER RISK ASSESSMENTS TO ENHANCE PATIENT UNDERSTANDING AND SELF- EFFICACY
}

\author{
A Thesis \\ Presented to \\ the faculty of the School of Engineering and Applied Science \\ University of Virginia
}

\begin{abstract}
In Partial Fulfillment
of the requirements for the Degree

Master of Science in Systems Engineering

by
\end{abstract}

Jennifer E. Prey

August 2012 


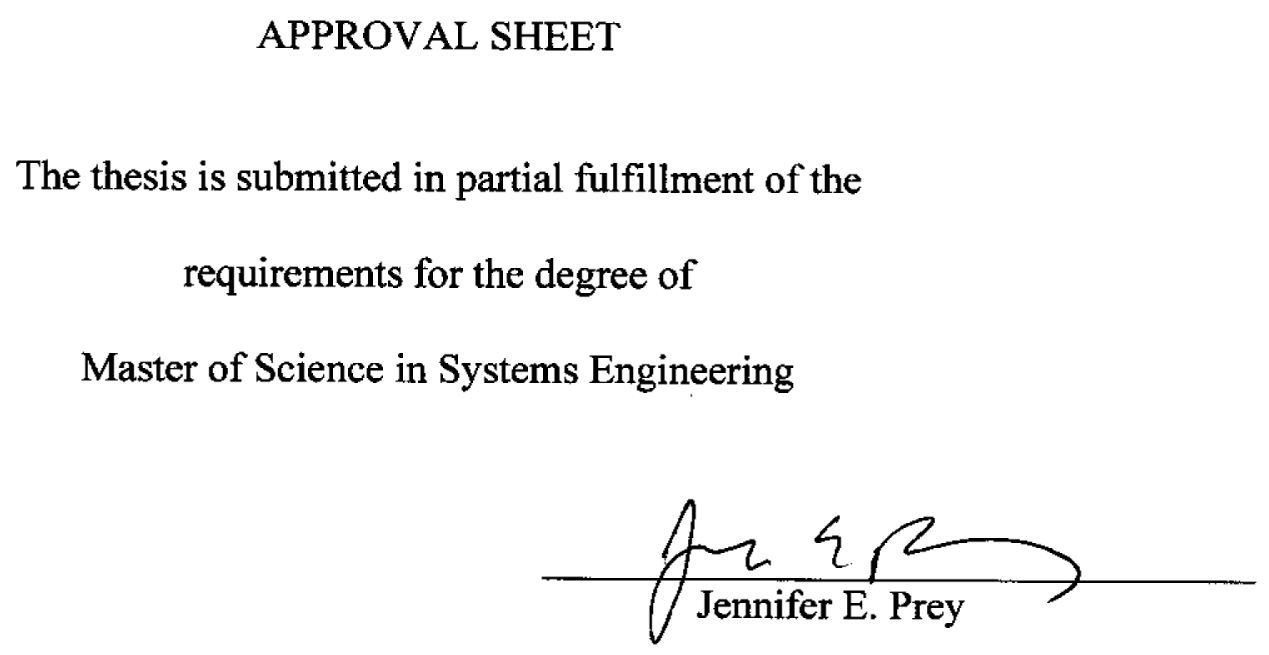

The thesis has been read and approved by the examining Committee:

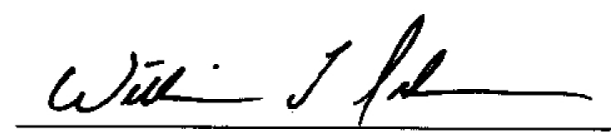

William T. Scherer - Thesis Advisor

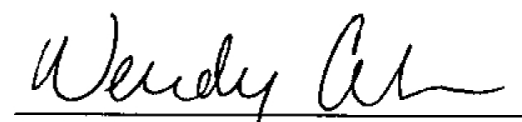

Wendy F. Cohn - Thesis Advisor

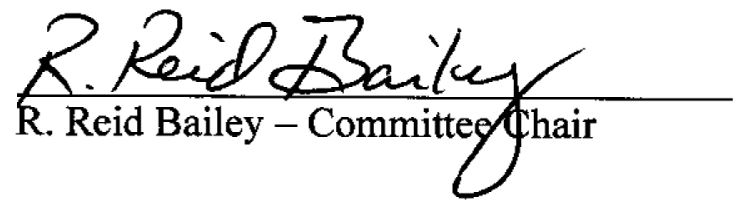

Accepted for the School of Engineering and Applied Science:

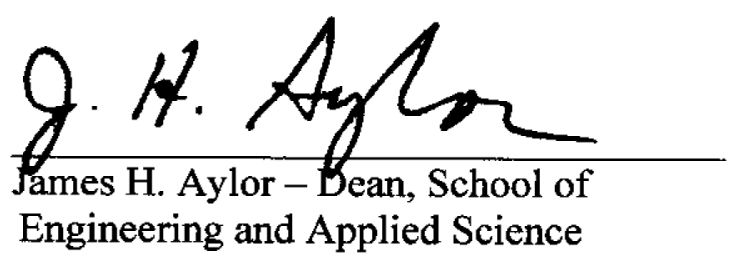

August 2012 


\section{Abstract}

The current healthcare environment is ripe with the development of new technological resources like electronic medical records and family health history tools. Additionally, further research has been conducted in to how genetic composition and prior health history can affect patient health risk. With the combination of new tools and genetic knowledge, there is now the ability to determine whether individuals are at risk for certain diseases and types of cancer. Determining how to best communicate this type of health risk information to people is a complicated task. General public literacy is low complicating communication. Additionally, with health information there is the further impediment of often complex and unfamiliar medical terms and operations, and different levels of success with each type of treatment making it difficult to know which actions are best in each situation. The utilization of a personalized risk report will be beneficial only if a person is able to understand what is being presented and feel confident that s/he can and should take the actions as recommended. This study investigated how varying design aspects of a risk report from a cancer risk assessment program, Health Heritage, impact the perceived levels of understanding and confidence in taking the recommended actions (self-efficacy) of patients. Three specific design attributes were chosen to study: the inclusion of a summary, use of icons to depict recommended activities, and the inclusion of icons depicting the process steps to complete the recommended activities. Results of this study demonstrate that patients prefer to receive information in both textual and graphical forms, and that the inclusion of action-oriented steps to perform a recommendation increased perceived understanding and the likelihood of the individual intending to complete the act. 


\section{Acknowledgement}

The research described was supported in part by Grant Number T15LM 009462 from the National Library of M edicine. The content is solely the responsibility of the authors and does not necessarily represent the official views of the National Library of M edicine or the National Institutes of Health. 


\section{Table of Contents}

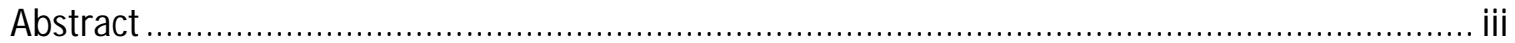

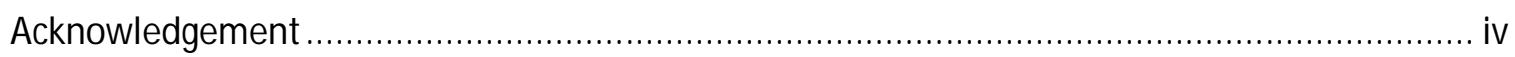

List of Figures...................................................................................................

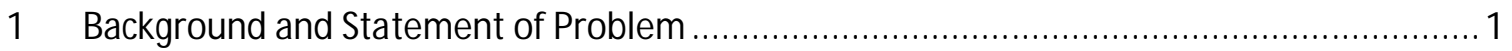

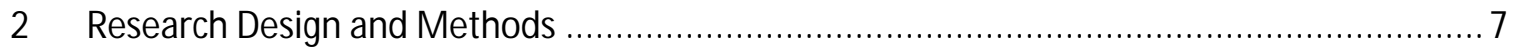

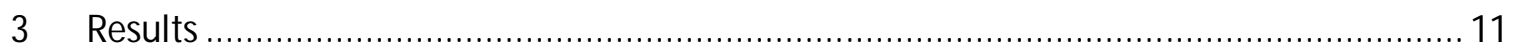

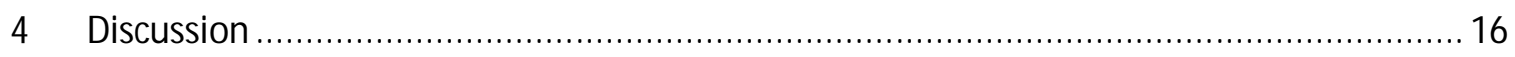

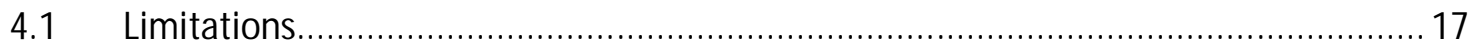

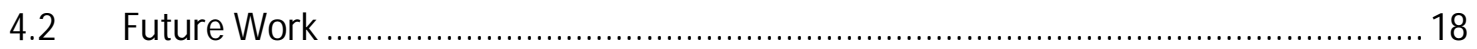

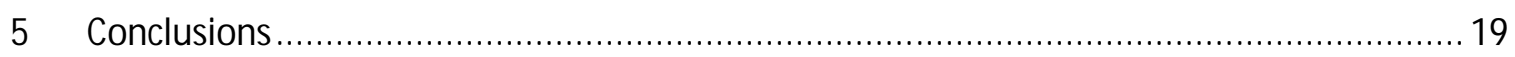

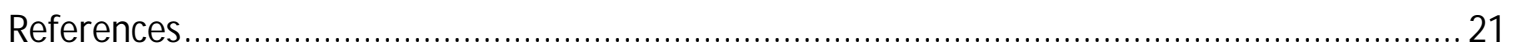

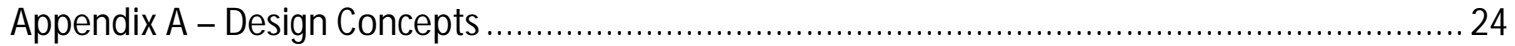

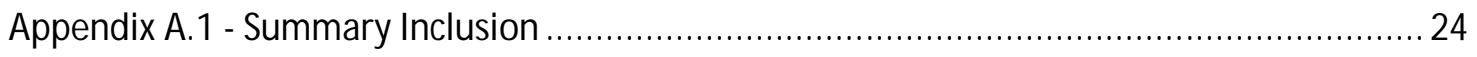

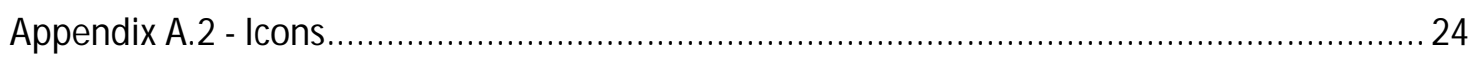

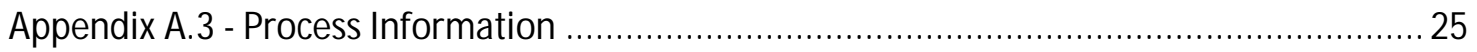

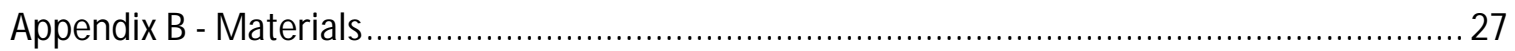

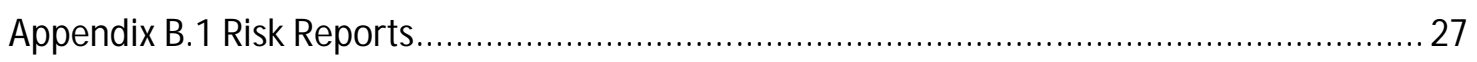

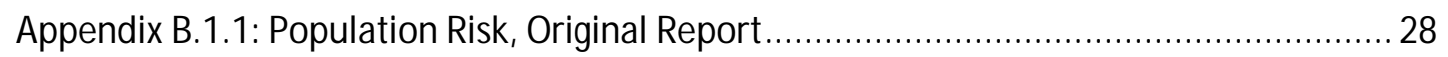

Appendix B.1.2: Population Risk, Text Summary ........................................................ 32

Appendix B.1.3: Population Risk, Text Summary with Activity Icons.................................. 33

Appendix B.1.4: Population Risk, Text Summary with Process Icons................................... 34

Appendix B.1.5: Moderate Risk, Original Report ............................................................ 35

Appendix B.1.6: M oderate Risk, Text Summary ………............................................... 39

Appendix B.1.7: M oderate Risk, Text Summary with Activity Icons .................................... 40

Appendix B.1.8: Moderate Risk, Text Summary with Process Icons ................................... 41

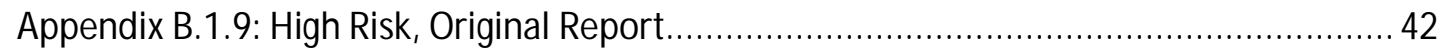

Appendix B.1.10: High Risk, Text Summary ............................................................... 47

Appendix B.1.11: High Risk, Text Summary with Activity Icons....................................... 48

Appendix B.1.12: High Risk, Text Summary with Process Icons........................................ 49 


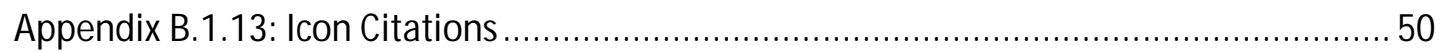

Appendix B.1.13 Procedure Recommendations by Risk Level....................................... 50

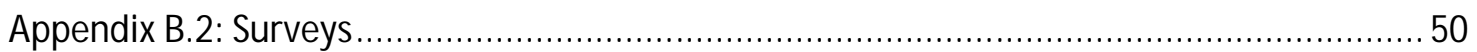

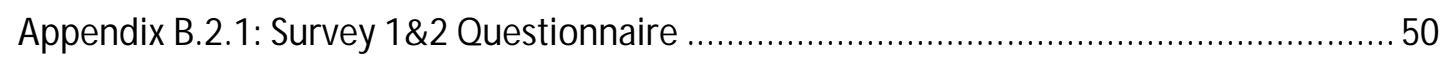

Appendix B.2.2: Survey 3 Questionnaire .................................................................... 51

Appendix B.2.3: Survey 4 Questionnaire .................................................................. 52

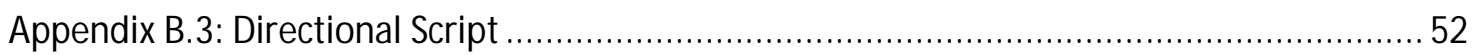

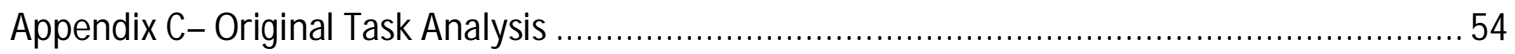

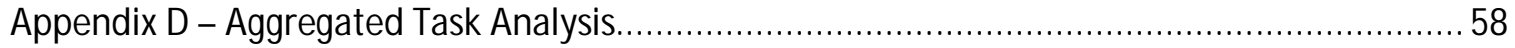

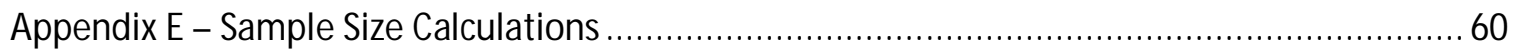

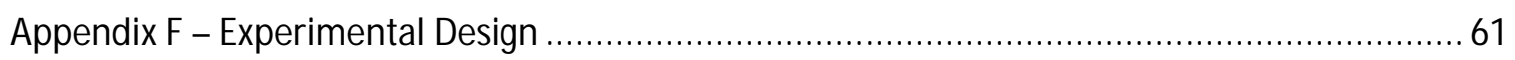

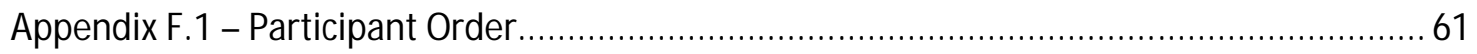

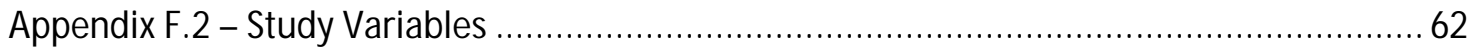

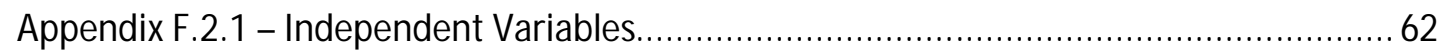

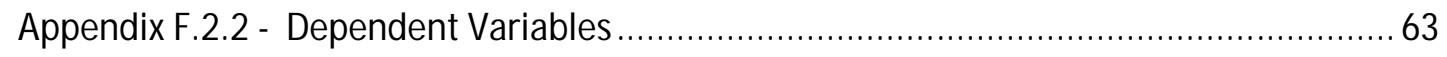

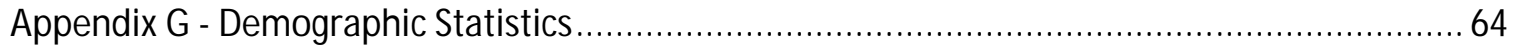

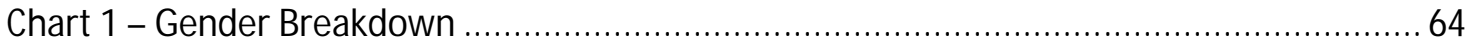

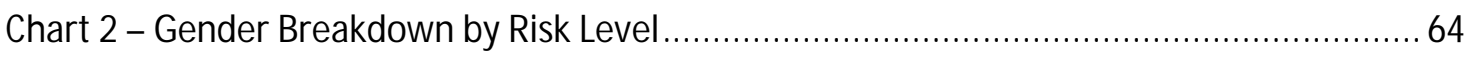

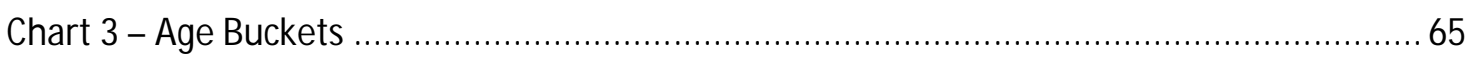

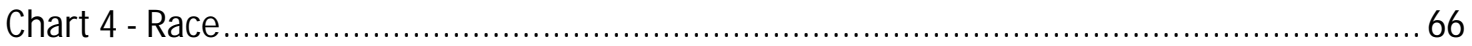

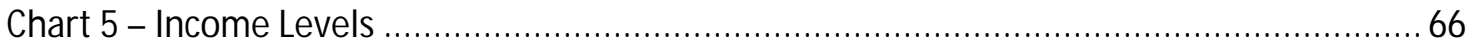

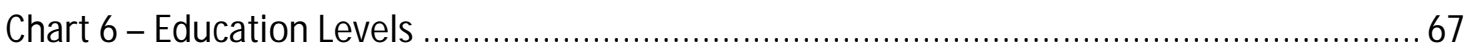

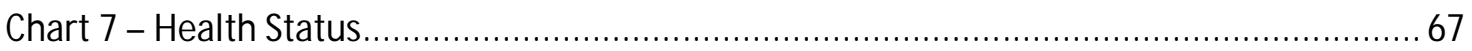

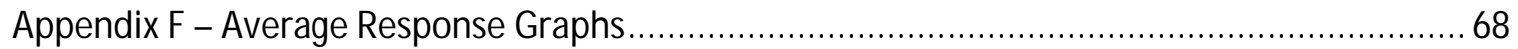

Appendix F.1 - Average Response per Procedure by Summary Type ……......................... 68

Appendix F.2 - Average Response per Question by Order Type........................................... 68

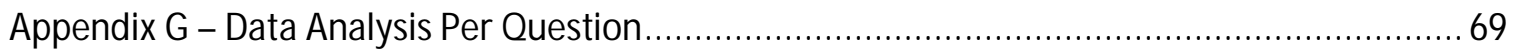

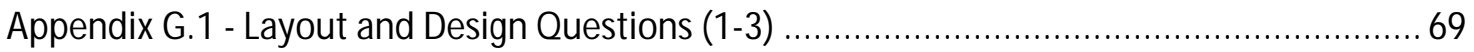

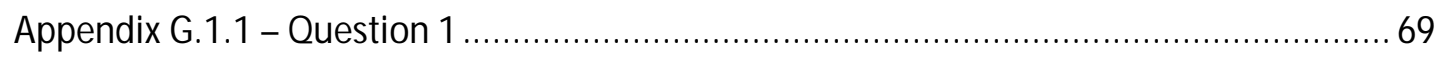

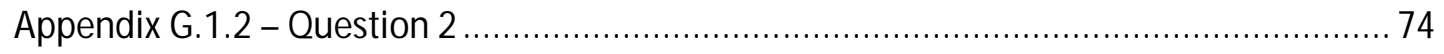

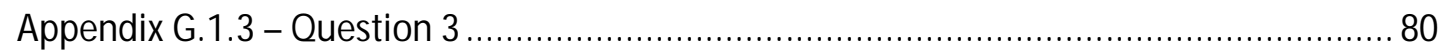

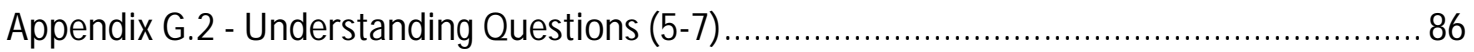




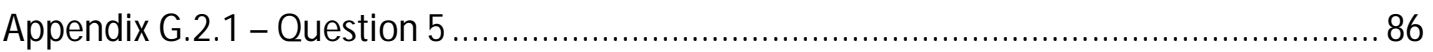

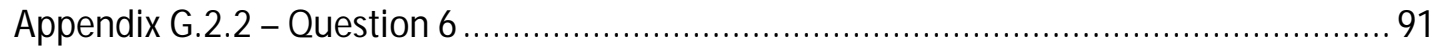

Appendix G.2.3 -Understanding Procedure ......................................................... 95

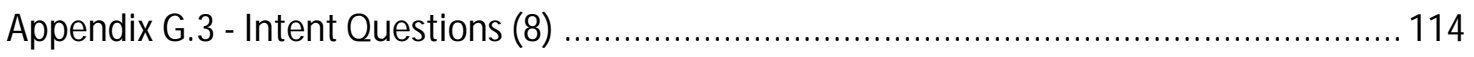

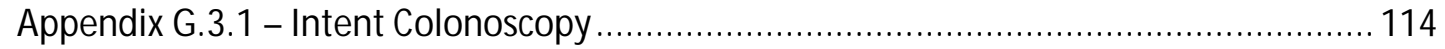

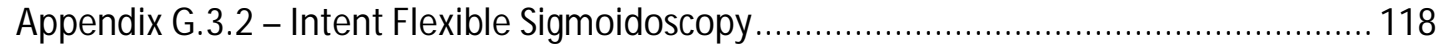

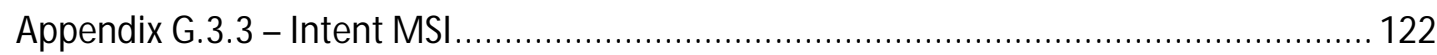

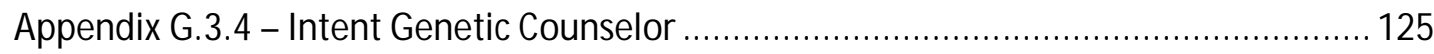

Appendix G.3.5 - Intent Upper Endoscopy ………………........................................ 129

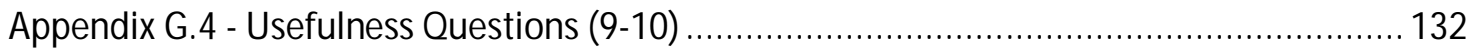

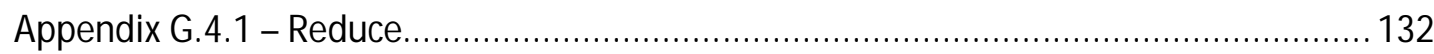

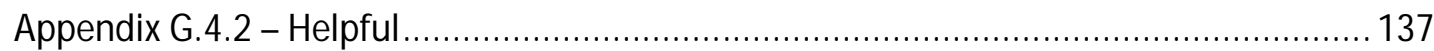

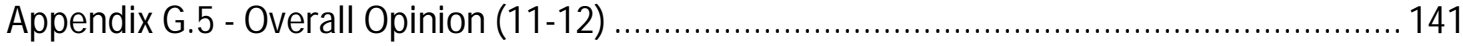

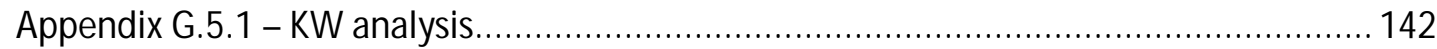

Appendix G.5.2 - Friedman Test........................................................................... 143 


\section{List of Figures}

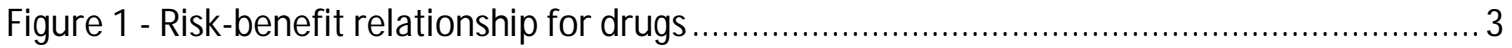

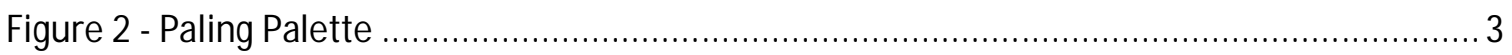

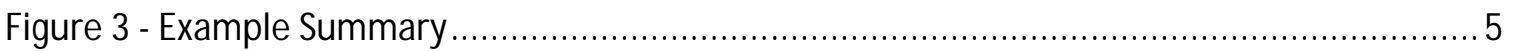

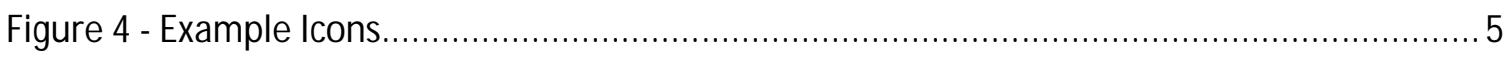

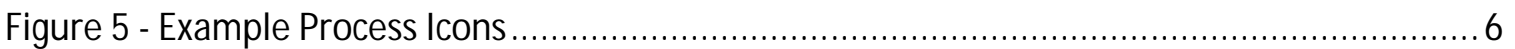

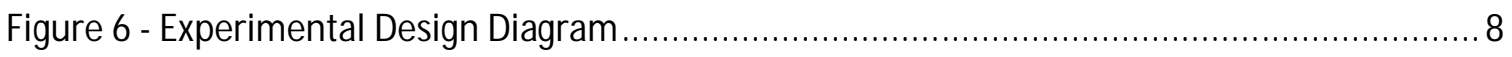

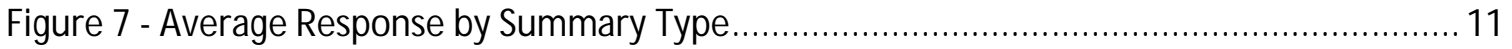

Figure 8 - Confidence Interval by Summary Type ......................................................... 12

Figure 9 - Average Response by Summary Type by Recommendation.................................. 13

Figure 10 - Average Response by Risk Level ........................................................ 13

Figure 11 - Interaction Analysis, Question 1........................................................ 15 


\section{Background and Statement of Problem}

In today's increasingly data-driven health care environment there is an "increased burden on patients to understand health-related information to make fully informed choices about their medical care" [1]. The development of new health information technologies provide the ability to generate patient-specific health risk reports based on personal and family health histories. The reports provide recommendations for the actions (i.e. specific tests or procedures)

that particular patient should take to mitigate a health condition for which they are at risk. It has been shown that "recipients of health communication messages have begun to adopt healthier lifestyles and engage in routine preventative screenings."[2] The information in these reports needs to be clearly communicated to patients to ensure full comprehension and to encourage the highest levels of self-efficacy in carrying out the recommendations. If patients receive effective health communication, they can feel empowered to "make informed health-related decisions and to engage in behaviors that can improve their health." [2]

Self-efficacy is defined as the confidence in one's ability to perform goal-directed behaviors [3]. Self-efficacy is important as "outcome and efficacy expectations are differentiated, because individuals can believe that a particular course of action will produce certain outcomes, but if they entertain serious doubts about whether they can perform the necessary activities such information does not influence their behavior"[4]. This notion of selfefficacy is especially important in the healthcare realm because "people's self-efficacy beliefs influence the health-related choices they make... for most health conditions, the greater the patients' self-efficacy beliefs, the better their health outcomes"[5]. It has been shown in various studies that self-efficacy levels are related to behavior and control of disease (e.g. diabetes 
control)[5]. Thus, it is important that the way information is conveyed within health risk reports be done in a manner which encourages high self-efficacy.

Studies have found that health prevention behaviors are largely related to patient "perceived susceptibility and seriousness of a health threat (personal risk), benefits and barriers to action... adequacy of information available to cue action, and self-efficacy." [6] The way information is formatted can greatly affect patient reaction and understanding. A format which is difficult to interpret can lead to misunderstanding and can result in inappropriate actions [7]. The structure of the health risk communication materials should be organized to support a range of patients and clearly convey data and recommendations. Health information is particularly difficult to clearly communicate because of multiple barriers. Patients are a heterogeneous group of individuals with diverse needs, preferences and behaviors. This means it has "become a prime importance to develop Information and Communication Technology (ICT) based tools that can provide tailored information... in order to support the consumer's capacity to understand health-related web-based resources"[8]. In health care, the "right" treatment often depends on patient preference, a concept known as "preference sensitive decisions". Therefore it is even more important that there is clear understanding of the tradeoffs and benefits/risks of certain procedures and actions [9]. Also contributing to communication challenges are low levels of literacy, specifically numerical literacy (a.k.a. numeracy). National surveys show that around half of the population in the United States has only very basic or below basic quantitative skills [10]. This low level of numeracy means that communicating risk using numerical values may result in confusion and incorrect understanding of the information. Other barriers to health communication include issues such as fear and optimistic bias. Fear "itself is a risk and must be part of risk-management policy making"[11], it can have both "facilitating (e.g., motivate appropriate self-protective responses) and interfering 
(e.g., avoidance) effects."[12] Optimistic bias is when people believe they are less likely to be affected than their peers. Optimistic bias may "seriously hinder efforts to promote risk-reducing behaviors." [13] Additionally, high perceived risk and low perceived benefit make it often make it difficult for patients to determine which actions are most appropriate. Figure 1[14] shows the risk-benefit curve for pharmaceutical drug use; the non-linearity of the curve indicates that risk

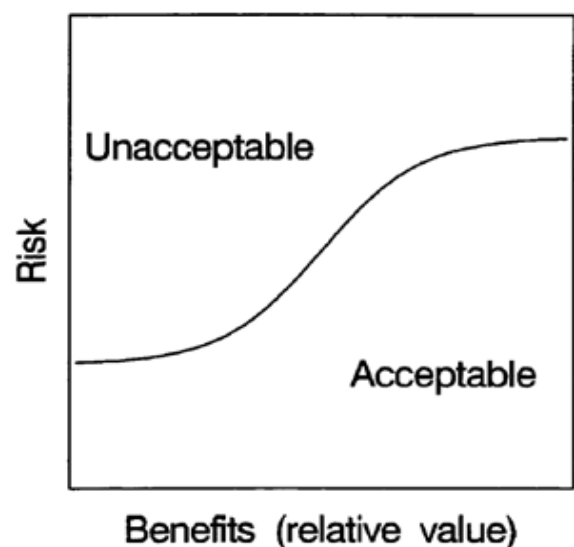

Figure 1 - Risk-benefit relationship for drugs

must be very low or benefit very high for patients to adopt use. To combat health

communication confusion, strategies such as avoiding using descriptive terms only (and including estimated numbers), using standardized vocabulary, consistent denominators and visual aids (such as a Paling Palette, see Figure 2) are encouraged [15]. The Paling Palette was

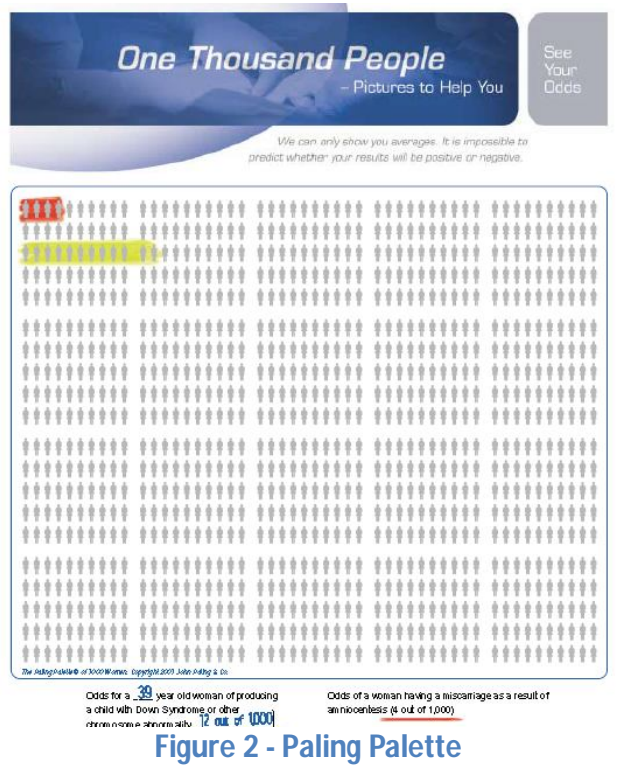


developed to address numeracy issues. It is often used to display medical risks which have a probability of less than 1 in 1000. It uses a graphical image of 1000 individuals and then colors are used to highlight the particular patient's risk. This type of visualization is shown to help patients be more informed and understand their risk more clearly.

At the University of Virginia (UVa), a web-based system, Health Heritage, provides personalized cancer risk assessments based on users' personal and familial health histories. Health Heritage was developed to help identify individuals who are "at risk for specific diseases and for identifying patterns of diseases and other health conditions in families" [16]. Health Heritage generates a cancer risk report for each patient based on the information s/ he enters. The personalized report generated by Health Heritage contains information explaining the potential cancer(s) the patient is at risk for (when appropriate), the patient's risk level (Population, Moderate or High) and what that entails, why the patient is at that particular risk level, and what the patient can do about his/her particular risk level to best mitigate future risk. Additional guidance is provided as to where the patient can find further information. The risk report was developed using a conceptual model of all the factors that might impact communication and understanding of the Health Heritage recommendations. Because of the detail and explanation involved in the risk report, it can be many pages long and potentially overwhelming for users. For this reason, it was chosen to be employed in a human-subjects experiment to help determine how specific design aspects of the health risk report itself can affect patient understanding and self-efficacy. The "optimal methods and outcomes of communicating individualized disease risk information have yet to be defined" [17]. This study focused on the graphic design (use of icons) and content (inclusion of a summary) used to communicate the user's risk and recommendations. In order to optimize the design of the risk assessments in Health Heritage this study researched what methods have been successful in the 
design of risk communication generally, and applied these concepts to health risk communication. This study focused on three different design aspects: the incorporation of a summary of the information within the report (Figure 3), the inclusion of icons that represent the recommendations within the report (Figure 4), and the inclusion of process icons which depict the specific steps the patient should take to complete the risk-mitigating actions (Figure

\section{YOUR RISK REPORT SUMMARY}

Risk Level: Population

Why: Did not report any risk factors that would raise your risk above people similar to you in the general population.

Actions:

Screening

- Regularly Scheduled Colonoscopy

- Regularly Scheduled Flexible Sigmoidoscopy

Figure 3 - Example Summary

5). Each of these design decisions have been shown to be effective in other general (non-health-

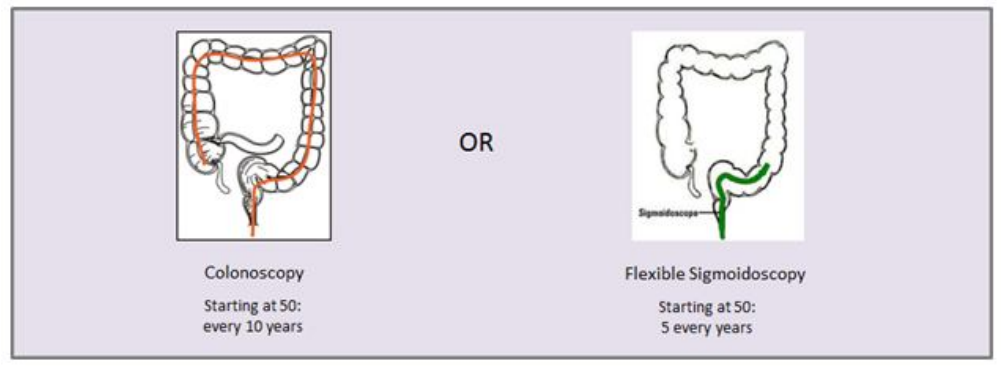

Figure 4 - Example Icons

related) types of risk communication (e.g. consumer products), further discussion of the support for these design aspects can be found in Appendix A. 


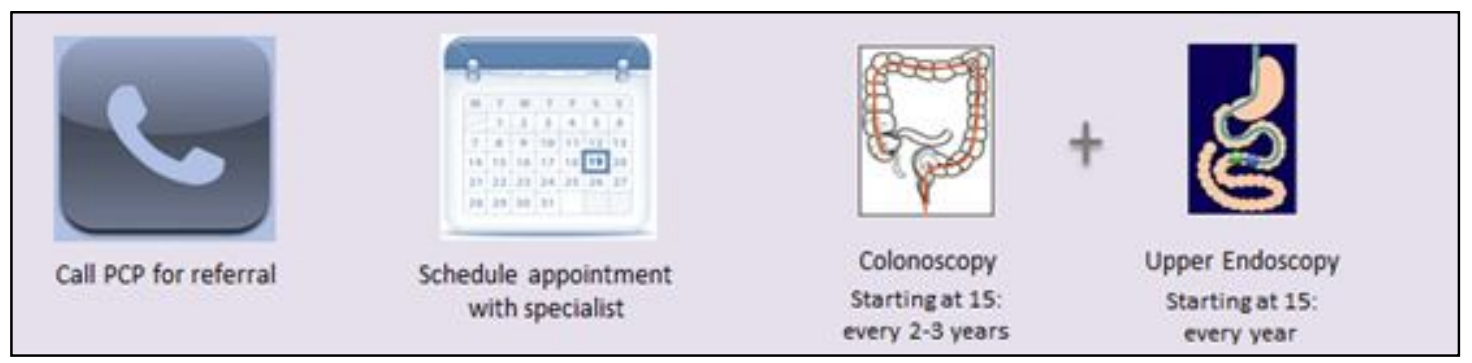

Figure 5 - Example Process Icons

For the purposes of this study, only cancer risk reports for colorectal cancer (CRC) were used. CRC was chosen as it is the third most prevalent cancer among both male and female adults in the United States and is the second leading cause of cancer deaths nationally. [6] Additionally, CRC-related knowledge levels are low and "misperceptions are common. Provider practices reinforce low levels of perceived risk [and] multiple barriers to screening exist, many of which are remediable." [6] CRC was also a good candidate for this study as there are many proven screening techniques which can be recommended for early detection of disease.

The primary aim of this study was to test whether participants responded differently to varying design aspects of a risk report, namely the inclusion of a summary, use of icons, and inclusion of action-orientated information. Responses were gathered in regard to four categories: layout and design, understanding, intent, and usefulness. The hypothesis was that the summary page type with a text summary and action-oriented icon steps (Summary Type C) would result in the highest levels of preference for design, highest understanding, highest intent to complete actions, and to be the most useful. This was expected as each summary page type builds on the version prior; Summary Type A is a text summary only, Summary Type B is a text summary and icons of the recommendations, Summary Type $\mathrm{C}$ is a text summary with actionoriented icons of process information. As each of these design aspects (inclusion of a summary, 
usage of graphics, and inclusion of process information) has been proven useful in other fields, it was hypothesized that the usage of all three would result in the most-preferred design choice.

\section{Research Design and Methods}

To investigate the effectiveness of the three different design elements on the Risk Report, a randomized complete block design (RCBD) experiment was conducted. Participants were randomly assigned to one of the three levels of risk (Population, M oderate, High) and shown three risk report summary pages types (Text Overview only - Summary Type A, Text Overview and Graphic Activity Icons - Summary Type B, Text Overview and Process Icons Summary Type C) and a full risk report, all at the same risk level. The Risk Reports (and their corresponding summary page types) were created prior to the study and were not based on an actual participant's personal health history. Each study participant saw the three different summary pages in an assigned randomized order, and then saw the full report (with no summary page) at the end. After each summary page viewing they responded to a set of survey questions regarding that particular summary page type. In the third survey, the participants also answered demographic information questions. The study design was constructed with the full report at the end for all participants to ensure completion of the three surveys concerning the three new summary page types, the completion of the fourth survey on the report as a whole was determined to be a lower priority. M aterials used in the study can be found in Appendix B.

In the development of the three new summary page types, a task analysis was completed to analyze the necessary actions to complete any one of the given recommendations which could be found on a risk report (Appendix C). This was done to identify the potential actions which patients might need to follow in order to complete a recommendation. Once a full 
task analysis was done, recommendations with identical action steps were aggregated into one, simpler, chart (Appendix D). This analysis is helpful for future development of summary pages to account for the various possible recommendations and their required steps from the system.

This study was approved by the University of Virginia's Institutional Review Board (IRB). Subjects for this study were recruited from a general practitioners' office, the University Physicians - Charlottesville, from 8 May 2012 until 16 May 2012 (weekdays only). Adult patients entered the waiting room and were given a sheet of paper containing information on the study from the front desk. The patient and friends or family members accompanying the patient were able to volunteer to participate in the study and were given a choice of snacks as compensation for participating.

In order to collect results which would be statistically significant, a sample size of 36 people was determined to be necessary (Appendix E). This resulted in 12 participants for each of the three levels of risk. Each of the 6 permutations of summary page type orders were shown to two participants per level (Appendix F). A diagram of this experimental design can be seen in Figure 6; note, this diagram does not include the viewing of the full assessment as the fourth item for each participant. Summary Type A contains only text, Summary Type B contains the activity icons as well as the text, and Summary Type $C$ contains the activity icons, text and process icons.

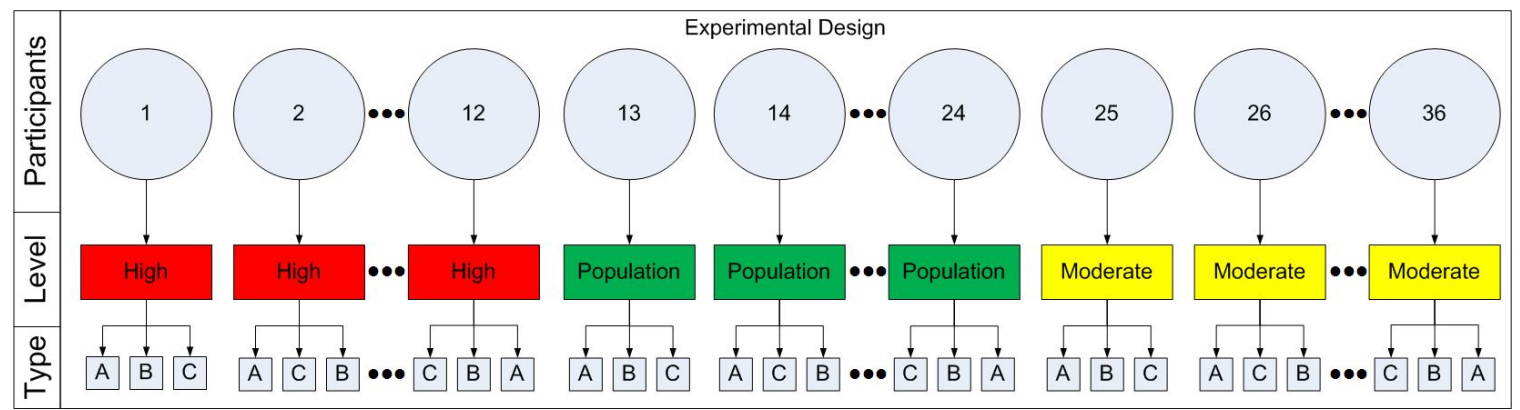

Figure 6 - Experimental Design Diagram 
When collecting the data, there were participants who did not complete all four surveys (due to being called in for an appointment or missing a full page). Participants who did not complete all four surveys had their data excluded from analysis. Additional participants were recruited to make up for those who did not fully finish. In total, 49 people participated, with 36 fully completing all questions. Of the completing participants, there were 21 females and 15 males, ranging in age from 21 to 75 with a median age of 53.5. Further description of the demographic makeup of participants can be found in Appendix G.

For simplification of data analysis, if a specific participant missed only one question, his/her answer was filled in with the value of the overall average for that question from the other participants within the same risk level.

Survey questions varied in structure between Likert-type scales of 1-5 (from strongly disagree to strongly agree), ordinal ranking of preference (e.g. list in order from 1 (most preferred) to 3 (least preferred)), and open-ended response. Additionally, one question was included which was developed using the Questionnaire for User Interface Satisfaction (QUIS) formatting; a rating scale ascending from 1 on the left to 10 on the right with adjectives used as endpoints (e.g. terrible to wonderful)[18] to judge overall reaction to the summary page type.

Four categories of questions were asked in the surveys. "Layout and Design" questions aimed to determine user preference for 'look and feel' of the summary page types. "Understanding" questions were used to determine whether the participant believed the information, recommendations generally, and recommendations specifically (for that risk level) were comprehendible and if the participant thought s/ he would know what to do next. "Intent" questions were used to identify whether the participant would actually follow through on the recommended actions as given in the risk report (if this were his/her actual report). The final 
category of questions, "Usefulness", was used to determine whether the participant thought the recommendations would actually reduce his/her CRC risk and if the participant thought a risk report of this nature would be helpful for his/her individual CRC risk.

Analysis of data for this study was completed using the statistical software tool, M initab 16. For each question in the surveys, an interaction analysis was run to determine whether there were any obvious effects between the survey level, the order in which the participant saw the report and the summary page type (A -text summary only, B- text and graphic icons, $\mathrm{C}$ - text process icons). Additional interaction analysis was completed using demographic data. After investigating interactions, general linear models (GLM) were created using participants as random factors due to the RCBD structure of the experiment. Participants were modeled as being nested within Risk Level and Order Type, and the Order Type was nested within Risk Level. Order Type was coded as to the order in which the summary page types were shown to the participant. There were six Order Types as seen in the experimental design (e.g. ABC, ACB, BAC, etc.). Post-hoc analysis was completed using Tukey tests and evaluated at the alpha $=0.05$ level. Carry-over analysis was completed to analyze the effect of participants viewing more than one report. Carry-over effects are defined as "a manifestation of treatment in subsequent periods of time" and means that "a treatment may persist into a later time period and influence or modify the effect of subsequently applied treatments." [19] Both first-order and second-order carryover effects were analyzed, but with the primary focus on the first-order as "the general view adopted... is that the existence of second-order carryover is much less likely than that of a first over carryover." [19]

As part of the third survey (after seeing all three summary page types), an additional question was asked to have the participants indicate their most preferred to least preferred of 
the summary page types ( 1 was most preferred, 3 was least preferred). A Krustal-Wallis (KW) analysis and a Friedman test analysis was completed on this data. The KW analysis was completed on the data within risk level and on the complete stack of data with all risk levels together.

\section{$3 \quad$ Results}

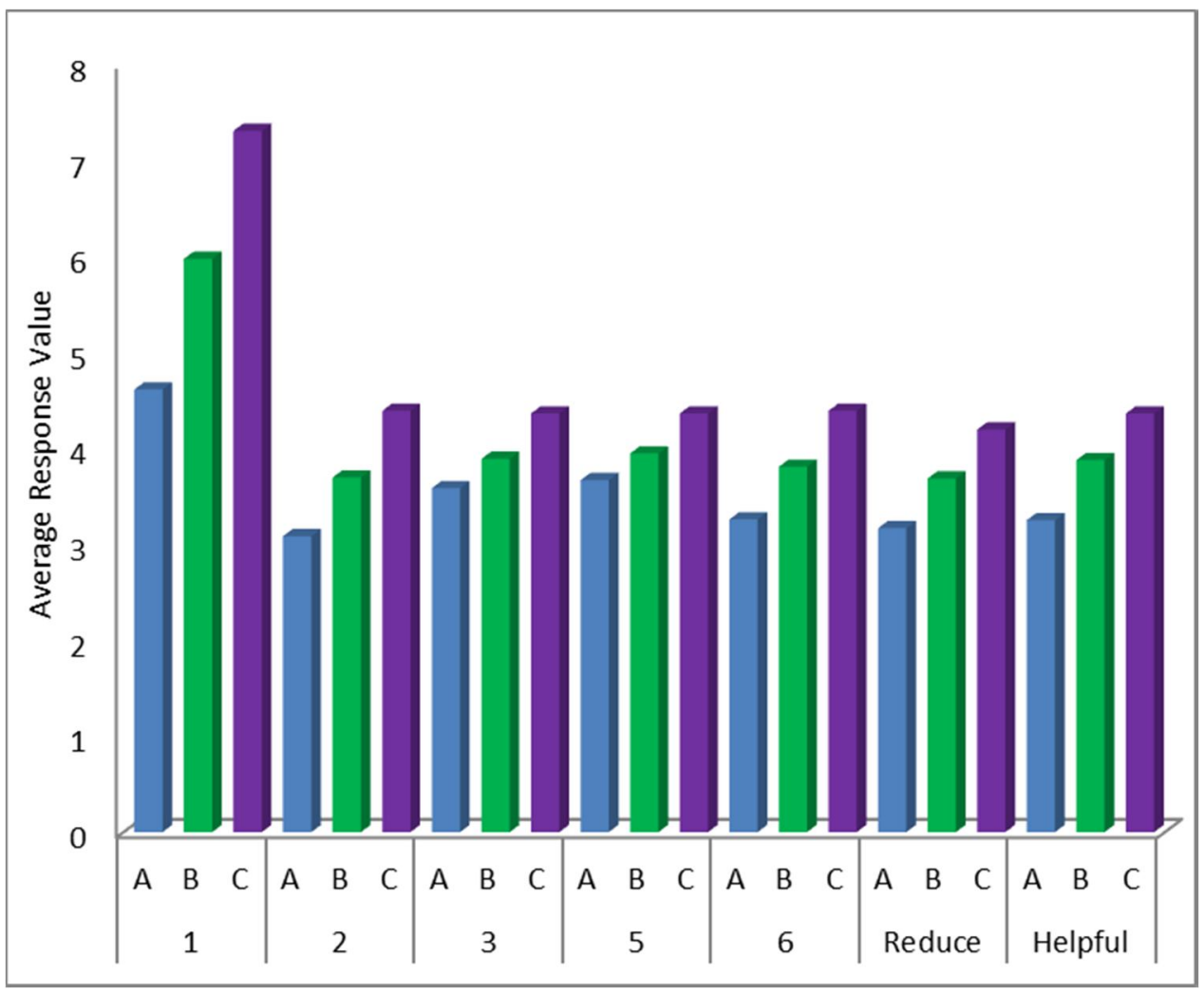

Figure 7 - Average Response by Summary Type 
As can be seen in Figure 7 above, there was a strong trend across the average response values for each question depending on the summary page type. Figure 8 shows the confidence intervals for each question. Summary Type C (text with process information) received a higher

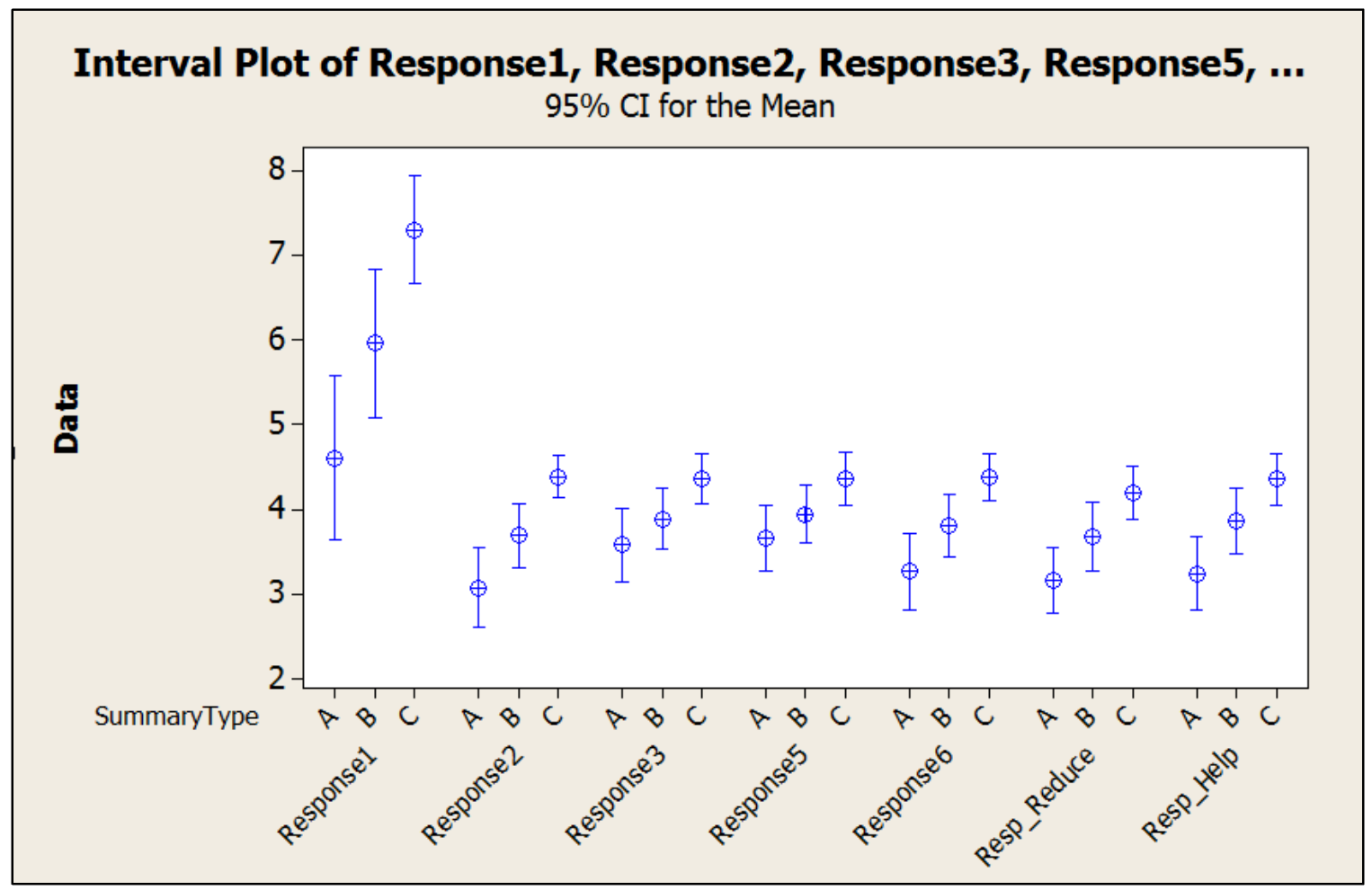

Figure 8 - Confidence Interval by Summary Type

average response value for each question within the survey. Question 1 had a scale of 0 - 9 while all other questions are on a scale of $1-5$. This trend was also found when analyzing the remaining questions on understanding and intent levels of the different possible procedures (Figure 9). Grey bars indicate that the difference between average responses not significant at $P$ $=0.05$ (i.e. understanding for MSI, and intent for genetic counseling and upper endoscopy). This pattern of higher average responses was not found if analyzing across risk levels (Population, M oderate, High) (Figure 10) indicating that regardless of risk level, the average response levels remain the same. 


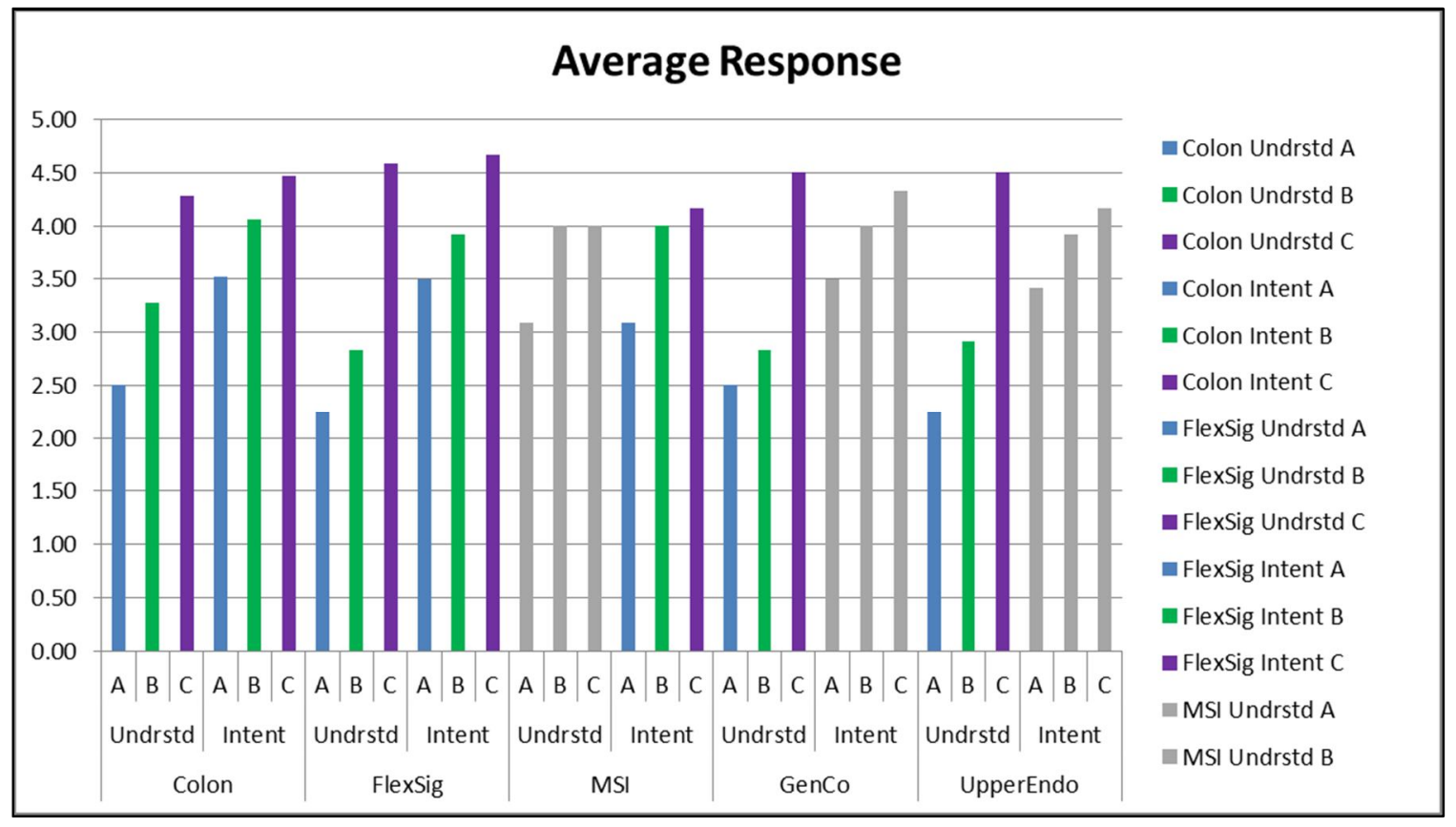

Figure 9 - Average Response by Summary Type by Recommendation

General Linear M odels were created for each of the questions and then analyzed for significance. Table 1 shows the tabulation of all the results of these GLMs. As can be seen from the table, the Summary Type was shown to be significant for all general questions and most procedure understanding and intent levels. Post-hoc analysis using a Tukey test showed that at minimum Summary Type C was significantly higher than Summary Type A. For questions 1, 2,

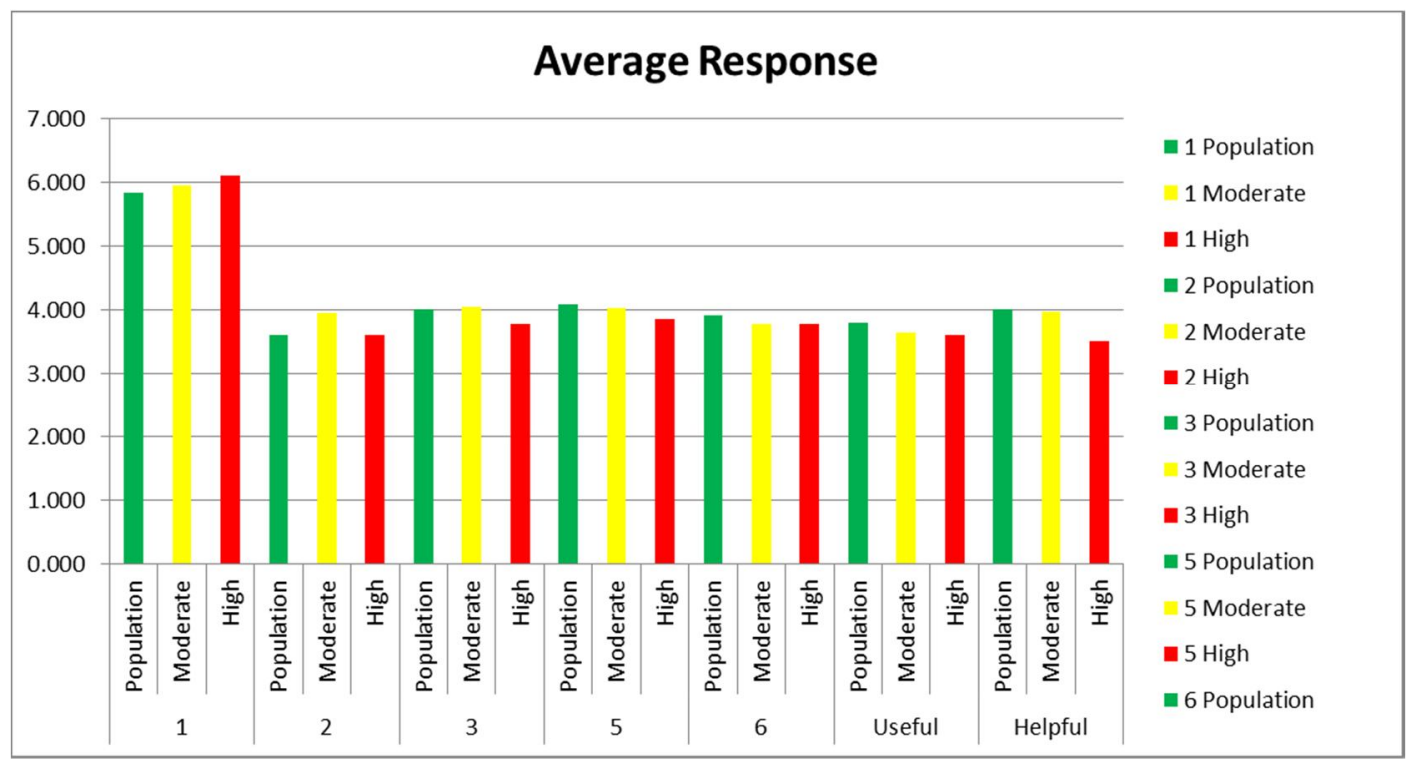

Figure 10 - Average Response by Risk Level 
reduce, and understanding of colonoscopy, there was enough difference to say that Summary Type $A$ was rated lower than both $B$ and $C$, and $C$ was rated higher than $A$ and $B$.

Table 1 - Summary of GLM Results

\begin{tabular}{|l|c|c|c|l|}
\hline Question & Participant & SumType & OrderType & Tukey - SumType \\
\hline $\mathbf{1}$ & 0.001 & 0.000 & 0.422 & All 3 different \\
\hline $\mathbf{2}$ & 0.009 & 0.001 & 0.845 & All 3 different \\
\hline $\mathbf{3}$ & 0.046 & 0.004 & 0.170 & A and C different \\
\hline $\mathbf{5}$ & 0.017 & 0.006 & 0.243 & A and C different \\
\hline $\mathbf{6}$ & 0.075 & 0.000 & 0.136 & C different from A and B \\
\hline Reduce & 0.000 & 0.000 & 0.298 & All 3 different \\
\hline Helpful & 0.000 & 0.000 & 0.384 & A different from B and C \\
\hline UnderColon & 0.003 & 0.000 & 0.110 & All 3 different \\
\hline IntentColon & 0.001 & 0.000 & 0.528 & C and B different from A \\
\hline UnderFlexSig & 0.057 & 0.000 & 0.655 & C different from A and B \\
\hline IntentFlexSig & 0.180 & 0.011 & 0.374 & A and C different \\
\hline UnderMSI & 0.025 & 0.058 & 0.601 & No difference \\
\hline IntentMSI & 0.116 & 0.034 & 0.744 & A and C different \\
\hline UnderGenC & 0.037 & 0.000 & 0.083 & C different from A and B \\
\hline IntentGenC & 0.086 & 0.054 & 0.428 & A and C different \\
\hline UnderUpperEndo & 0.321 & 0.000 & 0.453 & C different from A and B \\
\hline IntentUpperEndo & 0.085 & 0.058 & 0.372 & No difference \\
\hline
\end{tabular}

Analysis was completed to analyze the existence of any interaction effects between the survey levels, summary page types and order of summary page presentation. Figure 11 shows the interaction plot for Question 1. There seemed to be an interaction between Order and Summary Type. This graph seemed to indicate that the later in the sequence which a partipant saw summary type A, the lower score it got. For B and C, the later they were seen in the sequence, the higher score they received. This indicates that the result indicating preference for Type $C$ is very strong. Additionally, it shows that summary type A seemed to only receive high scores when it was seen first. Further analysis was completed to analyze the first-order and 
second-order carry-over effects (Appendix G). Second-order effects were stronger than firstorder, but still did not show significance at the $\mathrm{P}=0.05$ level.

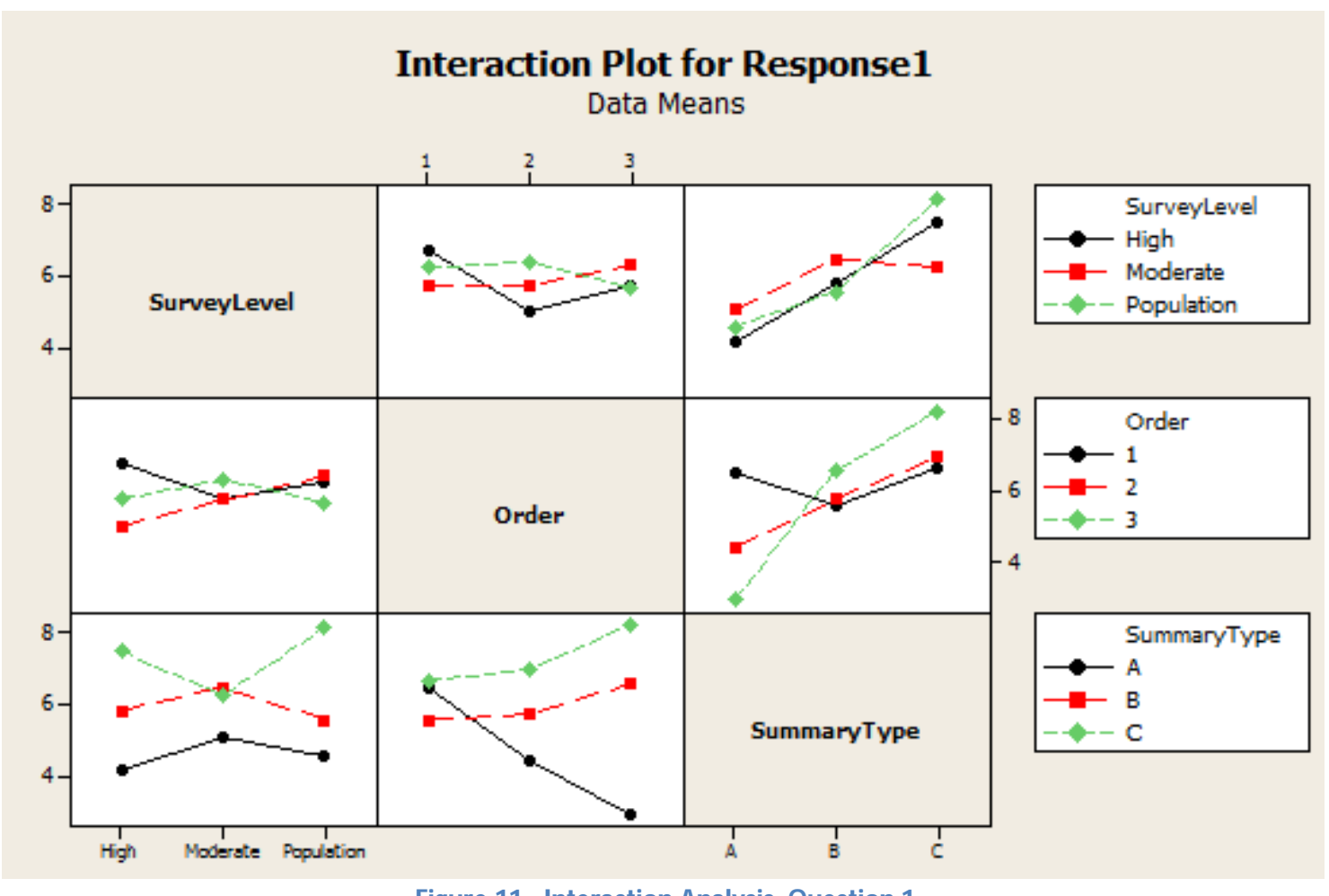

Figure 11 - Interaction Analysis, Question 1

Subsequent analysis per question can be found in Appendix G.

Two questions were included in the survey which required participants to put their preference of summary page type in order (first from 1-3 on the third survey, and then from 1-4 on the fourth survey). A Kruskal-Wallis test was conducted as well as a Friedman Test to determine whether there was a relationship between risk level, summary type, and rank. The KW test showed there was no relationship found in risk level versus summary type (Appendix G.5.1). The stacked data showed significant difference between rank and summary type. This indicates that there is a strong preference for Summary Type Cover both Summary Type B and A. The Friedman Test (Appendix G.5.2) confirmed these results and showed significant difference between the three summary types. 


\section{Discussion}

This experiment gives strong evidence that people find value in being given specific instructions as to how to carry out particular recommendations. Especially in a medical environment where patients can often feel confused as to how to complete the actions which their doctors advise, the addition of procedure steps in action completion help users better understand what they should do and have greater confidence in completing that action. This study can help inform the future design of risk communication and behavior change tools. As this experiment was conducted using three varying levels of risk (which seemingly had no effect on the responses of the individuals), it is believed to be generalizable across risk levels. Therefore both those people who have a low-level of risk as well as those who have a very serious condition which they need to consider and take action on can all benefit from the inclusion of graphic icons and process information.

The high interaction effect in Question 1 of the order in which the reports were shown makes sense within this context and actually strengthens the argument that Summary Type $\mathrm{C}$ is the most preferred overall. It can be imagined that if a participant saw Summary Type A first, and then saw $B$ and then saw $C$ that s/he might give an average score to Type $A$ and then upon seeing the $B$ and $C$ designs, decide that these were significantly better, and therefore give very high scores. The opposite can be true as well where if $\mathrm{C}$ is seen first, and then $\mathrm{B}$ and $\mathrm{A}$ are shown, it would be easy to give those summary page types very low scores if your most preferred page type was $C$. This is likely to have a greater effect than the $A B C$ order as participants might rank A highly if they do not know how else (or what else) could be shown as an option and so initial give a high score to type A. Again, when the first and second-order carryover effects were analyzed, this interaction effect did not show significance. 
Summary Type was found to not be significant for understanding M SI or genetic counseling. It is possible that these two recommendations are less well-known to the participants and therefore even provision of the steps to complete the actions does not help them understand what they need to do. It can be speculated that with the provision of the full report participants might better understand the recommendations and need more details to feel more confident in completing these less common activities.

One surprising finding is perhaps the lack of strong correlation between any of the demographic statistics (e.g. age, gender, education level, income) and responses. This could be due to the small sample size or means that the summary type preferences can be generalized across the population. Further study can be done to determine whether this is the case or not.

\subsection{Limitations}

There are a few limitations to the usefulness of this study. The greatest being that participants looked at pre-made, non-personalized risk assessments, so self-reported responses may not be exactly as they would be if they had had their actual risk assessments in front of them. This limits the generalizability of the study. As these were generic reports, it is possible that there were no differences found in summary page type preference across risk level because people did not fully take on the risk level of the report in which they were shown. Additionally, there is a confound in the report formats in that the process information included in the pictorial summary is not pre-existing in the report. It is new information being added within the summary. We believe this should not greatly affect the results, especially as each participant saw the summary page types prior to reading the full original report.

A within-subjects design was used for this study as participants were shown all three summary page designs. This presents the opportunity for biases to be introduced by the prior 
viewing of other designs. This was accounted for in analyzing the carryover effects, but a between-subjects design could also be used where each participant is only shown one summary page type. The within-subjects design does allow for faster data collection and can afford the statistical ability to help account for specific participant variation.

One issue noticed when analyzing the results is that there seemed to be a bit of confusion in asking participants to order their most preferred (1) to least preferred (3). Some participants seemed to put the order of their preference in the wrong order (as could be gleaned by the supporting comments) or would not use an ordinal ranking and would simply seem to rate each individual summary type on a 1-3 scale. In order to prevent this confusion in future studies it seems that a reorganization where subjects potentially draw lines in between the reports and their preferences might give more clear results.

As with all studies which use Likert-type scales there are issues with biases like the central tendency bias, the acquiescence bias [20] and the social desirability bias. [21] The social desirability bias is likely to be the most noticeable in this study as participants potentially would not want to give poor scores to summary page types.

\subsection{Future Work}

This work shows the potential benefit of the inclusion of graphic icons and process

information. Further analysis needs to be done to determine what icons best convey information in a non-intimidating way. Some participants of this study commented on the icons as being too gruesome or potentially scary (especially in larger form as in Summary Type B - text and icons). Additional analysis can be done to determine the level of detail which should be included in the process steps that is most effective. It is possible that including too many details will seem overwhelming or will require too much personalization to be feasible for a large 
system. Additionally, this study did not focus on a 'knowledge assessment' of the participants. It could be useful to run a study to assess how much information the participants are able to retain and report back.

It would also be very interesting to conduct this as a longitudinal study using participants who have risk assessments which are created specifically for them with their actual personal and familial health histories. Then, patient actions could be documented to determine not just self-reported intent, but actual actions which are completed. It could also be beneficial to conduct this study with a broader range of races and ethnicities to ensure there are no varying preferences based on background and culture and to include more participants on the whole.

Further work could be done to tease out the effectiveness of varying design types on the different types of self-efficacy. The umbrella of self-efficacy contains action self-efficacy (phase when individual is developing motivation to act), maintenance self-efficacy (belief in capability to deal with barriers), and recovery self-efficacy (ability to recover from setbacks) as sub-attributes. [22] Changing the presentation of health risk information might differently affect these sub-categories of self-efficacy.

\section{Conclusions}

This study successfully proved the hypothesis that inclusion of particular design aspects can be effective in increasing the understanding and self-efficacy of patients. Usage of a text summary along with graphic icons and process information has been shown to result in higher participant preference of the layout and design of the information, and self-reported understanding, intent and usefulness. It is recommended that future health communication tools utilize these design elements in the creation of patient-facing information. 


\section{References}

[1] V. F. Reyna, W. L. Nelson, P. K. Han, and N. F. Dieckmann, "How numeracy influences risk comprehension and medical decision making.," Psychological Bulletin, vol. 135, no. 6, pp. 943-973, 2009.

[2] D. Nelson, G. Kreps, B. Hesse, R. Croyle, G. Willis, N. Arora, B. Rimer, K. Vish Viswanath, N. Weinstein, and S. Alden, "The Health Information National Trends Survey (HINTS):

Development, Design, and Dissemination," Journal of Health Communication, vol. 9, no. 5, pp. 443-460, Sep. 2004.

[3] A. Bandura, Self-efficacy : the exercise of control. New York: W.H. Freeman, 1997.

[4] A. Bandura, "Self-efficacy: Toward a unifying theory of behavioral change.," Psychological Review, vol. 84, no. 2, pp. 191-215, 1977.

[5] K. A. Wallston, R. L. Rothman, and A. Cherrington, "Psychometric Properties of the Perceived Diabetes Self-M anagement Scale (PDSMS)," Journal of Behavioral M edicine, vol. 30, no. 5, pp. 395-401, May 2007.

[6] E. R. Weitzman, J. Zapka, B. Estabrook, and K. V. Goins, "Risk and Reluctance: Understanding Impediments to Colorectal Cancer Screening," Preventive M edicine, vol. 32, no. 6, pp. 502-513, Jun. 2001.

[7] E. A. Waters, H. W. Sullivan, W. Nelson, and B. W. Hesse, "What Is My Cancer Risk? How Internet-Based Cancer Risk Assessment Tools Communicate Individualized Risk Estimates to the Public: Content Analysis," Journal of Medical Internet Research, vol. 11, no. 3, Jul. 2009.

[8] Alpay, Laurence, Verhoef, John, Xie, Bo, Te'eni, Dov, and Zwetsloot-Schonk, J.H.M., "Current Challenge in Consumer Health Informatics: Bridging the Gap between Access to Information and Information Understanding," Biomedical Informatics Insights, vol. 2, no. 1, pp. 1-10, Jan. 2009.

[9] A. Fagerlin, B. J. Z kmund-Fisher, and P. A. Ubel, "Helping Patients Decide: Ten Steps to Better Risk Communication," JNCl Journal of the National Cancer Institute, vol. 103, no. 19, pp. 1436-1443, Sep. 2011.

[10] I. S. Kirsch, Educational Testing Service, and National Center for Education Statistics, Adult literacy in America : a first look at the results of the National Adult Literacy Survey. Washington, D.C.: Office of Educational Research and Improvement, U.S. Dept. of Education, 1993.

[11] G. M. Gray and D. P. Ropeik, "Dealing With The Dangers Of Fear: The Role Of Risk Communication," Health Affairs, vol. 21, no. 6, pp. 106-116, Nov. 2002.

[12] K. Witte and M. Allen, "A M eta-Analysis of Fear Appeals: Implications for Effective Public Health Campaigns," Health Education \& Behavior, vol. 27, no. 5, pp. 591-615, Oct. 2000.

[13] N. D. Weinstein, "Optimistic Biases about Personal Risks," Science, vol. 246, no. 4935, pp. 1232-1233, Dec. 1989.

[14] A. Breckenridge, "For the good of the patient: risks and benefits of medicines," Pharmacoepidemiology and Drug Safety, vol. 12, no. 2, pp. 145-150, M ar. 2003.

[15] J. Paling, "Strategies to help patients understand risks," BM J, vol. 327, no. 7417, pp. 745748, Sep. 2003.

[16] M. B. Kinzie, W. F. Cohn, M. F. Julian, and W. A. Knaus, "A User-centered Model for Web Site Design," J ournal of the American Medical Informatics Association, vol. 9, no. 4, pp. 320 330, 2002. 
[17] P. K. J. Han, W. M. P. Klein, T. Lehman, B. Killam, H. Massett, and A. N. Freedman, "Communication of Uncertainty Regarding Individualized Cancer Risk Estimates: Effects and Influential Factors," Medical Decision M aking, vol. 31, no. 2, pp. 354-366, Jul. 2010.

[18] J. P. Chin, V. A. Diehl, and L. K. Norman, "Development of an instrument measuring user satisfaction of the human-computer interface," 1988, pp. 213-218.

[19] D. A. Ratkowsky, M. A. Evans, and J. R. Alldredge, Eds., Cross-over experiments : design, analysis, and application /. New York :: Marcel Dekker,, c1993.

[20] C. E. Ross and J. M irowsky, "Socially-Desirable Response and Acquiescence in a CrossCultural Survey of M ental Health," Journal of Health and Social Behavior, vol. 25, no. 2, pp. 189-197, Jun. 1984.

[21] R. L. Worthington, M. M obley, R. P. Franks, and J. A. Tan, "Multicultural counseling competencies: Verbal content, counselor attributions, and social desirability.," Journal of Counseling Psychology, vol. 47, no. 4, pp. 460-468, 2000.

[22] R. Schwarzer, "M odeling Health Behavior Change: How to Predict and Modify the Adoption and Maintenance of Health Behaviors," Applied Psychology, vol. 57, no. 1, pp. 1-29, Jan. 2008.

[23] F. Ahmad, S. Hogg-Johnson, and H. A. Skinner, "Assessing Patient Attitudes to Computerized Screening in Primary Care: Psychometric Properties of the Computerized Lifestyle Assessment Scale," Journal of M edical Internet Research, vol. 10, no. 2, p. e11, Apr. 2008.

[24] K. Hornbæk and M. Hertzum, "The notion of overview in information visualization," International Journal of Human-Computer Studies, vol. 69, no. 7-8, pp. 509-525, Jul. 2011.

[25] D. R. Desaulniers, "Layout, Organization, and the Effectiveness of Consumer Product Warnings," Proceedings of the Human Factors and Ergonomics Society Annual M eeting, vol. 31, no. 1, pp. 56-60, Sep. 1987.

[26] M. B. M azis and L. A. Morris, "Channel," in Warnings and Risk Communication, M. S. Wogalter, D. M. Dejoy, and K. R. Laughery, Eds. London; Philadelphia, PA: Taylor \& Francis, 1999, pp. 108-110.

[27] S. D. Leonard and M. S. Wogalter, "Attention Capture and M aintenance," in Warnings and Risk Communication, M. S. Wogalter, D. M. Dejoy, and K. R. Laughery, Eds. London; Philadelphia, PA: Taylor \& Francis, 1999, p. 128.

[28] D. Nelson, "Remembering pictures and words: appearance, signficance, and name.," in Levels of processing in human memory, L. S. Cermak and F. I. M . Craik, Eds. Hillsdale, N.J.; New York: Lawrence Erlbaum Associates; Distributed by Halsted Press Division, Wiley, 1979.

[29] A. Paivio, Imagery and verbal processes. New York: Holt, Rinehart and Winston, 1971.

[30] A. Paivio, M ental representations : a dual coding approach. New York; Oxford [Oxfordshire]: Oxford University Press ; Clarendon Press, 1986.

[31] S. D. Leonard, H. Otani, and M. S. Wogalter, "Comprehension and Memory," in Warnings and Risk Communication, M. S. Wogalter, D. M. Dejoy, and K. R. Laughery, Eds. London; Philadelphia, PA: Taylor \& Francis, 1999, p. 158.

[32] D. M. Dejoy, "M otivation," in Warnings and Risk Communication, M. S. Wogalter, D. M. Dejoy, and K. R. Laughery, Eds. London; Philadelphia, PA: Taylor \& Francis, 1999, p. 228.

[33] "CM E Doctors' Resources - Endoscopy," The University of Auckland - Faculty of M edical and Health Sciences. [Online]. Available:

http:// www.fmhs.auckland.ac.nz/soph/centres/goodfellow/cpe/ resources/colonoscopy.asp x. [Accessed: 07-Mar-2012].

[34] "Flexible Sigmoidscopy Screening Procedure," Digestive \& Liver Disease Consultants, P.A. [Online]. Available: http:// www.gimed.net/sigmoidoscopy.html. [Accessed: 07-M ar-2012]. 
[35] "Leeds Institute of M edical Education - Intercalation: Biochemistry," University of Leeds School of M edicine - Biochemistry. [Online]. Available: http://www.leeds.ac.uk/medicine/intercalated/biochemistry.html. [Accessed: 07-Mar2012].

[36] "The Molecular Probes Technology Network: Group: Microscopy 101," M olecular Probes Technology. [Online]. Available: http://lifetechmp.hosted.jivesoftware.com/groups/microscopy-101. [Accessed: 07-M ar-2012].

[37] "Health Services - Facilities Services, Pillcam Capsule and Capsule Endoscopy," VGM Hospital. [Online]. Available: http:// www.indiamart.com/vgm-hospital/health-services.html. [Accessed: 07-Mar-2012].

[38] "Counselor Badge," M ehalo - Learn Anything. [Online]. Available: http:// www.mahalo.com/badges/counselor. [Accessed: 07-Mar-2012].

[39] “Blood Test Might Predict Patient's Response to an Antidepressant," A Health Blog. [Online]. Available: http:// www.ahealthblog.com/blood-test-predict-patients-responseantidepressant.html. [Accessed: 07-M ar-2012].

[40] A. Bandura, "Social Cognitive Theory: An Agentic Perspective," Annual Review of Psychology, vol. 52, no. 1, pp. 1-26, Feb. 2001.

[41] K. Hornbæk, "Current practice in measuring usability: Challenges to usability studies and research," International J ournal of Human-Computer Studies, vol. 64, no. 2, pp. 79-102, Feb. 2006.

[42] S. LeeTiernan and J. Grudin, "Fostering Engagement in Asynchronous Learning Through Collaborative Multimedia Annotation," Proceedings of INTERACT 2001., pp. 472-479.

[43] M. S. Wogalter, Handbook of warnings. Mahwah, N.J.: Lawrence Erlbaum Associates, 2006. 


\section{Appendix A - Design Concepts}

\section{Appendix A.1 - Summary Inclusion}

It has been found that "preventative behaviors... improve when perceived benefits

exceed perceived barriers" [23]. To communicate such benefits, information should be organized so the patient can perceive, navigate and understand what is being presented. An overview has been shown to improve users' subjective satisfaction and preference. There is also support for better learning and memory when an overview is included [24]. It has been shown that "hierarchically organized warnings in outline layout were ranked as having the greatest eye appeal, easiest to process, and were perceived to be the most effective" [25]. For this study, a design concept to be tested will be that of a text summary included at the beginning (as a cover page) of the risk report. It is hoped that this summary will help the patient understand the recommendations and more easily remember and take advantage of that which is being displayed.

\section{Appendix A.2 - Icons}

Icons are often used to present information so people remember and recognize information more easily. They are used on road signs, product labels, maps and many different types of technologies. On product labels, "studies have found also that pictorials, color, and signal icons, especially in combination with each other, improve warning noticeability and behavioral compliance." [26] When designing a good for a wide range of users, particularly those with low-literacy and/or non-English speakers, "safety symbols, particularly in combination with a short verbal message, can be helpful in communicating a warning clearly to the target audience."[26] Not only are symbols useful for conveying information but they are also useful at attention getting; "research shows that warnings with pictorial symbols are rated more noticeable than warnings without them." [27] Pictures/icons have been known to help 
with memorability of a concept. A theory, known as the picture superiority effect, states that pictures are generally easier to remember than words. [28] A partial explanation of this effect comes from Paivio's dual-code theory [29], [30] which hypothesizes two types of coding systems in memory: "verbal and imaginal (visuo-spatial). Words are assumed to be coded verbally, and pictures are assumed to be imaged... High imagery words may activate both codes, which makes encoding into memory more effective and subsequent retrieval easier... Thus, according to dualcode theory and the picture superiority effect, warnings with symbols should be more effective in terms of encoding and retrieval."[31] There are potential drawbacks to the use of icons. Han states that "representing risk visually vs. textually may heighten risk perceptions and affective responses to risk information."[17] Therefore the selection of icons must be chosen carefully and studied to determine whether in this setting such adverse effects are present.

\section{Appendix A.3 - Process Information}

The third design concept to be incorporated in this study involves the inclusion of process information within the summary of the report. It has been suggested that "the instructions portion of a warning message is important to ultimate compliance... warnings that provided instructions about reducing or eliminating a hazard were more likely to be complied with." [27] By providing the specific instructions as to how to complete the recommended task it is hoped that the user will be more confident in carrying out the action. It has been shown that “messages specifically recommending a particular action had a greater influence than the overall amount of risk information." [27] Desaulniers described the four components of a successful warning to be "a signal word, statement of the hazard, statement of the consequences, and instructions." [25] If any of these four elements is missing, there is shown to be a "reduced perceived effectiveness, but [the] removal of either the hazard statement or the instructions statement produced the greatest reductions in rated effectiveness."[32] It is hoped 
that the inclusion of process information helps the patient understand and feel more confident about his/her health options. 


\section{Appendix B - Materials}

The materials for this study include 12 different risk reports (4 different versions at each of the 3

levels of risk; Appendix B.1), 4 survey evaluations (Appendix B.2), and directional scripts (Appendix B.3) for the study administrator.

\section{Appendix B.1 Risk Reports}

There are three possible levels of risk generated by the Health Heritage system. Each patient is evaluated to be at Population, M oderate or High risk. For each of these 3 levels, there are 4 different format options.

These 4 options are a select combination of the following 3 attributes:

- Summary: $\{$ Yes, No $\}$

- A text summary of the information within the original report, listed at the top of the new design

- Activities as Icons: $\{$ Yes, No\}

- Icons of the recommended activities that the patient should complete

- Process Icons: $\{$ Yes, No\}

- Icons of the steps to complete the recommended activities (includes the end activity icon as well)

The specific cases (and format options) are:

1. Summary $=$ No, Activities as Icons $=$ No, Process Icons $=$ No

a. Original report of Health Heritage

2. Summary $=$ Yes, Activities as Icons $=$ No, Process Icons $=$ No

a. Summary level text only

3. Summary $=$ Yes, Activities as Icons $=$ Yes, Process Icons=No

a. Summary level text with Activity Icons

i. Redundant coding (via text and iconography) of summary level information

4. Summary $=$ Yes, Activities As Icons $=$ Yes, Process Icons $=$ Yes

a. Summary level text with Activity Icons, and additional content (not within the report) of Process Icons

i. Redundant coding and new content in icon format 
Each original report (one at each risk level) was generated in Health Heritage and the subsequent 3 reports designed off these original reports.

The reasoning for these select cases and not all 8 possibilities is two-fold. It was decided initially that including only icons with no text summary would leave too much information out for the patient and would not be effective (eliminating 3 cases of reports). The last report type (Summary $=$ Yes, Activities as Icons $=$ No, Process Icons $=$ Yes) is not a feasible option as the process icons incorporate the activities icons within them.

\section{Appendix B.1.1: Population Risk, Original Report}

\section{WHAT IS COLORECTAL CANCER?}

Colorectal cancer is cancer in the colon or rectum. Sometimes it is called colon cancer for short. The colon is the large intestine and the rectum is the passageway that connects the colon to the anus.

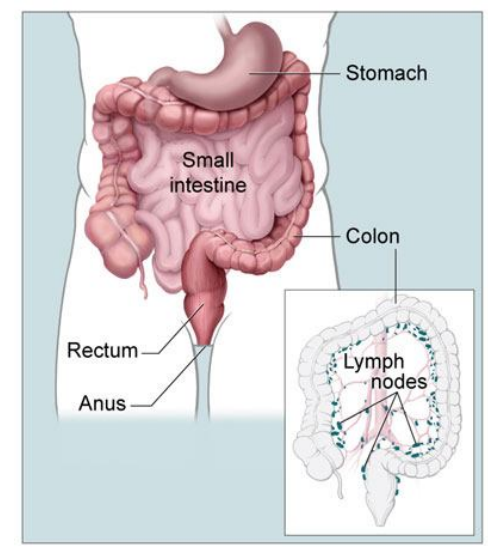

Excluding skin cancers, colorectal cancer is the third most common cancer in men and women in the United States.

Although it is quite common, colorectal cancer is one of the easiest to find. When colorectal cancer does happen, it usually develops slowly. The earlier it is found, the more likely it is to be treatable. There are things you can do to lower your risk of colon cancer or treat it if it does happen. Knowing about your risk can help you and your health care provider make decisions about what to do.

WHAT IS MY RISK fOr COLORECTAL CANCER? 


\section{Population}

\section{You are at Population Level (or average) Risk for colorectal cancer.}

This means that you did not report any risk factors that would raise your risk above people similar to you in the general population.

A risk factor is something that may influence a person's chance of developing a disease, such as cancer. Research has shown that people with certain risk factors are more likely than others to develop colorectal cancer. However, about $75 \%$ of colorectal cancers occur in people who do not have any of the risk factors we know about.

During your lifetime, there is a $5 \%$ (1 in 20) chance of your developing colorectal cancer.

Risk factors for colorectal cancer include:

- Age over 50 . Risk increases dramatically after age 50 ; more than $90 \%$ of all colorectal cancers occur after this age

- Adenomatous polyps (also called adenomas)

- Inflammatory Bowel Disease (IBD), including ulcerative colitis and Crohn's disease

- Family history of one or more first-degree relatives with colorectal cancer or adenomatous polyps. Your first-degree relatives are your parents, siblings, or children.

- Inherited syndromes, such as Familial Adenomatous Polyposis (FAP) and Lynch syndrome (also called Hereditary Non-Polyposis Colorectal Cancer)

- African-American or Ashkenazi Jewish heritage

However, having a risk factor does not mean you will get colorectal cancer. Also, sometimes people who get it may not have any of the risk factors that we know about.

When you think about risk of cancer you may have different emotions, including anxiety and worry. These are normal reactions. Everyone has their own way of coping with difficult situations. Some people find it helpful to talk about how they are feeling with a relative, a close friend, a counselor, or their health care provider.

\section{WHY AM I AT THIS LEVEL of RISK?}

The health information you provided did not identify any risk factors that would raise your risk of colorectal cancer over that of people similar to you.

\section{WHAT CAN I DO?}

What you believe about your health and what you expect from your health care is important. Feeling confident in your doctors and that what they recommend can take 
care of your cancer risk can help. Knowing that there are things you can do to lower your risk of colon cancer will make it easier for you to do the things they suggest.

It can be hard to deal with your risk of cancer and to do the things that have been suggested to lower your cancer risk, but they are very important to do to stay healthy. Think about ways you have been able to do this in the past. Ask others for help or support.

The following suggestions are based on guidelines from a national group of experts.

\section{Talk to your doctor about getting screened for colorectal cancer:}

Screening is looking for cancer before a person has any symptoms. By the time symptoms appear, cancer may have begun to spread and be harder to treat.

Removing polyps prevents colorectal cancer from ever starting. And cancers found in an early stage are more easily treated.

- Colorectal cancer usually starts from polyps in the colon or rectum. A polyp is a growth that shouldn't be there. Click here to see what a polyp looks like.

- Over time, some polyps can turn into cancer. This usually takes about 1015 years.

- Some screening tests can find polyps, so they can be removed before they turn into cancer.

- Screening tests can also find colorectal cancer early. When it is found early, the chance of being cured is good.

For men and women at population level risk, regular colorectal cancer screening should start at age 50, following ONE of these testing schedules:

Two screening tests are available that can detect colon cancer and colon polyps. Screening tests that can detect polyps as well as early cancer are preferred.

1. Colonoscopy every 10 years

- A colonoscopy is an exam that allows a doctor to closely look at the inside of the entire colon. The doctor uses a thin (about the thickness of a finger), flexible, hollow, lighted tube that has a tiny video camera. The exam itself takes about 30 minutes. Patients are usually given medicine to help them relax and sleep during the procedure. It may also have a tool to remove polyps or tissue samples, which are checked under a microscope for signs of cancer.

- Many people get colonoscopies. Click here to watch Katie Couric get a colonoscopy. (Source: Colon Cancer Resource)

2. Flexible sigmoidoscopy every 5 years

- During this procedure, about a third of the colon is examined. Polyps may be removed only from that part of the colon at the same time. 
A third screening test finds colon cancer primarily and is not able to find polyps:

3. Fecal occult blood testing every year

- This test checks for hidden blood in three consecutive stool samples. A positive test would be followed by colonoscopy to look for the source of blood.

Talk with your doctor about what screening would be right for you.

To schedule your screening at the University of Virginia, talk to your doctor.

\section{WHERE CAN I FIND OUT MORE?}

\section{- (National Cancer Institute)}

\section{CAUTIONS}

- Your Health Heritage Risk Report is based on personal and/or family history information that you provided. If the information is not correct or is incomplete, this Risk Report may not be correct.

- If your family is very small, Your Risk Report may not be accurate.

- If your personal and/or family health information changes, you should update your information in Health Heritage. Then click "Update My Risk Report", because the new information may change Your Risk Report.

- New knowledge about colorectal cancer risk may also change recommendations in Your Risk Report.

- In addition to your personal and family history, other risk factors such as your lifestyle or environment may also make a difference in your risk for colorectal cancer.

- Your Risk Report does not predict whether you will develop colorectal cancer. It reflects only the evidence for colorectal cancer risk in your personal and family history and is limited by the information you supplied. 
Appendix B.1.2: Population Risk, Text Summary

\section{YOUR RISK REPORT SUMMARY}

Risk Level: Population

Why: Did not report any risk factors that would raise your risk above people similar to you in the general population.

Actions:

Screening

- Regularly Scheduled Colonoscopy

- Regularly Scheduled Flexible Sigmoidoscopy 
Appendix B.1.3: Population Risk, Text Summary with Activity Icons

\section{YOUR RISK REPORT SUMMARY}

Risk Level: Population

Why: Did not report any risk factors that would raise your risk above people similar to you in the general population.

\section{Actions:}

Screening

- Regularly Scheduled Colonoscopy

- Regularly Scheduled Flexible Sigmoidoscopy

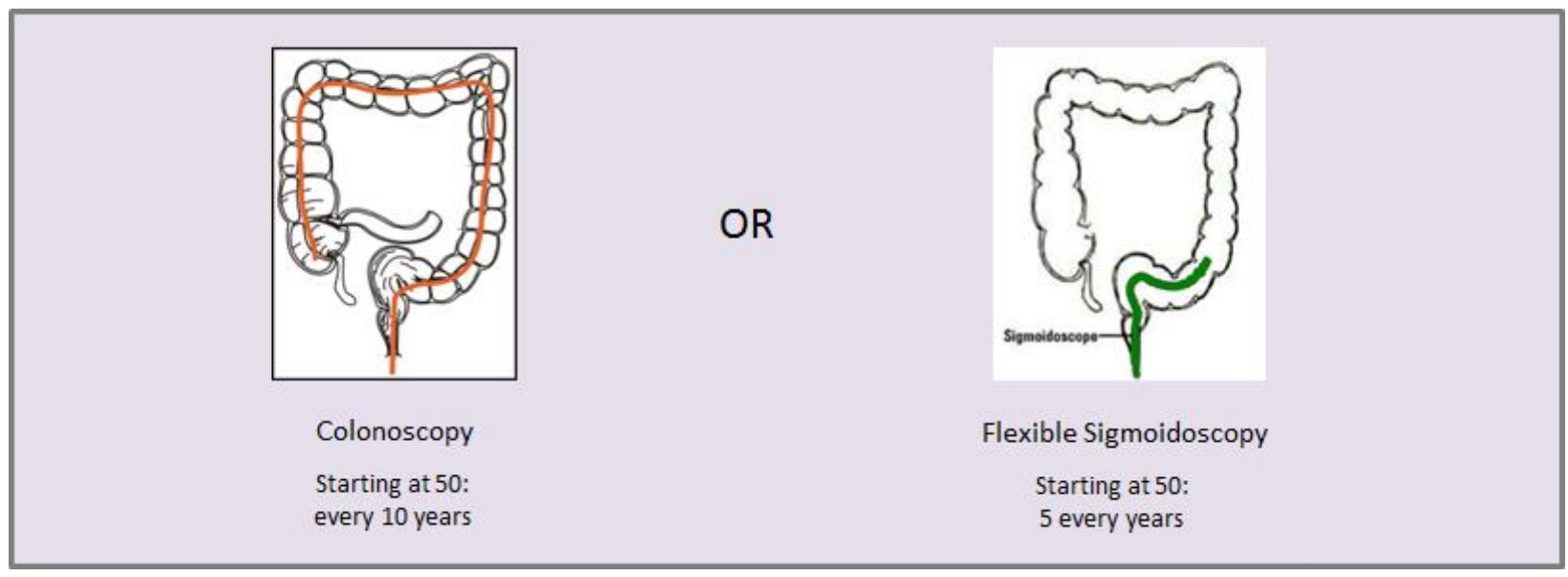


Appendix B.1.4: Population Risk, Text Summary with Process Icons

\section{YOUR RISK REPORT SUMMARY}

Risk Level: Population

Why: Did not report any risk factors that would raise your risk above people similar to you in the general population.

\section{Actions:}

\section{Screening}

- Regularly Scheduled Colonoscopy

- Regularly Scheduled Flexible Sigmoidoscopy

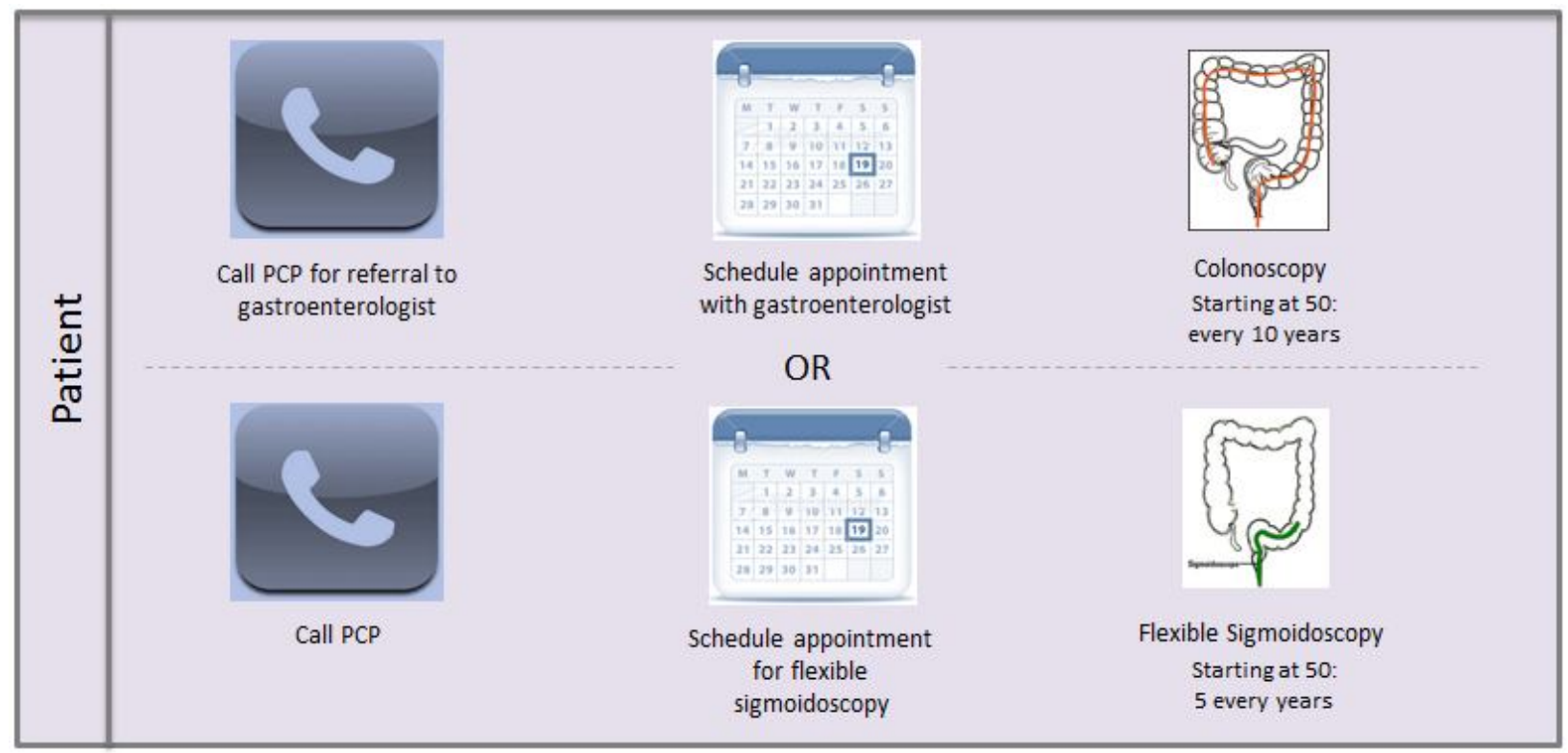


Appendix B.1.5: Moderate Risk, Original Report

\section{WHAT IS COLORECTAL CANCER?}

Colorectal cancer is cancer in the colon or rectum. Sometimes it is called colon cancer for short. The colon is the large intestine and the rectum is the passageway that connects the colon to the anus.

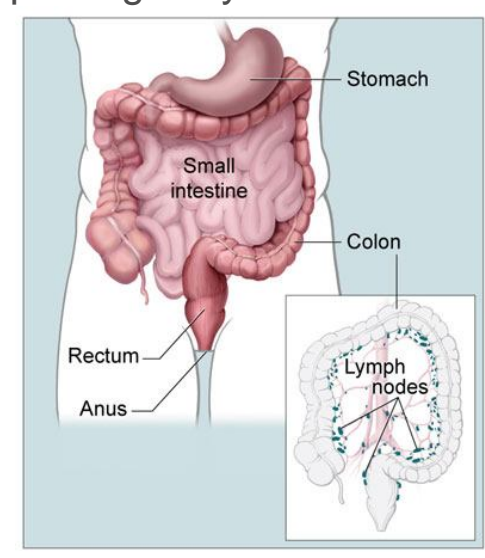

Excluding skin cancers, colorectal cancer is the third most common cancer in men and women in the United States.

Although it is quite common, colorectal cancer is one of the easiest to find. When colorectal cancer does happen, it usually develops slowly. The earlier it is found, the more likely it is to be treatable. There are things you can do to lower your risk of colon cancer or treat it if it does happen. Knowing about your risk can help you and your health care provider make decisions about what to do.

\section{WHAT IS MY RISK for COLORECTAL CANCER?}

\section{Population Moderate High}

\section{You may be at Moderate Risk for colorectal cancer.}

A risk factor is something that may influence the chance of developing a disease, such as cancer. Research has shown that people with certain risk factors are more likely than others to develop colorectal cancer.

Risk factors for colorectal cancer include:

- Age over 50. Risk increases a lot after age 50; more than $90 \%$ (9 in 10) of all colorectal cancers occur after age 50. 
- Adenomatous polyps (also called adenomas)

- Inflammatory Bowel Disease (IBD), including ulcerative colitis and Crohn's disease Family history of one or more first-degree relatives with colorectal cancer or adenomatous polyps. Your first-degree relatives are your parents, siblings, or children.

- Inherited syndromes, such as Familial Adenomatous Polyposis (FAP) and Lynch syndrome (also called Hereditary Non-Polyposis Colorectal Cancer)

- African-American or Ashkenazi Jewish heritage

Having a risk factor does not mean you will definitely get colorectal cancer. About $75 \%$ of colorectal cancers occur in people who do not have any of the risk factors we know about.

When you think about risk of cancer you may have different emotions, including anxiety and worry. These are normal reactions. Everyone has their own way of coping with difficult situations. Some people find it helpful to talk about how they are feeling with a relative, a close friend, a counselor, or their health care provider.

\section{WHY AM I AT THIS LEVEL of RISK?}

The health information you provided shows that:

- You have a significant family history of colorectal cancer or polyps

People who have a family history of colorectal cancer or polyps, especially at younger ages, are at increased risk for colorectal cancer.

\section{WHAT CAN I DO?}

What you believe about your health and what you expect from your health care is important. Feeling confident in your doctors and that what they recommend can take care of your cancer risk can help. Knowing that there are things you can do to lower your risk of colon cancer will make it easier for you to do the things they suggest.

It can be hard to deal with your risk of cancer and to do the things that have been suggested to lower your cancer risk, but they are very important to do to stay healthy. Think about ways you have been able to do this in the past. Ask others for help or support.

The following suggestions are based on guidelines from a national group of experts. 


\section{Talk to your doctor about:}

\section{Getting screened for cancer}

Screening is looking for cancer before a person has any symptoms. By the time symptoms appear, cancer may have begun to spread and be harder to treat.

Removing polyps prevents colorectal cancer from ever starting. And cancers found in an early stage are more easily treated.

- Colorectal cancer usually starts from polyps in the colon or rectum. A polyp is a growth on the inside lining of the colon. Click here to see what a polyp looks like.

- Over time, some polyps can turn into cancer.

- Screening tests can find polyps, so they can be removed before they turn into cancer.

- Screening tests can also find colorectal cancer early. When it is found early, the chance of being cured is good.

Because you have a significant family history of colorectal cancer or polyps, experts recommend that you:

- Get a colonoscopy to check your colon and rectum for polyps. You should get your first colonoscopy at age 40 , or 10 years younger than the youngest diagnosis of colorectal cancer in your family (whichever is earlier). Repeat the exam every 3-5 years depending on your family history of cancer.

- A colonoscopy is an exam that allows a doctor to closely look at the inside of the entire colon. The doctor uses a thin (about the thickness of a finger), flexible, hollow, lighted tube that has a tiny video camera. The exam itself takes about 30 minutes. Patients are usually given medicine to help them relax and sleep during the procedure. It may also have a tool to remove polyps or tissue samples, which are checked under a microscope for signs of cancer.

- Many people get colonoscopies. Click here to watch Katie Couric get a colonoscopy. (Source: $\underline{\text { Colon Cancer }}$ Resource)

- To schedule your screening at the University of Virginia, talk to your doctor.

2. Tests that can be done on your family member's colorectal cancer

About 3 in every 100 people with colorectal cancer have a hereditary disorder called Lynch syndrome. 
The results of special tests on colorectal tumors can help guide whether more testing should be done for Lynch syndrome.

If Lynch syndrome is found in your family, you may need to get colonoscopies earlier and more frequently. You may also need to get screening tests for other types of cancer.

\section{WHERE CAN I FIND OUT MORE?}

- (National Cancer Institute)

- (American Society of Clinical Oncology)

\section{CAUTIONS}

- Your Health Heritage Risk Report is based on personal and/or family history information that you provided. If the information is not correct or is incomplete, this Risk Report may not be correct.

- If your family is very small, Your Risk Report may not be accurate.

- If your personal and/or family health information changes, you should update your information in Health Heritage. Then click "Update My Risk Report", because the new information may change Your Risk Report.

- New knowledge about colorectal cancer risk may also change recommendations in Your Risk Report.

- In addition to your personal and family history, other risk factors such as your lifestyle or environment may also make a difference in your risk for colorectal cancer.

- Your Risk Report does not predict whether you will develop colorectal cancer. It reflects only the evidence for colorectal cancer risk in your personal and family history and is limited by the information you supplied. 
Appendix B.1.6: Moderate Risk, Text Summary

\section{YOUR RISK REPORT SUMMARY}

Risk Level: Moderate

Why: Significant family history of colorectal cancer or polyps

Actions:

Screening

- Colonoscopy

Testing

- Familial testing for Lynch Syndrome 
Appendix B.1.7: Moderate Risk, Text Summary with Activity Icons

\section{YOUR RISK REPORT SUMMARY}

Risk Level: Moderate

Why: Significant family history of colorectal cancer or polyps

\section{Actions:}

Screening

- Colonoscopy

Testing

- Familial testing for Lynch Syndrome

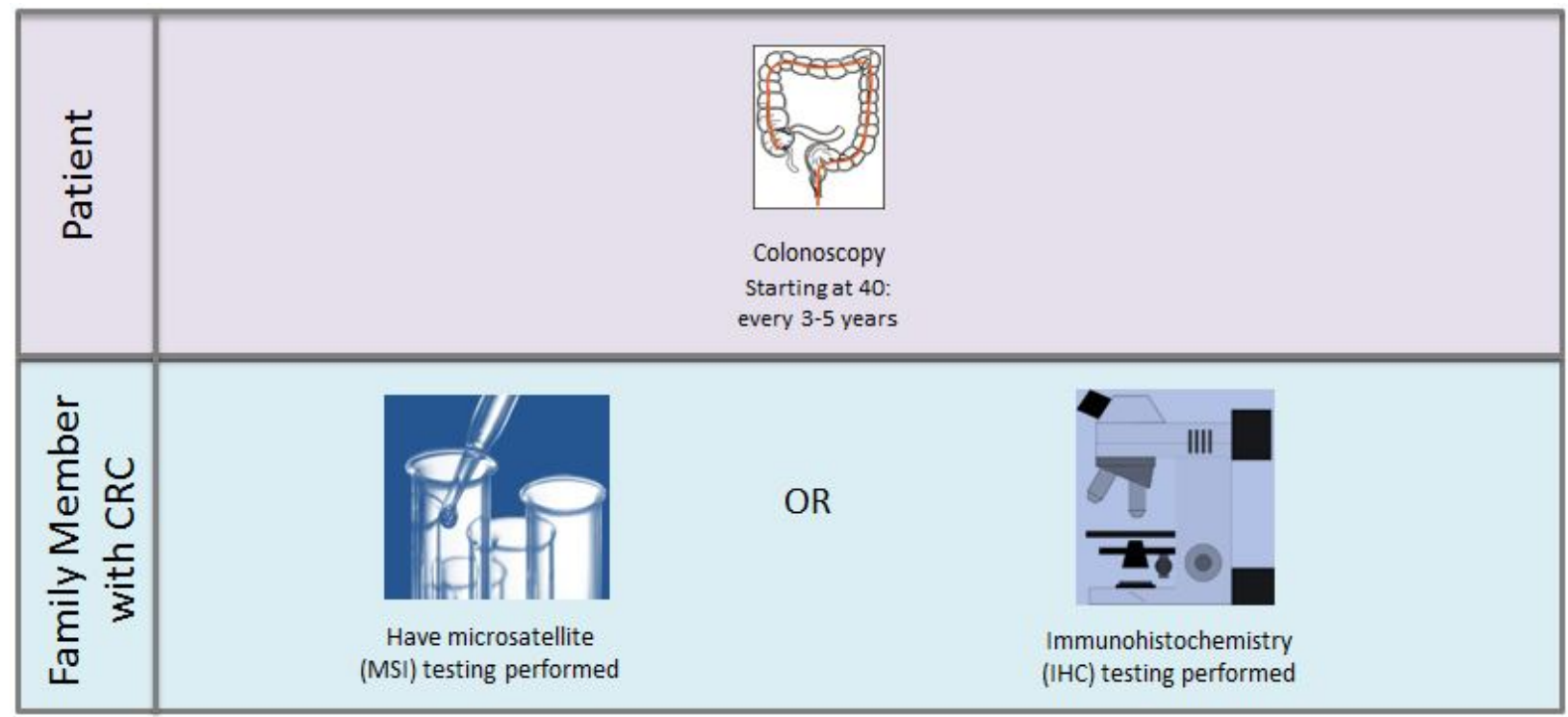


Appendix B.1.8: Moderate Risk, Text Summary with Process Icons

\section{YOUR RISK REPORT SUMMARY}

Risk Level: Moderate

Why: Significant family history of colorectal cancer or polyps

\section{Actions:}

Screening

- Colonoscopy

Testing

- Familial testing for Lynch Syndrome

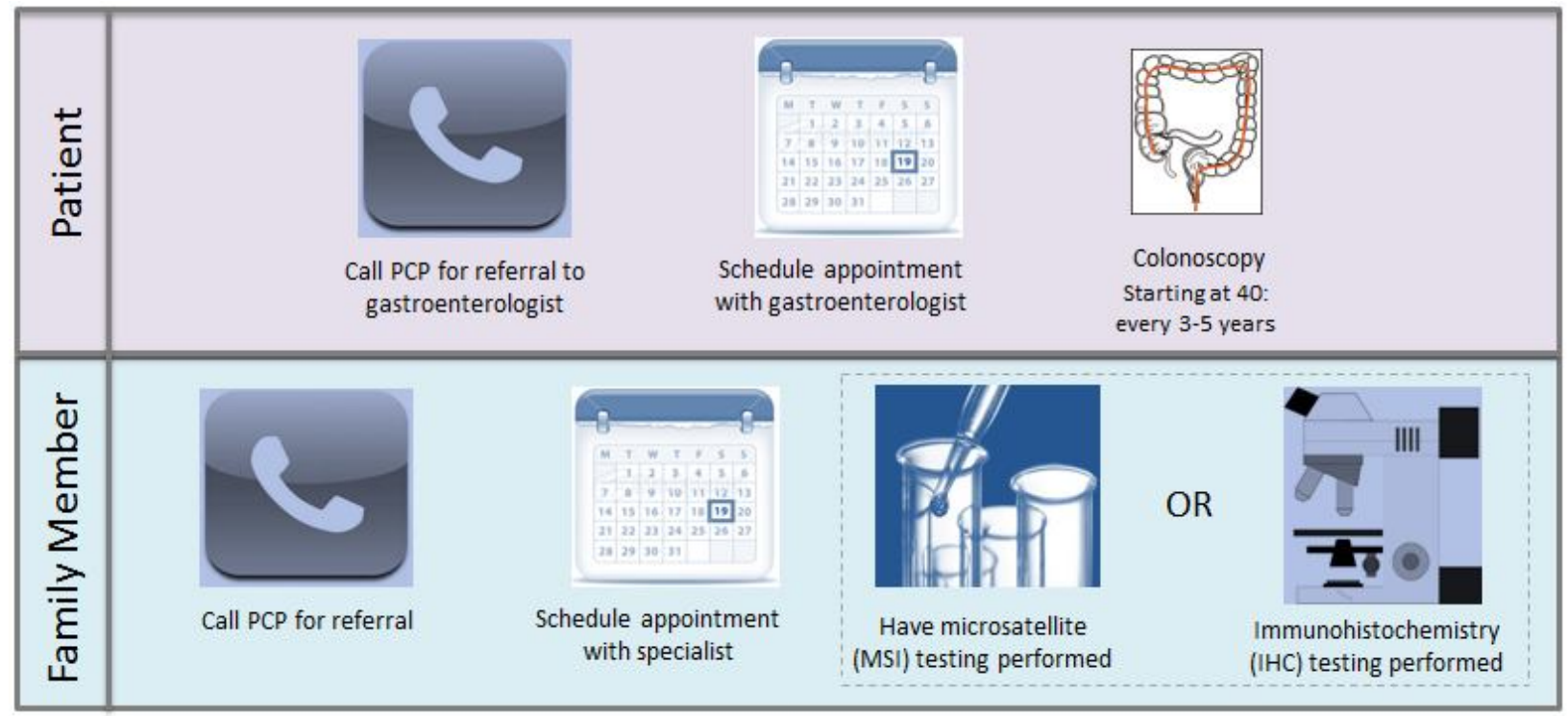


Appendix B.1.9: High Risk, Original Report

\section{WHAT IS COLORECTAL CANCER?}

Colorectal cancer is cancer in the colon or rectum. Sometimes it is called colon cancer for short. The colon is the large intestine and the rectum is the passageway that connects the colon to the anus.

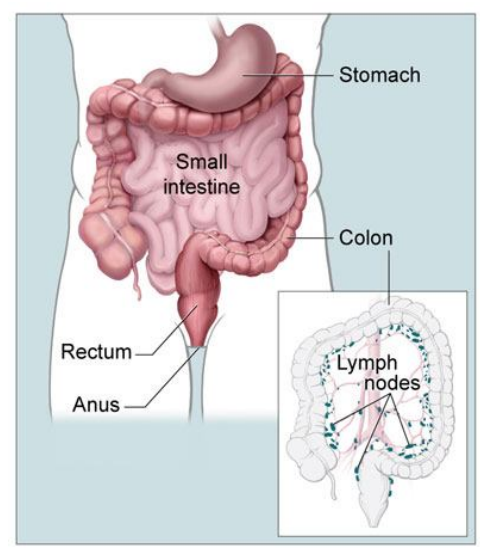

Excluding skin cancers, colorectal cancer is the third most common cancer in men and women in the United States.

Although it is quite common, colorectal cancer is one of the easiest to find. When colorectal cancer does happen, it usually develops slowly. The earlier it is found, the more likely it is to be treatable. There are things you can do to lower your risk of colon cancer or treat it if it does happen. Knowing about your risk can help you and your health care provider make decisions about what to do.

\section{WHAT IS MY RISK for COLORECTAL CANCER?}

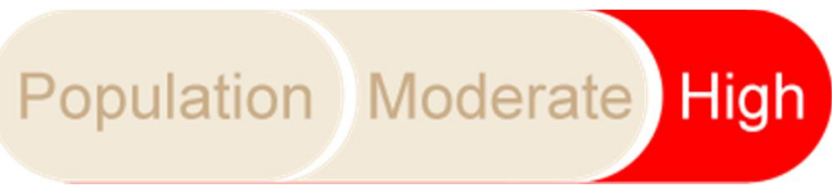

\section{You may be at high risk for colorectal cancer.}

A risk factor is something that may influence a person's chance of developing a disease, such as cancer. Research has shown that people with certain risk factors are more likely than others to develop colorectal cancer. However, about $75 \%$ of colorectal cancers occur in people who do not have any of the risk factors we know about.

Risk factors for colorectal cancer include: 
- Age over 50. Risk increases dramatically after age 50 ; more than $90 \%$ of all colorectal cancers occur after this age

- Adenomatous polyps (also called adenomas)

- Inflammatory Bowel Disease (IBD), including ulcerative colitis and Crohn's disease

- Family history of one or more first-degree relatives with colorectal cancer or adenomatous polyps. Your first-degree relatives are your parents, siblings, or children.

- Inherited syndromes, such as Familial Adenomatous Polyposis (FAP) and Lynch syndrome (also called Hereditary Non-Polyposis Colorectal Cancer)

- African-American or Ashkenazi Jewish heritage

However, having a risk factor does not mean you will get colorectal cancer. Also, sometimes people who get it may not have any of the risk factors that we know about.

When you think about risk of cancer you may have different emotions, including anxiety and worry. These are normal reactions. Everyone has their own way of coping with difficult situations. Some people find it helpful to talk about how they are feeling with a relative, a close friend, a counselor, or their health care provider.

\section{WHY AM I AT THIS LEVEL OF RISK?}

The health information you provided shows that the main reason you are at risk for colorectal cancer is:

- You have tested positive for a mutation in the SMAD4 gene.

The SMAD4 gene is related to a hereditary disorder called Juvenile Polyposis syndrome (JPS). People with JPS can develop one or more polyps of a type known as a juvenile polyp. These can form in the stomach, small intestine, colon, and rectum. People with JPS are at increased risk to develop cancers of the colon and stomach. Each child of a parent with JPS is at $50 \%$ risk, or 1 -in-2 risk, to inherit JPS as well.

The health information you provided also shows other reasons you are at risk for colorectal cancer:

- you have a personal history of colorectal cancer

- you have a family history of colorectal cancer

\section{WHAT CAN I DO?}

What you believe about your health and what you expect from your health care is important. Feeling confident in your doctors and that what they recommend can 
take care of your cancer risk can help. Knowing that there are things you can do to lower your risk of colon cancer will make it easier for you to do the things they suggest.

It can be hard to deal with your risk of cancer and to do the things that have been suggested to lower your cancer risk, but they are very important to do to stay healthy. Think about ways you have been able to do this in the past. Ask others for help or support.

The following suggestions are based on guidelines from a national group of experts. They recommend that patients with this problem get their health care from physicians or centers who are experts in JPS.

\section{Talk to your doctor about:}

1. Getting a risk consultation

If you have not already seen a genetic counselor, you may benefit from meeting with one.

- Genetic counselors are experts in hereditary disorders. After you see a genetic counselor, you can check back with him/her if you have more questions later.

- Because you have tested positive for a SMAD4 mutation, your relatives may benefit from being tested for it as well, since mutations can run in families. Your relatives' medical care may change, depending on whether they do or do not have the mutation. A genetic counselor can see your relatives, explain the condition, and arrange the testing.

- To find a genetic counselor at the University of Virginia, call Joanna Horn in the Cancer Genetics Clinic: 434-982-6476.

\section{Getting screened for cancer}

Screening is looking for cancer before a person has any symptoms. By the time symptoms appear, cancer may have begun to spread and be harder to treat.

Removing polyps prevents colorectal cancer from ever starting. Cancers found in an early stage are more easily treated.

- Colorectal cancer usually starts from polyps in the colon or rectum. A polyp is a growth on the inside lining of the colon. Click here to see what polyps look like.

- Over time, some polyps can turn into cancer.

- Screening tests can find polyps so they can be removed before they turn into cancer. 
Screening tests can also find colorectal cancer early. When it is found early, the chance of being cured is good.

Because you have a SMAD4 mutation, experts recommend that you start screening for certain types of cancer earlier than usual.

- Get a colonoscopy to check your colon and rectum for polyps. You should get your first colonoscopy when you are about 15 years old. If no polyps are found, then the next colonoscopy can be done in 2-3 years. However, if polyps are found, then you should get a colonoscopy every year.

- A colonoscopy is an exam that allows a doctor to closely look at the inside of the entire colon. The doctor uses a thin (about the thickness of a finger), flexible, hollow, lighted tube that has a tiny video camera. The exam itself takes about 30 minutes. Patients are usually given medicine to help them relax and sleep during the procedure. It may also have a tool to remove polyps or tissue samples, which are checked under a microscope for cancer.

- Many people get colonoscopies. Click here to watch Katie Couric get a colonoscopy. (Source: Colon Cancer Resource)

- Get an upper endoscopy to check your stomach for polyps, also beginning around age 15. If no polyps are found, then you should get an upper endoscopy every year.

doctor.

To schedule your screening at the University of Virginia, talk to your

3. Lowering your risk

If your screening tests show that you have very many polyps, it might be too hard for the doctor to remove all of them. If this is the case, your doctor may suggest that it would be safer to remove your entire colon or stomach. However, many people will not need this surgery.

\section{WHERE CAN I FIND OUT MORE?}

- Juvenile Polyposis Syndrome (National Library of Medicine)

- Juvenile Polyposis Syndrome (American Society of Clinical Oncology)

- Genetic Counseling FAQs (National Society of Genetic Counselors)

\section{CAUTIONS}


- Your Health Heritage Risk Report is based on personal and/or family history information that you provided. If the information is not correct or is incomplete, this Risk Report may not be correct.

- If your family is very small, Your Risk Report may not be accurate.

- If your personal and/or family health information changes, you should update your information in Health Heritage. Then click "Update My Risk Report", because the new information may change Your Risk Report.

- New knowledge about colorectal cancer risk may also change recommendations in Your Risk Report.

- In addition to your personal and family history, other risk factors such as your lifestyle or environment may also make a difference in your risk for colorectal cancer.

- Your Risk Report does not predict whether you will develop colorectal cancer. It reflects only the evidence for colorectal cancer risk in your personal and family history and is limited by the information you supplied. 


\section{YOUR RISK REPORT SUMMARY}

Risk Level: High

Why: Tested positive for mutation in SMAD4 gene

\section{Actions:}

Consultation

- Meet with genetic counselor

- Have relatives tested for mutation

Screening

- Colonoscopy

- Upper Endoscopy

Lowering Risk

- If screening shows there are many polyps, your doctor might suggest removal of your entire colon or stomach. Not many people will need this surgery. 


\section{YOUR RISK REPORT SUMMARY}

Risk Level: High

Why: Tested positive for mutation in SMAD4 gene

\section{Actions:}

Consultation

- Meet with genetic counselor

- Have relatives tested for mutation

Screening

- Colonoscopy

- Upper Endoscopy

Lowering Risk: If screening shows there are many polyps, your doctor might suggest removal of your entire colon or stomach. Not many people will need this surgery.

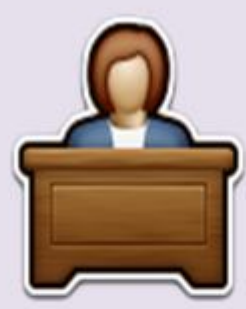

Genetic Counselor

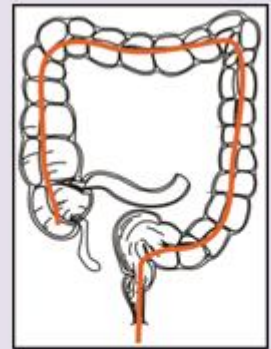

Colonoscopy

Starting at 15 : every $2-3$ years

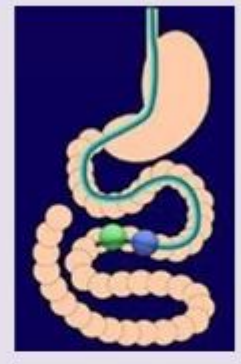

Upper Endoscopy Starting at 15: every year 
Appendix B.1.12: High Risk, Text Summary with Process Icons

\section{YOUR RISK REPORT SUMMARY}

Risk Level: High

Why: Tested positive for mutation in SMAD4 gene

\section{Actions:}

Consultation

- Meet with genetic counselor

- Have relatives tested for mutation

Screening

- Colonoscopy

- Upper Endoscopy

Lowering Risk: If screening shows there are many polyps, your doctor might suggest removal of your entire colon or stomach. Not many people will need this surgery.

\section{What you need to do:}

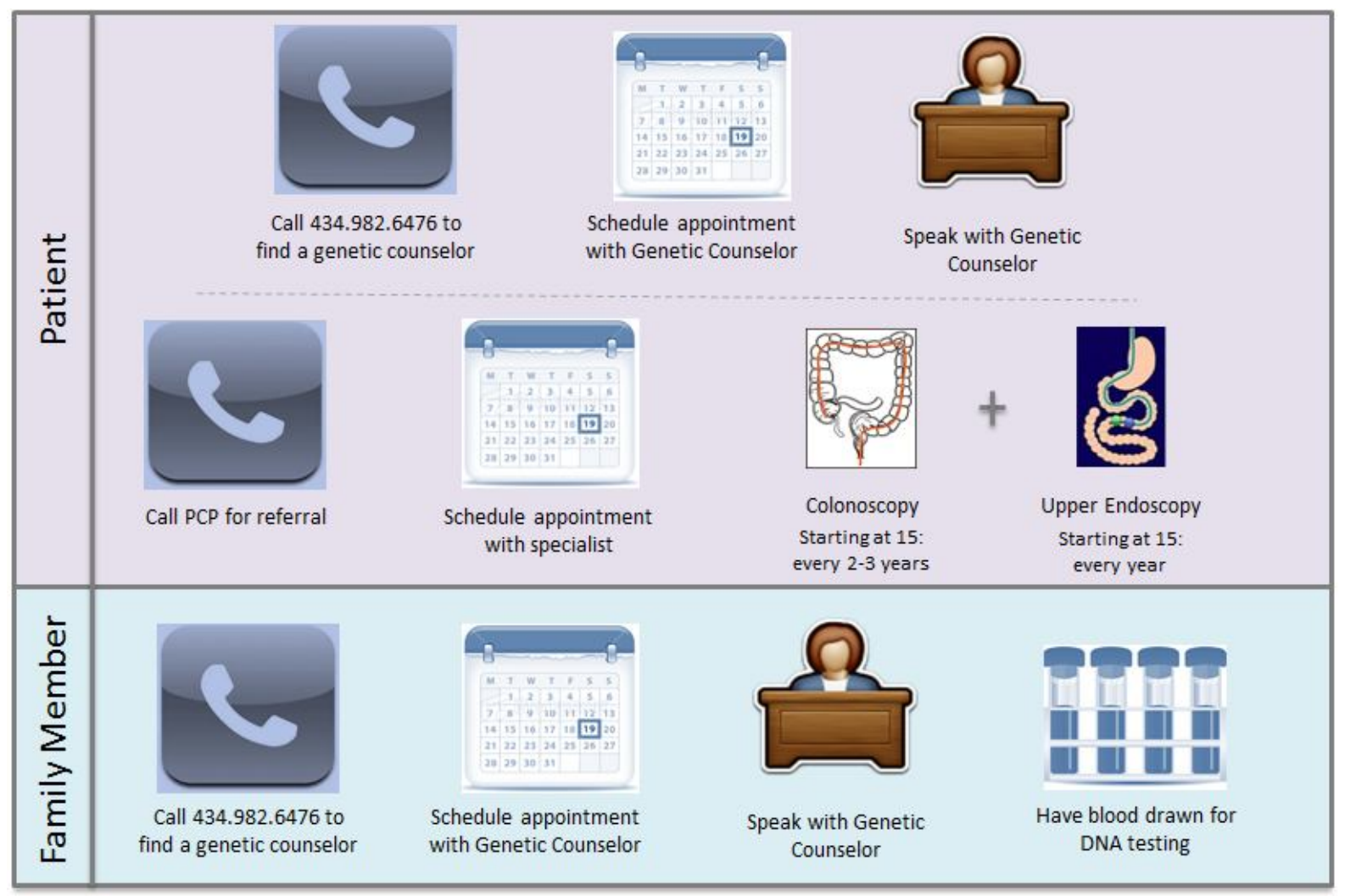


Appendix B.1.13: Icon Citations

- Colonoscopy [33]:

http:// www.fmhs.auckland.ac.nz/soph/centres/goodfellow/cpe/resources/colonoscopy. aspx

- Flexible Sigmoidoscopy [34]: http://www.gimed.net/sigmoidoscopy.html (Plus personal edits)

- Microsatellite Testing [35]:

http:// www.leeds.ac.uk/medicine/intercalated/biochemistry.html

- Immunohistochemistry [36]: http://lifetech-

mp.hosted.jivesoftware.com/groups/microscopy-101

- Upper Endoscopy [37]: http://www.indiamart.com/vgm-hospital/health-services.html

- Genetic Counselor [38]: http://www.mahalo.com/badges/counselor

- Test Tubes [39]: http://www.ahealthblog.com/blood-test-predict-patients-responseantidepressant.html

Appendix B.1.13 Procedure Recommendations by Risk Level

\begin{tabular}{|c|c|c|c|c|}
\hline & & & \multicolumn{2}{|c|}{ Question \# } \\
\hline & & Procedures & Understand & Intent \\
\hline \multirow{7}{*}{$\frac{\frac{n}{10}}{\frac{y}{y}}$} & \multirow{2}{*}{ Population } & Colonoscopy & 7 & 9 \\
\hline & & Flexible Sigmoidoscopy & 8 & 10 \\
\hline & \multirow[b]{2}{*}{ Moderate } & Colonoscopy & 7 & 9 \\
\hline & & $\begin{array}{l}\text { Family Member - } \\
\text { MSI/IHC }\end{array}$ & 8 & 10 \\
\hline & \multirow{3}{*}{ High } & Genetic Counselor & 7 & 10 \\
\hline & & Colonoscopy & 8 & 11 \\
\hline & & Upper Endoscopy & 9 & 12 \\
\hline
\end{tabular}

\section{Appendix B.2: Surveys}

Questionnaires will be used to determine the perceived levels of self-efficacy and understanding of the participants. Demographic questions will also be included in these questionnaires. The purpose of the inclusion of demographic questions is to assess the specific health knowledge background of each participant in the study. The questionnaire includes questions as to whether the participant has any personal experience with cancer (specifically colorectal cancer) themselves or within their family. It also asks if the participant has a medical education background. This information will help to inform whether different report aspects work better for different types of people.

\section{Appendix B.2.1: Survey 1\&2 Questionnaire}

1. Self-efficacy 
a. If I received these results I would feel confident that I could $\varangle$ schedule an appointment with genetic counselor/get a colonoscopy/etc.>

i. Strongly Disagree, Disagree, Neither Agree Nor Disagree, Agree, Strongly Agree

ii. These will be specific per risk level given to each participant

b. If I received these results I would feel confident that the recommendations would help reduce my $\mathrm{CRC}$ risk.

i. Strongly Disagree, Disagree, Neither Agree Nor Disagree, Agree, Strongly Agree

2. Satisfaction

a. How satisfied were you with this report format? (Hornbaek)

i. $0=$ very unsatisfied; $6=$ very satisfied

b. Overall reaction to report (QUIS)

i. Terrible - wonderful (0-9)

c. Overall I liked how the information was formatted.

i. Strongly Disagree, Disagree, Neither Agree Nor Disagree, Agree, Strongly Agree

d. The information is clear and easy to read. (Olson)

i. Strongly Disagree, Disagree, Neither Agree Nor Disagree, Agree, Strongly Agree

3. Understanding

a. Overall I found this report easy to understand

i. Strongly Disagree, Disagree, Neither Agree Nor Disagree, Agree, Strongly Agree

b. If I received this report, I would know what actions I should take.

i. Strongly Disagree, Disagree, Neither Agree Nor Disagree, Agree, Strongly Agree

c. If I had just completed a health survey and received this report, I would find this report helpful.

i. Strongly Disagree, Disagree, Neither Agree Nor Disagree, Agree, Strongly Agree

\section{Appendix B.2.2: Survey 3 Questionnaire}

$\varangle$ Repeat of Survey $1 \& 2$ Questions>

1. Preference

a. Please rank each of these three reports in order from the most preferred (1) to the least preferred (3). (Hornbaek)

2. Demographic Information

a. Gender

i. Male, Female, Prefer not to answer

b. Race (NIH) 
i. Hispanic or Latino; Not Hispanic or Latino

ii. American Indian or Alaska Native, Asian, Native Hawaiian or Other Pacific Islander, Black or African American, White

c. Age group (American M arketing Association)

i. 21 and under, 22-34, 35-44, 45-54, 55-64, 65 and over, Prefer not to answer

d. Do you work in a health related industry (e.g. physician, nurse, pharmacist)?

i. Yes/No

e. Health Status (Anthem)

i. In general, how would you rate your own health? Would you say...

1. Excellent, Good, Fair, Poor, Don't Know, Prefer not to answer

f. Health History

i. Have you or anyone in your family had experience with colorectal cancer?

g. Income Level (Anthem)

i. Less than $\$ 15,000 ; \$ 15,000$ - $\$ 34,999 ; \$ 35,000$ - $\$ 49,999 ; \$ 50,000$ $\$ 74,999 ; \$ 75,000$ - $\$ 99,999 ; \$ 100,000$ - $\$ 149,999 ; \$ 150,000$ or more; Don't know; Prefer not to answer

h. Education Level

i. Please select the highest level of education you have completed:

1. Less than high school education, high school graduate, college graduate, completed advanced graduate or professional degree (M.A./M.S./M.D./J.D./Ph.D.)

i. Learning Type (Olson)

i. Would you describe yourself as a:

1. Text-based learner, Visual Learner, Both/Other, Do not know, Prefer not to answer

Appendix B.2.3: Survey 4 Questionnaire

<Repeat of Survey $1 \& 2$ Questions>

1. Preference (Hornbaek)

a. Having seen the full report, please rank the initial 3 reports and the option of no summary page in order from most preferred (1) to least preferred (4).

2. Attention M aintenance (Frantz)

a. If you were given cover page $1 / 2 / 3$ of the report, how much would you read the full report?

i. Not at all, skim somewhat, skim, read most, read all

\section{Appendix B.3: Directional Script}

The purpose of directional scripts is so each participant in the study will start with the same information and be instructed in the same way. This is meant to give the participants a baseline 
level of knowledge. The directional scripts include word-for-word statements to deliver as well as instructions on which materials to administer and when.

$\mathrm{Hi}$, my name is , I'm a student at the University of Virginia. We're conducting a study to assess different designs of health risk communication materials. If you are willing to participate I will show you a few different generic reports and then have you respond to surveys regarding your opinion on them. This is completely voluntary, and you may decide to stop at any time. Your responses will be anonymous and this should take less than 15 minutes.

Would you like to participate in this study? «Receive Verbal Yes/No >

Great, let's get started. We're working with a tool known as Health Heritage which takes a patient's personal and family health history and generates a cancer risk report. This risk report provides information regarding the patient's risk level for specific cancer and recommendations as to what to do to mitigate that risk.

For this study, you will be shown a series of 3 pages. These are each potential front pages of the full risk report for colorectal cancer (which you will see at the end). I'd like you to imagine that the reports you are seeing were generated based on your personal and family health histories.

$\varangle$ Give first report> Here is your first example. Please take your time to review, and when you are ready answer the questions on this survey. «Give first survey>

$\varangle$ Give second report> Here is your second example. Again, please take your time to review the information and then respond to the survey when you are ready. «Give second survey>

$\varangle$ Give third report>Here is your third example. The survey for this report contains the same questions as the first two, but also contains a few additional questions which have you compare the reports, and some demographic questions for you to answer. Feel free to leave questions you do not feel comfortable with, or do not know the answer to, blank. «Give third survey>

$\varangle$ Give full report> This is the full Health Heritage report that patients currently receive. I'd like you to read through this, and then I have a fourth survey for you to respond to. If you run out of time, you can take the full report with you, and I have surveys which can be mailed back once you have had time to review. «Give fourth survey, and envelope if necessary>

Thank you for your participation in this study. If you have any further questions on this study please contact me. «Give contact card> 


\section{Appendix C- Original Task Analysis}

\begin{tabular}{|c|c|c|c|c|c|c|c|c|c|c|c|c|c|}
\hline & & $\begin{array}{l}\text { Call PCP } \\
\text { For } \\
\text { appt/ for } \\
\text { referral }\end{array}$ & $\begin{array}{l}\text { Call } \\
\text { PCP } \\
\text { for } \\
\text { appt }\end{array}$ & $\begin{array}{l}\text { Call } \\
\text { specialist }\end{array}$ & $\begin{array}{l}\text { Call for } \\
\text { info on } \\
\text { gen } \\
\text { counselor }\end{array}$ & $\begin{array}{l}\text { Call gen } \\
\text { counselor } \\
\text { for appt }\end{array}$ & $\begin{array}{l}\text { Personal } \\
\text { action } \\
\text { Self } \\
\text { exam, } \\
\text { workout, } \\
\text { maintain } \\
\text { low } \\
\text { weight }\end{array}$ & $\begin{array}{l}\text { Speak } \\
\text { with gen } \\
\text { counselor }\end{array}$ & $\begin{array}{l}\text { Have test } \\
\text { performed }\end{array}$ & $\begin{array}{l}\text { Have } \\
\text { screening } \\
\text { done }\end{array}$ & Procedure & $\begin{array}{l}\text { Invasive } \\
\text { procedure }\end{array}$ & $\begin{array}{l}\text { Follow- } \\
\text { up/Repeat } \\
\text { at certain } \\
\text { interval }\end{array}$ \\
\hline 1 & $\begin{array}{l}\text { M utation specific } \\
\text { testing for familial } \\
\text { members }\end{array}$ & $F$ & & & & & & & $F$ & & & & \\
\hline 2 & $\begin{array}{l}\text { Send patient to } \\
\text { physician or center } \\
\text { with expertise }\end{array}$ & & & $P$ & & & & $P$ & & & & & \\
\hline 3 & $\begin{array}{l}\text { Send patient for gen } \\
\text { services and DNA } \\
\text { testing/etc }\end{array}$ & & & & $P$ & $P$ & & $P$ & $P$ & & & & \\
\hline 4 & $\begin{array}{l}\text { Follow up w genetic } \\
\text { services }\end{array}$ & & & & & $P$ & & $P$ & & & & & \\
\hline 5 & $\begin{array}{l}\text { Genetic services for } \\
\text { family members }\end{array}$ & & & & $P$ & $F$ & & $F$ & & & & & \\
\hline 6 & $\begin{array}{l}\text { Review and update } \\
\text { pedigree?? }\end{array}$ & & & & & & & & & & & & \\
\hline 7 & $\begin{array}{l}\text { Until high-risk ruled } \\
\text { out get melanoma } \\
\text { screening/pancreatic } \\
\text { cancer screening }\end{array}$ & $P ?$ & & $P$ & & & & & & $P$ & & & \\
\hline 8 & $\begin{array}{l}\text { Send patient to } \\
\text { melanoma screening }\end{array}$ & $P$ & & $P$ & & & & & & $P$ & & & \\
\hline
\end{tabular}




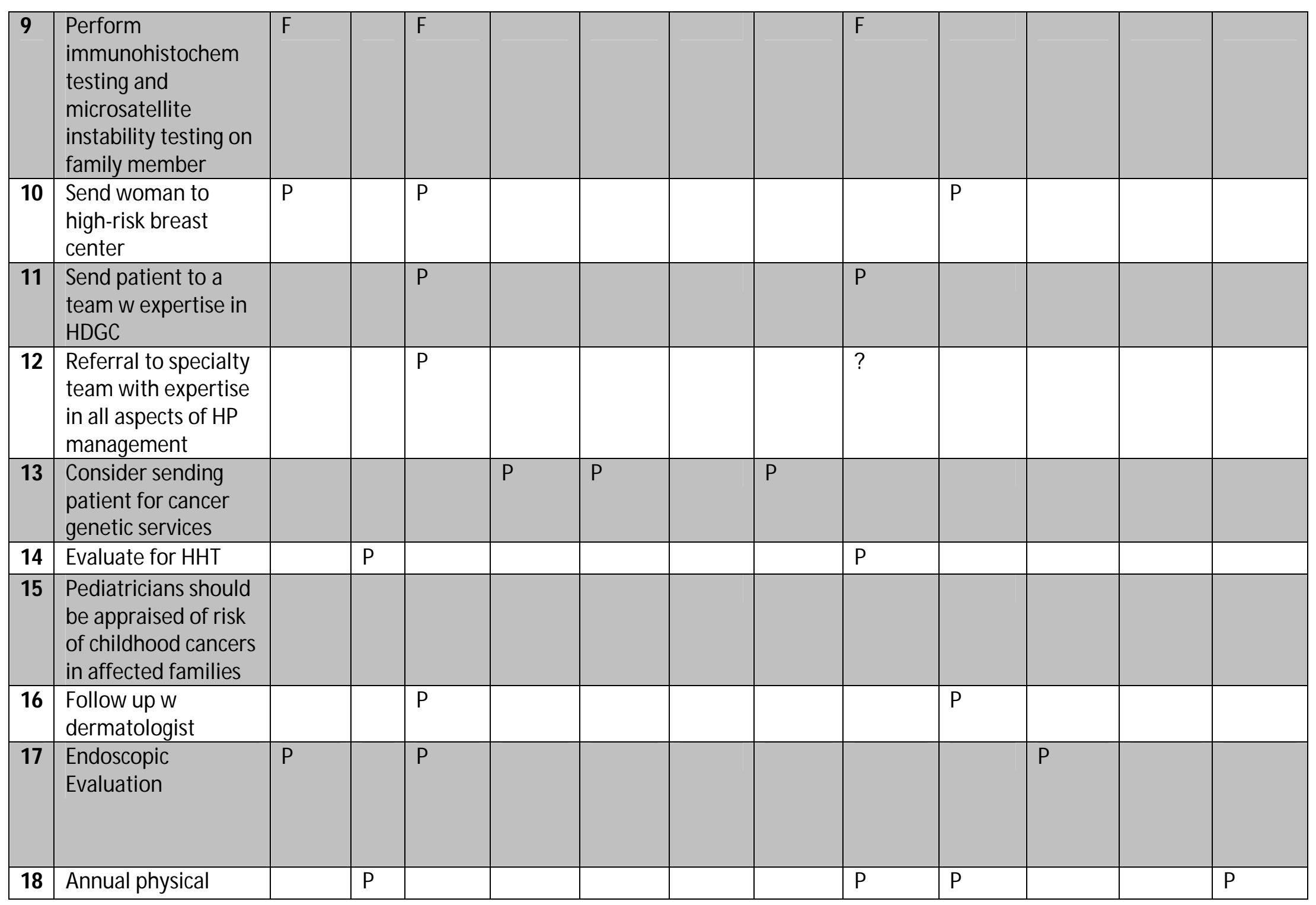




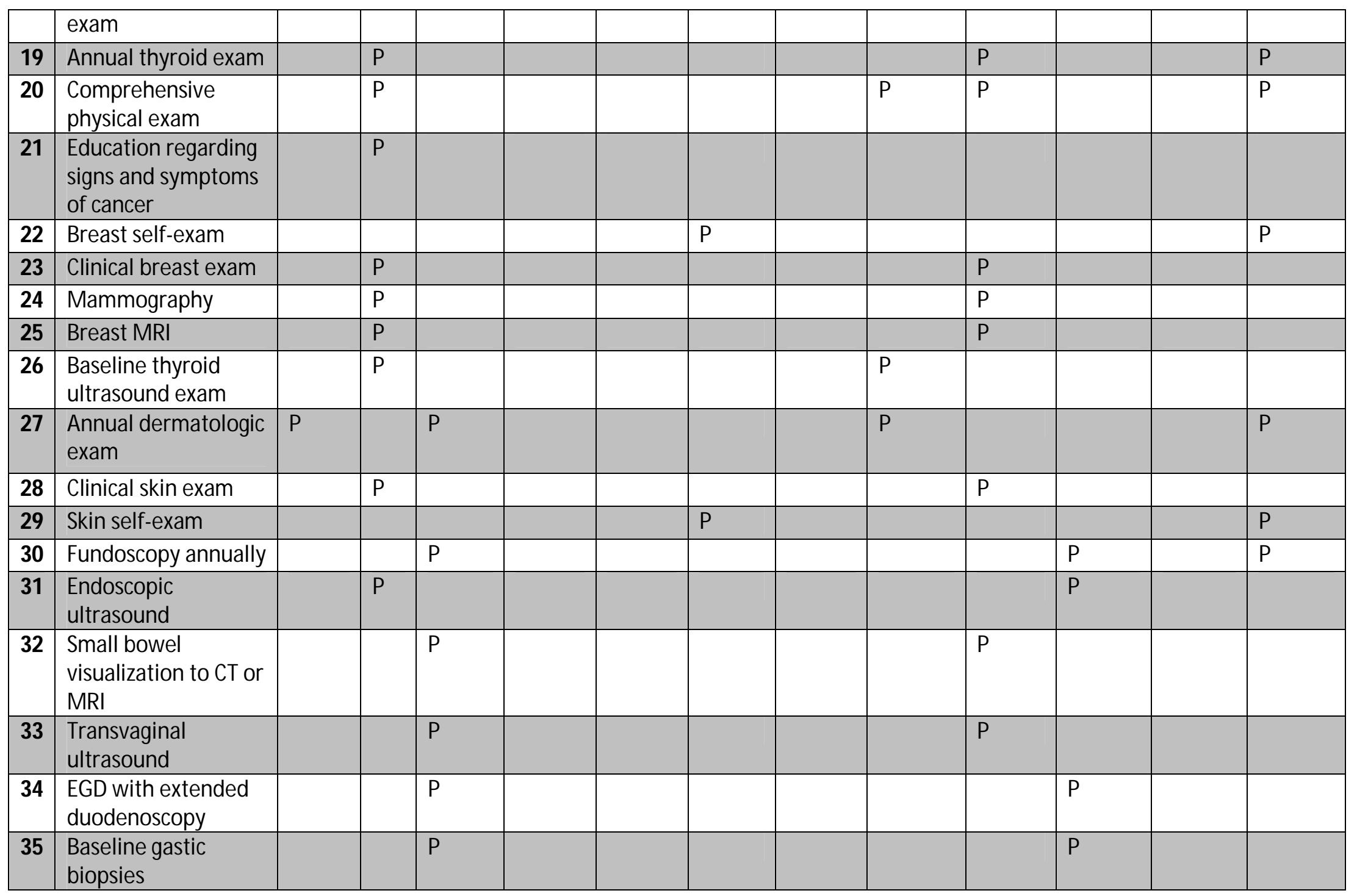




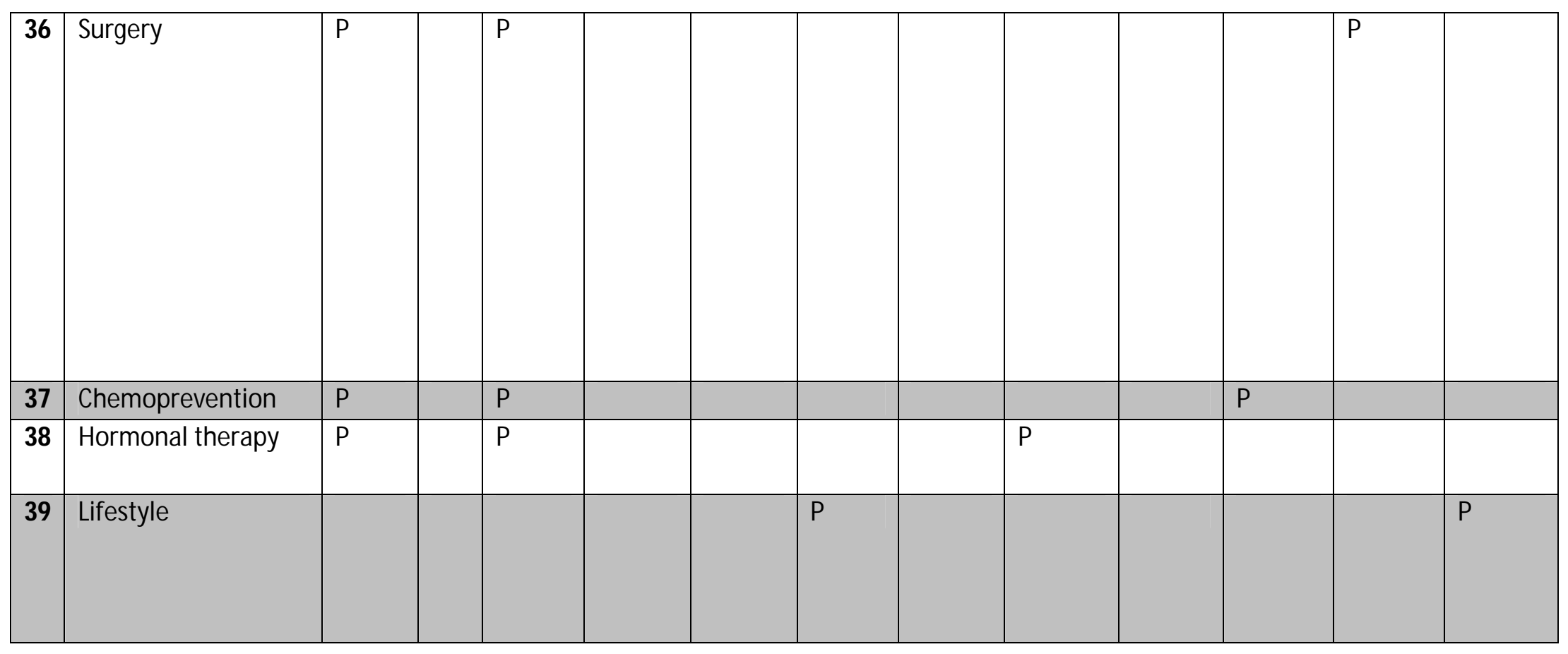

P - Patient Action, F - Family M ember Action 


\section{Appendix D - Aggregated Task Analysis}

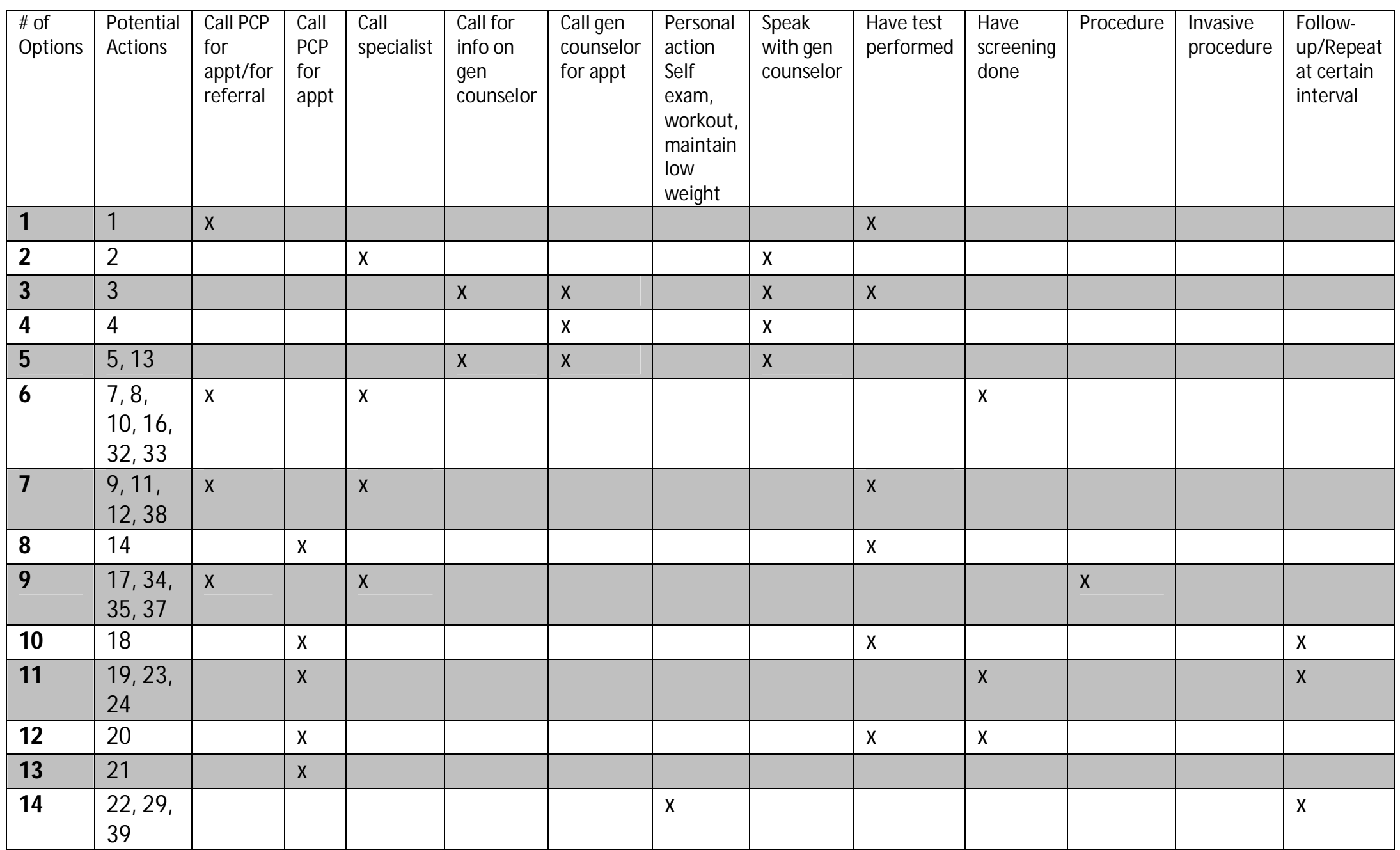




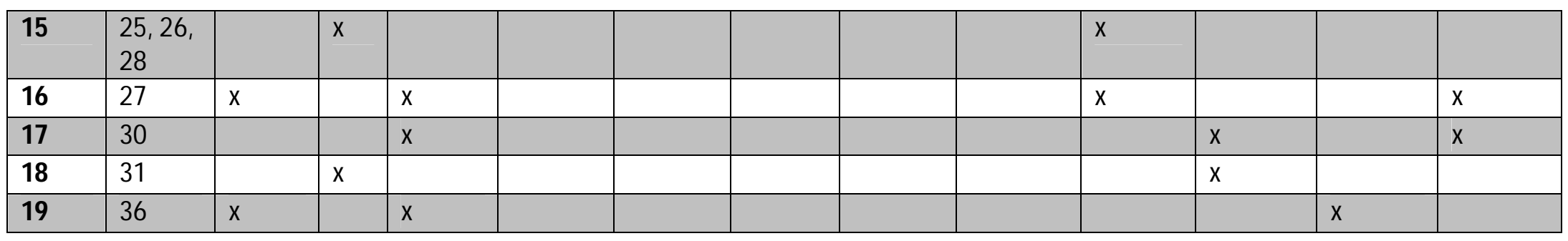




\section{Appendix E - Sample Size Calculations}

For standard deviation of 0.6 :
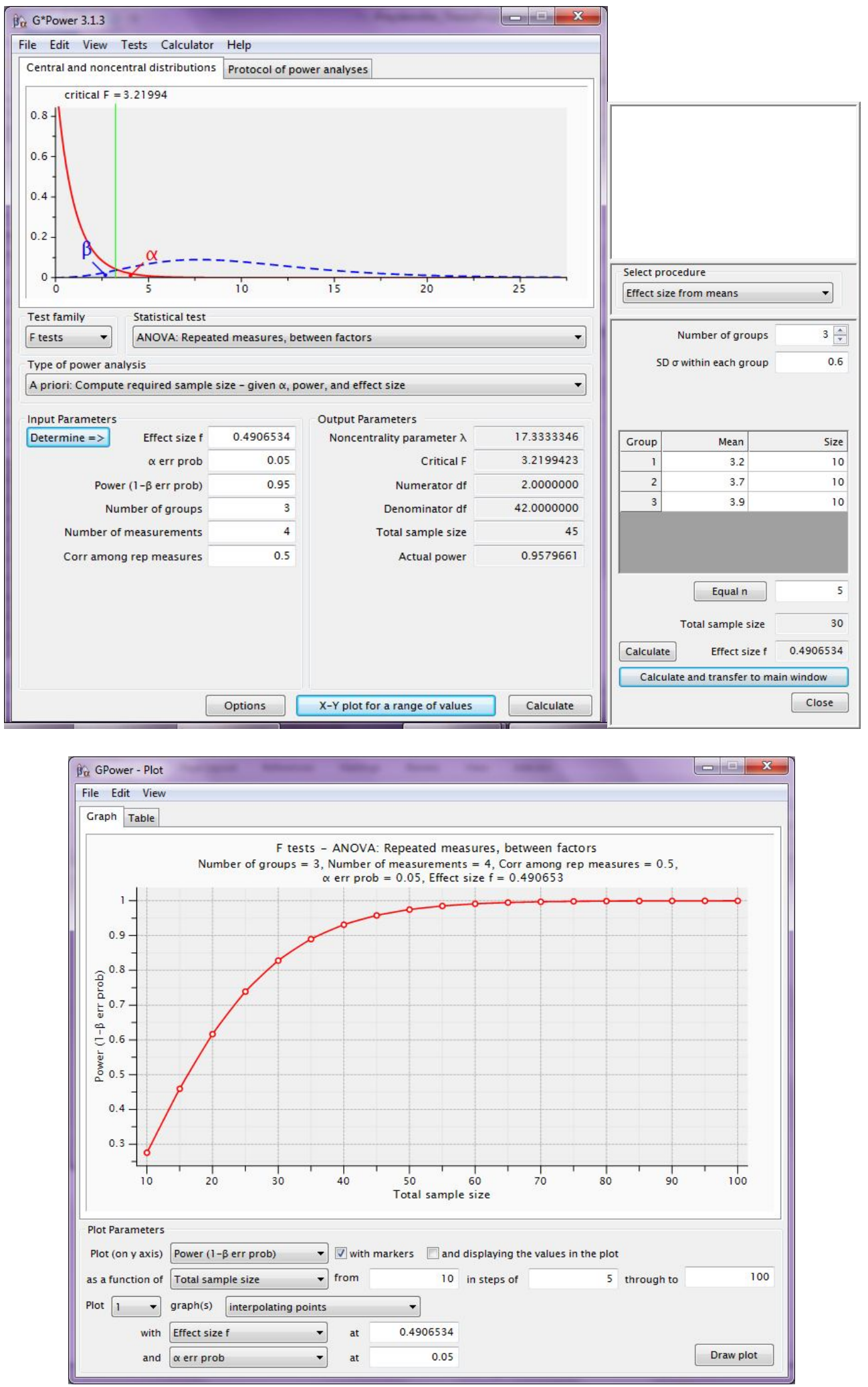


\section{Appendix F - Experimental Design}

\section{Appendix F.1 - Participant Order}

\begin{tabular}{|l|l|}
\hline \multicolumn{2}{|l|}{ Legend } \\
\hline A & Text Summary \\
\hline B & Summary with Activity Icons \\
\hline C & Summary with Process Icons \\
\hline D & Original Report \\
\hline
\end{tabular}

\begin{tabular}{|c|c|c|c|c|c|c|c|c|}
\hline Groups & Risk Level & \multirow{2}{*}{$\begin{array}{c}\text { Participants } \\
1 \\
\end{array}$} & \multicolumn{4}{|c|}{ Format of Report } & \multirow{2}{*}{$\begin{array}{c}\text { Completed } \\
\text { Yes } \\
\end{array}$} & \multirow{2}{*}{$\frac{\text { Makeup }}{\mathrm{N} / \mathrm{A}}$} \\
\hline \multirow{12}{*}{1} & \multirow{12}{*}{$\frac{\text { 든 }}{\frac{0}{1}}$} & & A & $\mathrm{B}$ & $\mathrm{C}$ & $D$ & & \\
\hline & & 2 & A & C & B & $\mathrm{D}$ & No & 37 \\
\hline & & 3 & $\mathrm{~B}$ & A & $\mathrm{C}$ & $\mathrm{D}$ & No & 45 \\
\hline & & 4 & $\mathrm{~B}$ & C & A & $\mathrm{D}$ & Yes & N/A \\
\hline & & 5 & C & A & $B$ & $\mathrm{D}$ & Yes & N/A \\
\hline & & 6 & $\mathrm{C}$ & B & A & $\mathrm{D}$ & Yes & $\mathrm{N} / \mathrm{A}$ \\
\hline & & 7 & A & B & C & D & No & 38 \\
\hline & & 8 & A & C & B & $\mathrm{D}$ & Yes & $\mathrm{N} / \mathrm{A}$ \\
\hline & & 9 & $\mathrm{~B}$ & A & $\mathrm{C}$ & $\mathrm{D}$ & Yes & $\mathrm{N} / \mathrm{A}$ \\
\hline & & 10 & $\mathrm{~B}$ & $\mathrm{C}$ & A & D & Yes & $\mathrm{N} / \mathrm{A}$ \\
\hline & & 11 & $\mathrm{C}$ & A & B & D & No & 39 \\
\hline & & 12 & C & $B$ & A & $\mathrm{D}$ & Yes & $\mathrm{N} / \mathrm{A}$ \\
\hline \multirow{12}{*}{2} & \multirow{12}{*}{$\begin{array}{l}\frac{.}{0} \\
\frac{0}{0} \\
\frac{\pi}{2} \\
0 \\
0\end{array}$} & 13 & A & $B$ & C & $\mathrm{D}$ & Yes & $\mathrm{N} / \mathrm{A}$ \\
\hline & & 14 & A & C & $B$ & $\mathrm{D}$ & Yes & $\mathrm{N} / \mathrm{A}$ \\
\hline & & 15 & $B$ & $A$ & $C$ & $D$ & Yes & $\mathrm{N} / \mathrm{A}$ \\
\hline & & 16 & B & $C$ & A & $D$ & Yes & $\mathrm{N} / \mathrm{A}$ \\
\hline & & 17 & C & A & $B$ & $D$ & Yes & $\mathrm{N} / \mathrm{A}$ \\
\hline & & 18 & C & $B$ & A & $\mathrm{D}$ & No & 40 \\
\hline & & 19 & $\mathrm{~A}$ & $B$ & $C$ & $D$ & Yes & N/A \\
\hline & & 20 & A & $C$ & $B$ & $D$ & Yes & $\mathrm{N} / \mathrm{A}$ \\
\hline & & 21 & B & A & $C$ & $D$ & Yes & N/A \\
\hline & & 22 & $B$ & C & A & $D$ & Yes & $\mathrm{N} / \mathrm{A}$ \\
\hline & & 23 & C & A & $B$ & $D$ & Yes & $\mathrm{N} / \mathrm{A}$ \\
\hline & & 24 & C & $B$ & A & $D$ & Yes & $\mathrm{N} / \mathrm{A}$ \\
\hline \multirow{5}{*}{3} & \multirow{5}{*}{$\begin{array}{l}\frac{0}{\frac{0}{0}} \\
\frac{0}{8} \\
\frac{0}{\Sigma}\end{array}$} & 25 & A & B & C & D & No & 41 \\
\hline & & 26 & A & C & B & $D$ & No & 46 \\
\hline & & 27 & B & A & $C$ & $D$ & Yes & $\mathrm{N} / \mathrm{A}$ \\
\hline & & 28 & $B$ & C & A & $D$ & Yes & $\mathrm{N} / \mathrm{A}$ \\
\hline & & 29 & C & A & B & D & No & 42 \\
\hline
\end{tabular}




\begin{tabular}{|c|c|c|c|c|c|c|c|c|}
\hline & & 30 & C & B & A & D & No & 43 \\
\hline & & 31 & A & B & C & D & No & 47 \\
\hline & & 32 & A & C & B & D & Yes & $\mathrm{N} / \mathrm{A}$ \\
\hline & & 33 & $B$ & A & $C$ & $D$ & Yes & $\mathrm{N} / \mathrm{A}$ \\
\hline & & 34 & B & C & A & D & Yes & $\mathrm{N} / \mathrm{A}$ \\
\hline & & 35 & C & A & B & D & Yes & $\mathrm{N} / \mathrm{A}$ \\
\hline & & 36 & C & B & A & D & No & 44 \\
\hline \multirow{13}{*}{$\begin{array}{l}\frac{O}{\vec{d}} \\
\frac{\mathrm{v}}{\mathrm{N}} \\
\Sigma\end{array}$} & High & 37 & $A$ & $C$ & $B$ & $D$ & No & 48 \\
\hline & High & 38 & A & $B$ & C & $\mathrm{D}$ & Yes & $\mathrm{N} / \mathrm{A}$ \\
\hline & High & 39 & C & A & B & D & Yes & $\mathrm{N} / \mathrm{A}$ \\
\hline & Moderate & 40 & C & B & A & D & Yes & $\mathrm{N} / \mathrm{A}$ \\
\hline & Moderate & 41 & A & B & C & D & Yes & $\mathrm{N} / \mathrm{A}$ \\
\hline & Moderate & 42 & C & A & B & D & Yes & $\mathrm{N} / \mathrm{A}$ \\
\hline & Moderate & 43 & C & $B$ & A & $\mathrm{D}$ & Yes & $\mathrm{N} / \mathrm{A}$ \\
\hline & Moderate & 44 & C & $B$ & A & $\mathrm{D}$ & Yes & $\mathrm{N} / \mathrm{A}$ \\
\hline & High & 45 & $B$ & A & $C$ & $D$ & Yes & $\mathrm{N} / \mathrm{A}$ \\
\hline & Moderate & 46 & A & C & $B$ & $D$ & Yes & $\mathrm{N} / \mathrm{A}$ \\
\hline & High & 47 & A & $B$ & $C$ & $\mathrm{D}$ & Yes & $\mathrm{N} / \mathrm{A}$ \\
\hline & Moderate & 48 & A & $C$ & $B$ & $\mathrm{D}$ & No & 49 \\
\hline & High & 49 & A & C & B & D & Yes & $\mathrm{N} / \mathrm{A}$ \\
\hline
\end{tabular}

\section{Appendix F.2 - Study Variables}

\section{Appendix F.2.1 - Independent Variables}

The independent variables are:

- Risk level of the report

$$
\begin{array}{ll}
\text { - Population } \\
\text { - Moderate } \\
\text { - High }
\end{array}
$$

- Format of the report

$$
\begin{array}{ll}
- & \text { Original } \\
- & \text { Text Summary only } \\
\text { - Text Summary + Activity Icons } \\
\text { - Text Summary + Process Icons }
\end{array}
$$

- Order of display of formats

- 3 unique orderings per risk level

- Original report always last 


\section{Appendix F.2.2 - Dependent Variables}

The dependent variables include data collected from the surveys. The participants will answer survey questions with Likert scales associated.

Description of dependent variables:

- Self-efficacy: self-efficacy relates to the confidence the participant has in being able to carry out an action. Bandura states that "unless people believe they can produce desired results and forestall detrimental ones by their actions, they have little incentive to act or to persevere in the face of difficulties... It is partly on the basis of efficacy beliefs that people choose what challenges to undertake, how much effort to expend in the endeavor, [and] how long to persevere in the face of obstacles and failures."[40] In health communication, the hope is to encourage high self-efficacy so the patient will take action to mitigate their risk.

- This study will focus on the following two categories of self-efficacy:

- Confidence in being able to complete intervention

- Confidence in effectiveness of intervention in reducing risk of cancer

- Satisfaction: this measure is meant to determine the subjective satisfaction and perception of the ease-of-use of the individual report formats. Questions will ask the participant how satisfied $s /$ he is with the information, the way it is displayed and format generally. [41] They will also be asked if they found the report easy-to-use and then additionally to rank their reaction to the report as is done in QUIS. [18]

- Perceived Clarity of Information: this measure is meant to determine how clear the user perceives the information to be.

- Perception of Comprehension: this measure is to evaluate the users' perception of comprehension and learning of the information provided. [42]

- Ease-of-Use: this will measure general satisfaction with the interface. [41]

- Preference: this measure will require the participants to put in rank order the different versions of the report which they see. They will answer this question twice, once after seeing the initial 3 reports, and then again after seeing the whole $4^{\text {th }}$ report. 


\section{Appendix G - Demographic Statistics}

\section{Chart 1 - Gender Breakdown}

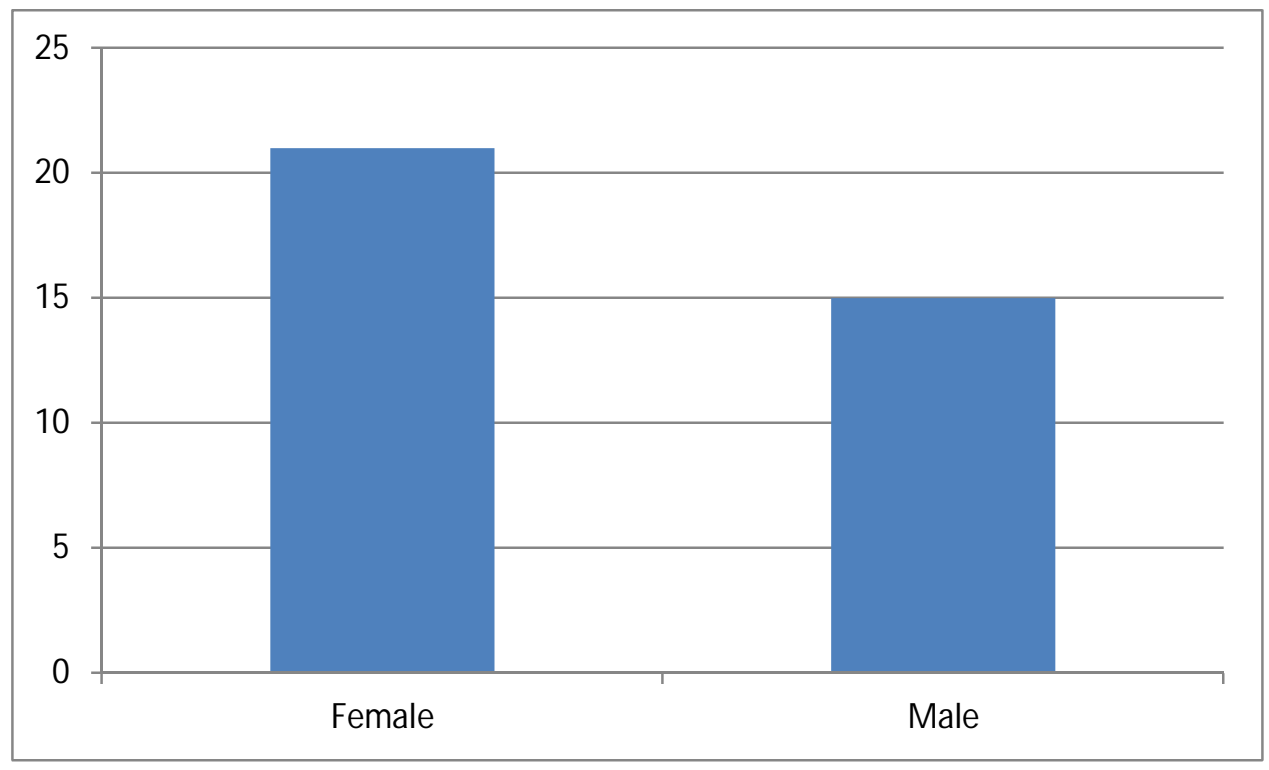

Chart 2 - Gender Breakdown by Risk Level

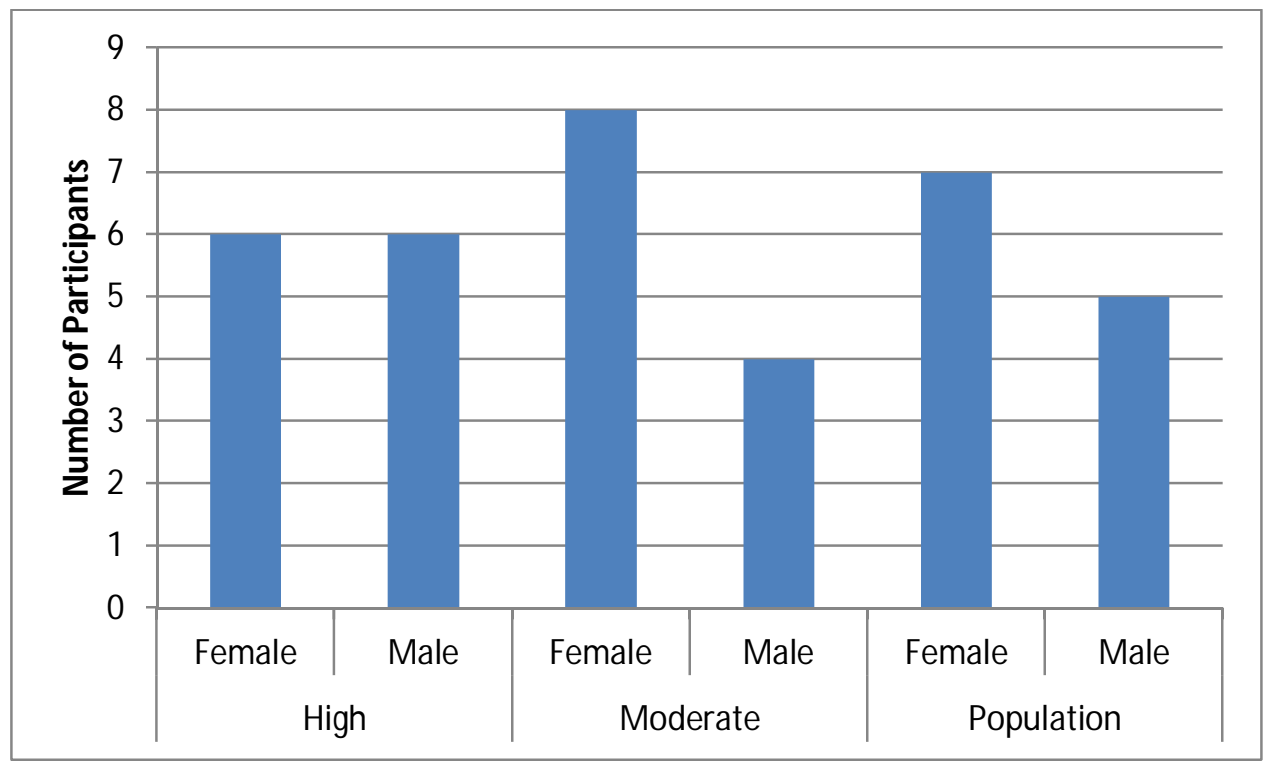


Chart 3 - Age Buckets

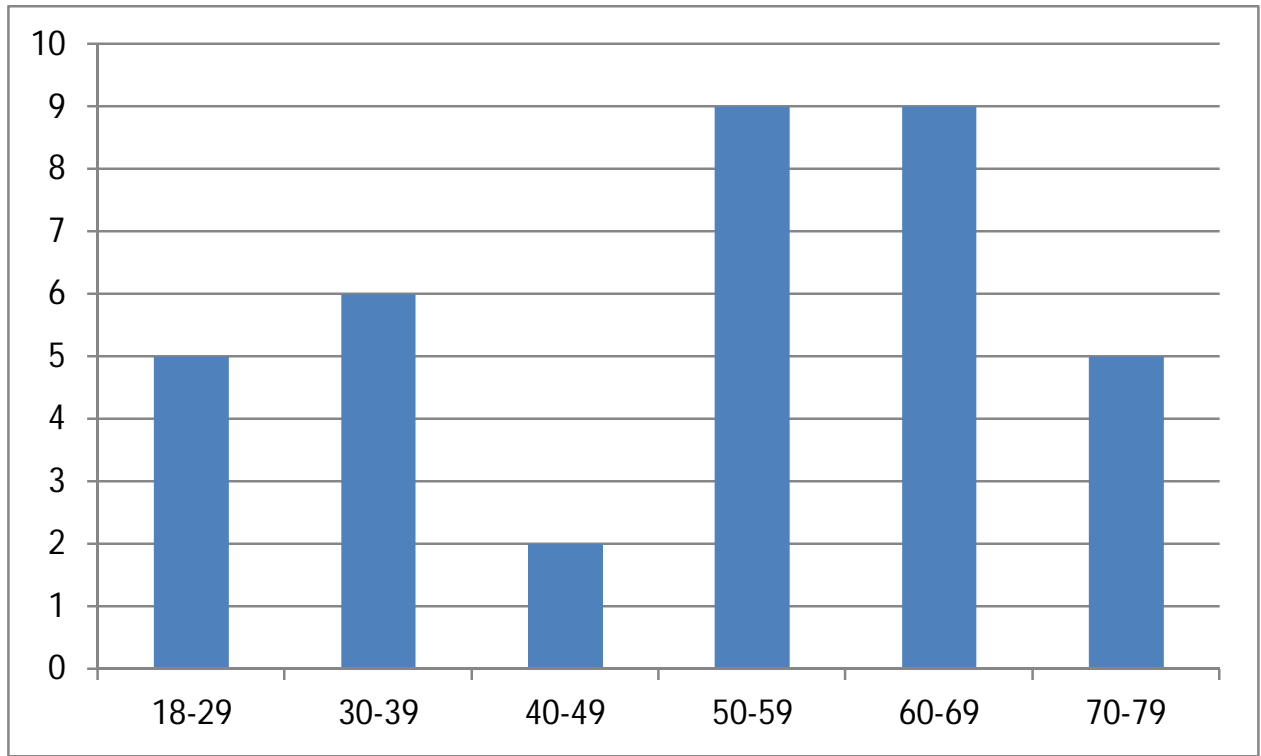


Chart 4 - Race

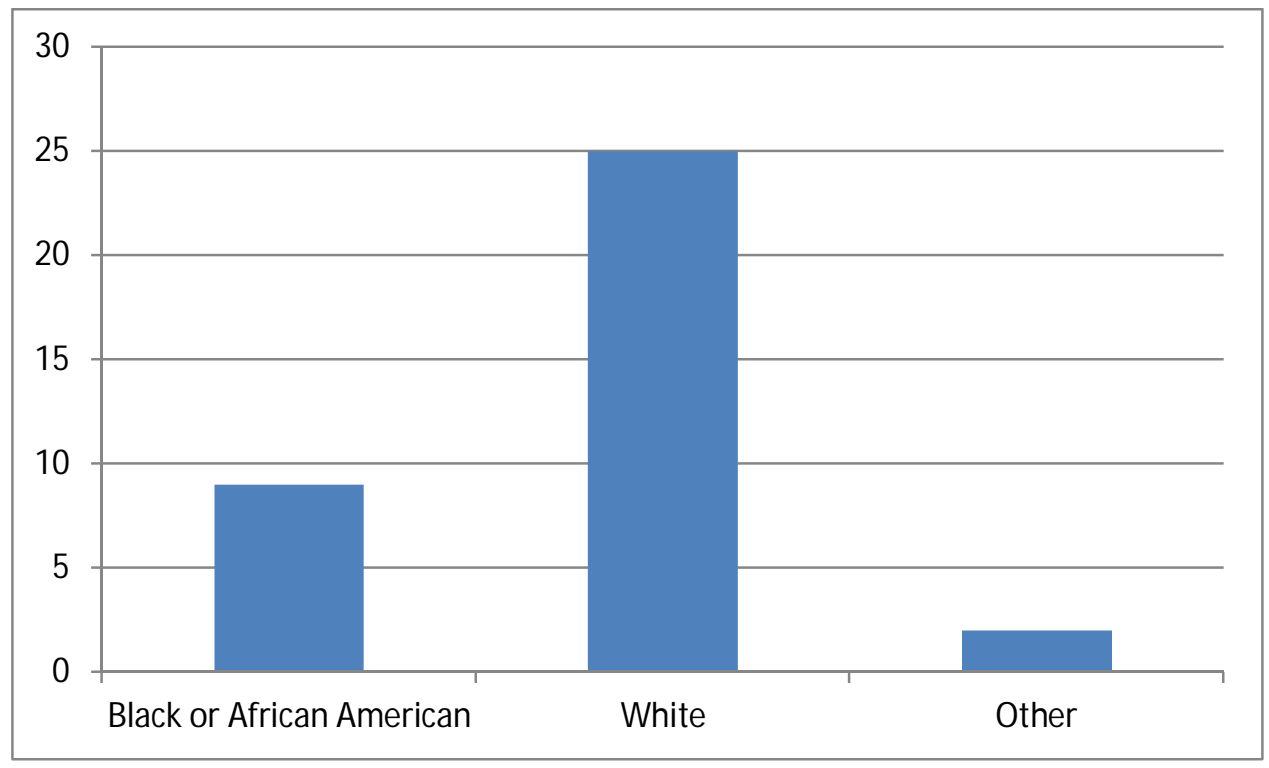

\section{Chart 5 - Income Levels}

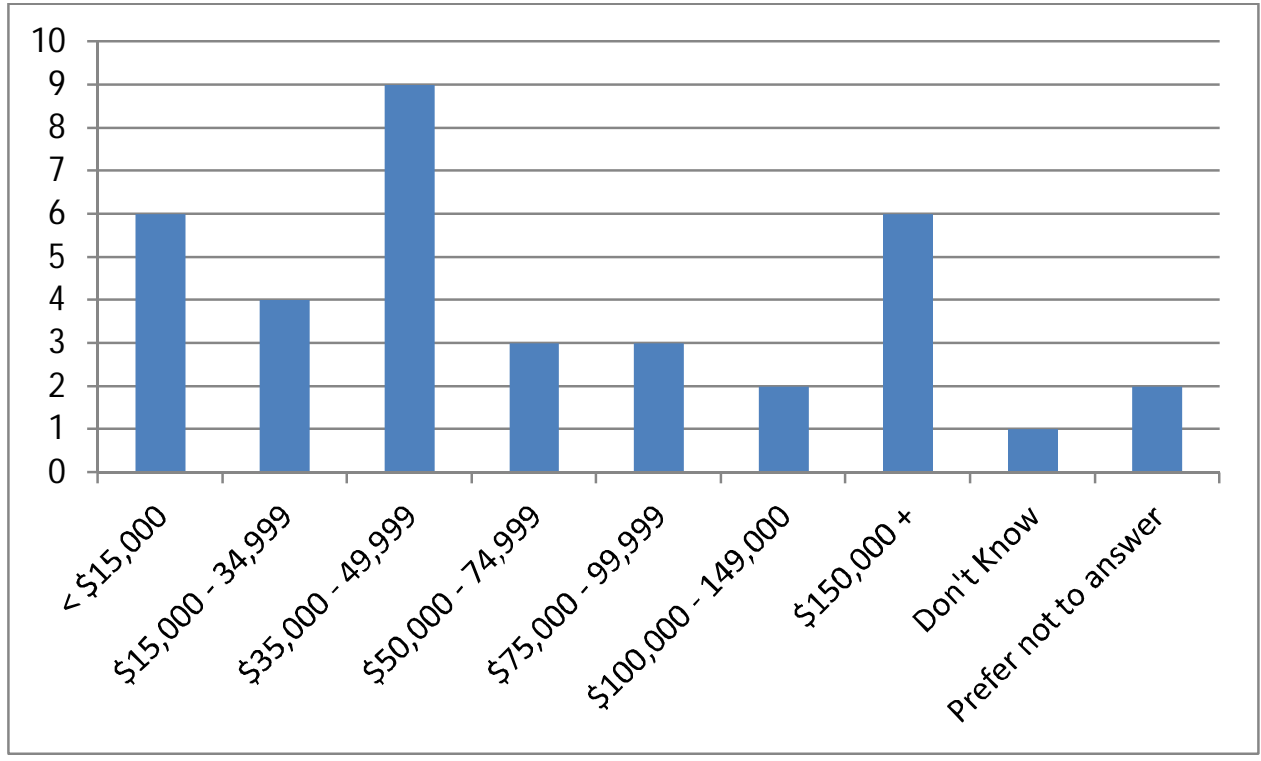




\section{Chart 6 - Education Levels}

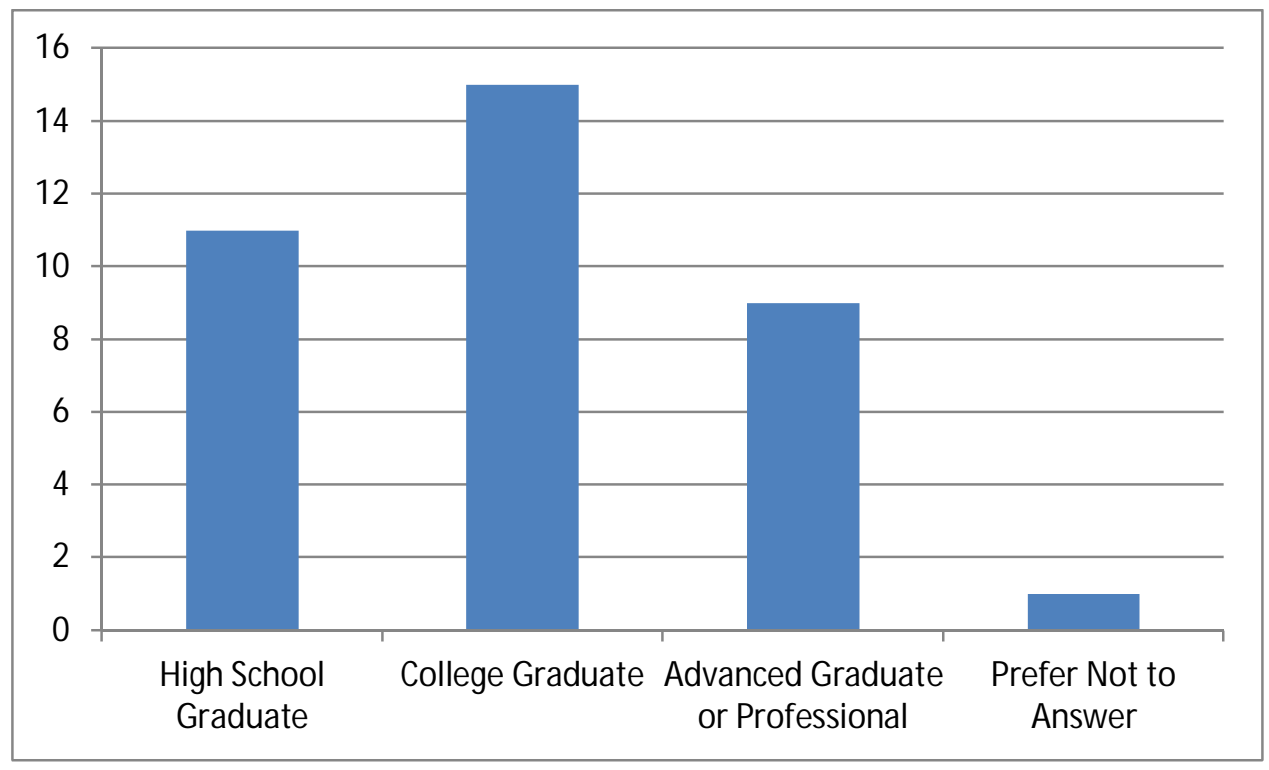

\section{Chart 7 - Health Status}

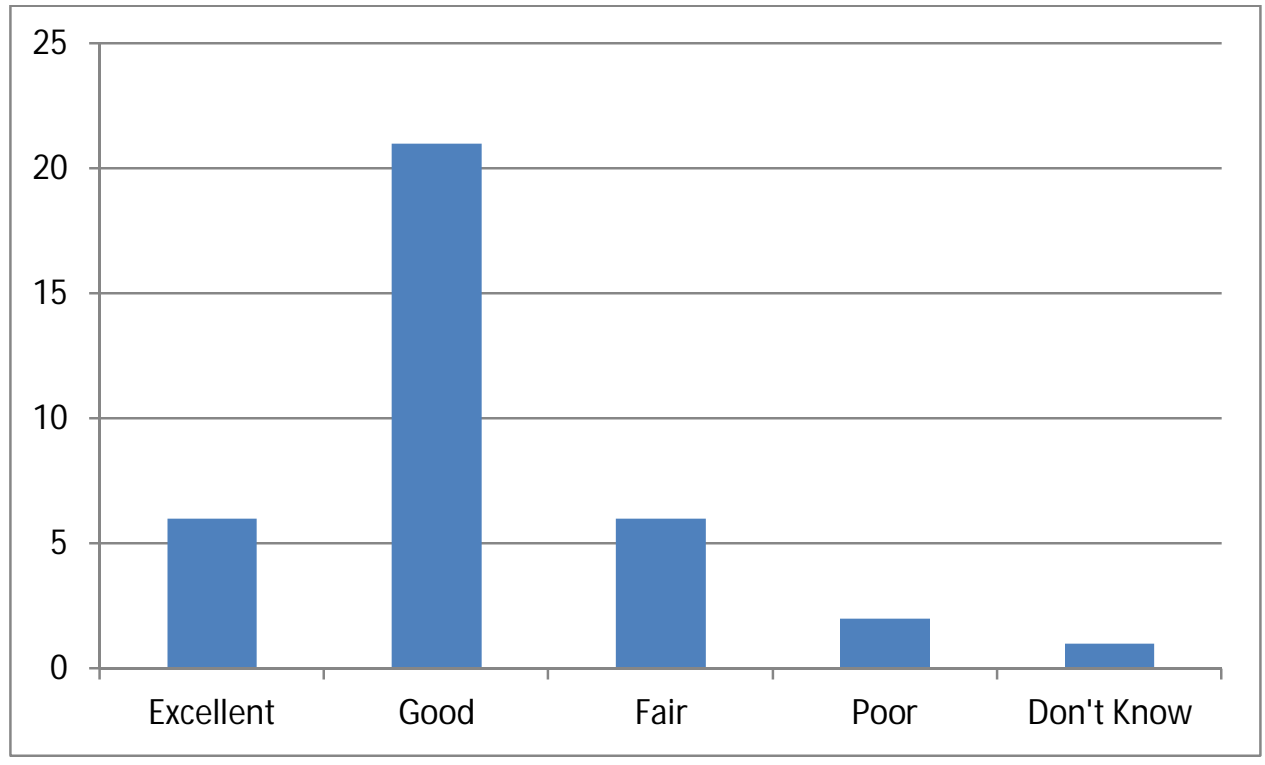


Appendix F - Average Response Graphs

Appendix F.1 - Average Response per Procedure by Summary Type

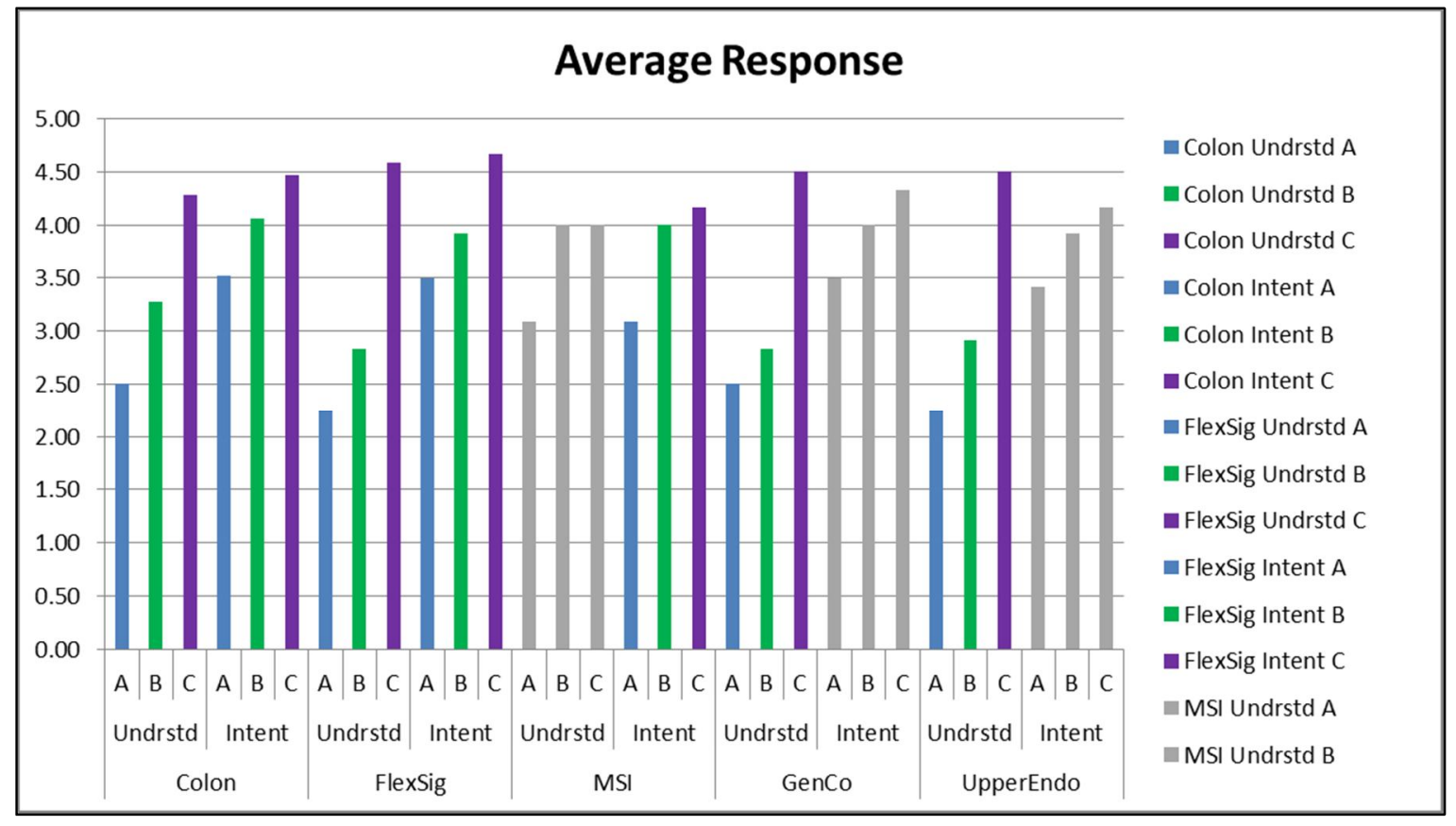

Grey columns are not statistically significant at alpha $=0.05$

Appendix F.2 - Average Response per Question by Order Type

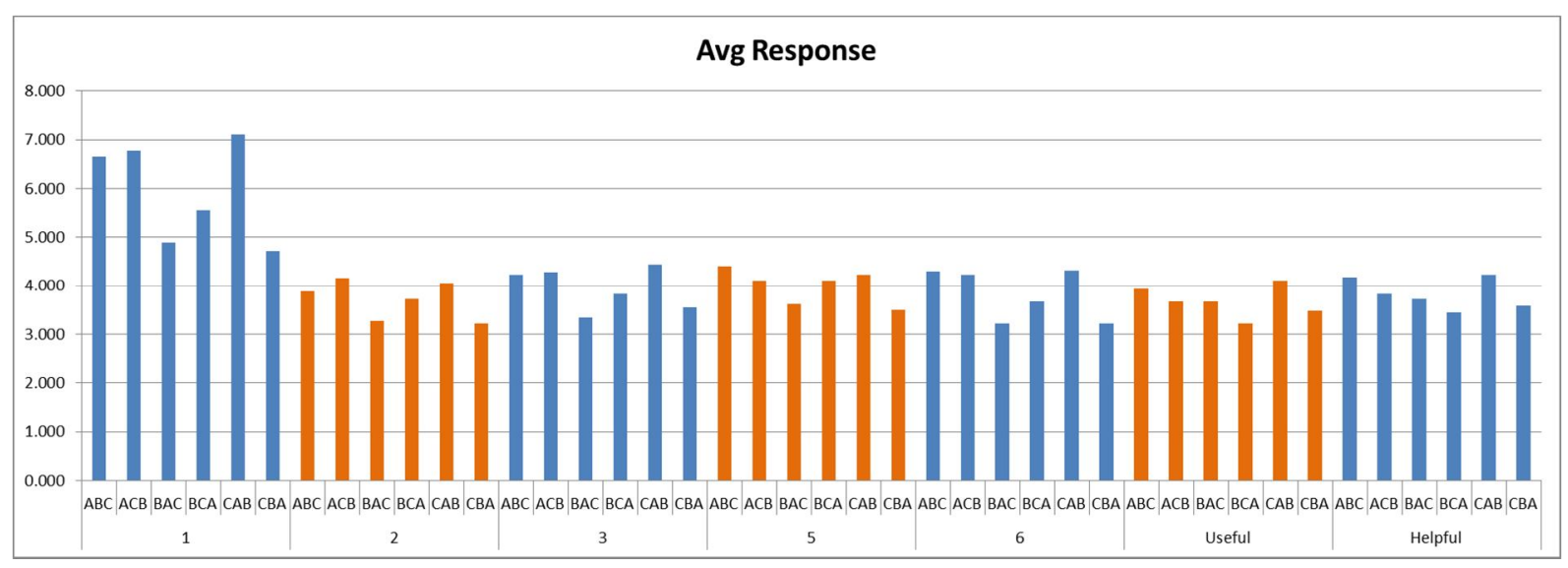




\section{Appendix G - Data Analysis Per Question}

\section{Appendix G.1 - Layout and Design Questions (1-3)}

Analysis of the data concerning participants overall reaction to the three summary page types indicated that subjects significantly preferred Summary Type C (containing process information) more than either $\mathrm{A}$ or $\mathrm{B}$.

\section{Appendix G.1.1 - Question 1}

Question 1: Which number best represents your overall reaction to this summary page type? Responses: 0 (Terrible) to 9 (Wonderful).
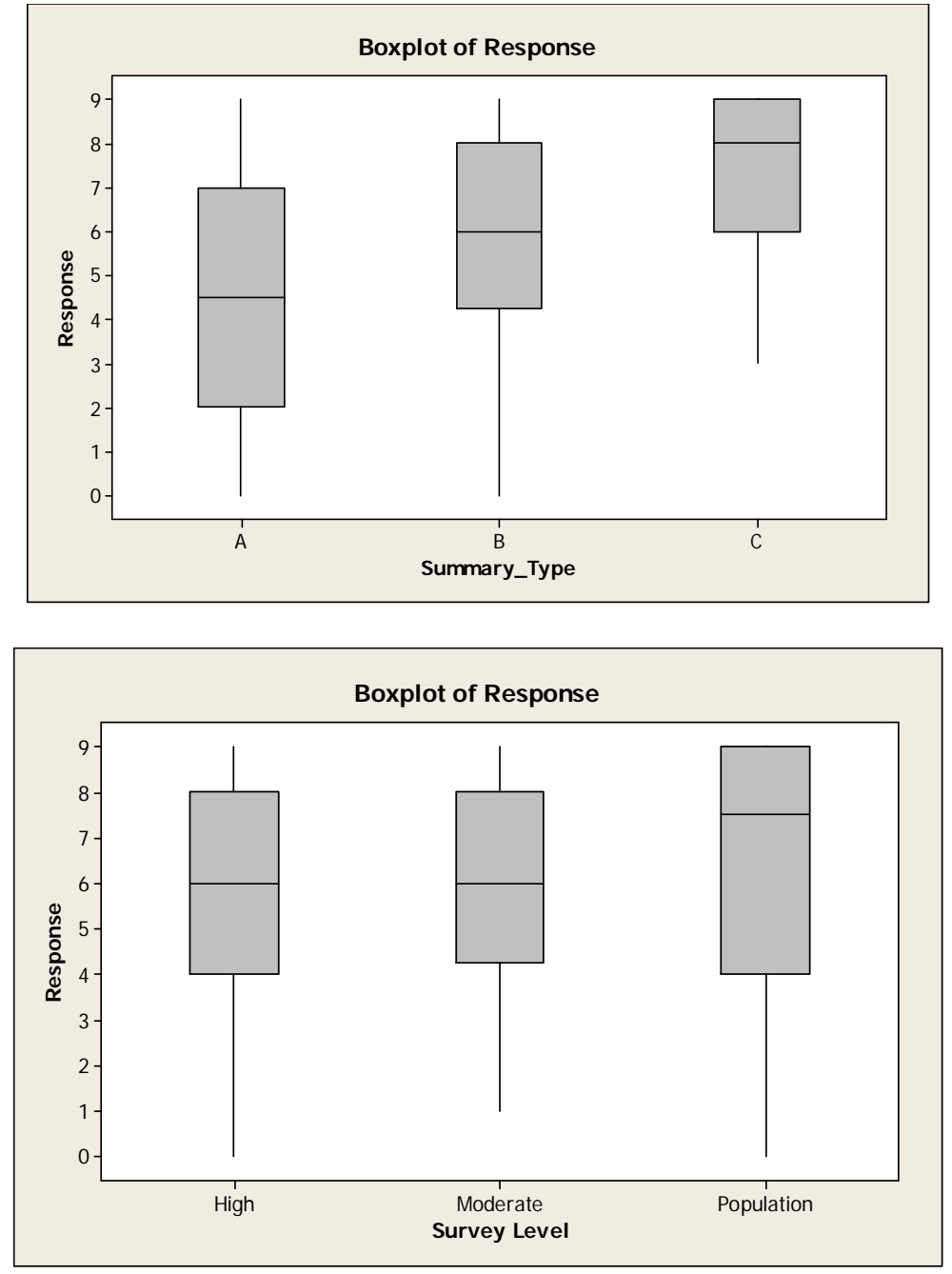

\section{Descriptive Statistics: Response by Summary Type}

Variable Summary_type N $\mathrm{N}^{*}$ Mean SE Mean StDev Minimum Q1 Median 


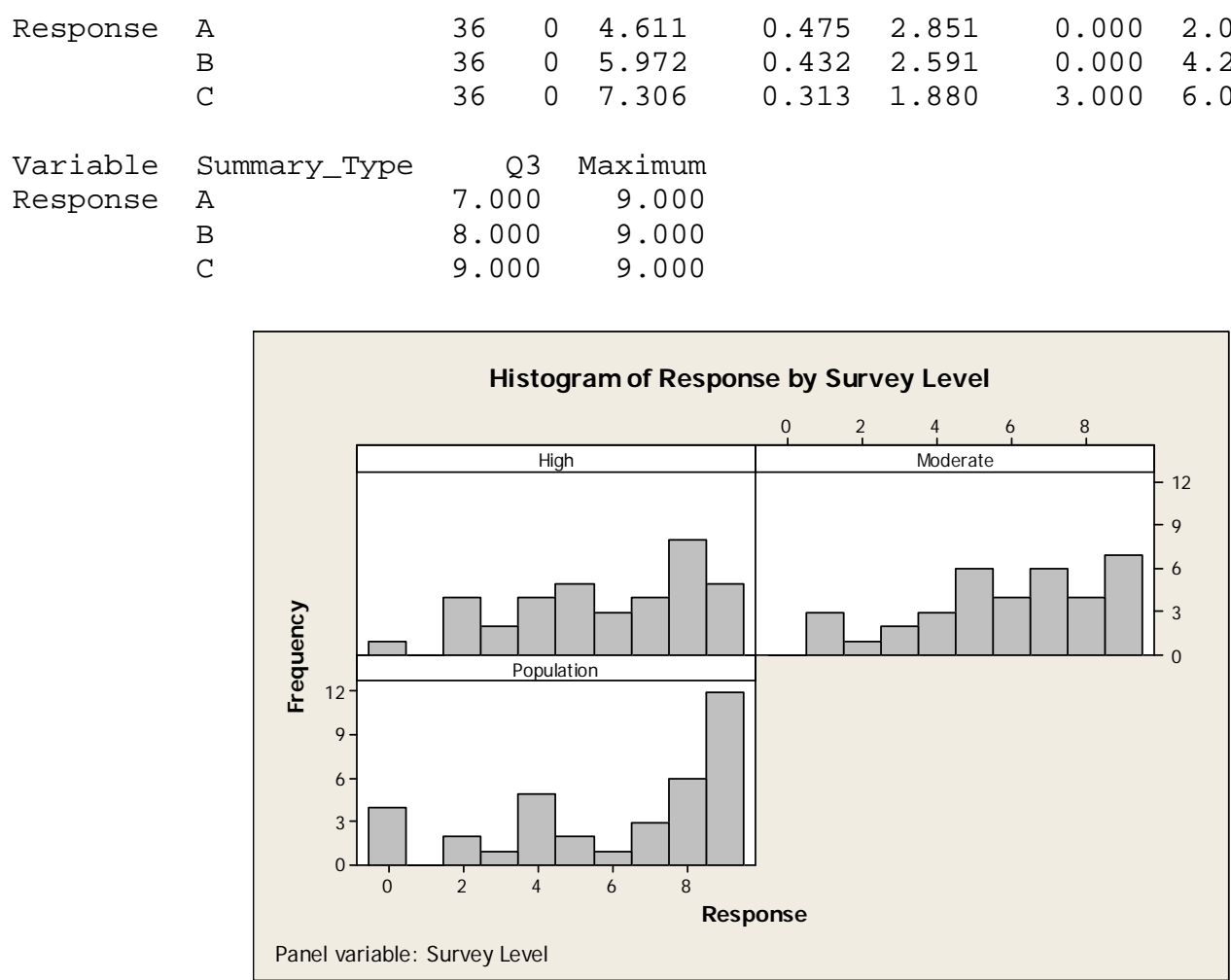

\section{Descriptive Statistics: Response by Survey Level}

$\begin{array}{llrrr}\text { Variable } & \text { Survey Level } & \text { N } & N^{*} & \text { Mean } \\ \text { Response } & \text { High } & 36 & 0 & 5.833 \\ & \text { Moderate } & 36 & 0 & 5.944 \\ & \text { Population } & 36 & 0 & 6.111 \\ \text { Variable } & \text { Survey Level } & \text { Q3 } & \text { Maximum } \\ \text { Response } & \text { High } & 8.000 & 9.000 \\ & \text { Moderate } & 8.000 & 9.000 \\ & \text { Population } & 9.000 & 9.000\end{array}$

$\begin{array}{rrrrr}\text { SE Mean } & \text { StDev } & \text { Minimum } & \text { Q1 } & \text { Median } \\ 0.417 & 2.501 & 0.000 & 4.000 & 6.000 \\ 0.410 & 2.460 & 1.000 & 4.250 & 6.000 \\ 0.521 & 3.124 & 0.000 & 4.000 & 7.500\end{array}$




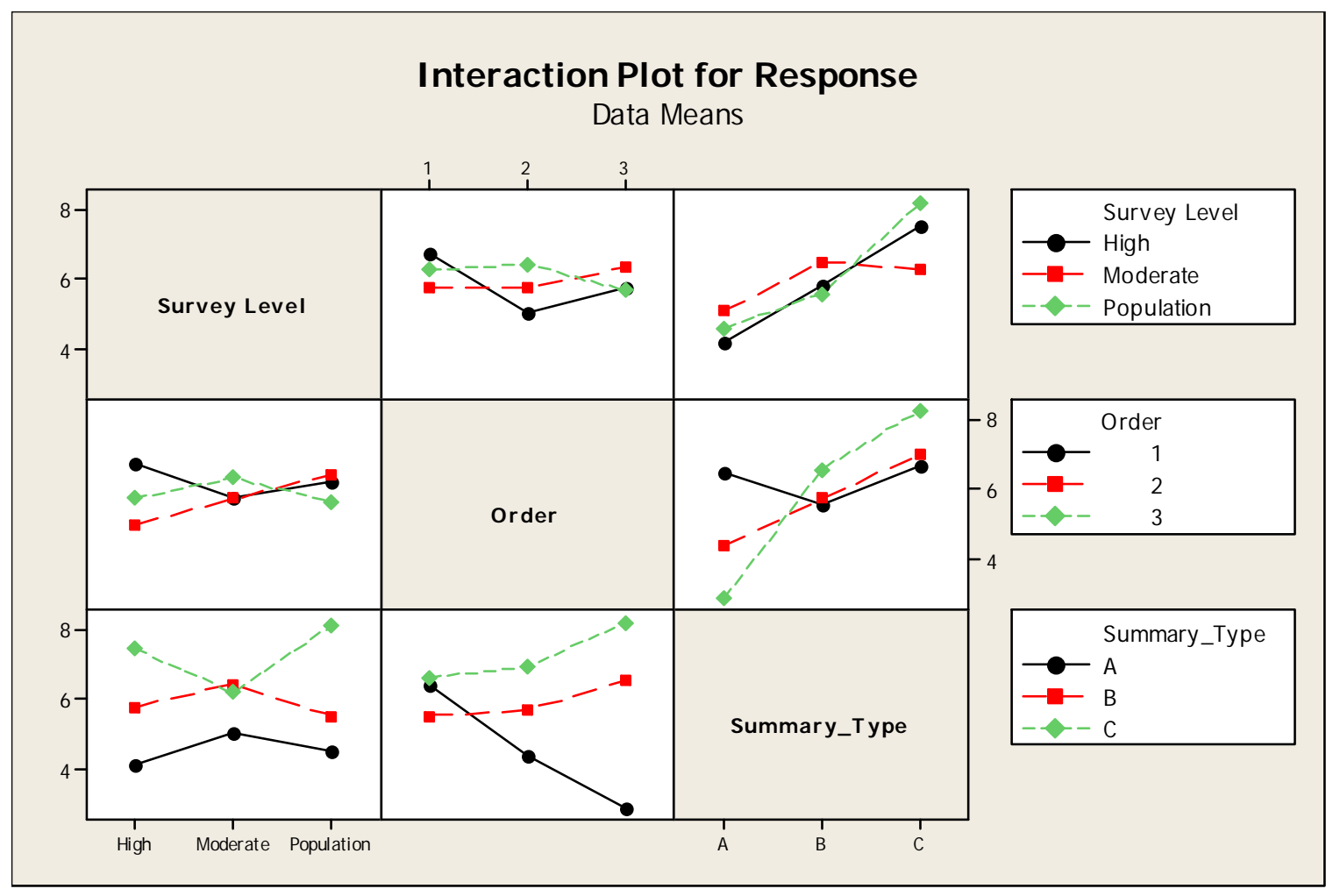

\section{General Linear Model: Response1 versus SummaryType, SurveyLevel, ...}

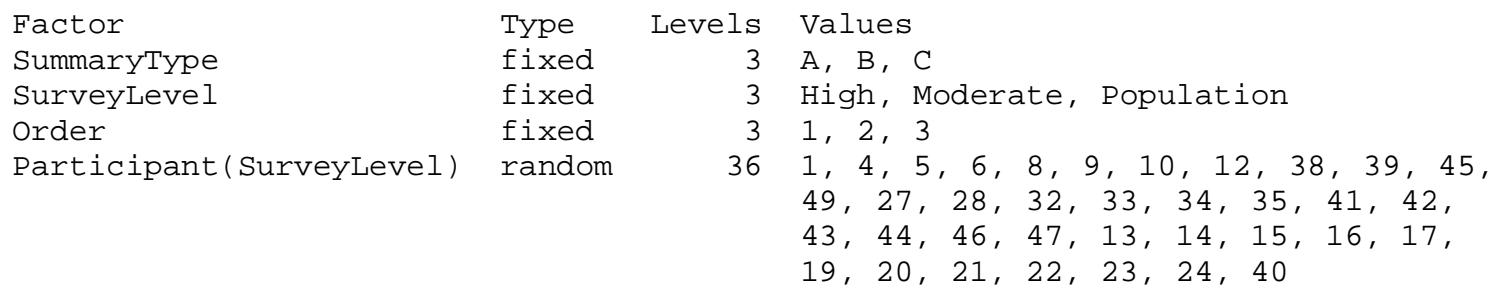

Analysis of Variance for Responsel, using Adjusted SS for Tests

$\begin{array}{lrrrrrr}\text { Source } & \text { DF } & \text { Seq SS } & \text { Adj SS } & \text { Adj MS } & \text { F } & \text { P } \\ \text { SummaryType } & 2 & 130.685 & 130.685 & 65.343 & 17.60 & 0.000 \\ \text { SurveyLevel } & 2 & 1.407 & 1.407 & 0.704 & 0.07 & 0.929 \times \\ \text { Order } & 2 & 5.130 & 5.130 & 2.565 & 0.69 & 0.505 \\ \text { Participant (SurveyLeve1) } & 33 & 351.111 & 302.759 & 9.175 & 2.47 & 0.001 \\ \text { SummaryType*Order } & 4 & 47.852 & 47.852 & 11.963 & 3.22 & 0.018 \\ \text { Error } & 64 & 237.667 & 237.667 & 3.714 & & \\ \text { Total } & 107 & 773.852 & & & & \end{array}$

$\mathrm{x}$ Not an exact F-test.

$S=1.92706 \quad \mathrm{R}-\mathrm{Sq}=69.29 \% \mathrm{R}-\mathrm{Sq}(\operatorname{adj})=48.65 \%$

Unusual Observations for Response1

Obs Responsel Fit SE Fit Residual St Resid

$\begin{array}{llllll}7 & 2.00000 & 5.33333 & 1.23001 & -3.33333 & -2.25 \mathrm{R}\end{array}$ 


$\begin{array}{llllrrl}38 & 0.00000 & 3.27778 & 1.23001 & -3.27778 & -2.21 & R \\ 39 & 9.00000 & 6.00000 & 1.23001 & 3.00000 & 2.02 & R \\ 58 & 0.00000 & 3.80556 & 1.23001 & -3.80556 & -2.57 & R \\ 66 & 9.00000 & 5.61111 & 1.23001 & 3.38889 & 2.28 & R \\ 76 & 7.00000 & 3.72222 & 1.23001 & 3.27778 & 2.21 & R \\ 78 & 5.00000 & 8.00000 & 1.23001 & -3.00000 & -2.02 & R\end{array}$

$\mathrm{R}$ denotes an observation with a large standardized residual.

Grouping Information Using Tukey Method and 95.0\% Confidence

\begin{tabular}{|c|c|c|c|}
\hline Summaryтype & $\mathrm{N}$ & Mean & Grouping \\
\hline C & 36 & 7.3 & A \\
\hline B & 36 & 6.0 & B \\
\hline A & 36 & 4.6 & $\mathrm{C}$ \\
\hline
\end{tabular}

Means that do not share a letter are significantly different.

Tukey 95.0\% Simultaneous Confidence Intervals

Response Variable Response1

All Pairwise Comparisons among Levels of SummaryType

SummaryType = A subtracted from:

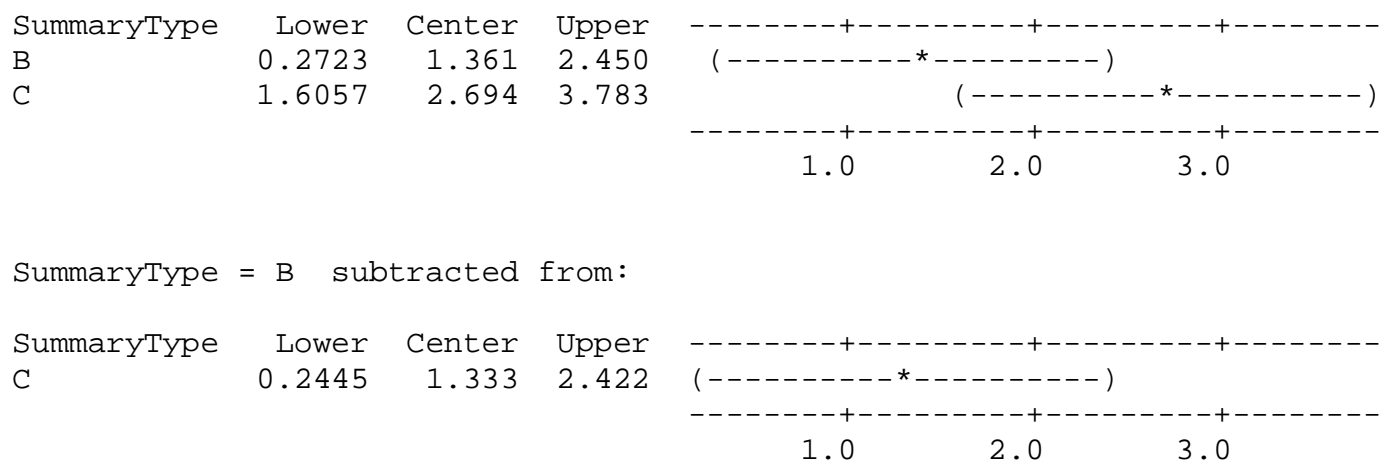

Tukey Simultaneous Tests

Response Variable Response1

All Pairwise Comparisons among Levels of Summarytype

SummaryType $=$ A subtracted from:

$\begin{array}{lrrrr} & \text { Difference } & \text { SE of } & \text { Adjusted } \\ \text { Summarytype } & \text { of Means } & \text { Difference } & \text { T-Value } & \text { P-Value } \\ \text { B } & 1.361 & 0.4542 & 2.997 & 0.0107 \\ \text { C } & 2.694 & 0.4542 & 5.932 & 0.0000\end{array}$

\begin{tabular}{lrrrr} 
SummaryType $=\mathrm{B}$ & \multicolumn{2}{c}{ subtracted from: } \\
& Difference & SE of & \\
SummaryType & of Means & Difference & T-Value & P-Value \\
C & 1.333 & 0.4542 & 2.935 & 0.0127
\end{tabular}




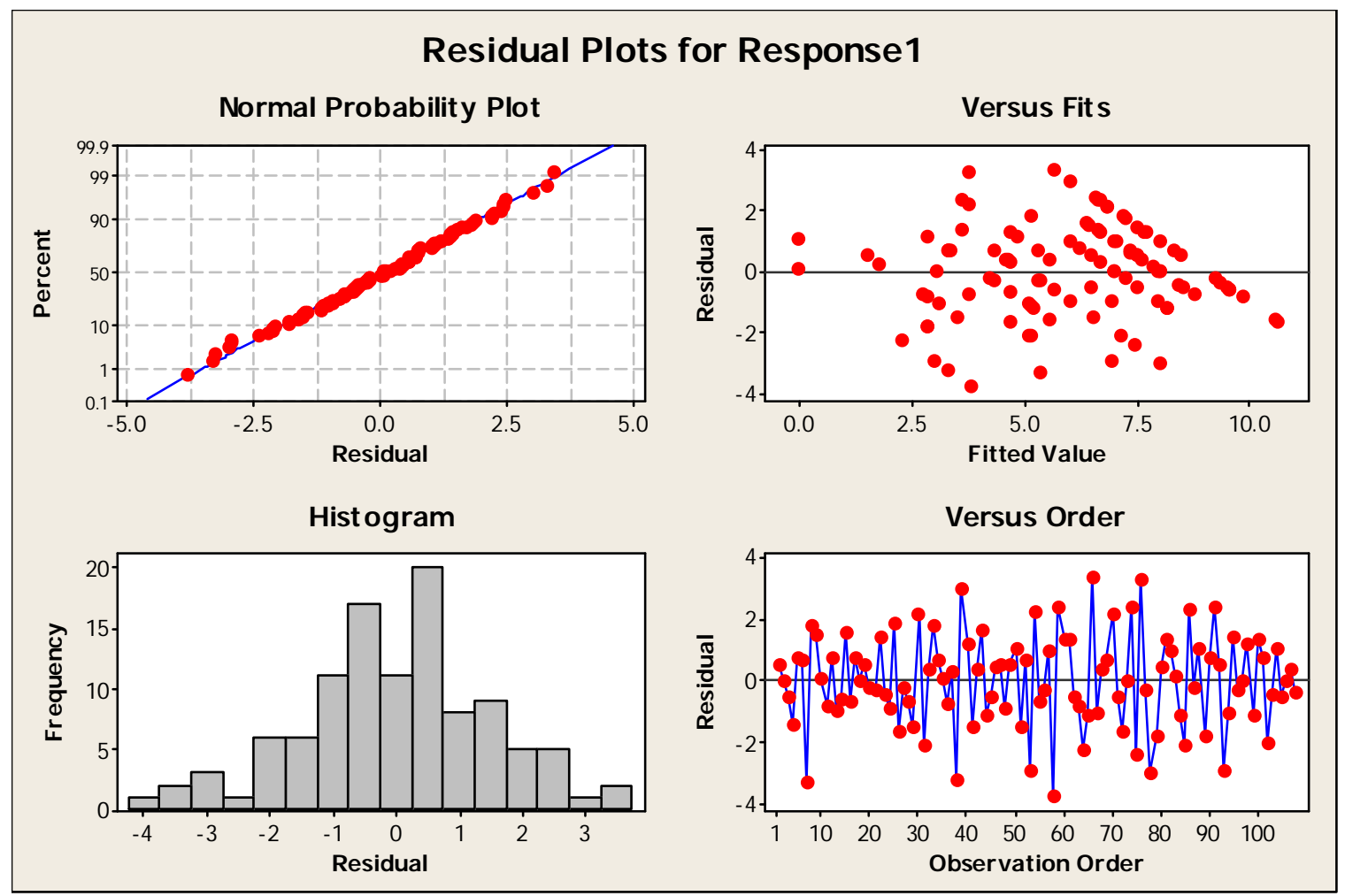

Analysis with first-order carryover effects:

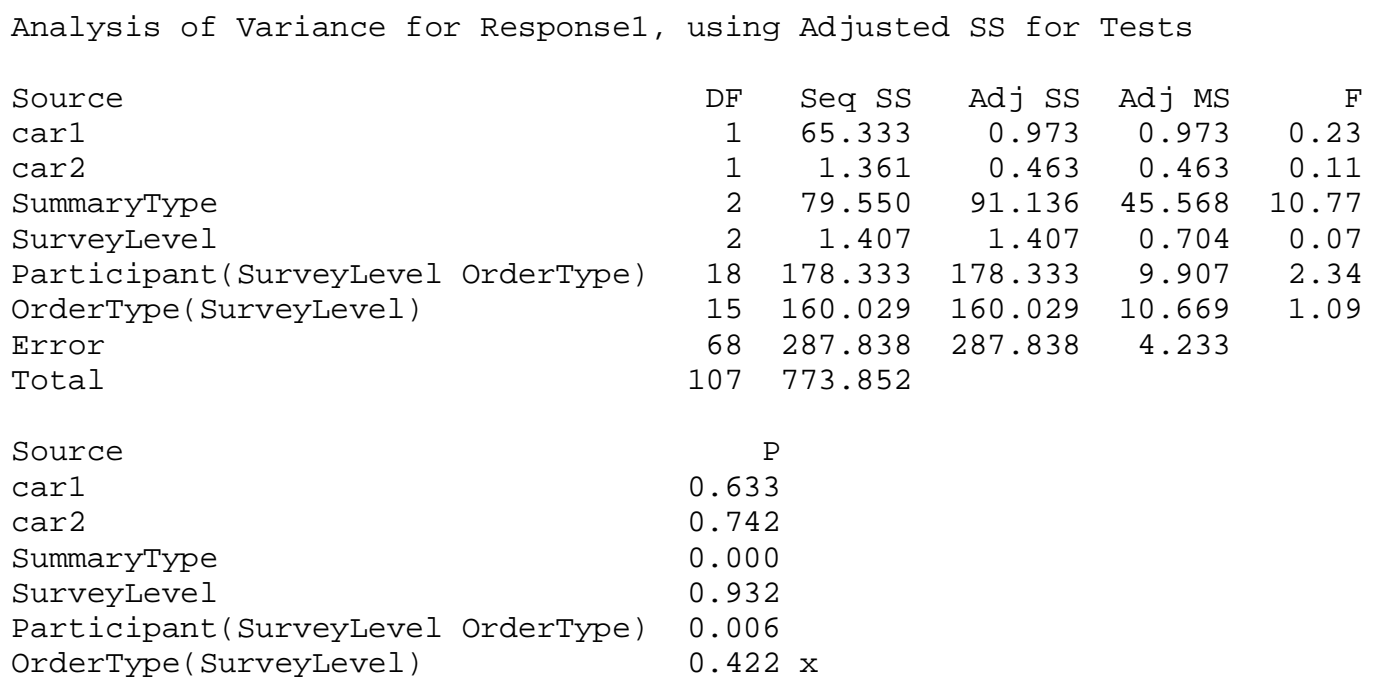

Analysis with second-order carryover effects: 


\begin{tabular}{|c|c|c|c|c|c|}
\hline Source & $\mathrm{DF}$ & Seq SS & Adj $S S$ & Adj MS & $\mathrm{F}$ \\
\hline car1_xtra & 1 & 44.083 & 13.836 & 13.836 & 3.52 \\
\hline car2_xtra & 1 & 7.111 & 1.681 & 1.681 & 0.43 \\
\hline SummaryType & 2 & 109.864 & 103.271 & 51.636 & 13.15 \\
\hline SurveyLevel & 2 & 1.407 & 1.407 & 0.704 & 0.07 \\
\hline Participant (SurveyLevel OrderType) & 18 & 178.333 & 178.333 & 9.907 & 2.52 \\
\hline OrderType (SurveyLevel) & 15 & 165.963 & 165.963 & 11.064 & 1.16 \\
\hline Error & 68 & 267.090 & 267.090 & 3.928 & \\
\hline Total & 107 & 773.852 & & & \\
\hline Source & $\mathrm{E}$ & & & & \\
\hline car1_xtra & 0.065 & & & & \\
\hline car2_xtra & 0.515 & & & & \\
\hline SummaryType & 0.000 & & & & \\
\hline SurveyLevel & 0.932 & & & & \\
\hline Participant (SurveyLevel OrderType) & 0.003 & & & & \\
\hline OrderType (SurveyLevel) & 0.373 & $x$ & & & \\
\hline
\end{tabular}

Appendix G.1.2 - Question 2

Question 2: I am satisfied with the way this summary page looks.

Responses: 1 (Strongly Disagree) to 5 (Strongly Agree)

\section{Question 2}

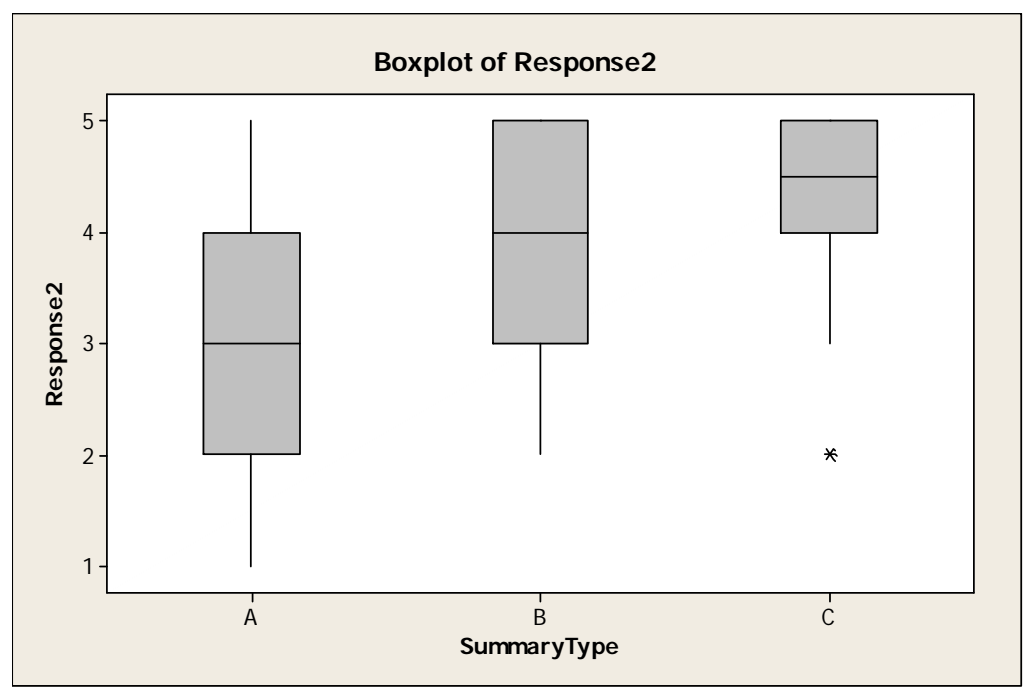




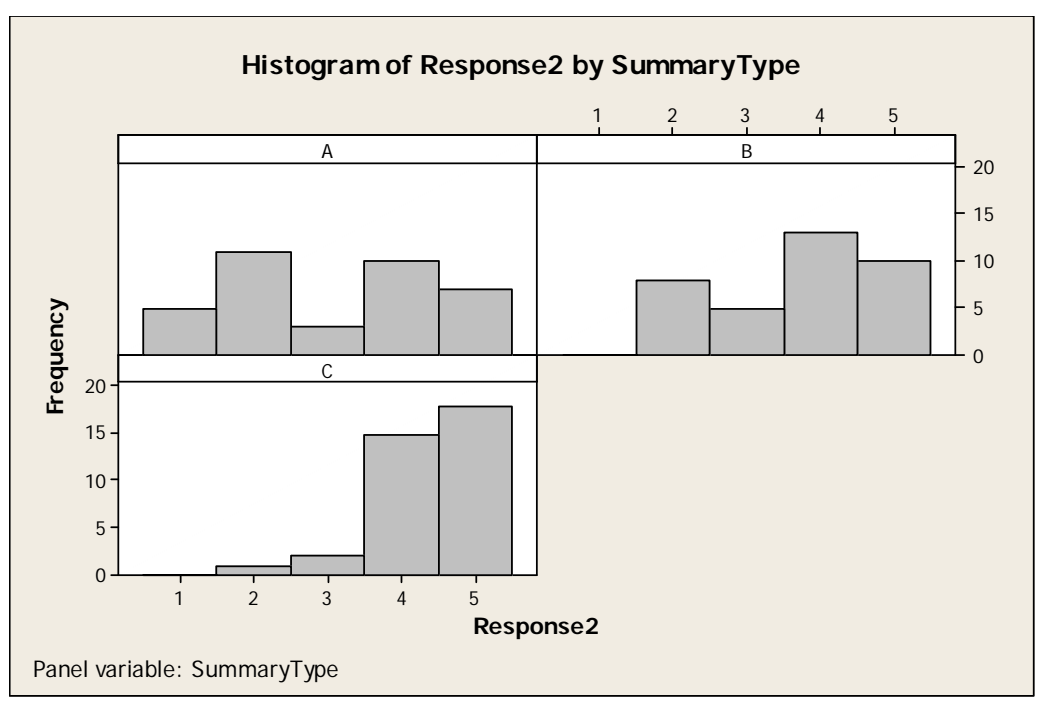

\section{Descriptive Statistics: Response2}

$\begin{array}{llrrr}\text { Variable } & \text { SummaryType } & \mathrm{N} & \mathrm{N}^{*} & \text { Mean } \\ \text { Response2 } & \text { A } & 36 & 0 & 3.083 \\ & \mathrm{~B} & 36 & 0 & 3.694 \\ & \mathrm{C} & 36 & 0 & 4.389 \\ \text { Variable } & \text { SummaryType } & \mathrm{Q} 3 & \text { Maximum } \\ \text { Response2 } & \text { A } & 4.000 & 5.000 \\ & \text { B } & 5.000 & 5.000 \\ & \text { C } & 5.000 & 5.000\end{array}$

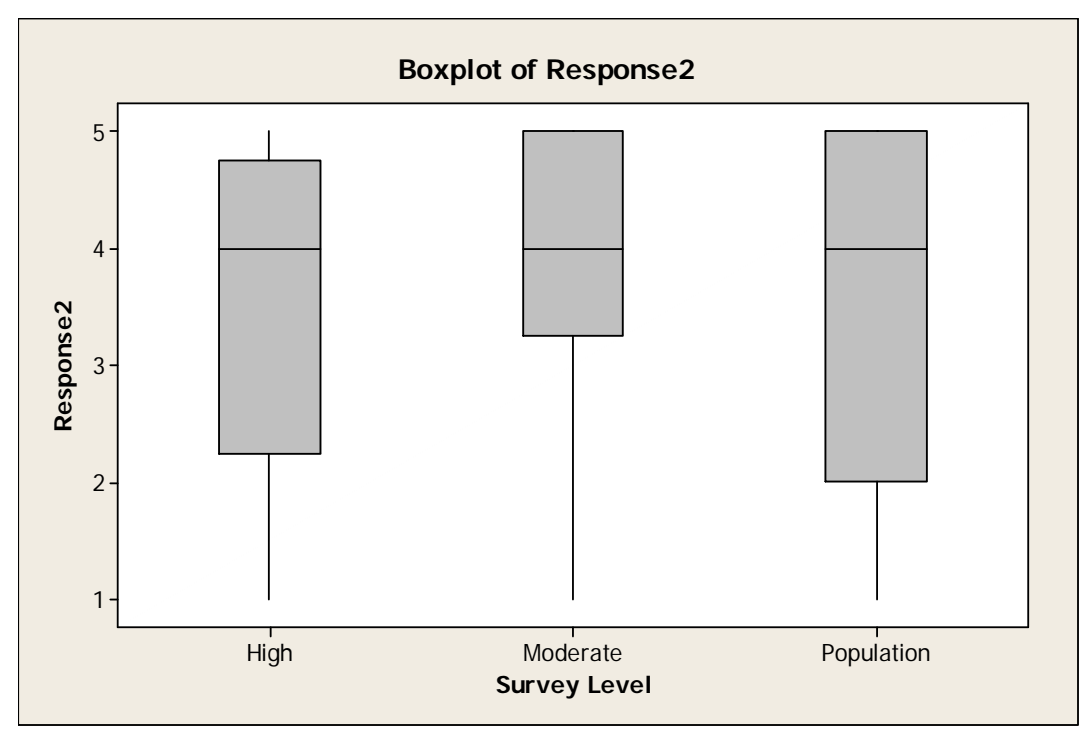




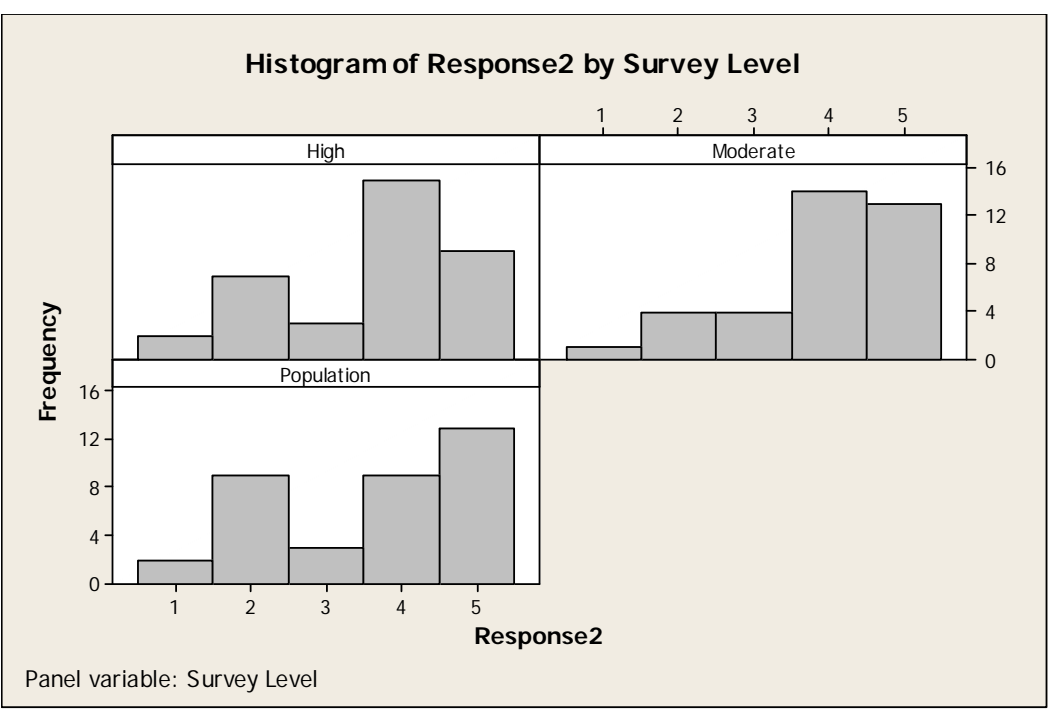

\section{Descriptive Statistics: Response2}

\begin{tabular}{|c|c|c|c|c|c|c|c|c|c|}
\hline \multirow{4}{*}{$\begin{array}{l}\text { Variable } \\
\text { Response2 }\end{array}$} & Survey Level & $\mathrm{N}$ & $N^{*}$ & Mean & SE Mean & StDev & Minimum & Q1 & Median \\
\hline & High & 36 & 0 & 3.611 & 0.204 & 1.225 & 1.000 & 2.250 & 4.000 \\
\hline & Moderate & 36 & 0 & 3.944 & 0.182 & 1.094 & 1.000 & 3.250 & 4.0 \\
\hline & Population & 36 & 0 & 3.611 & 0.226 & 1.358 & 1.000 & 2.000 & 4 \\
\hline Variable & Survey Level & & 23 & Maximum & & & & & \\
\hline Response2 & High & 4.7 & & 5.000 & & & & & \\
\hline & Moderate & 5. & & 5.000 & & & & & \\
\hline & Population & 5. & & 5.000 & & & & & \\
\hline
\end{tabular}

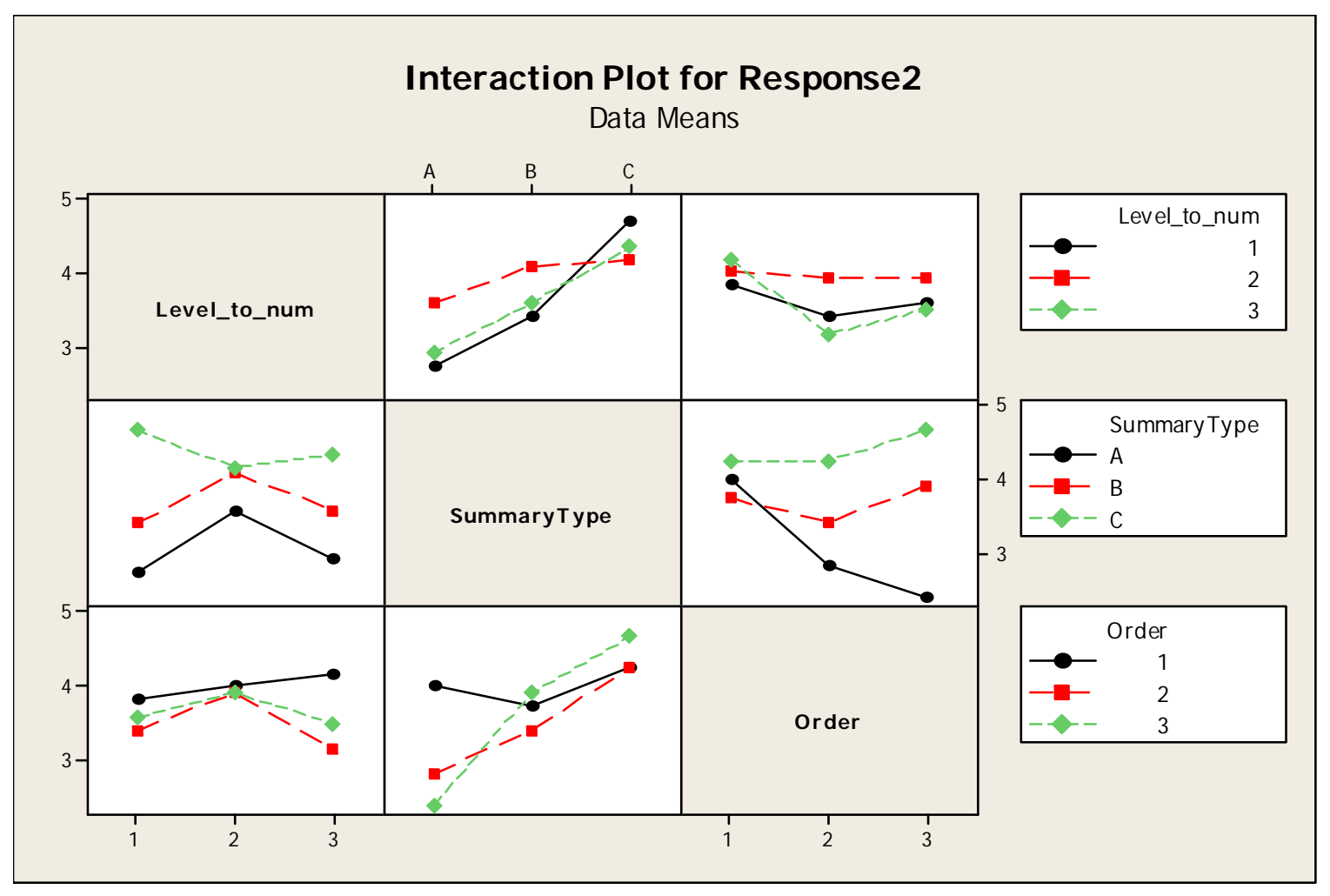



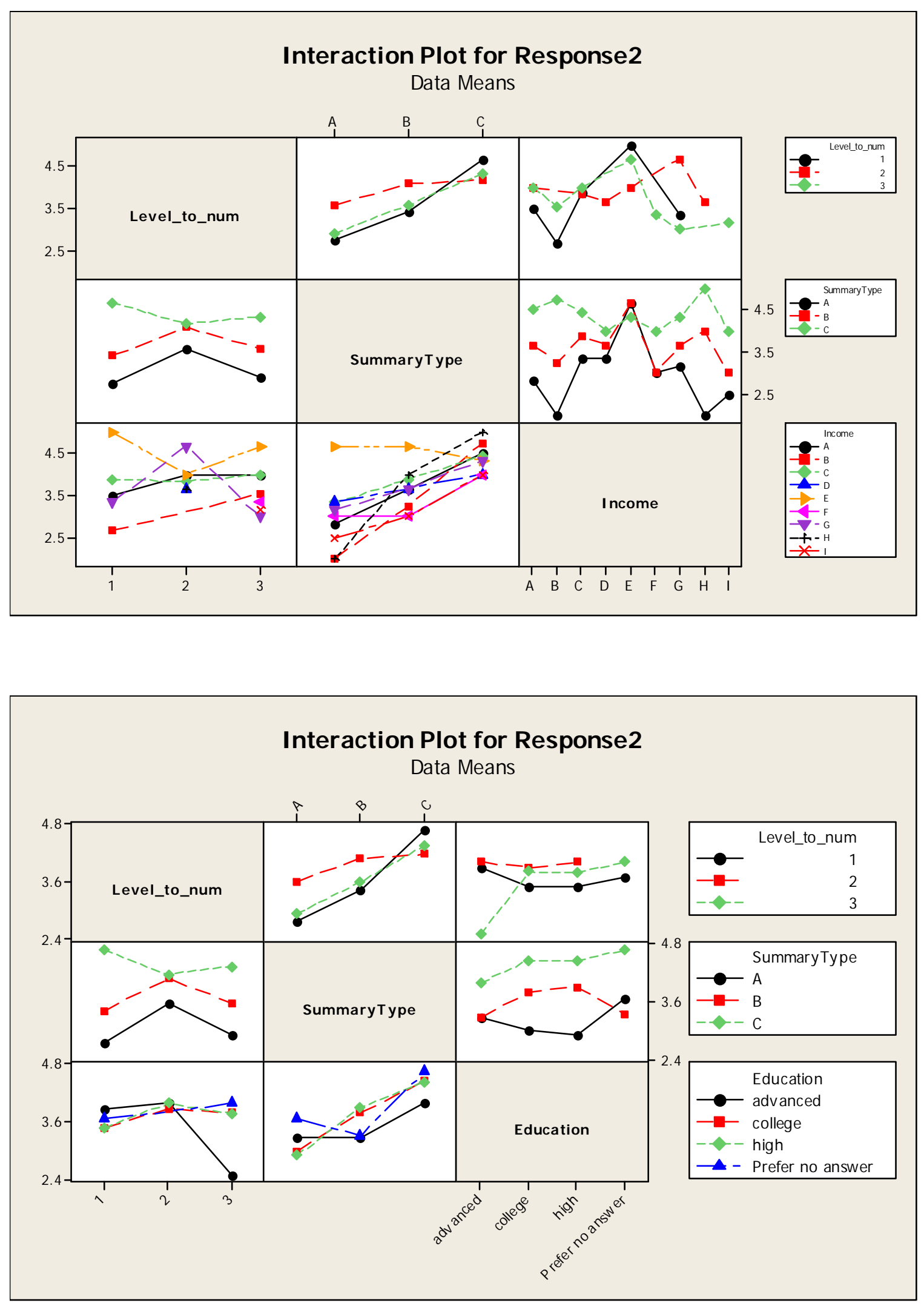
Interaction w/ gender - shows no interesting results

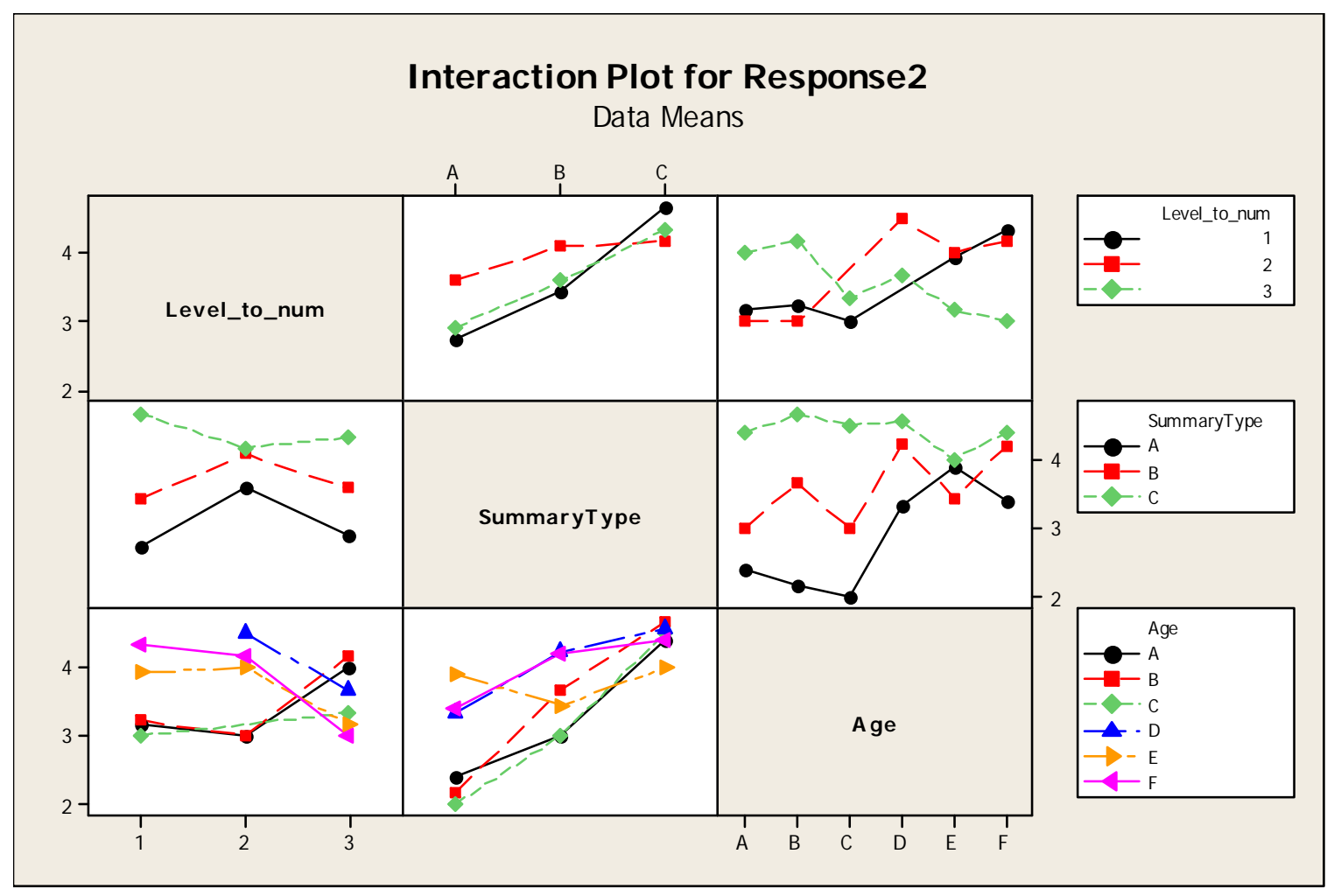

General Linear Model: Response2 versus SummaryType, SurveyLevel, ...

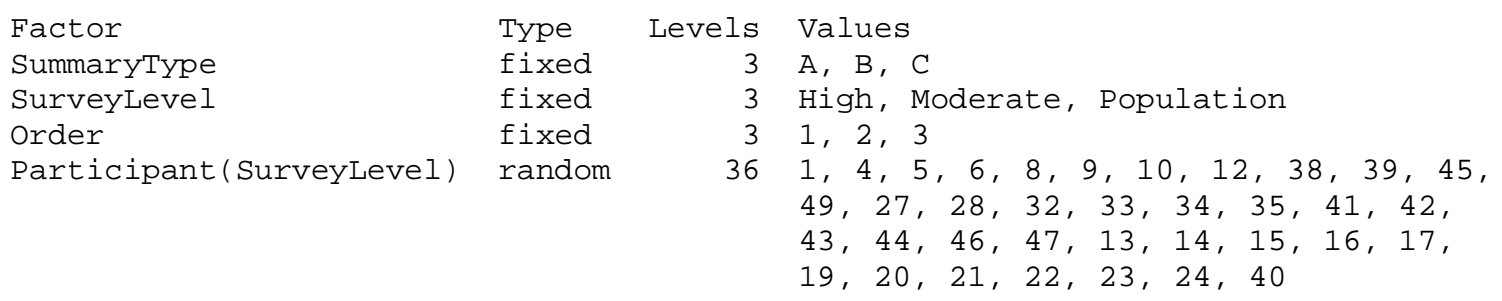

2. 2222

0.8394

$\begin{array}{rr}F & P \\ 18.30 & 0.000 \\ 0.77 & 0.472 \times \\ 2.78 & 0.070 \\ 2.00 & 0.009 \\ 2.65 & 0.041\end{array}$

$x$ Not an exact F-test.

$S=0.916193 \quad R-S q=66.77 \% \quad R-S q(\operatorname{adj})=44.44 \%$ 


$\begin{array}{rrrrrr}\text { Obs } & \text { Response2 } & \text { Fit } & \text { SE Fit } & \text { Residual } & \text { St Resid } \\ 7 & 1.00000 & 2.86111 & 0.58479 & -1.86111 & -2.64 \mathrm{R} \\ 58 & 1.00000 & 2.63889 & 0.58479 & -1.63889 & -2.32 \mathrm{R} \\ 66 & 5.00000 & 3.44444 & 0.58479 & 1.55556 & 2.21 \mathrm{R} \\ 93 & 3.00000 & 4.77778 & 0.58479 & -1.77778 & -2.52 \mathrm{R}\end{array}$

$\mathrm{R}$ denotes an observation with a large standardized residual.

Grouping Information Using Tukey Method and 95.0\% Confidence

\begin{tabular}{lrrrr} 
SummaryType & N & Mean & Grouping \\
C & 36 & 4.4 & A & \\
B & 36 & 3.7 & \multicolumn{2}{c}{ B } \\
A & 36 & 3.1 & \multicolumn{2}{c}{ C }
\end{tabular}

Means that do not share a letter are significantly different.

Tukey 95.0\% Simultaneous Confidence Intervals

Response Variable Response2

All Pairwise Comparisons among Levels of SummaryType

SummaryType $=\mathrm{A}$ subtracted from:

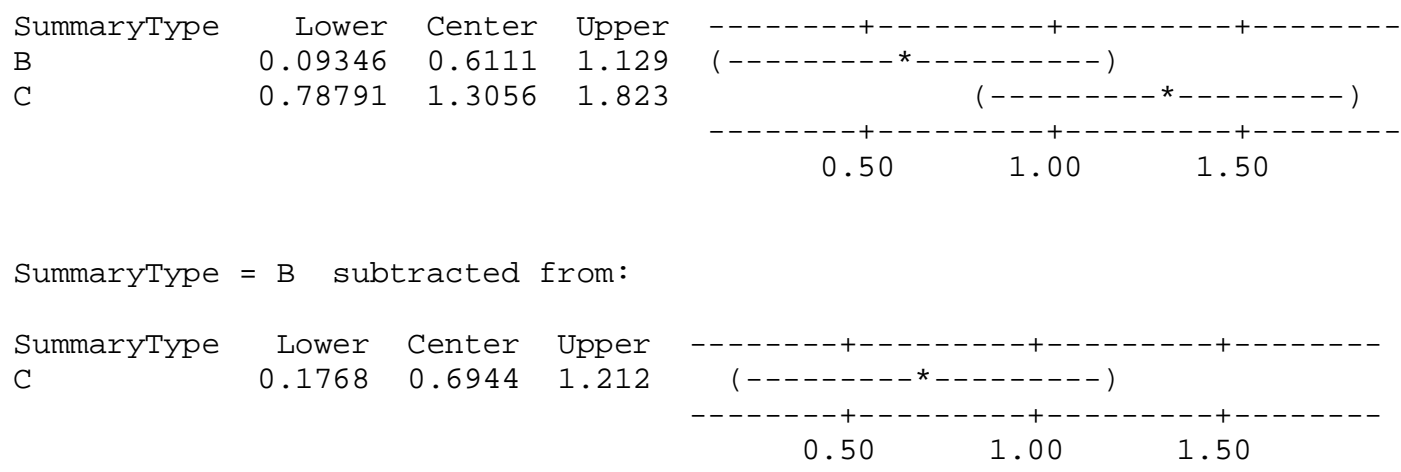

Tukey Simultaneous Tests

Response Variable Response2

All Pairwise Comparisons among Levels of SummaryType

SummaryType $=$ A subtracted from:

$\begin{array}{lrrrr} & \text { Difference } & \text { SE of } & \text { Adjusted } \\ \text { SummaryType } & \text { of Means } & \text { Difference } & \text { T-Value } & \text { P-Value } \\ \text { B } & 0.6111 & 0.2159 & 2.830 & 0.0169 \\ \text { C } & 1.3056 & 0.2159 & 6.046 & 0.0000\end{array}$

\begin{tabular}{|c|c|c|c|}
\hline SummaryType & $\begin{array}{r}\text { Difference } \\
\text { of Means }\end{array}$ & $\begin{array}{r}S E \text { of } \\
\text { Difference }\end{array}$ & T-Value \\
\hline
\end{tabular}




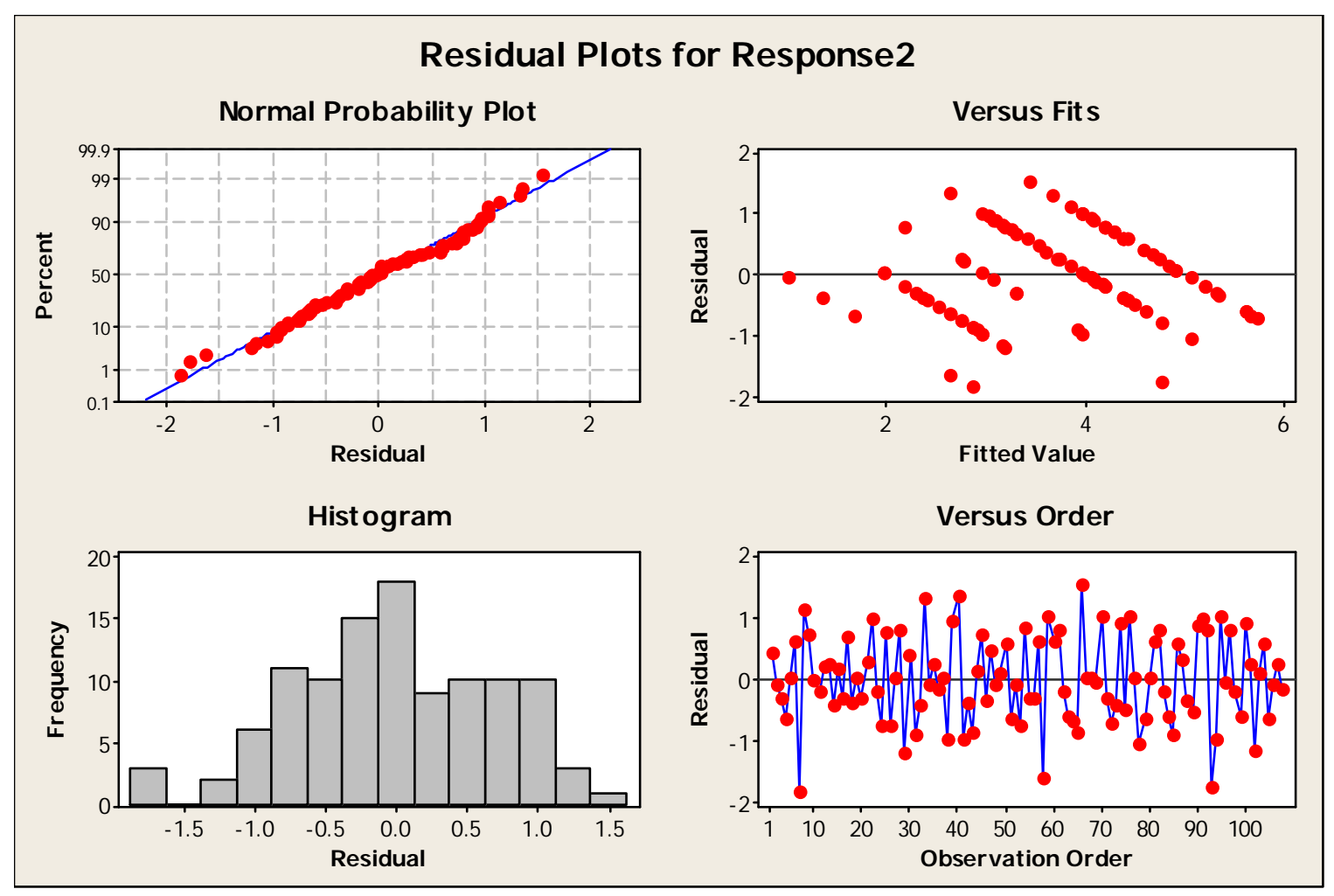

Appendix G.1.3 - Question 3

Question 3: Overall, I found this summary page to be clear and easy to read.

Response: 1 (Strongly Disagree) to 5 (Strongly Agree)

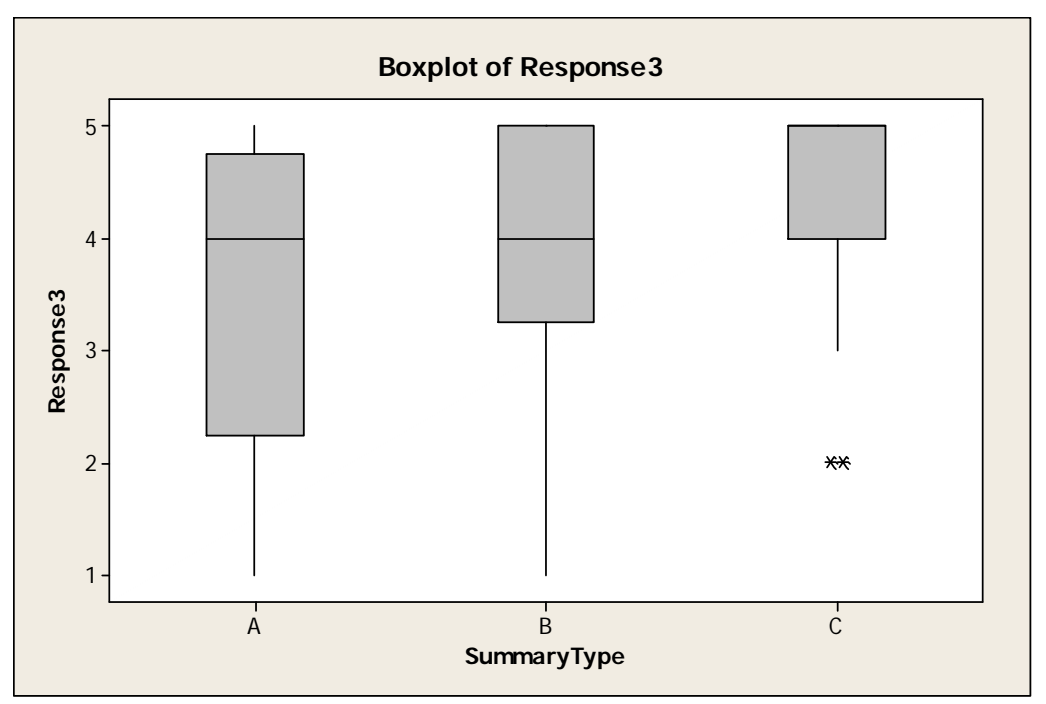




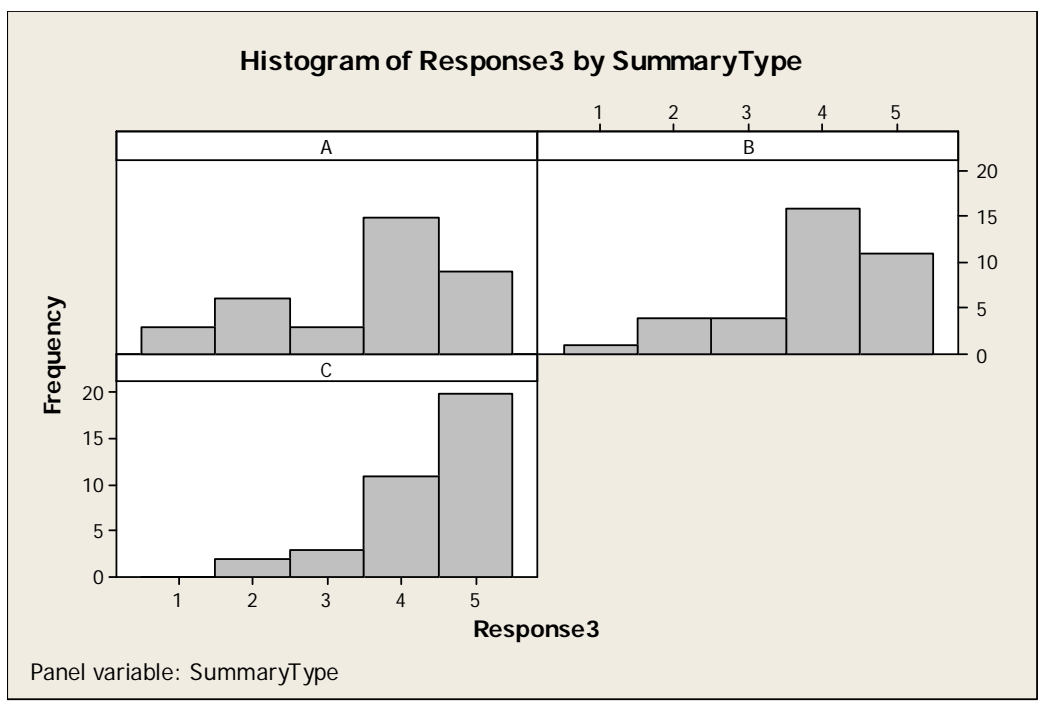

\section{Descriptive Statistics: Response3}

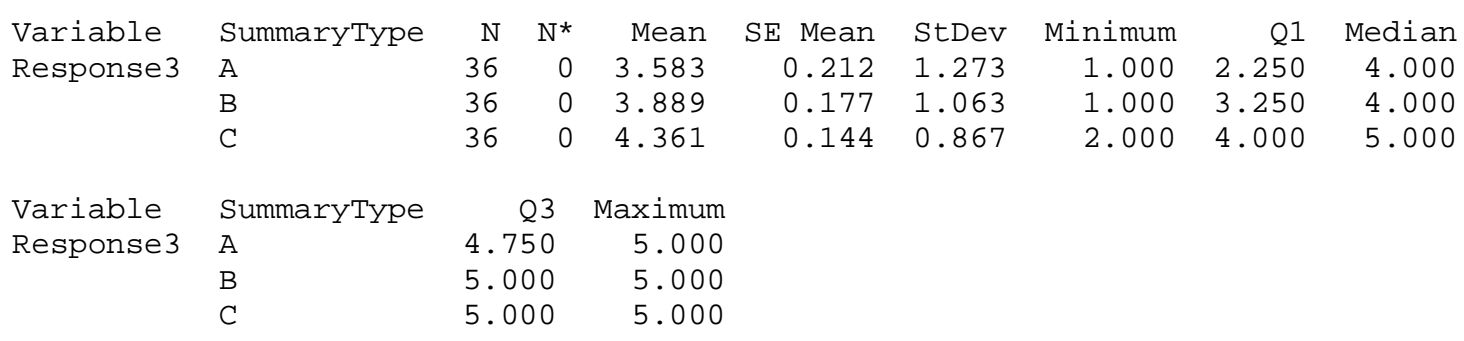

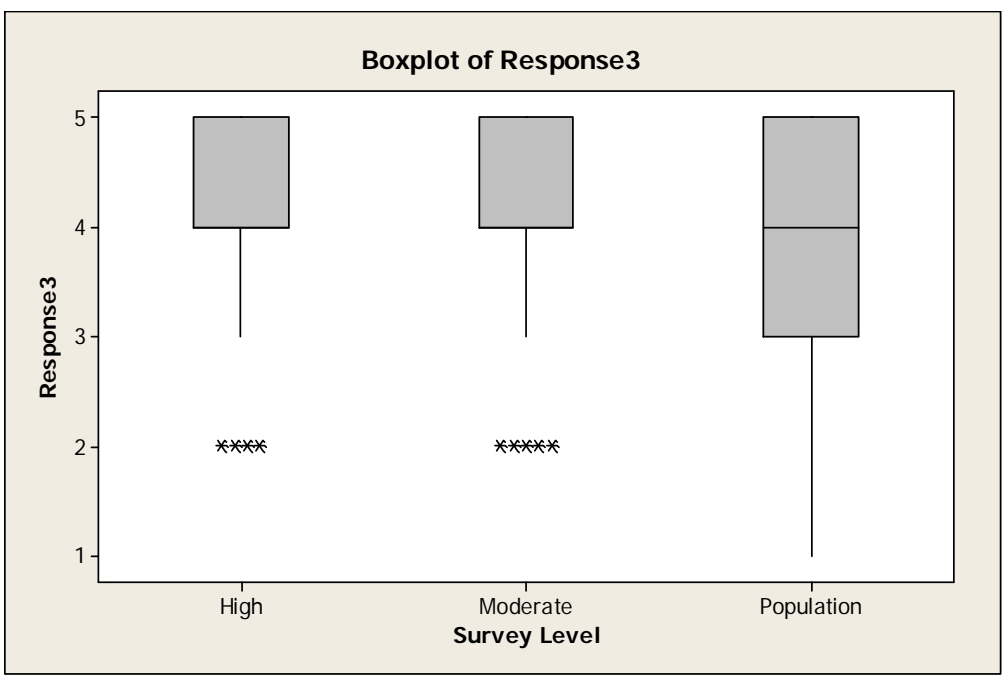




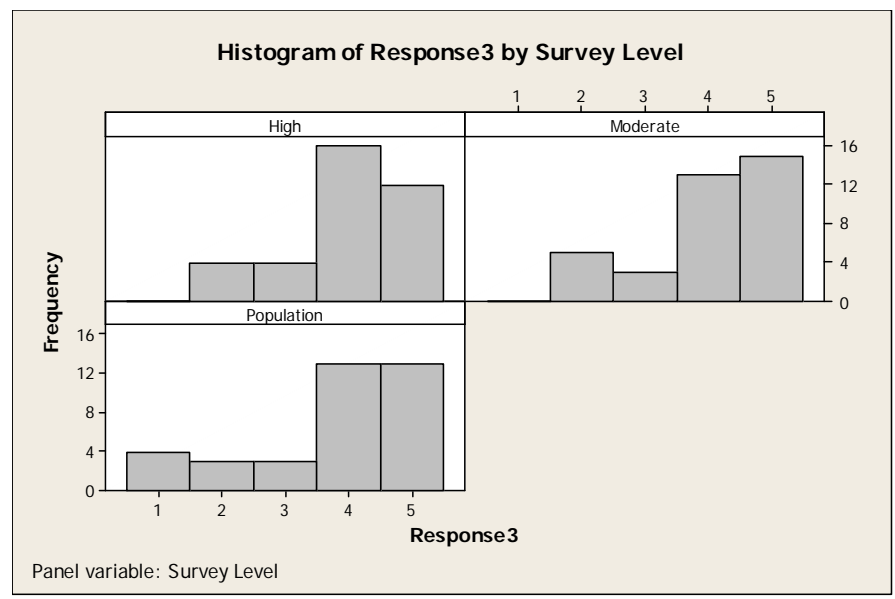

\section{Descriptive Statistics: Response3}

$\begin{array}{llrrr}\text { Variable } & \text { Survey Level } & \mathrm{N} & \mathrm{N}^{*} & \text { Mean } \\ \text { Response3 } & \text { High } & 36 & 0 & 4.000 \\ & \begin{array}{l}\text { Moderate } \\ \text { Population }\end{array} & 36 & 0 & 4.056 \\ & & 0 & 3.778 \\ \text { Variable } & \text { Survey Level } & \text { Q3 } & \text { Maximum } \\ \text { Response3 } & \text { High } & 5.000 & 5.000 \\ & \text { Moderate } & 5.000 & 5.000 \\ & \text { Population } & 5.000 & 5.000\end{array}$

$\begin{array}{rrrrr}\text { SE Mean } & \text { StDev } & \text { Minimum } & \text { Q1 } & \text { Median } \\ 0.159 & 0.956 & 2.000 & 4.000 & 4.000 \\ 0.173 & 1.040 & 2.000 & 4.000 & 4.000 \\ 0.222 & 1.333 & 1.000 & 3.000 & 4.000\end{array}$



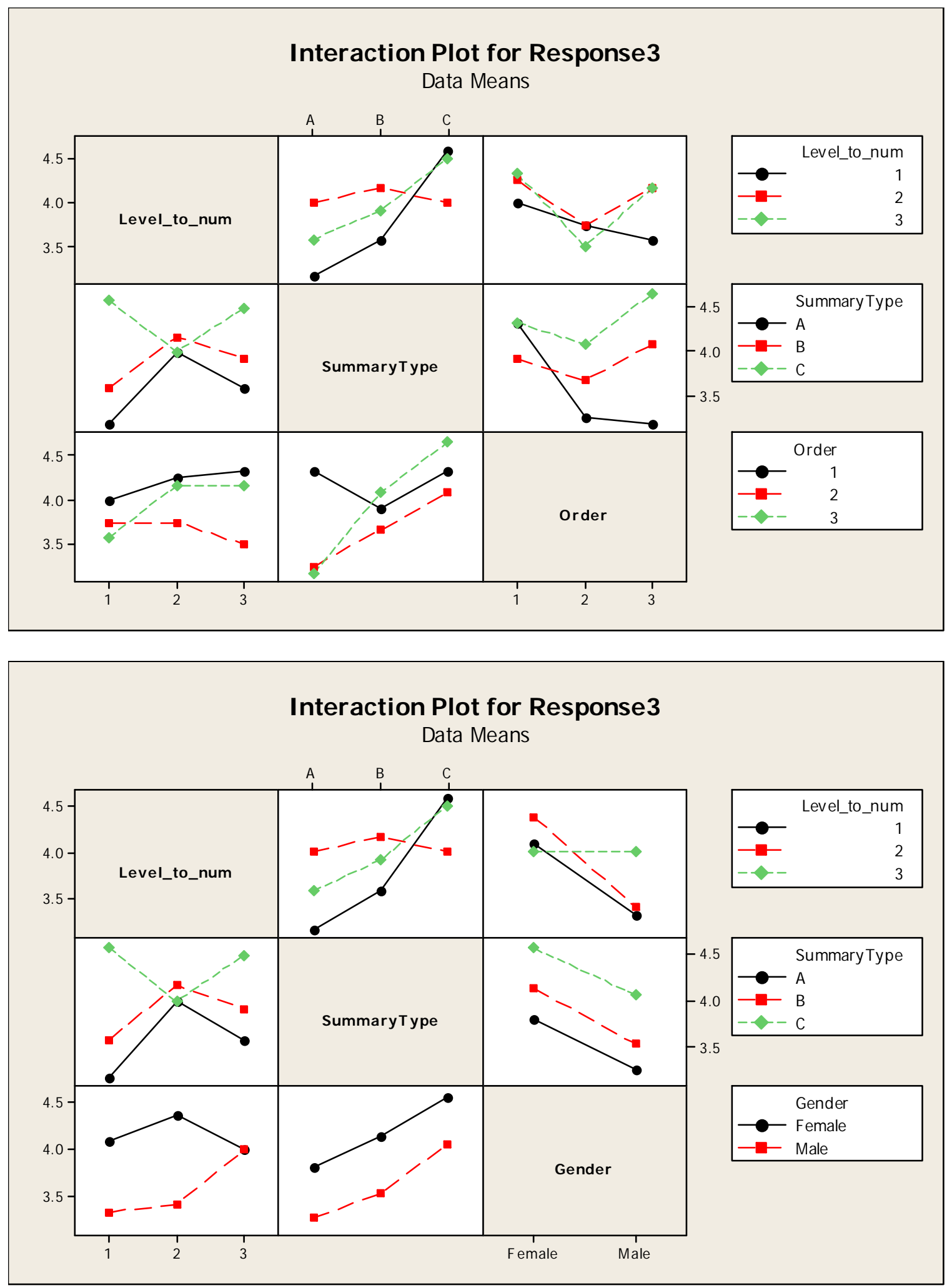

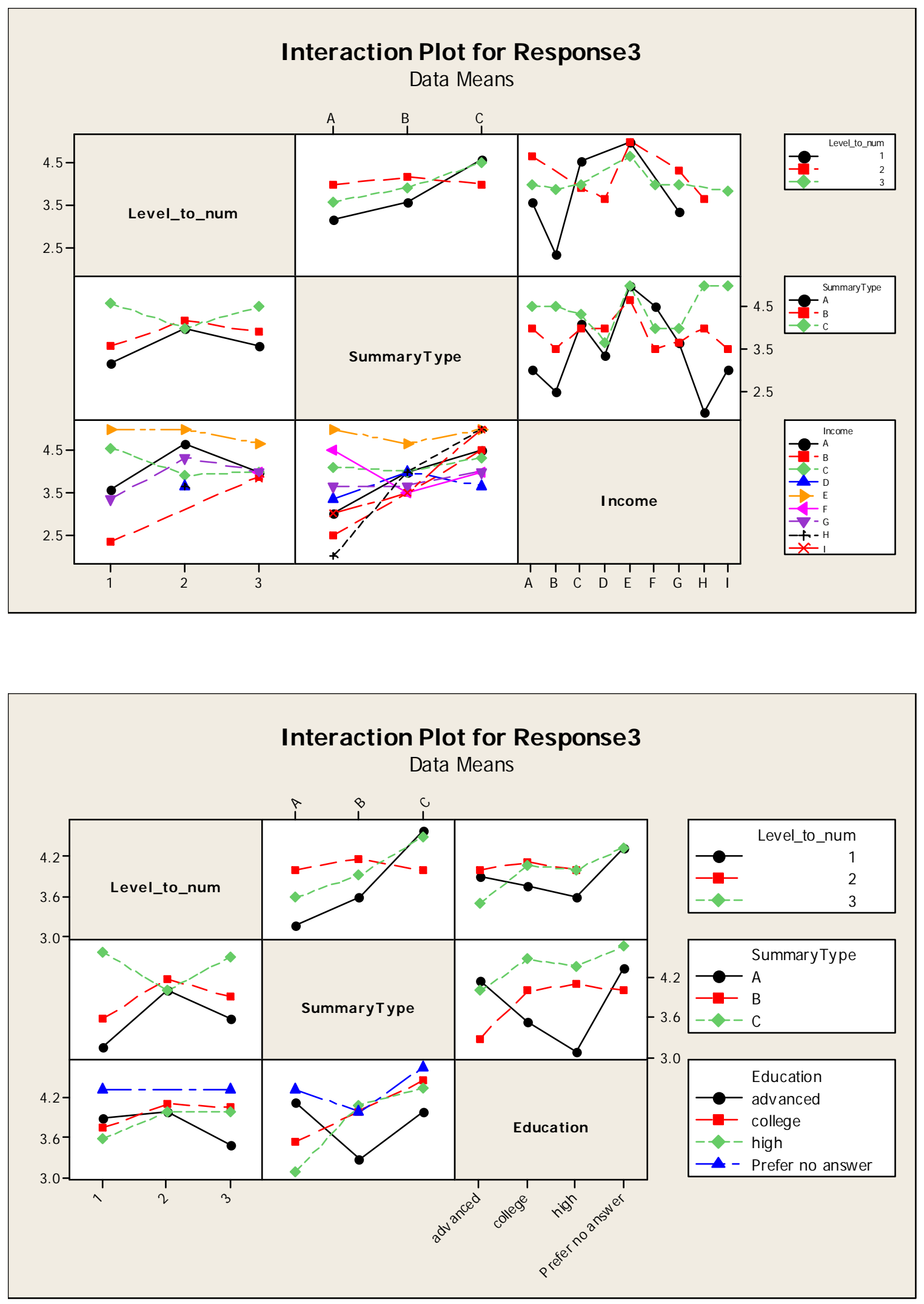

General Linear Model: Response3 versus SummaryType, SurveyLevel, ... 


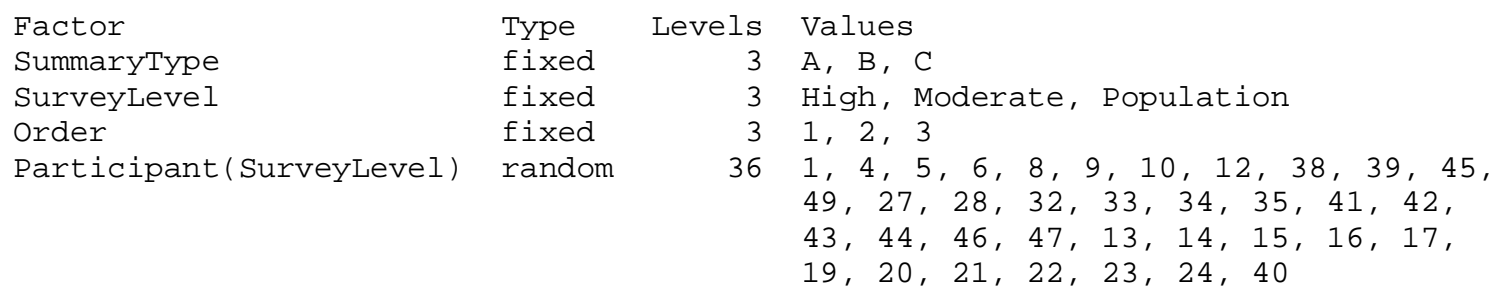

Analysis of Variance for Response3, using Adjusted SS for Tests

\begin{tabular}{|c|c|c|c|c|c|c|}
\hline \multicolumn{2}{|l|}{ Source } & $\mathrm{DF}$ & Seq SS & $\operatorname{Adj} S$ & & Adj $M$ \\
\hline \multicolumn{2}{|l|}{ SummaryType } & 2 & 11.0556 & 11.055 & & 5.527 \\
\hline \multicolumn{2}{|l|}{ SurveyLevel } & 2 & 1.5556 & 1.555 & & 0.777 \\
\hline \multicolumn{2}{|l|}{ Order } & 2 & 5.0556 & 5.055 & & 2.527 \\
\hline \multicolumn{2}{|c|}{ Participant (SurveyLevel) } & 33 & 51.4444 & 49.296 & & 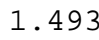 \\
\hline \multicolumn{2}{|c|}{ SummaryType*order } & 4 & 6.0741 & 6.074 & & \\
\hline \multicolumn{2}{|l|}{ Error } & 64 & 58.4815 & 58.481 & & \\
\hline \multicolumn{2}{|l|}{ Total } & 107 & .33 .6667 & & & \\
\hline \multicolumn{7}{|c|}{$x$ Not an exact $F$-test. } \\
\hline$S=0.955915$ & \multicolumn{2}{|c|}{$\mathrm{R}-\mathrm{Sq}=56.25 \%$} & $R-S q(\operatorname{adj})$ & \multicolumn{3}{|c|}{$=26.85 \%$} \\
\hline \multicolumn{7}{|c|}{ Unusual Observations for Response 3} \\
\hline Response 3 & Fit & SE Fit & Residua & St & $\operatorname{Re}$ & sid \\
\hline 1.00000 & 3.10185 & 0.61015 & -2.1018 & & & .86 \\
\hline 1.00000 & 3.03704 & 0.61015 & -2.0370 & & & .77 \\
\hline 5.00000 & 3.37963 & 0.61015 & 1.6203 & & & .20 \\
\hline 2.00000 & 3.71296 & 0.61015 & -1.7129 & & -2 & .33 \\
\hline
\end{tabular}

$\mathrm{R}$ denotes an observation with a large standardized residual.

Grouping Information Using Tukey Method and 95.0\% Confidence

$\begin{array}{lrrl}\text { SummaryType } & \text { N } & \text { Mean } & \text { Grouping } \\ \text { C } & 36 & 4.4 & \text { A } \\ \text { B } & 36 & 3.9 & \text { A B } \\ \text { A } & 36 & 3.6 & \text { B }\end{array}$

Means that do not share a letter are significantly different.

Tukey 95.0\% Simultaneous Confidence Intervals Response Variable Response 3

All Pairwise Comparisons among Levels of SummaryType SummaryType $=\mathrm{A}$ subtracted from:

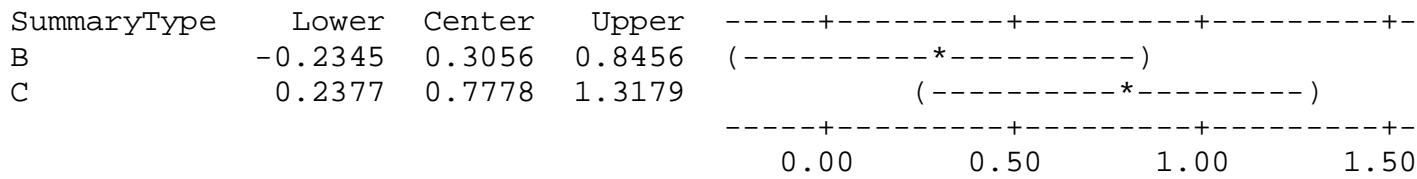

SummaryType $=$ B subtracted from: 


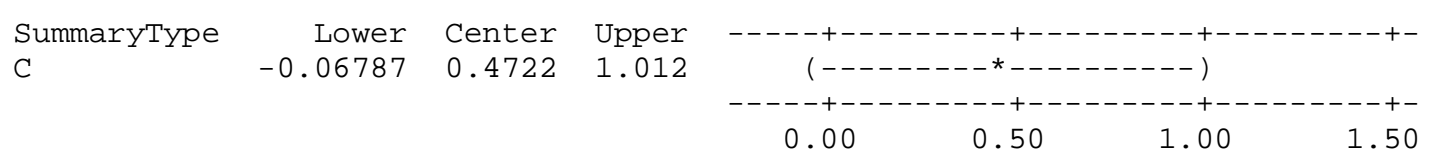

Tukey Simultaneous Tests

Response Variable Response 3

All Pairwise Comparisons among Levels of SummaryType

SummaryType $=\mathrm{A}$ subtracted from:

$\begin{array}{lrrrr} & \text { Difference } & \text { SE of } & \text { Adjusted } \\ \text { SummaryType } & \text { of Means } & \text { Difference } & \text { T-Value } & \text { P-Value } \\ \text { B } & 0.3056 & 0.2253 & 1.356 & 0.3699 \\ \text { C } & 0.7778 & 0.2253 & 3.452 & 0.0028\end{array}$

SummaryType $=$ B subtracted from:

$\begin{array}{lrrrr} & \text { Difference } & \text { SE of } & \text { Adjusted } \\ \text { SummaryType } & \text { of Means } & \text { Difference } & \text { T-Value } & \text { P-Value } \\ \text { C } & 0.4722 & 0.2253 & 2.096 & 0.0987\end{array}$

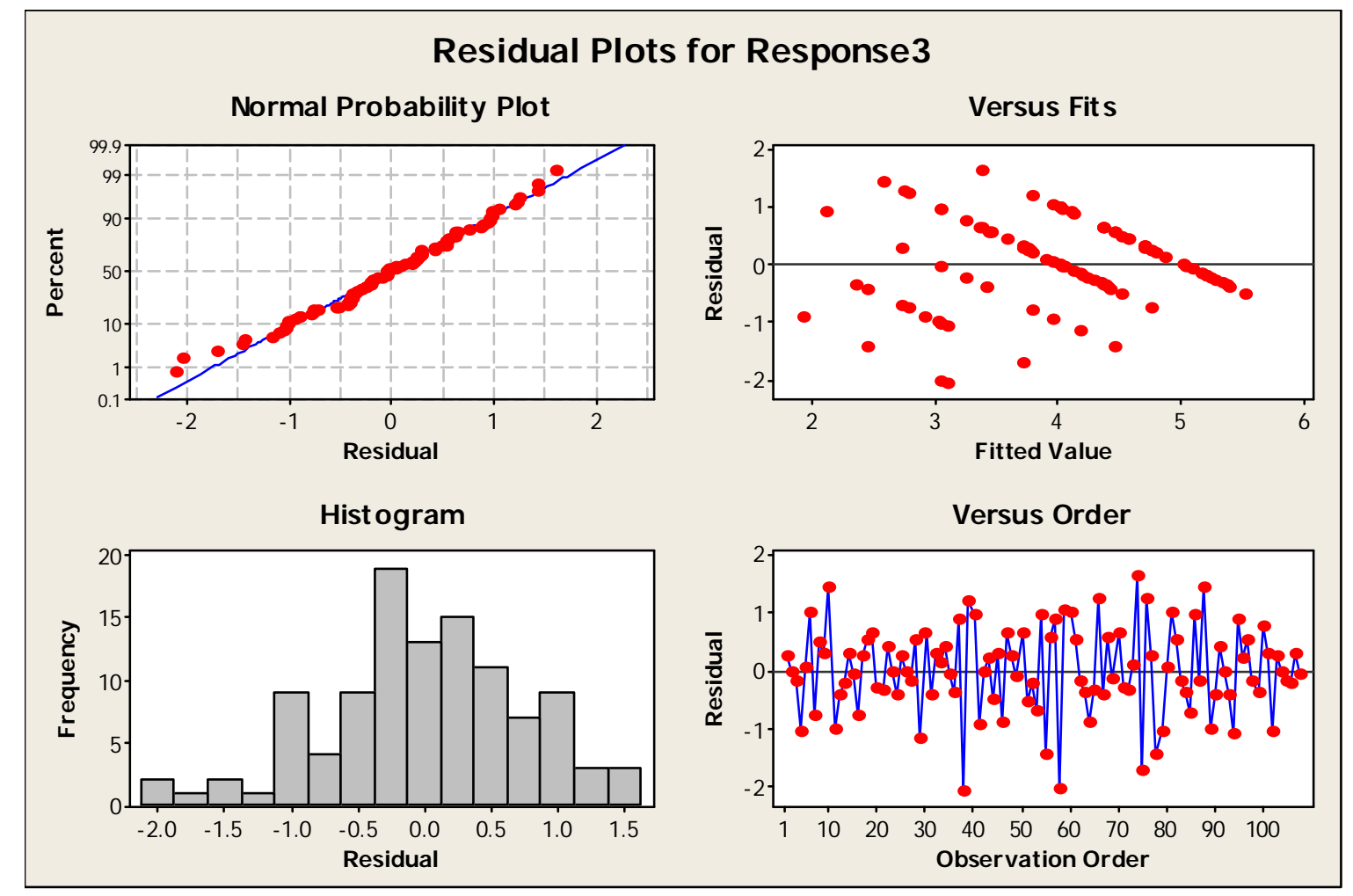

\section{Appendix G.2 - Understanding Questions (5-7)}

Appendix G.2.1 - Question 5

Question 5: The information on this summary page was easy to understand. 
Response: 1 (Strongly Disagree) to 5 (Strongly Agree)
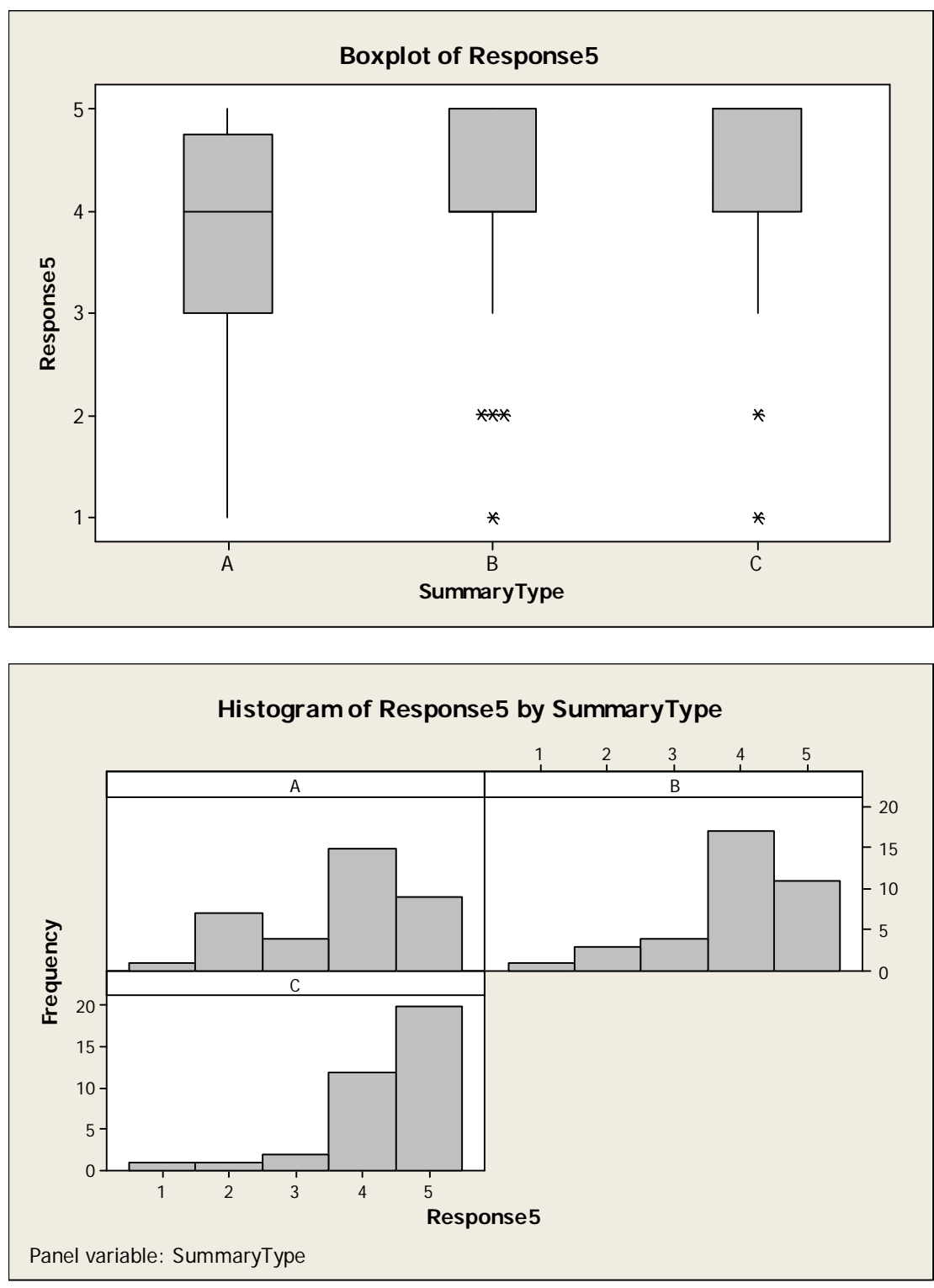

\section{Descriptive Statistics: Response5}

$\begin{array}{llrrr}\text { Variable } & \text { SummaryType } & \mathrm{N} & \mathrm{N}^{*} & \text { Mean } \\ \text { Response5 } & \text { A } & 36 & 0 & 3.667 \\ & \mathrm{~B} & 36 & 0 & 3.944 \\ & \mathrm{C} & 36 & 0 & 4.361 \\ \text { Variable } & \text { SummaryType } & \mathrm{Q} 3 & \text { Maximum } \\ \text { Response5 } & \text { A } & 4.750 & 5.000 \\ & \text { B } & 5.000 & 5.000 \\ & \text { C } & 5.000 & 5.000\end{array}$



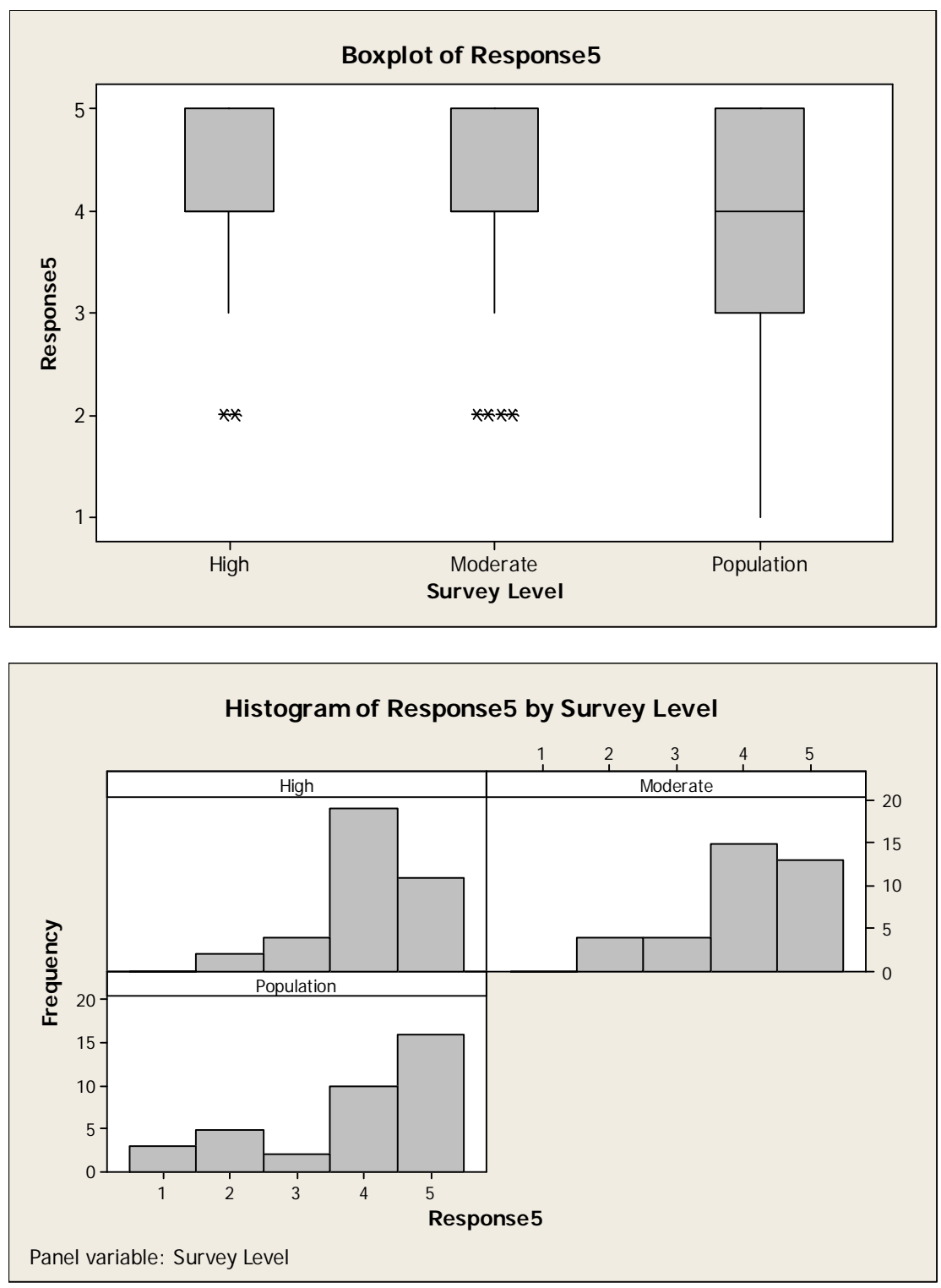

\section{Descriptive Statistics: Response5}

\begin{tabular}{|c|c|c|c|c|c|c|c|c|c|}
\hline Variable & Survey Level & $\mathrm{N}$ & $\mathrm{N}^{*}$ & Mean & SE Mean & StDev & Minimum & Q1 & Median \\
\hline \multirow[t]{3}{*}{ Response 5} & High & 36 & 0 & 4.083 & 0.134 & 0.806 & 2.000 & 4.000 & 4.000 \\
\hline & Moderate & 36 & 0 & 4.028 & 0.162 & 0.971 & 2.000 & 4.000 & 4.000 \\
\hline & Population & 36 & 0 & 3.861 & 0.226 & 1.355 & 1.000 & 3.000 & 4.000 \\
\hline Variable & Survey Level & & 23 & Maximum & & & & & \\
\hline \multirow[t]{3}{*}{ Response 5} & $\mathrm{High}$ & 5.0 & & 5.000 & & & & & \\
\hline & Moderate & 5.0 & & 5.000 & & & & & \\
\hline & Population & 5.0 & & 5.000 & & & & & \\
\hline
\end{tabular}




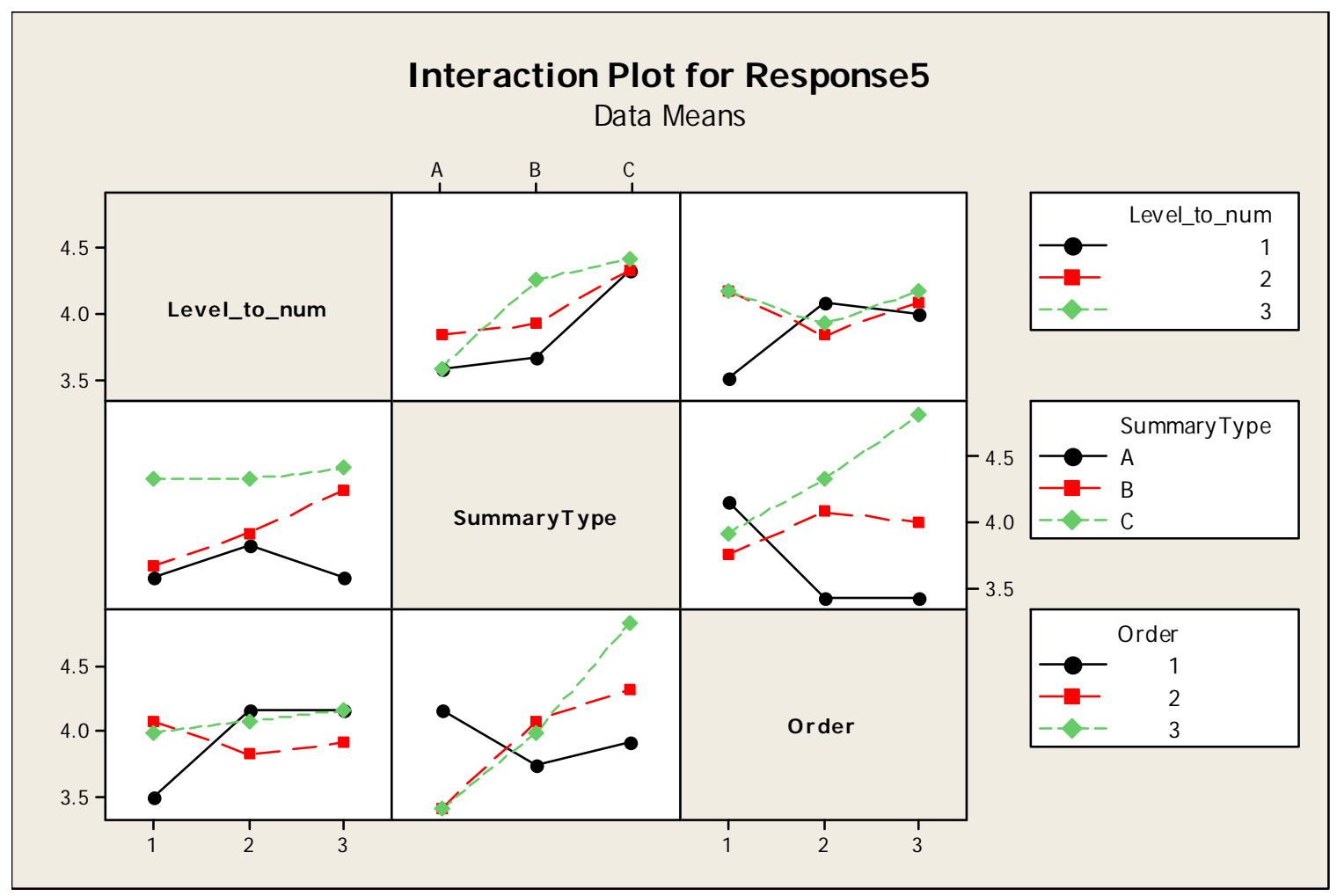

\section{General Linear Model: Response5 versus SummaryType, SurveyLevel, ...}

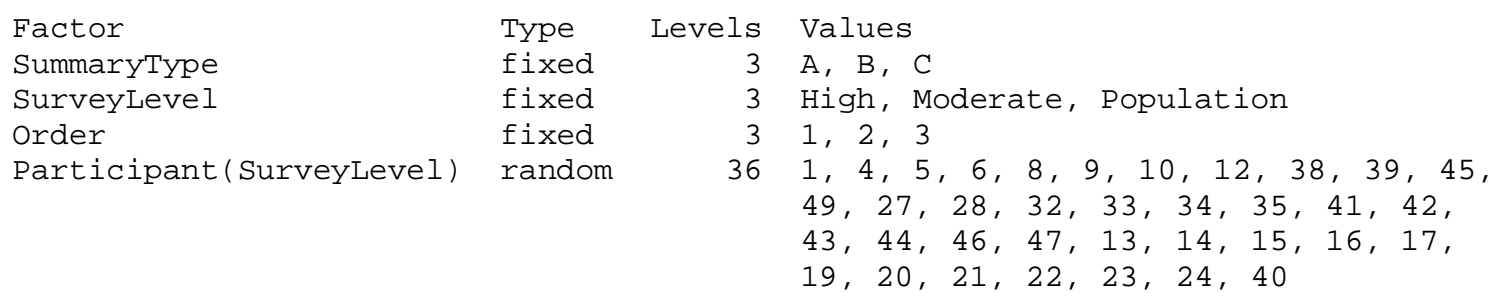

Analysis of Variance for Response5, using Adjusted SS for Tests

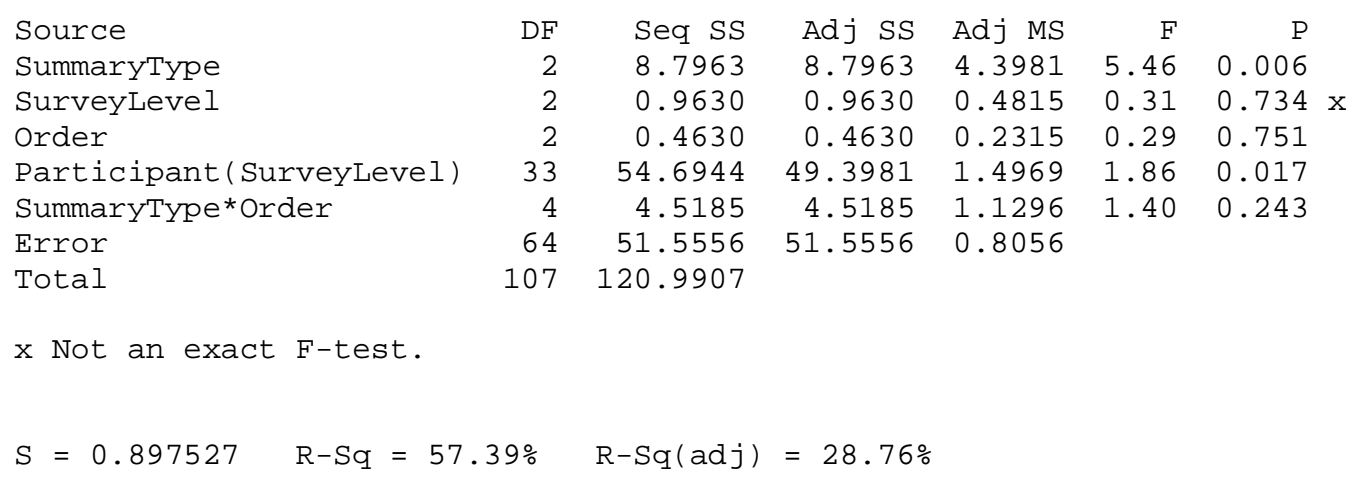

$\mathrm{x}$ Not an exact F-test.

$S=0.897527 \quad R-S q=57.39 \% \quad R-S q(\operatorname{adj})=28.76 \%$ 


$\begin{array}{rrrrrr}\text { Obs } & \text { Response5 } & \text { Fit } & \text { SE Fit } & \text { Residual } & \text { St Resid } \\ 38 & 1.00000 & 3.05556 & 0.57288 & -2.05556 & -2.98 \mathrm{R} \\ 61 & 5.00000 & 3.33333 & 0.57288 & 1.66667 & 2.41 \mathrm{R} \\ 63 & 1.00000 & 3.75000 & 0.57288 & -2.75000 & -3.98 \mathrm{R} \\ 66 & 4.00000 & 2.52778 & 0.57288 & 1.47222 & 2.13 \mathrm{R} \\ 100 & 4.00000 & 2.61111 & 0.57288 & 1.38889 & 2.01 \mathrm{R}\end{array}$

$\mathrm{R}$ denotes an observation with a large standardized residual.

Grouping Information Using Tukey Method and 95.0\% Confidence

\begin{tabular}{|c|c|c|c|}
\hline SummaryType & $\mathrm{N}$ & Mean & Grouping \\
\hline C & 36 & 4.4 & A \\
\hline B & 36 & 3.9 & A B \\
\hline A & 36 & 3.7 & B \\
\hline
\end{tabular}

Tukey 95.0\% Simultaneous Confidence Intervals

Response Variable Response 5

All Pairwise Comparisons among Levels of SummaryType SummaryType $=\mathrm{A}$ subtracted from:

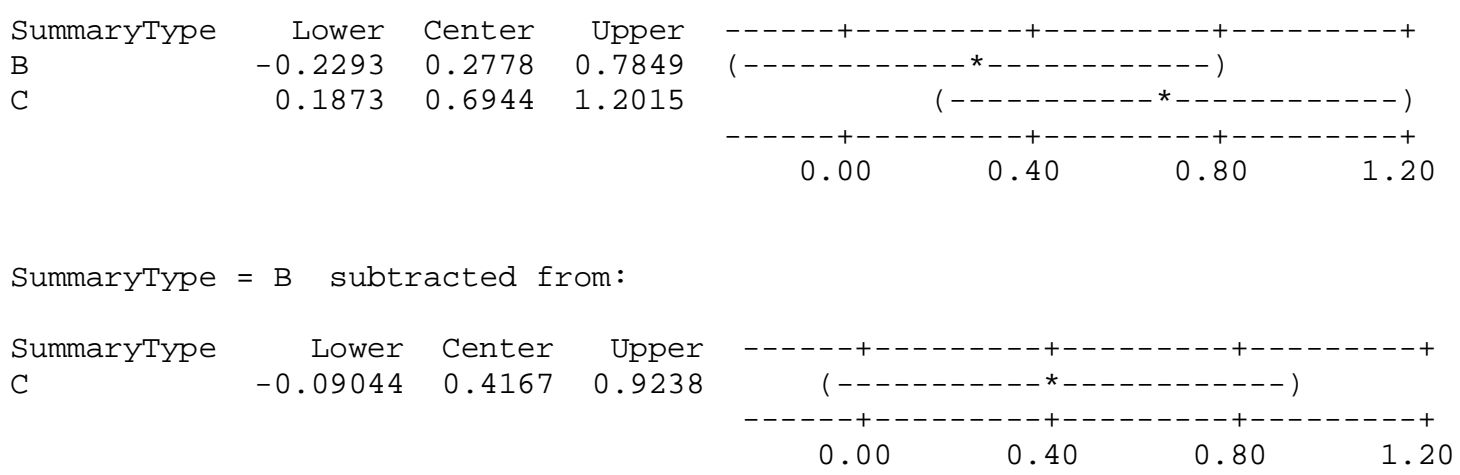

Tukey Simultaneous Tests

Response Variable Response5

All Pairwise Comparisons among Levels of Summarytype

SummaryType $=$ A subtracted from:

$\begin{array}{lrrrr} & \text { Difference } & \text { SE of } & \text { Adjusted } \\ \text { SummaryType } & \text { of Means } & \text { Difference } & \text { T-Value } & \text { P-Value } \\ \text { B } & 0.2778 & 0.2115 & 1.313 & 0.3932 \\ \text { C } & 0.6944 & 0.2115 & 3.283 & 0.0047\end{array}$

\begin{tabular}{lrrrr} 
SummaryType $=\mathrm{B}$ & \multicolumn{2}{c}{ subtracted from: } \\
& Difference & SE of & & Adjusted \\
SummaryType & of Means & Difference & T-Value & P-Value \\
C & 0.4167 & 0.2115 & 1.970 & 0.1281
\end{tabular}




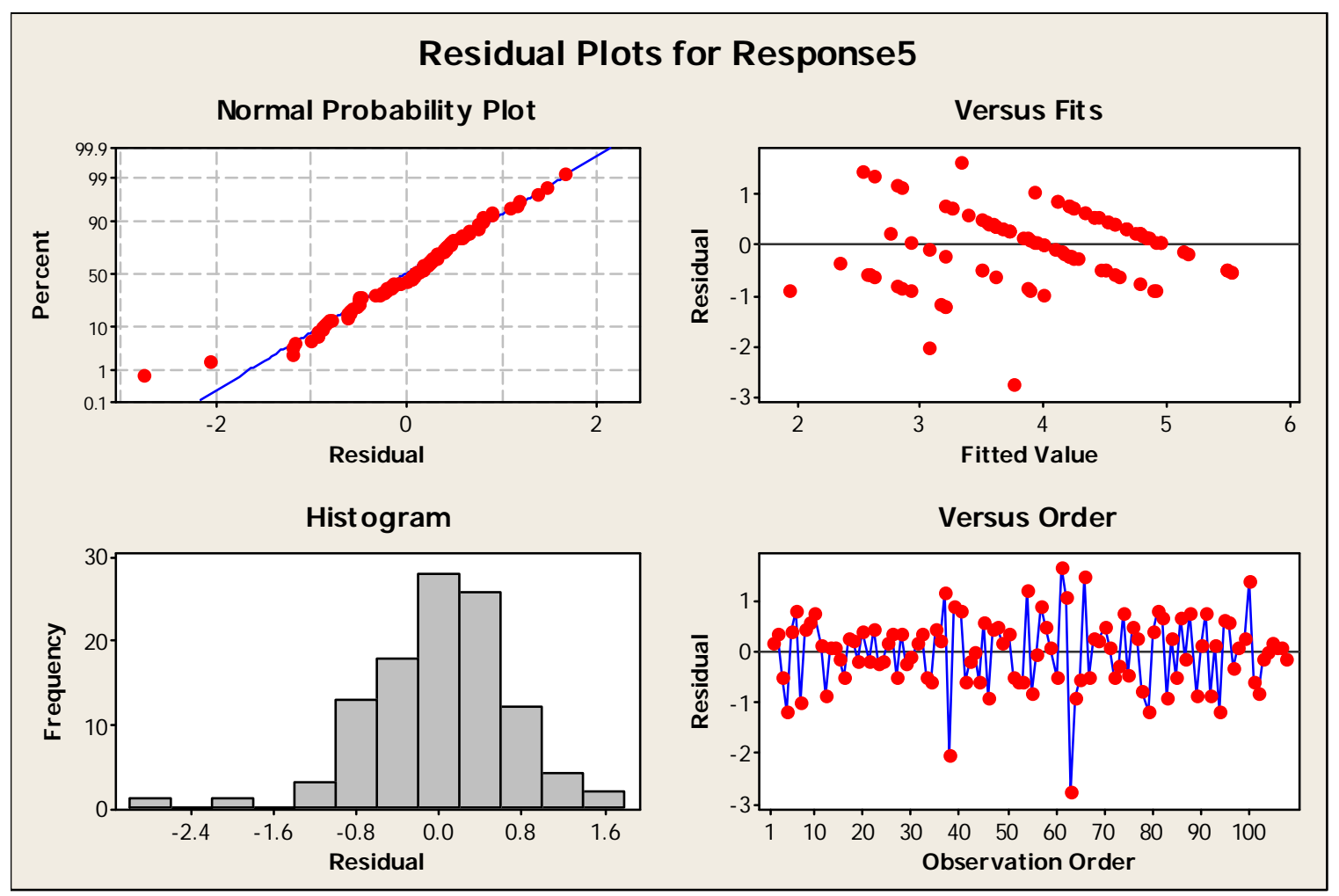

Appendix G.2.2 - Question 6

Question 6: If I received this report, I would know what actions I should take.

Response: 1 (Strongly Disagree) to 5 (Strongly Agree)

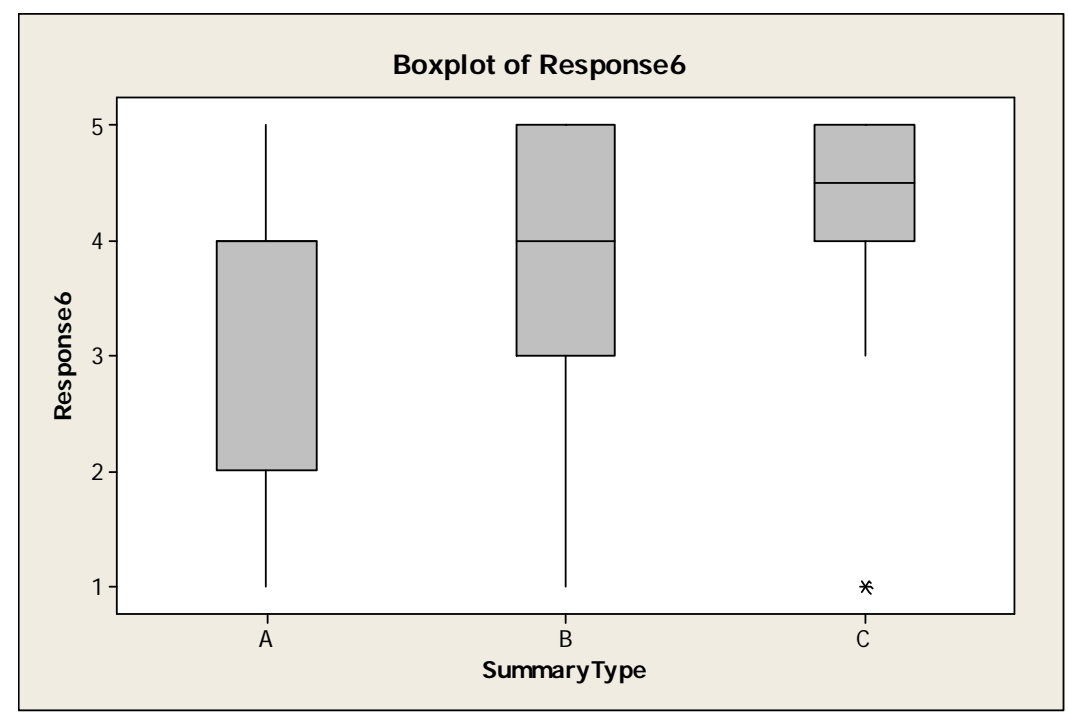




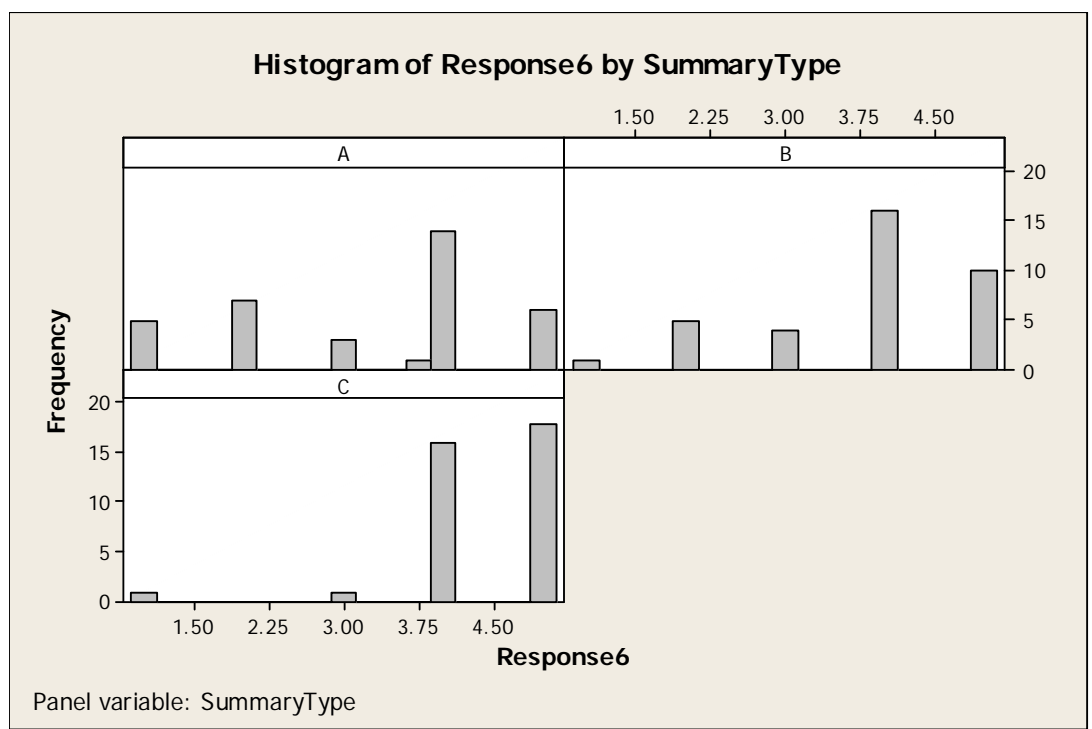

\section{Descriptive Statistics: Response6}

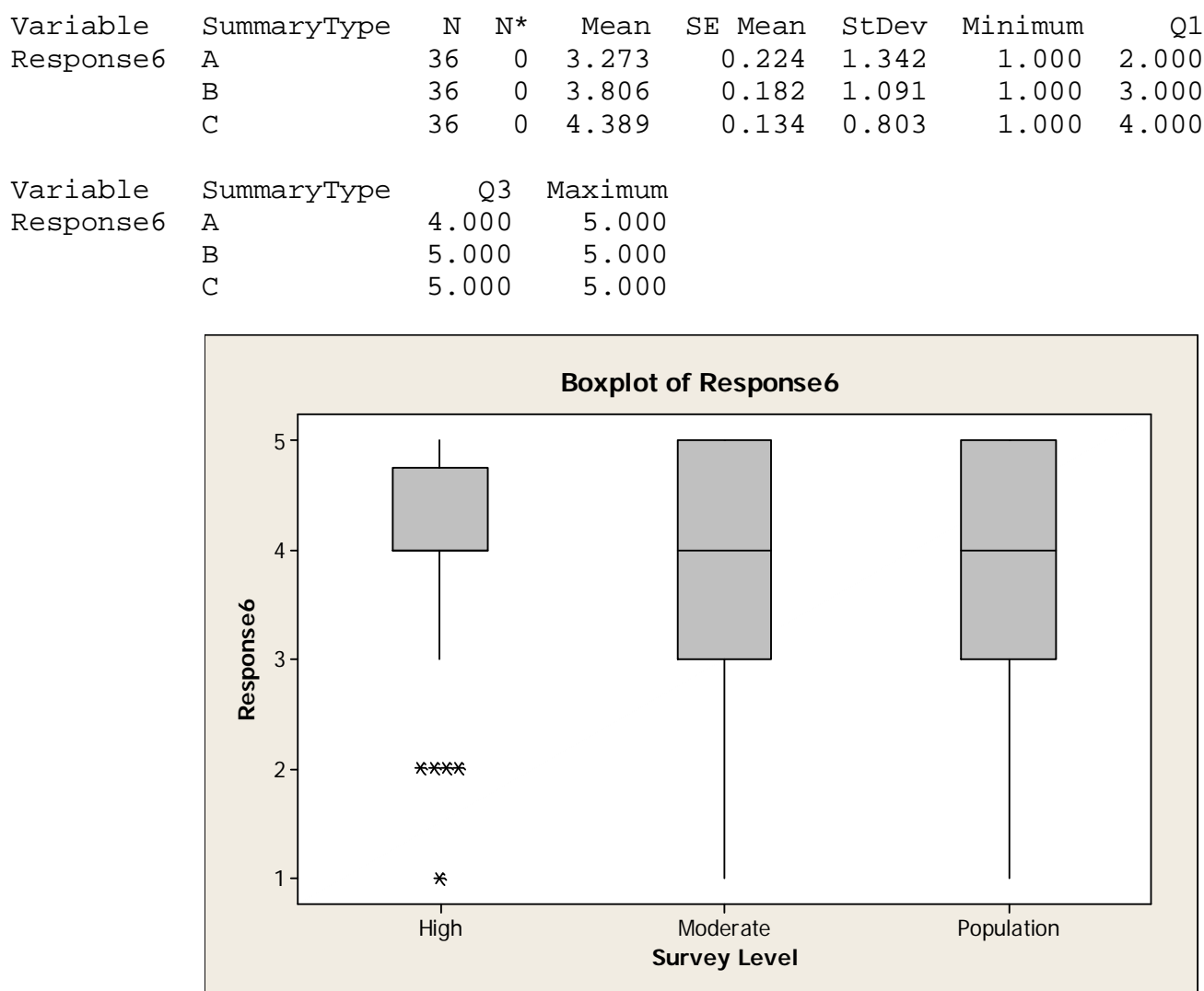




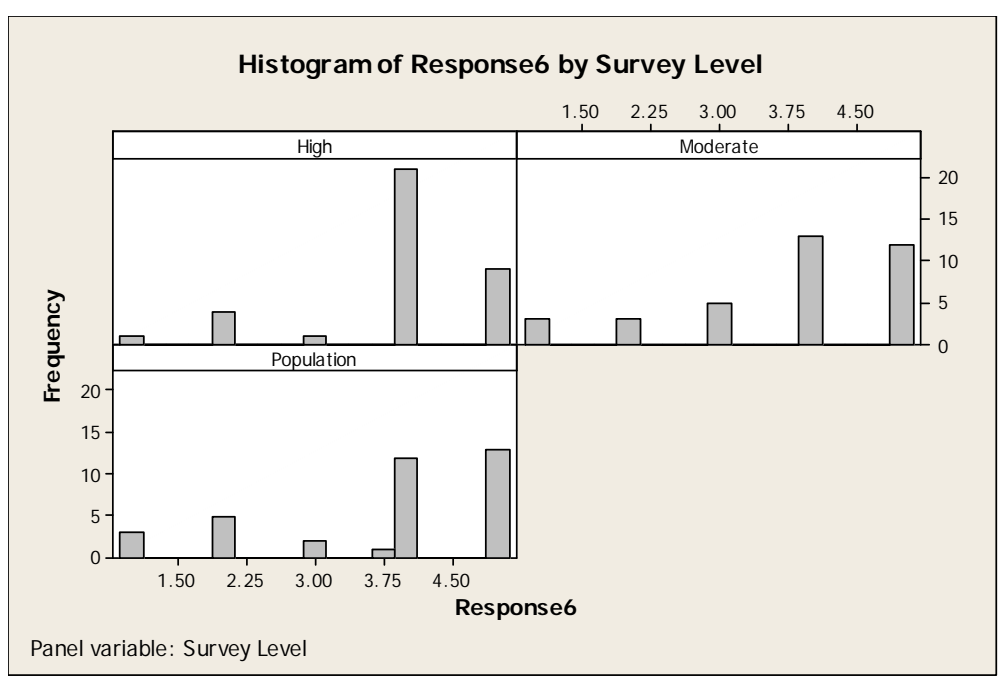

\section{Descriptive Statistics: Response6}

\begin{tabular}{|c|c|c|c|c|c|c|c|c|c|}
\hline \multirow{4}{*}{$\begin{array}{l}\text { Variable } \\
\text { Response } 6\end{array}$} & Survey Level & $\mathrm{N}$ & $N^{*}$ & Mean & SE Mean & StDev & Minimum & Q1 & Median \\
\hline & $\mathrm{High}$ & 36 & 0 & 3.917 & 0.166 & 0.996 & 1.000 & 4.000 & 4.000 \\
\hline & Moderate & 36 & 0 & 3.778 & 0.207 & 1.245 & 1.000 & 3.000 & 4.000 \\
\hline & Population & 36 & 0 & 3.773 & 0.219 & 1.311 & 1.000 & 3.000 & 4.000 \\
\hline \multirow{4}{*}{$\begin{array}{l}\text { Variable } \\
\text { Response } 6\end{array}$} & Survey Level & & Q3 & Maximum & & & & & \\
\hline & High & 4.7 & & 5.000 & & & & & \\
\hline & Moderate & 5.0 & & 5.000 & & & & & \\
\hline & Population & 5.0 & & 5.000 & & & & & \\
\hline
\end{tabular}

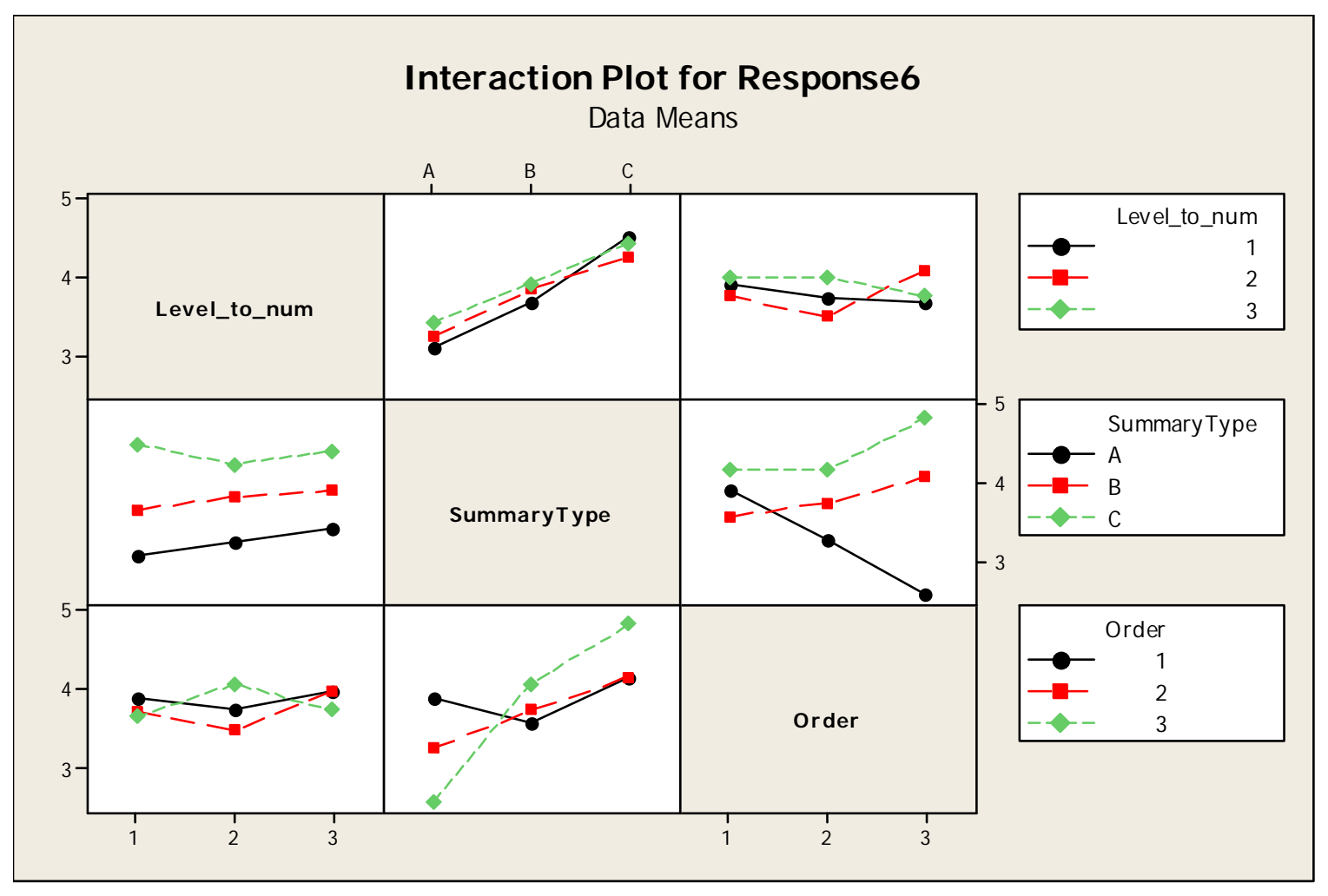




\section{General Linear Model: Response6 versus SummaryType, SurveyLevel, ...}

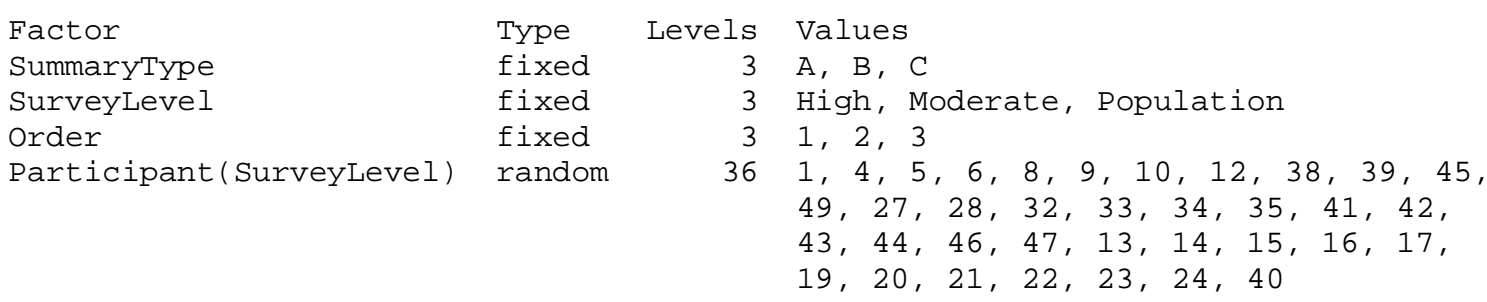

Levels

Values

$A, B, C$

High, Moderate, Population

$1,2,3$

$361,4,5,6,8,9,10,12,38,39,45$, $49,27,28,32,33,34,35,41,42$, $43,44,46,47,13,14,15,16,17$, $19,20,21,22,23,24,40$

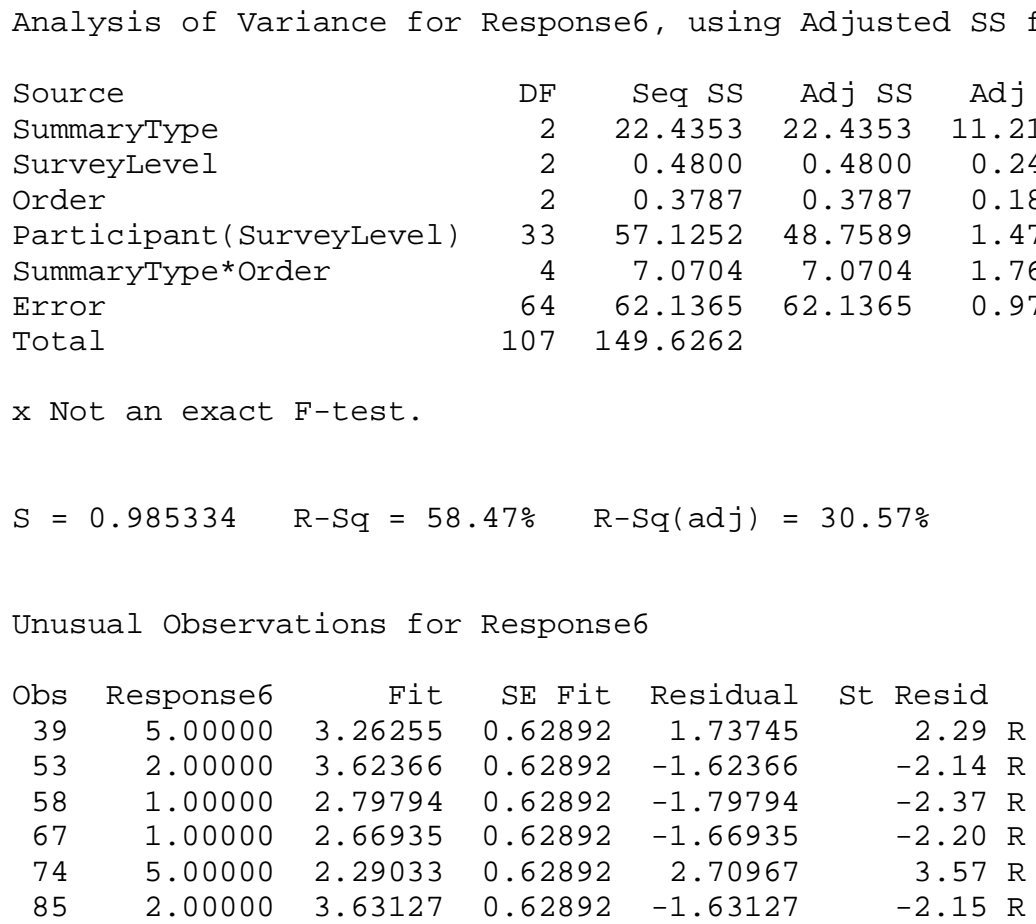

$\mathrm{R}$ denotes an observation with a large standardized residual.

Grouping Information Using Tukey Method and 95.0\% Confidence

$\begin{array}{lrrc}\text { SummaryType } & \text { N } & \text { Mean } & \text { Grouping } \\ \text { C } & 36 & 4.4 & \text { A } \\ \text { B } & 36 & 3.8 & \text { B } \\ \text { A } & 36 & 3.3 & \text { B }\end{array}$

Means that do not share a letter are significantly different.

Tukey 95.0\% Simultaneous Confidence Intervals

Response Variable Response6

All Pairwise Comparisons among Levels of SummaryType

SummaryType $=\mathrm{A}$ subtracted from:

$\begin{array}{lrrr}\text { SummaryType } & \text { Lower } & \text { Center } & \text { Upper } \\ \text { B } & -0.02400 & 0.5327 & 1.089 \\ \text { C } & 0.55933 & 1.1160 & 1.673\end{array}$

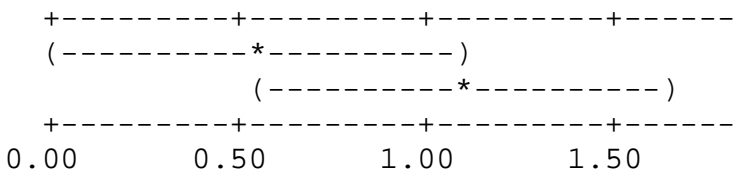



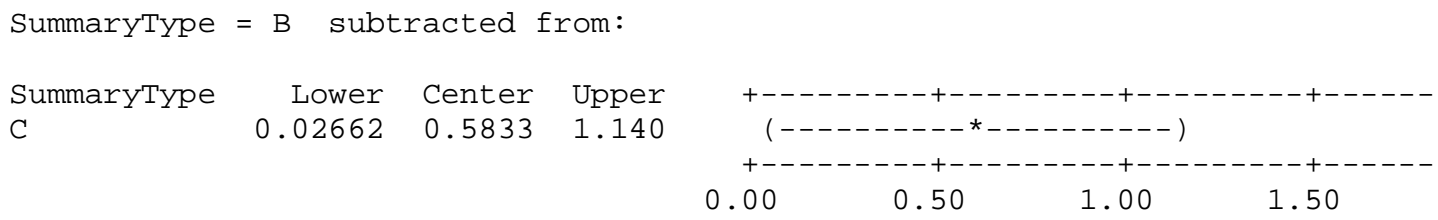

Tukey Simultaneous Tests

Response Variable Response 6

All Pairwise Comparisons among Levels of SummaryType

SummaryType $=$ A subtracted from:

$\begin{array}{lrrrr} & \text { Difference } & \text { SE of } & \text { Adjusted } \\ \text { SummaryType } & \text { of Means } & \text { Difference } & \text { T-Value } & \text { P-Value } \\ \text { B } & 0.5327 & 0.2322 & 2.294 & 0.0639 \\ \text { C } & 1.1160 & 0.2322 & 4.805 & 0.0000\end{array}$

SummaryType $=$ B subtracted from:

$\begin{array}{lrrrr} & \text { Difference } & \text { SE of } & \text { Adjusted } \\ \text { SummaryType } & \text { of Means } & \text { Difference } & \text { T-Value } & \text { P-Value } \\ \text { C } & 0.5833 & 0.2322 & 2.512 & 0.0382\end{array}$

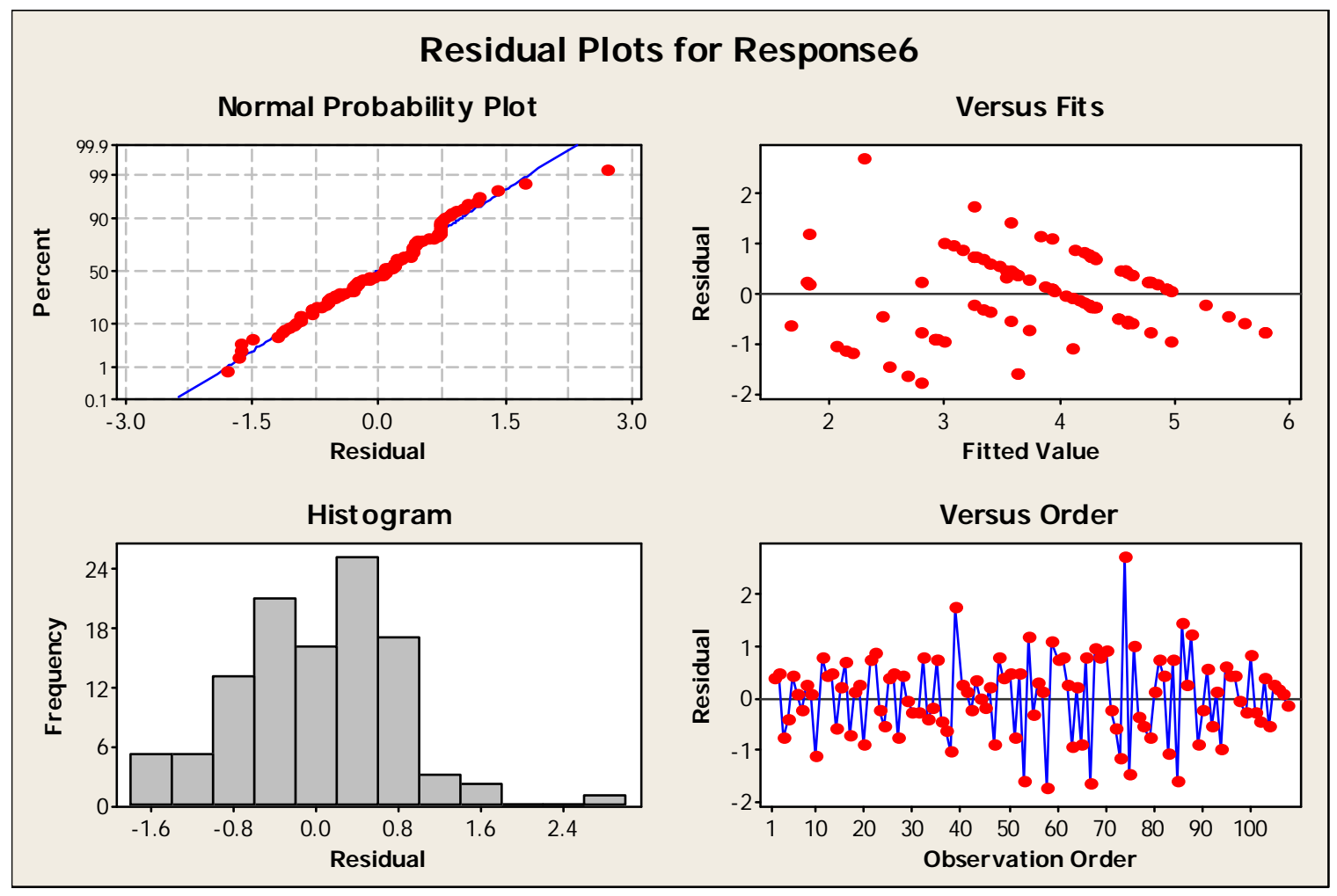

Appendix G.2.3 - Understanding Procedure

Question: If I received these results, I would know the steps to take to

Response: 1 (Strongly Disagree) to 5 (Strongly Agree) 
Appendix G.2.3.1 - Understanding Colonoscopy

Population \#7, Moderate \#7, High \#8
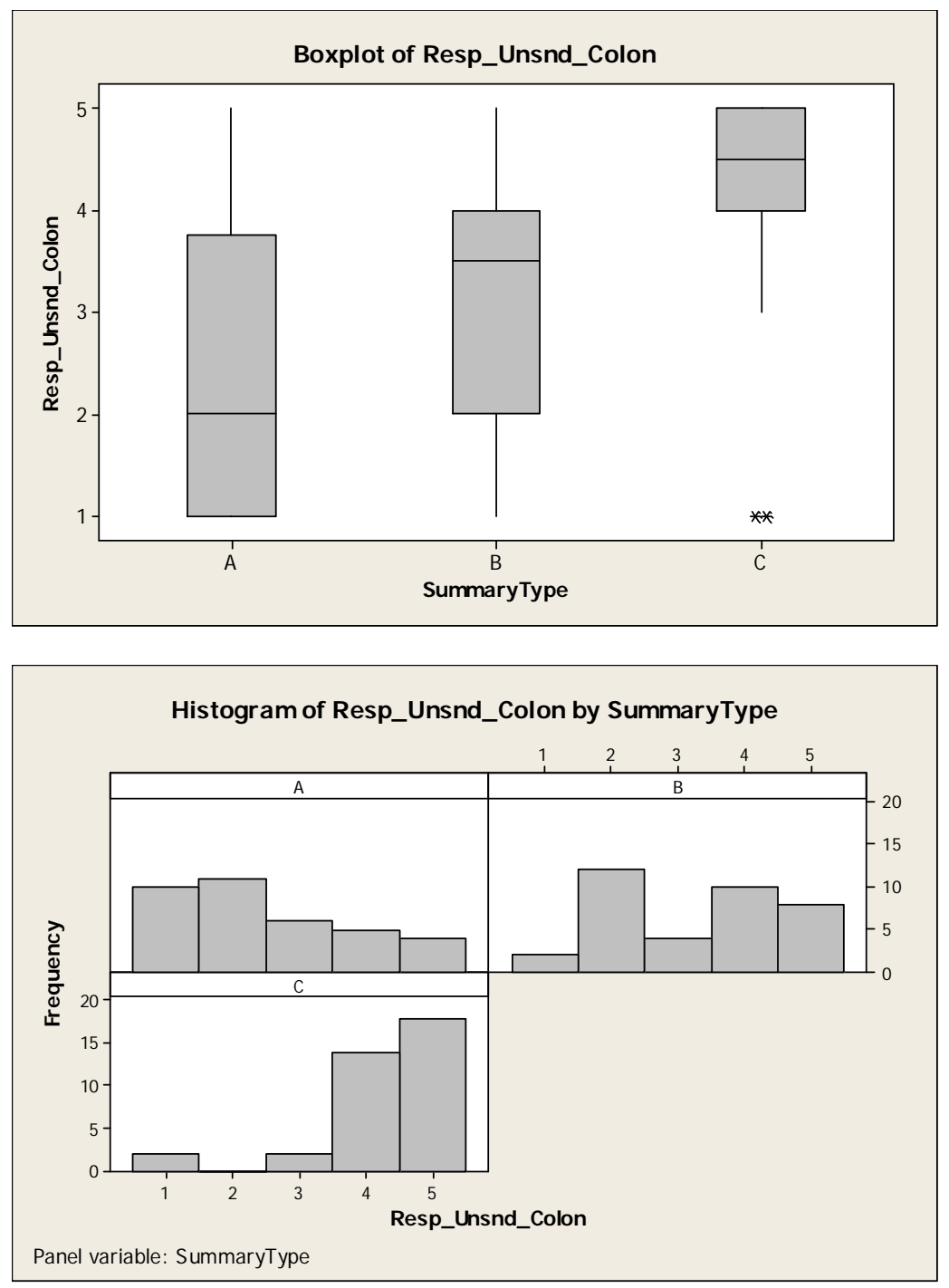

\section{Descriptive Statistics: Resp_Unsnd_Colon}

$\begin{array}{llrrrrrrr}\text { Variable } & \text { SummaryType } & \text { N } & N^{*} & \text { Mean } & \text { SE Mean } & \text { StDev } & \text { Minimum } & \text { Q1 } \\ \text { Resp_Unsnd_Colon } & \text { A } & 36 & 0 & 2.500 & 0.224 & 1.342 & 1.000 & 1.000 \\ & \text { B } & 36 & 0 & 3.278 & 0.217 & 1.301 & 1.000 & 2.000 \\ & \text { C } & 36 & 0 & 4.278 & 0.167 & 1.003 & 1.000 & 4.000 \\ \text { Variable } & \text { SummaryType } & \text { Median } & \text { Q3 } & \text { Maximum } & & & \\ \text { Resp_Unsnd_Colon } & \text { A } & 2.000 & 3.750 & 5.000 & & \\ & \text { B } & 3.500 & 4.000 & 5.000 & & \\ & \text { C } & 4.500 & 5.000 & 5.000 & & \end{array}$



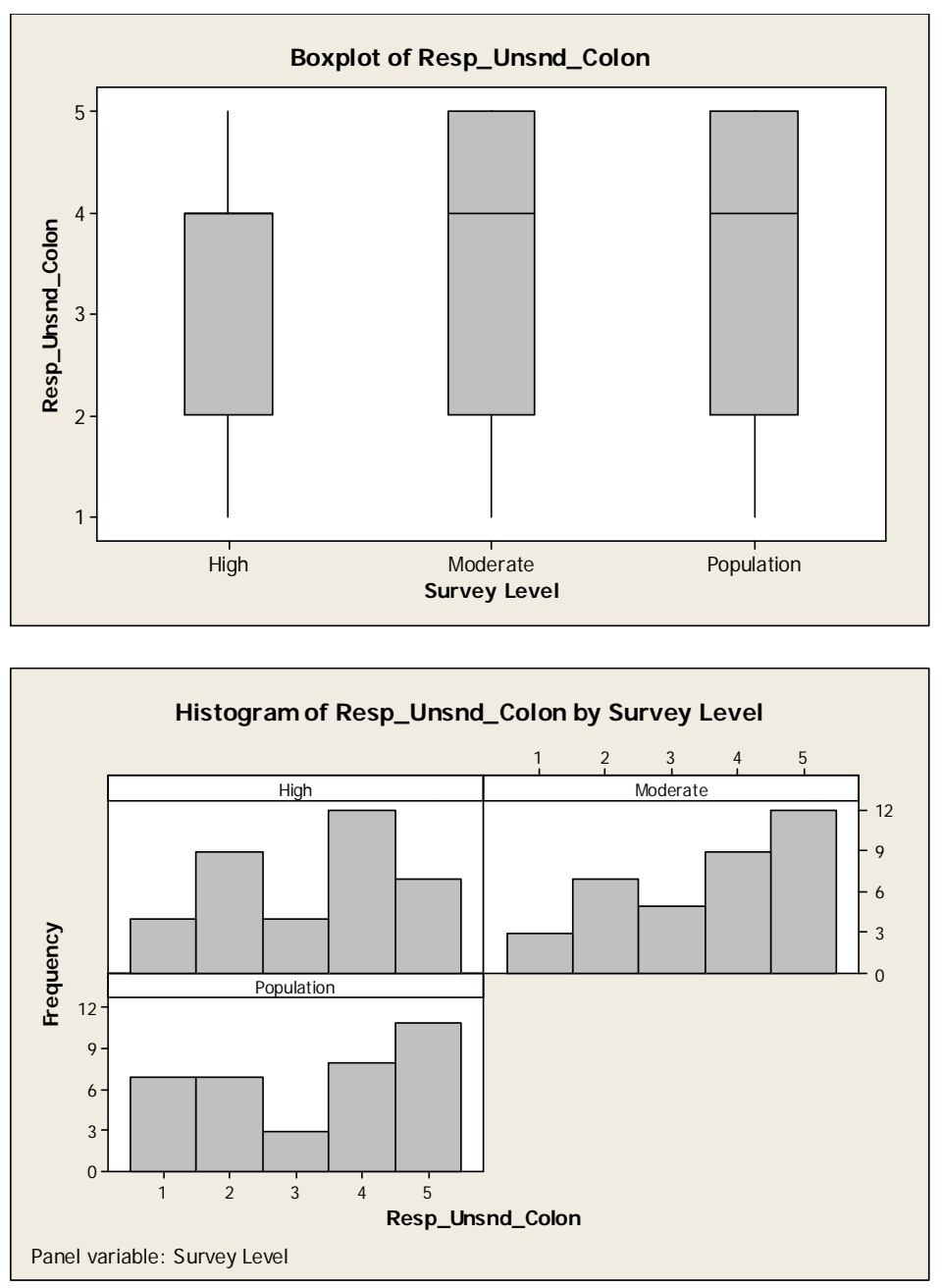

\section{Descriptive Statistics: Resp_Unsnd_Colon}

$\begin{array}{llrrrrrrr}\text { Variable } & \begin{array}{l}\text { Survey Level } \\ \text { Resp_Unsnd_Colon }\end{array} & \text { N } & N^{*} & \text { Mean } & \text { SE Mean } & \text { StDev } & \text { Minimum } & \text { Q1 } \\ & \text { High } & 36 & 0 & 3.250 & 0.223 & 1.339 & 1.000 & 2.000 \\ & \begin{array}{l}\text { Moderate } \\ \text { Population }\end{array} & 36 & 0 & 3.556 & 0.227 & 1.362 & 1.000 & 2.000 \\ & & & 0 & 3.250 & 0.259 & 1.556 & 1.000 & 2.000 \\ \text { Variable } & \text { Survey Level } & \text { Median } & \text { Q3 } & \text { Maximum } & & & \\ \text { Resp_Unsnd_Colon } & \text { High } & 4.000 & 4.000 & 5.000 & & \\ & \begin{array}{l}\text { Moderate } \\ \text { Population }\end{array} & 4.000 & 5.000 & 5.000 & & \\ & 4.000 & 5.000 & 5.000 & & \end{array}$




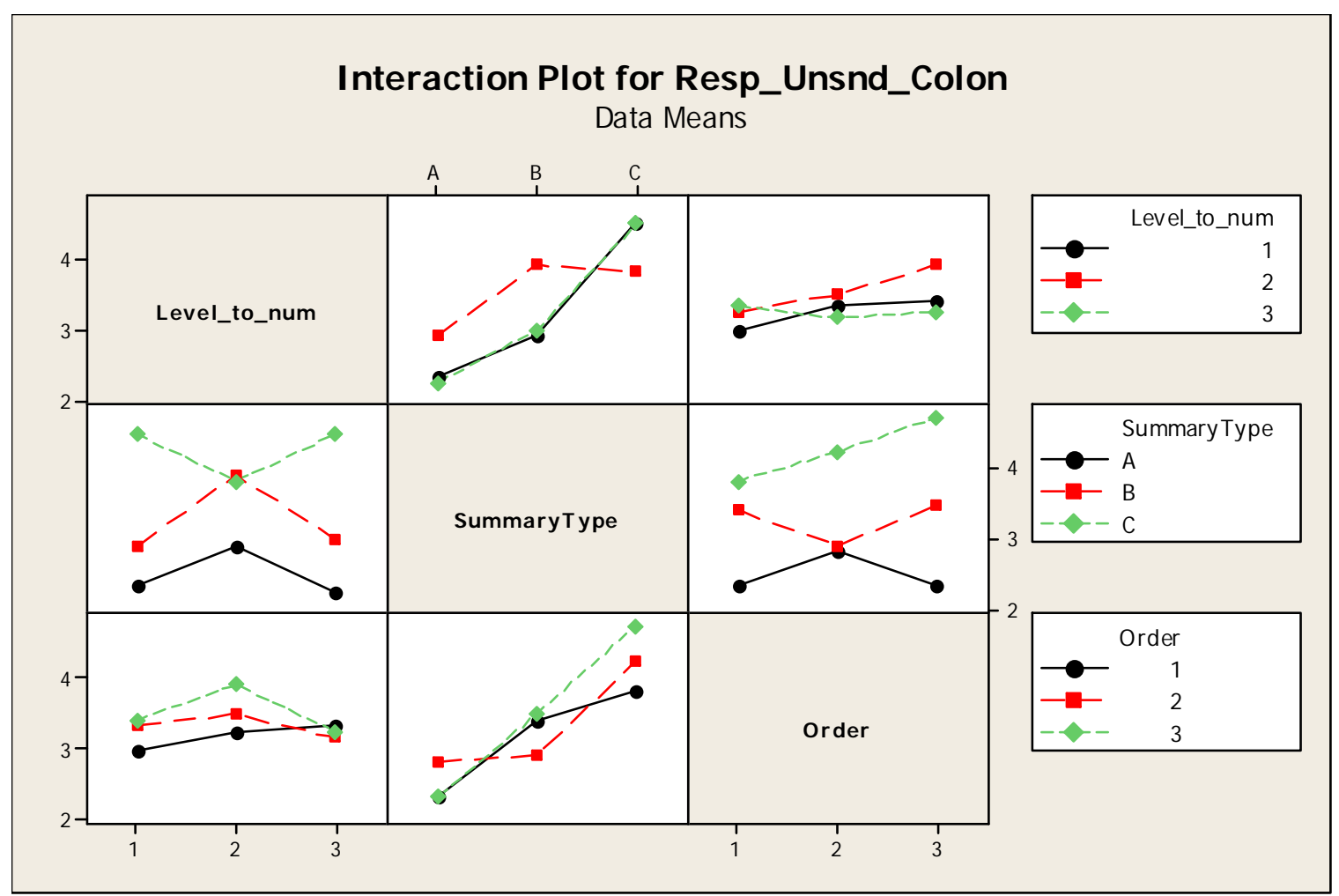

\section{General Linear Model: Resp_Unsnd_C versus SummaryType, SurveyLevel, ...}

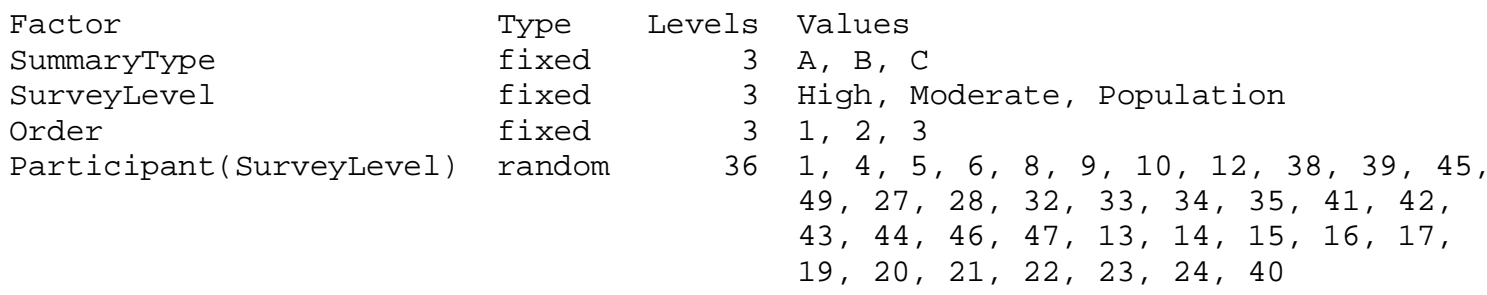

Analysis of Variance for Resp_Unsnd_Colon, using Adjusted SS for Tests

$\begin{array}{lrrrrrr}\text { Source } & \text { DF } & \text { Seq SS } & \text { Adj SS } & \text { Adj MS } & \text { F } & \text { P } \\ \text { SummaryType } & 2 & 57.185 & 57.185 & 28.593 & 27.23 & 0.000 \\ \text { SurveyLevel } & 2 & 2.241 & 2.241 & 1.120 & 0.45 & 0.639 x \\ \text { Order } & 2 & 2.019 & 2.019 & 1.009 & 0.96 & 0.388 \\ \text { Participant (SurveyLevel) } & 33 & 77.722 & 78.556 & 2.380 & 2.27 & 0.003 \\ \text { SummaryType*Order } & 4 & 8.259 & 8.259 & 2.065 & 1.97 & 0.110 \\ \text { Error } & 64 & 67.204 & 67.204 & 1.050 & & \\ \text { Total } & 107 & 214.630 & & & & \end{array}$

$x$ Not an exact $F$-test.

$S=1.02472 \quad \mathrm{R}-\mathrm{Sq}=68.69 \% \quad \mathrm{R}-\mathrm{Sq}(\operatorname{adj})=47.65 \%$

Unusual Observations for Resp_Unsnd_Colon

Obs Resp_Unsnd_Colon Fit SE Fit Residual St Resid

$\begin{array}{llllll}39 & 5.00000 & 3.39815 & 0.65407 & 1.60185 & 2.03 \mathrm{R}\end{array}$




\begin{tabular}{|c|c|c|c|c|c|}
\hline 74 & 5.00000 & 2.50926 & 0.65407 & 2.49074 & $3.16 \mathrm{R}$ \\
\hline 75 & 1.00000 & 3.20370 & 0.65407 & -2.20370 & $-2.79 R$ \\
\hline 86 & 5.00000 & 3.40741 & 0.65407 & 1.59259 & $2.02 \mathrm{R}$ \\
\hline
\end{tabular}

$\mathrm{R}$ denotes an observation with a large standardized residual.

Grouping Information Using Tukey Method and 95.0\% Confidence

$\begin{array}{lrrr}\text { SummaryType } & \text { N } & \text { Mean } & \text { Grouping } \\ \text { C } & 36 & 4.3 & \text { A } \\ \text { B } & 36 & 3.3 & \text { B } \\ \text { A } & 36 & 2.5 & \text { C }\end{array}$

Means that do not share a letter are significantly different.

Tukey 95.0\% Simultaneous Confidence Intervals

Response Variable Resp_Unsnd_Colon

All Pairwise Comparisons among Levels of SummaryType

SummaryType $=\mathrm{A}$ subtracted from:

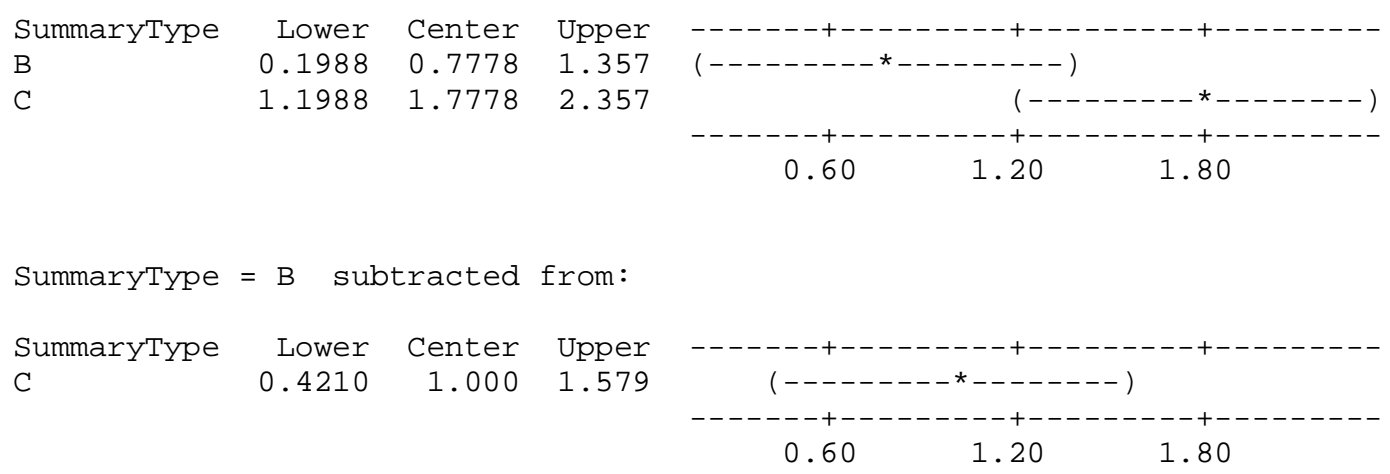

Tukey Simultaneous Tests

Response Variable Resp_Unsnd_Colon

All Pairwise Comparisons among Levels of Summarytype

SummaryType $=$ A subtracted from:

$\begin{array}{lrrrr} & \text { Difference } & \text { SE of } & \text { Adjusted } \\ \text { SummaryType } & \text { of Means } & \text { Difference } & \text { T-Value } & \text { P-Value } \\ \text { B } & 0.7778 & 0.2415 & 3.220 & 0.0056 \\ \text { C } & 1.7778 & 0.2415 & 7.360 & 0.0000\end{array}$

$\begin{array}{lrrrr}\text { SummaryType }= & \text { B subtracted from: } & \\ & \text { Difference } & \text { SE of } & \text { Adjusted } \\ \text { SummaryType } & \text { of Means } & \text { Difference } & \text { T-Value } & \text { P-Value } \\ \text { C } & 1.000 & 0.2415 & 4.140 & 0.0003\end{array}$




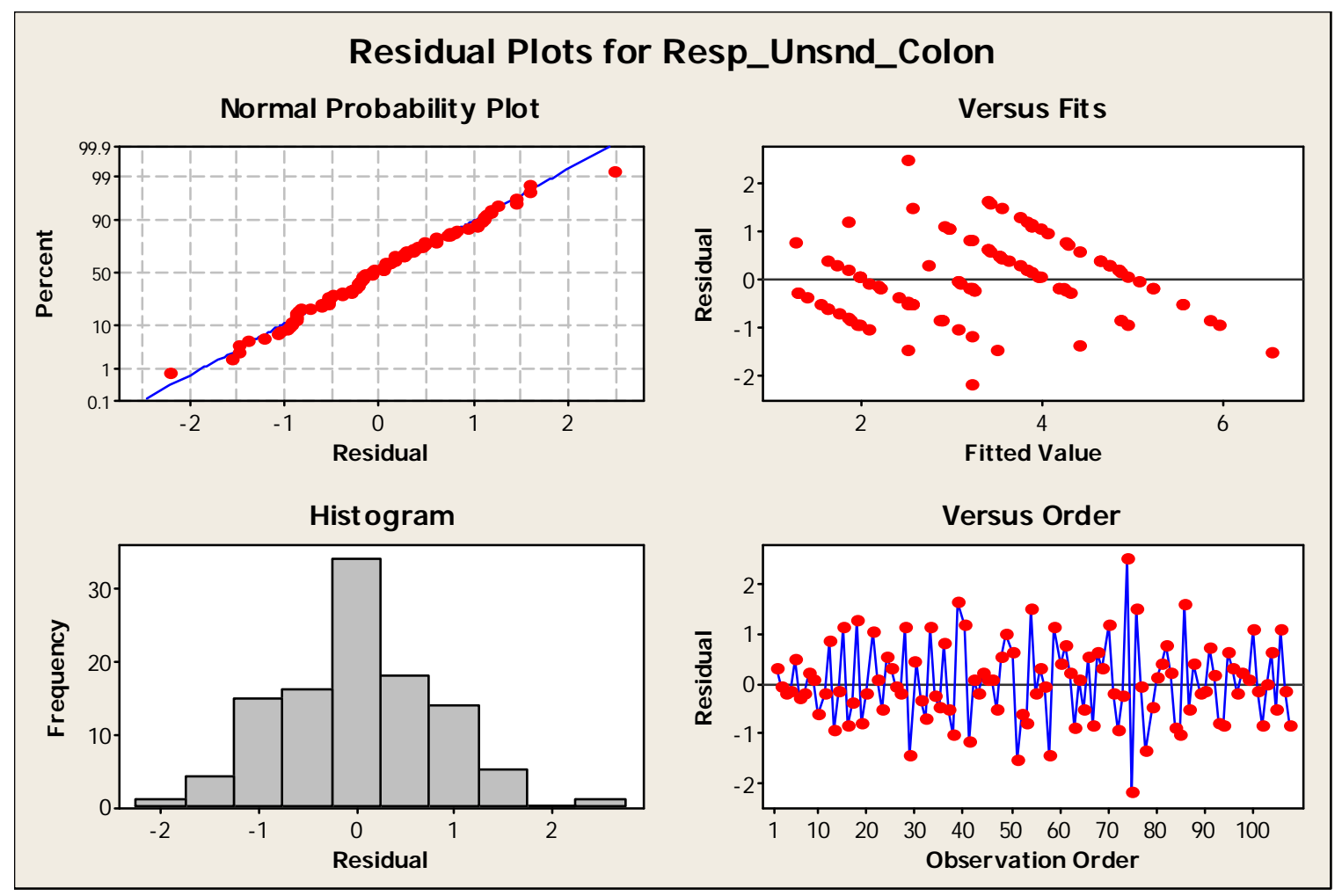

Appendix G.2.3.2 - Understanding Flexible Sigmoidoscopy

Pop \#; no summary level descriptive statistics bc only one level, nor resting of participant

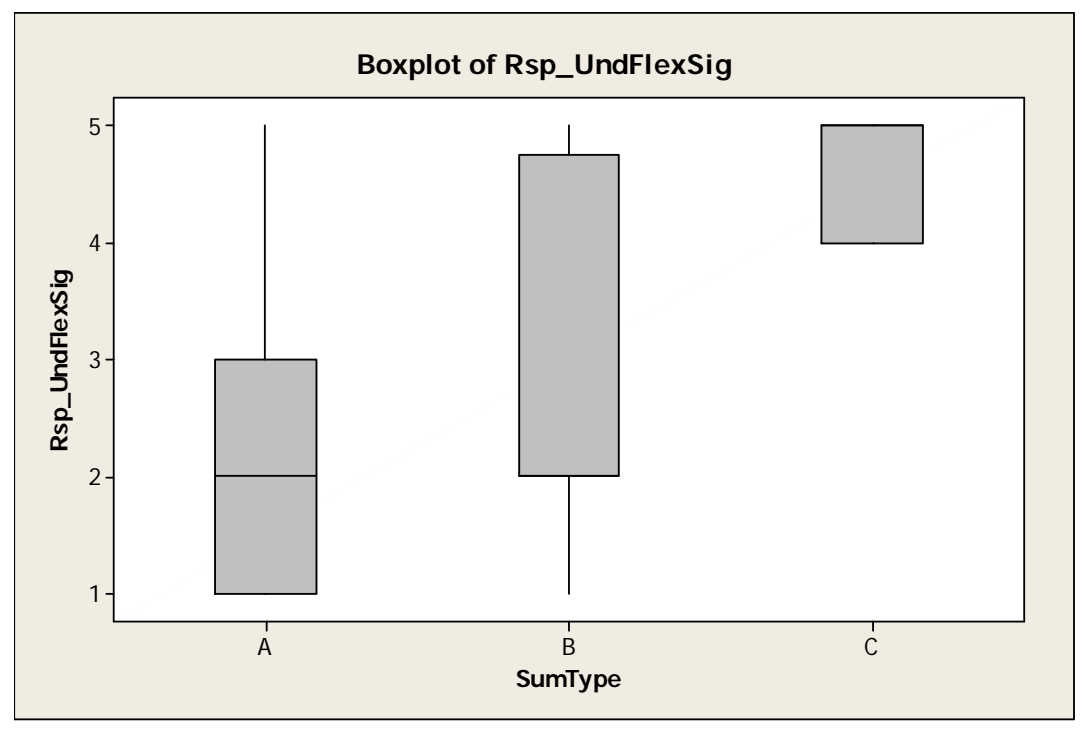




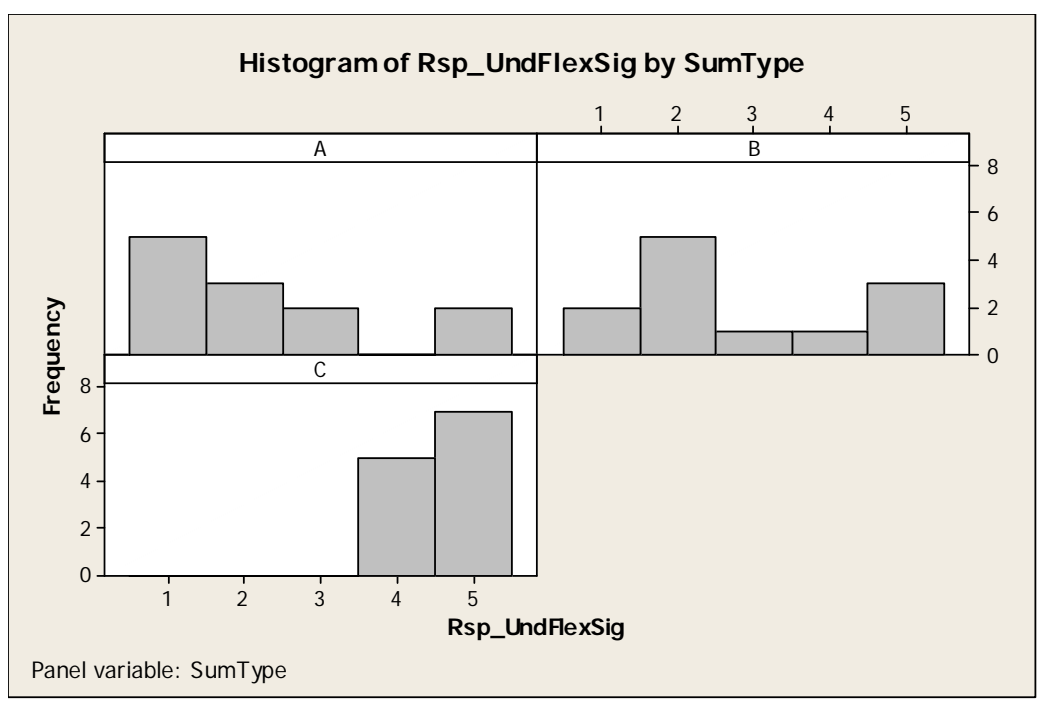

\section{Descriptive Statistics: Rsp_UndFlexSig}

\begin{tabular}{|c|c|c|c|c|c|c|c|c|c|}
\hline Variable & SumType & $\mathrm{N}$ & $\mathrm{N}^{*}$ & Mean & SE Mean & StDev & Minimum & Q1 & Median \\
\hline \multirow[t]{3}{*}{ Rsp_UndFlexSig } & A & 12 & 0 & 2.250 & 0.429 & 1.485 & 1.000 & 1.000 & 2.000 \\
\hline & B & 12 & 0 & 2.833 & 0.441 & 1.528 & 1.000 & 2.000 & 2.000 \\
\hline & $\mathrm{C}$ & 12 & 0 & 4.583 & 0.149 & 0.515 & 4.000 & 4.000 & 5.000 \\
\hline Variable & SumType & & Q3 & Maximum & & & & & \\
\hline \multirow[t]{3}{*}{ Rsp_UndFlexSig } & $\mathrm{A}$ & 3.0 & & 5.000 & & & & & \\
\hline & B & 4.7 & & 5.000 & & & & & \\
\hline & C & 5.0 & & 5.000 & & & & & \\
\hline
\end{tabular}

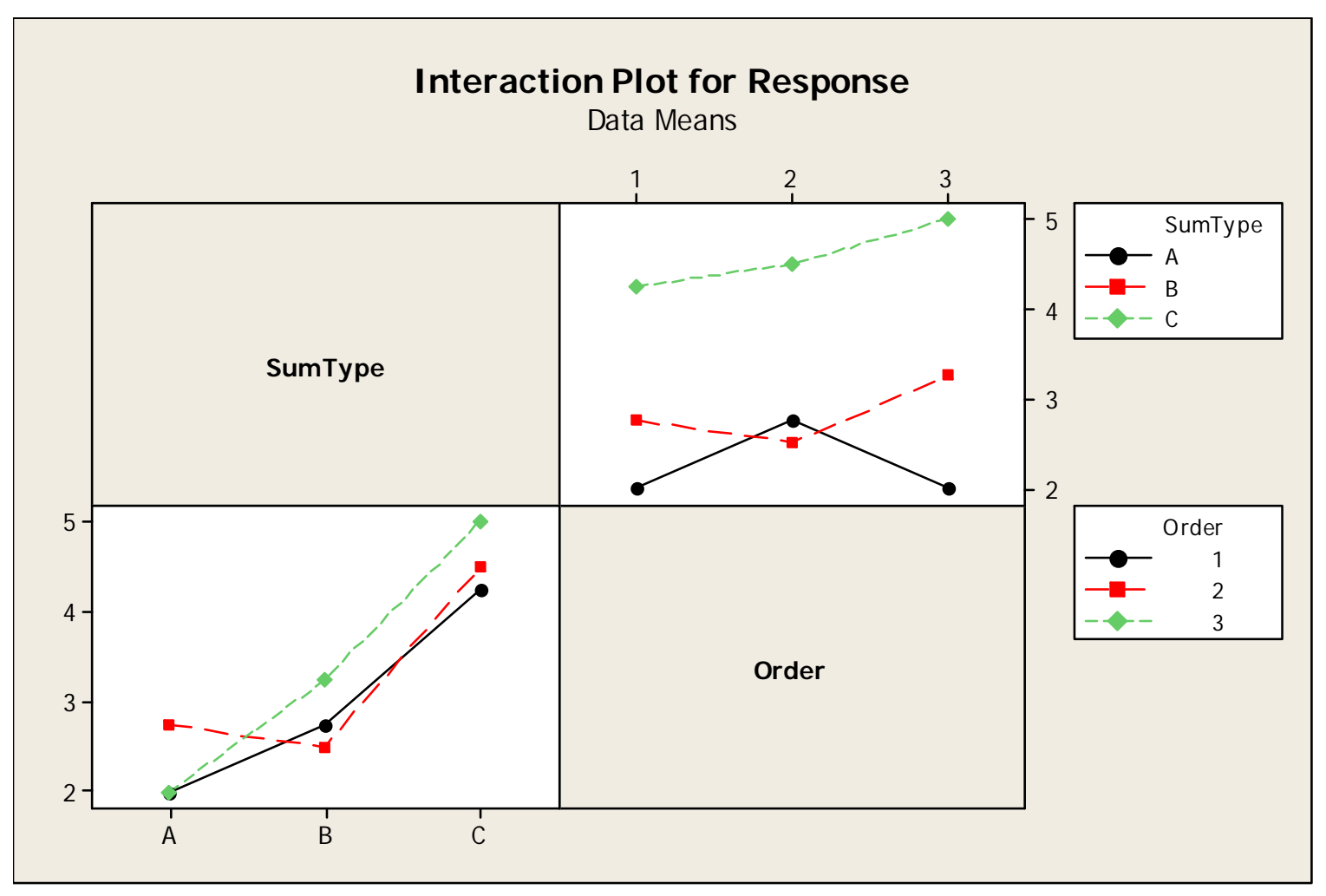




\section{General Linear Model: Rsp_UndFlexSig versus SummaryType, Order, ...}

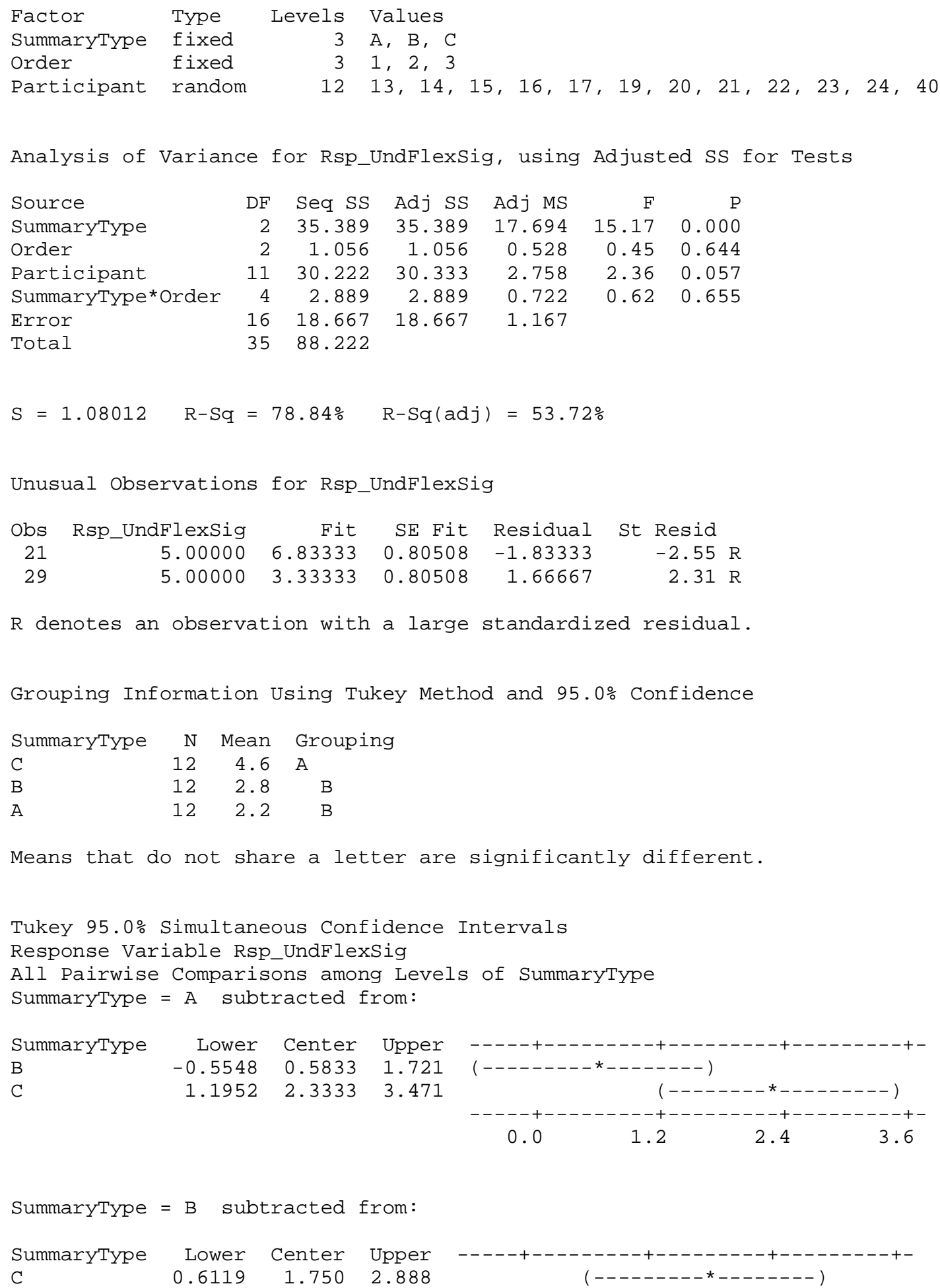

Tukey Simultaneous Tests

Response Variable Rsp_UndFlexSig 

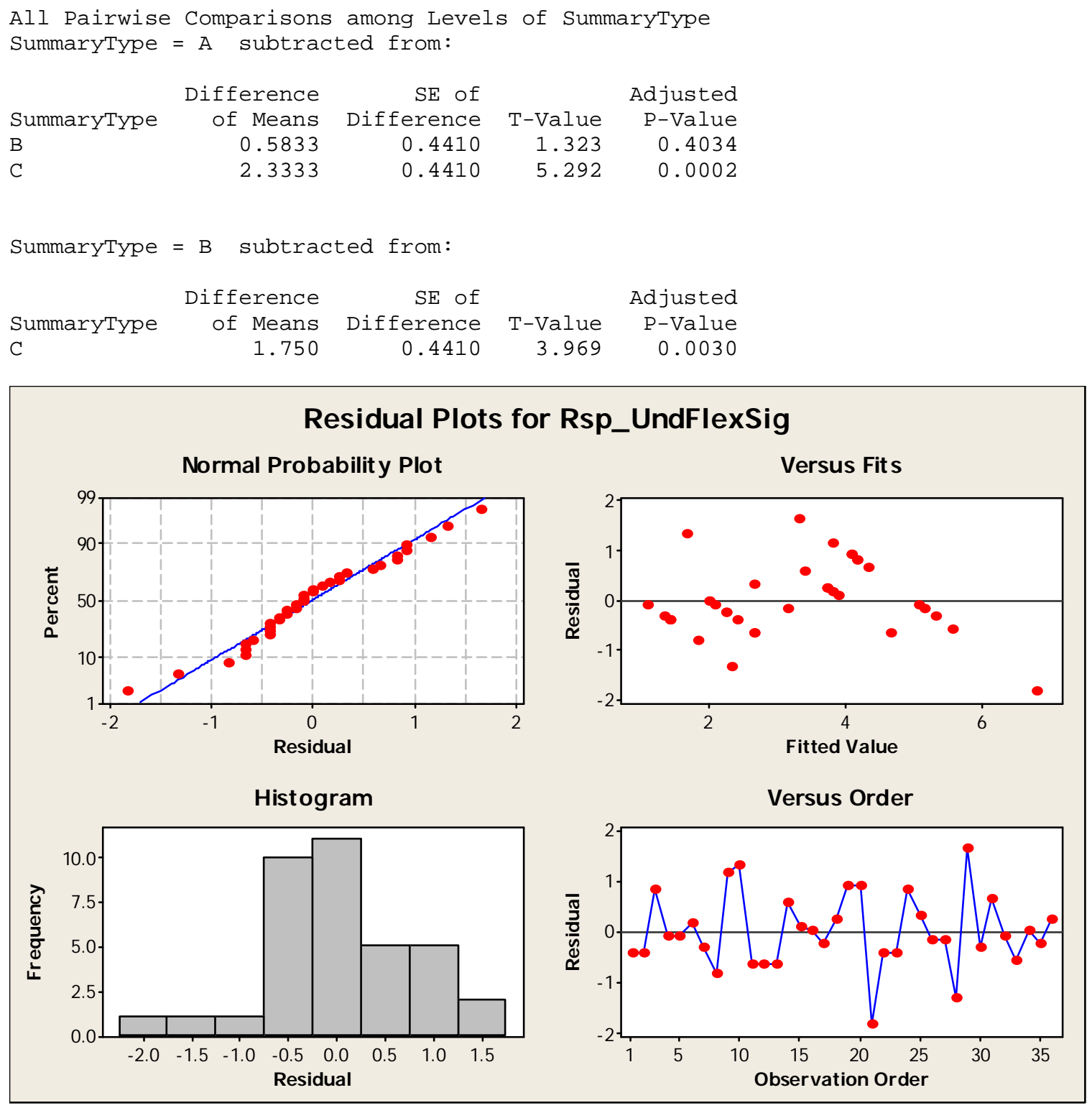

Appendix G.2.3.3 - Understanding MSI Mod \#8 

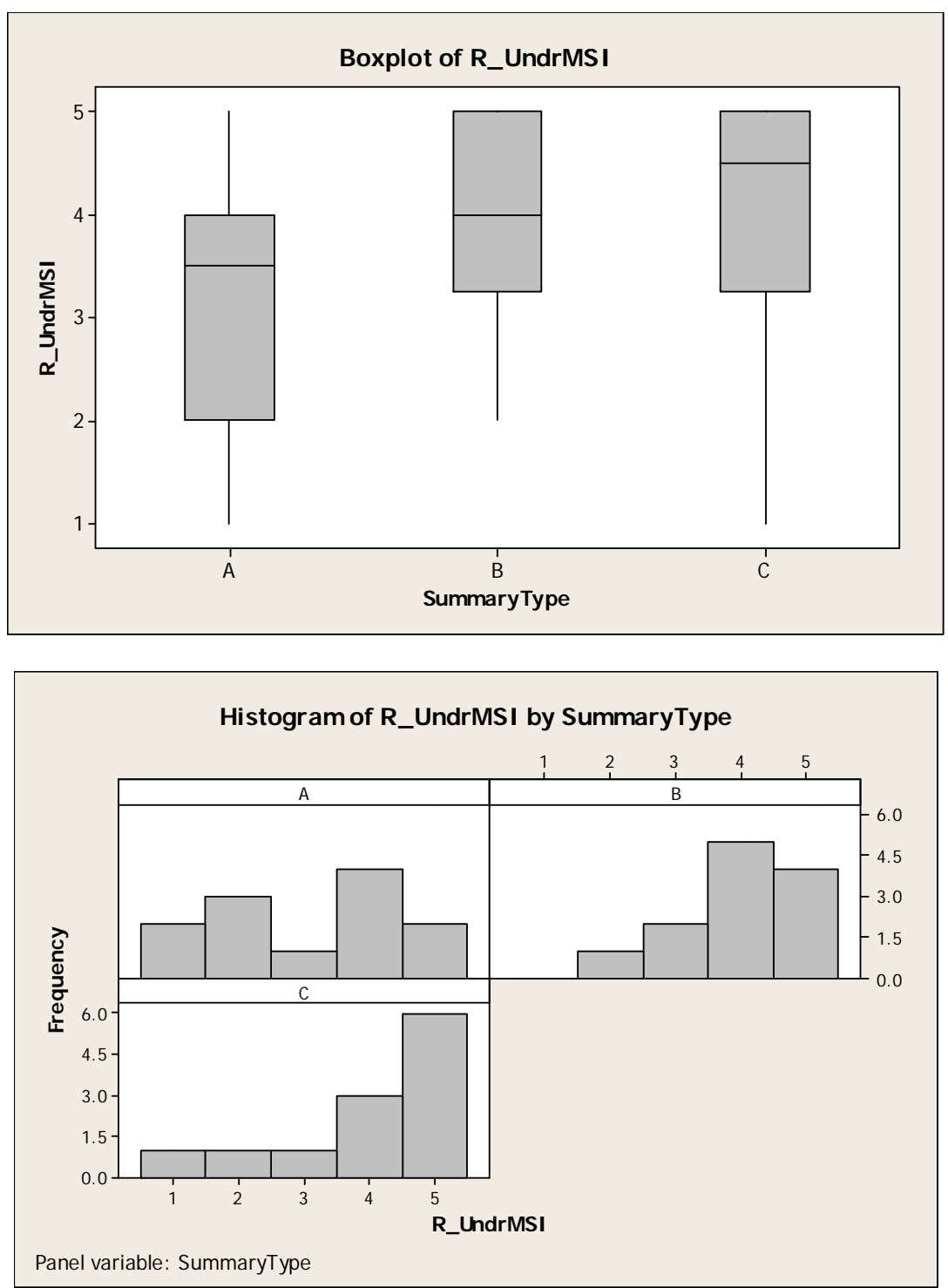

\section{Descriptive Statistics: R_UndrMSI}

$\begin{array}{llrrr}\text { Variable } & \text { Summarytype } & \mathrm{N} & \mathrm{N}^{*} & \text { Mean } \\ \text { R_UndrMSI } & \text { A } & 12 & 0 & 3.083 \\ & \text { B } & 12 & 0 & 4.000 \\ & \text { C } & 12 & 0 & 4.000 \\ \text { Variable } & \text { SummaryType } & & & \\ \text { R_UndrMSI } & \text { A } & \text { Maximum } \\ & \text { B } & 4.000 & 5.000 \\ & \text { C } & 5.000 & 5.000 \\ & & 5.000 & 5.000\end{array}$

$\begin{array}{rrrrr}\text { SE Mean } & \text { StDev } & \text { Minimum } & \text { Q1 } & \text { Median } \\ 0.417 & 1.443 & 1.000 & 2.000 & 3.500 \\ 0.275 & 0.953 & 2.000 & 3.250 & 4.000 \\ 0.389 & 1.348 & 1.000 & 3.250 & 4.500\end{array}$




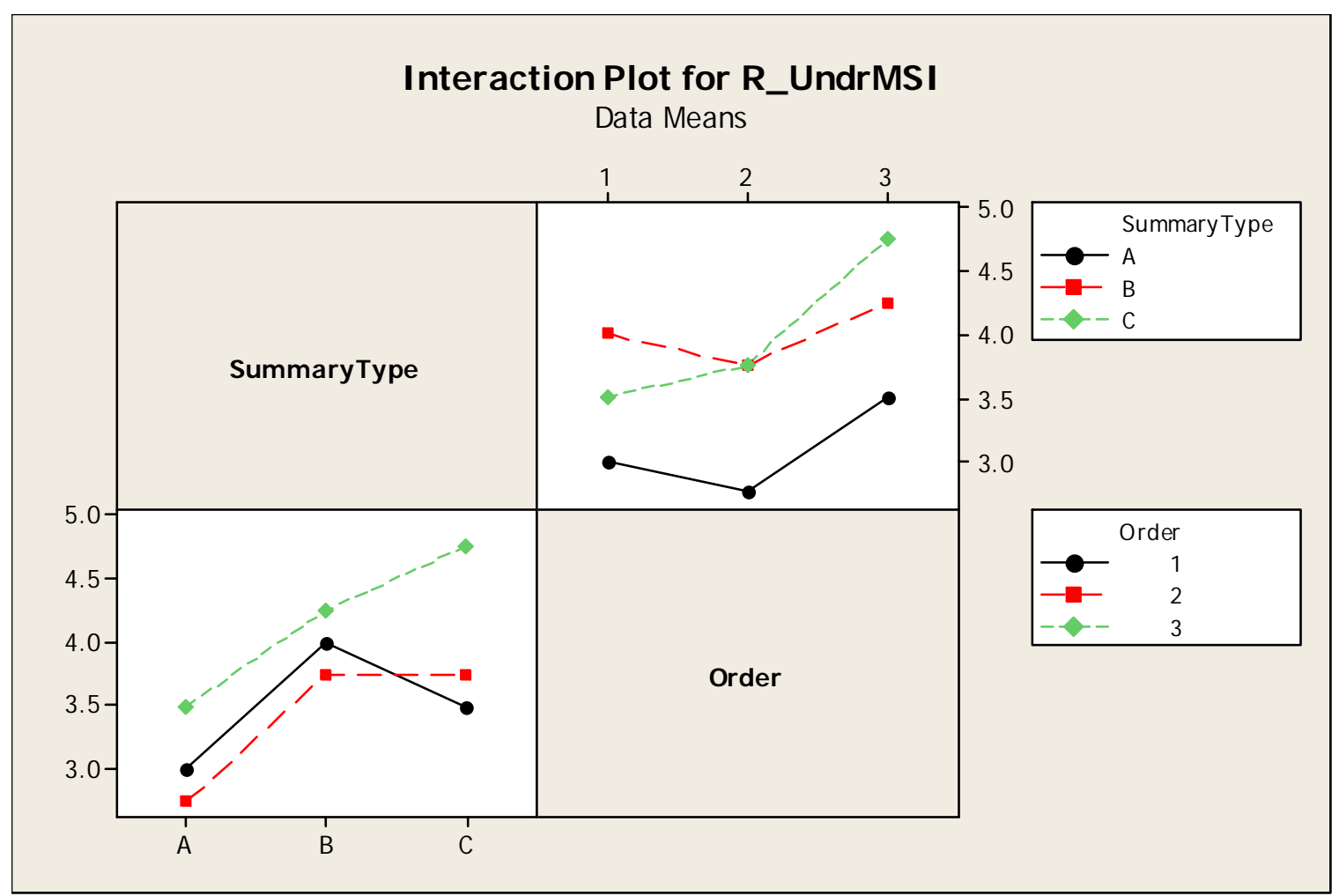

\section{General Linear Model: R_UndrMSI versus Participant, SummaryType, Order}

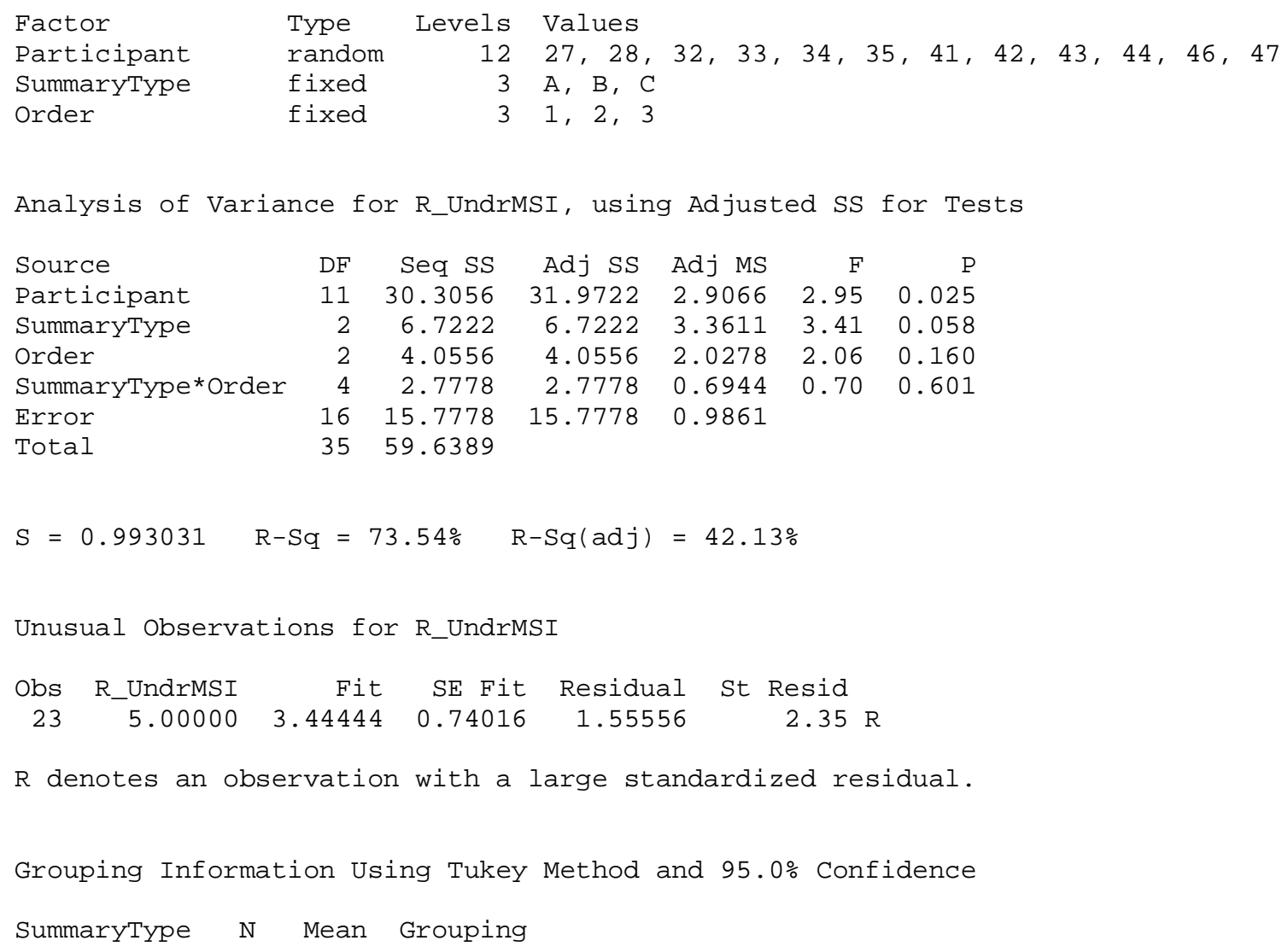




$\begin{array}{lrrr}\mathrm{C} & 12 & 4.000 & \mathrm{~A} \\ \mathrm{~B} & 12 & 4.000 & \mathrm{~A} \\ \mathrm{~A} & 12 & 3.083 \mathrm{~A} & \\ & \end{array}$

Tukey 95.0\% Simultaneous Confidence Intervals Response Variable R_UndrMSI

All Pairwise Comparisons among Levels of Summarytype

SummaryType $=\mathrm{A}$ subtracted from:

$\begin{array}{lrrr}\text { SummaryType } & \text { Lower } & \text { Center } & \text { Upper } \\ \text { B } & -0.1297 & 0.9167 & 1.963 \\ \text { C } & -0.1297 & 0.9167 & 1.963\end{array}$

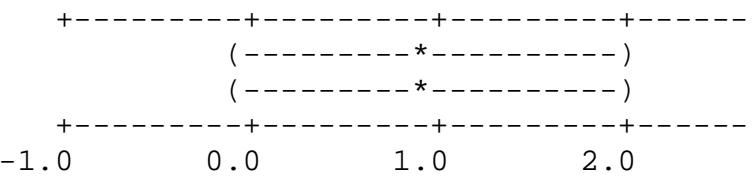

Summaryтype $=$ B subtracted from:

SummaryType Lower Center Upper

$\begin{array}{llll}\text { C } & -1.046 & 0.000000 & 1.046\end{array}$

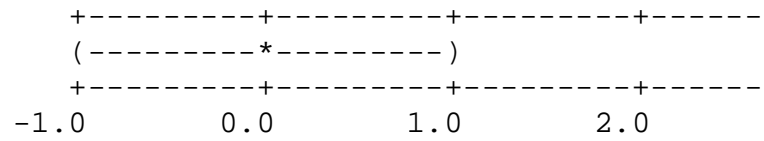

Tukey Simultaneous Tests

Response Variable R_UndrMSI

All Pairwise Comparisons among Levels of SummaryType SummaryType $=$ A subtracted from:

$\begin{array}{lrrrr} & \text { Difference } & \text { SE of } & \text { Adjusted } \\ \text { SummaryType } & \text { of Means } & \text { Difference } & \text { T-Value } & \text { P-Value } \\ \text { B } & 0.9167 & 0.4054 & 2.261 & 0.0910 \\ \text { C } & 0.9167 & 0.4054 & 2.261 & 0.0910\end{array}$

\begin{tabular}{lrrrr} 
SummaryType $=$ B & \multicolumn{2}{c}{ subtracted from: } & \\
& Difference & SE of & Adjusted \\
SummaryType & of Means & Difference & T-Value & P-Value \\
C & 0.000000 & 0.4054 & 0.000000 & 1.000
\end{tabular}




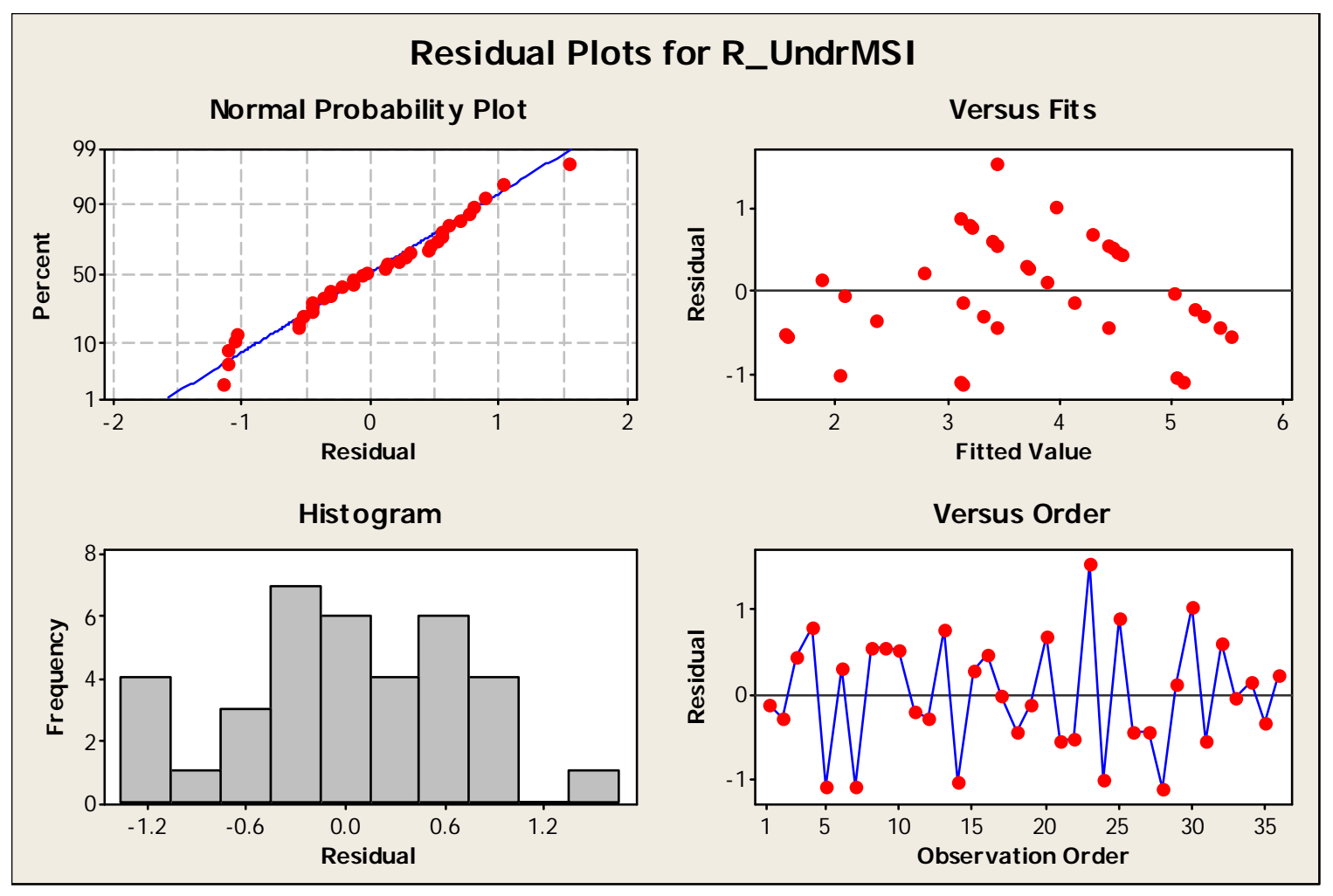

Appendix G.2.3.4 - Understanding Genetic Counselor High \#7

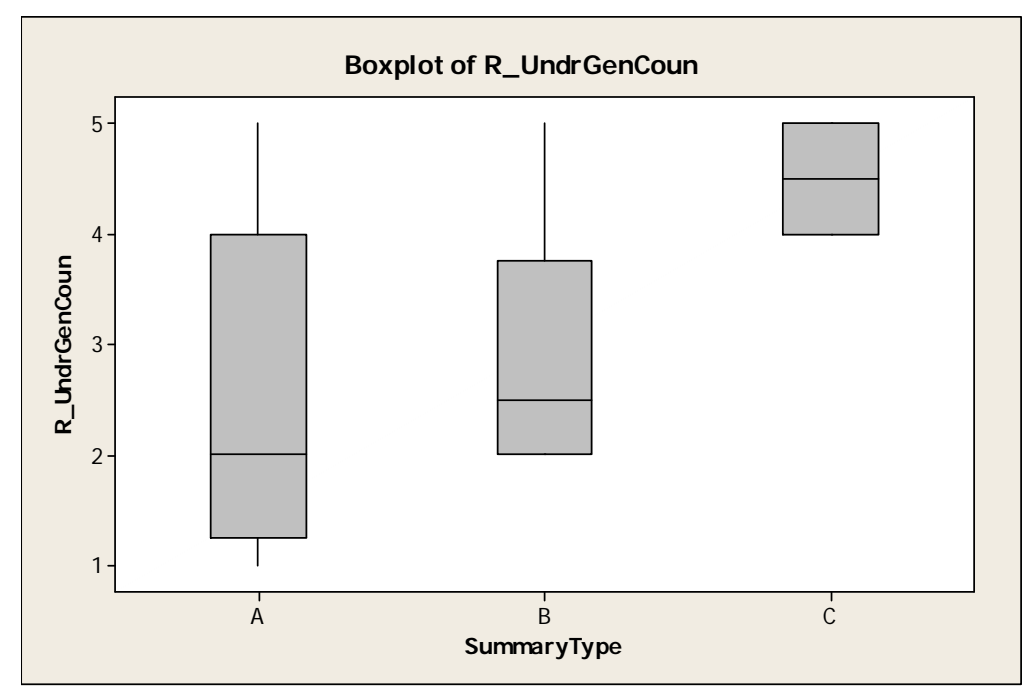




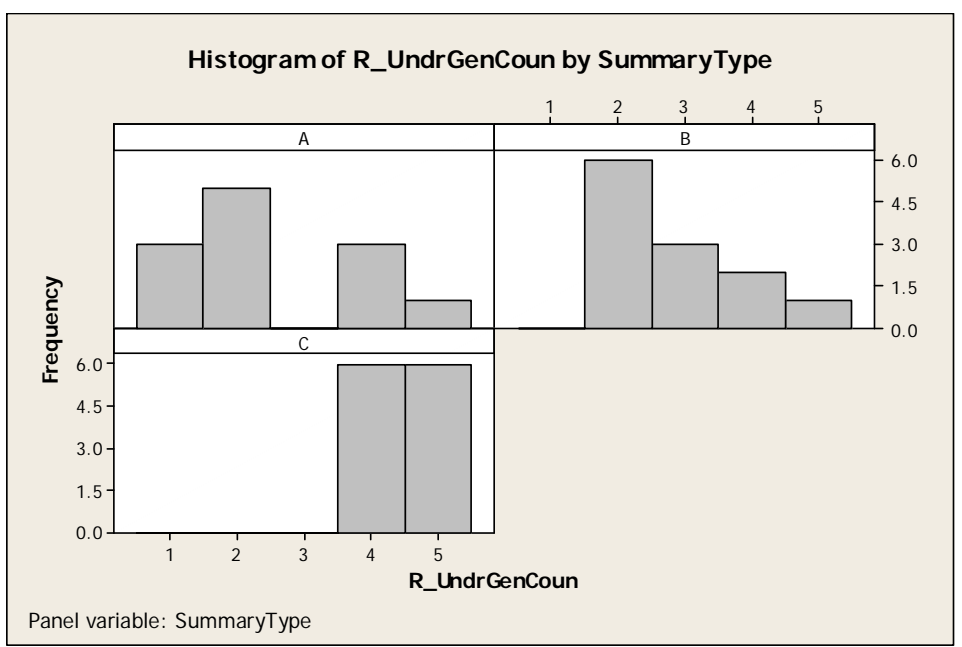

\section{Descriptive Statistics: R_UndrGenCoun}

\begin{tabular}{|c|c|c|c|c|c|c|c|c|}
\hline Variable & SummaryType & $\mathrm{N}$ & $\mathrm{N}^{\star}$ & Mean & SE Mean & StDev & Minimum & Q1 \\
\hline \multirow[t]{3}{*}{ R_UndrGenCoun } & $\mathrm{A}$ & 12 & 0 & 2.500 & 0.399 & 1.382 & 1.000 & 1.250 \\
\hline & B & 12 & 0 & 2.833 & 0.297 & 1.030 & 2.000 & 2.000 \\
\hline & $\mathrm{C}$ & 12 & 0 & 4.500 & 0.151 & 0.522 & 4.000 & 4.000 \\
\hline Variable & SummaryType & $\mathrm{Mec}$ & ian & Q3 & Maximum & & & \\
\hline \multirow[t]{3}{*}{ R_UndrGenCoun } & $\mathrm{A}$ & & 000 & 4.000 & 5.000 & & & \\
\hline & B & & 500 & 3.750 & 5.000 & & & \\
\hline & $\mathrm{C}$ & 4. & 500 & 5.000 & 5.000 & & & \\
\hline
\end{tabular}

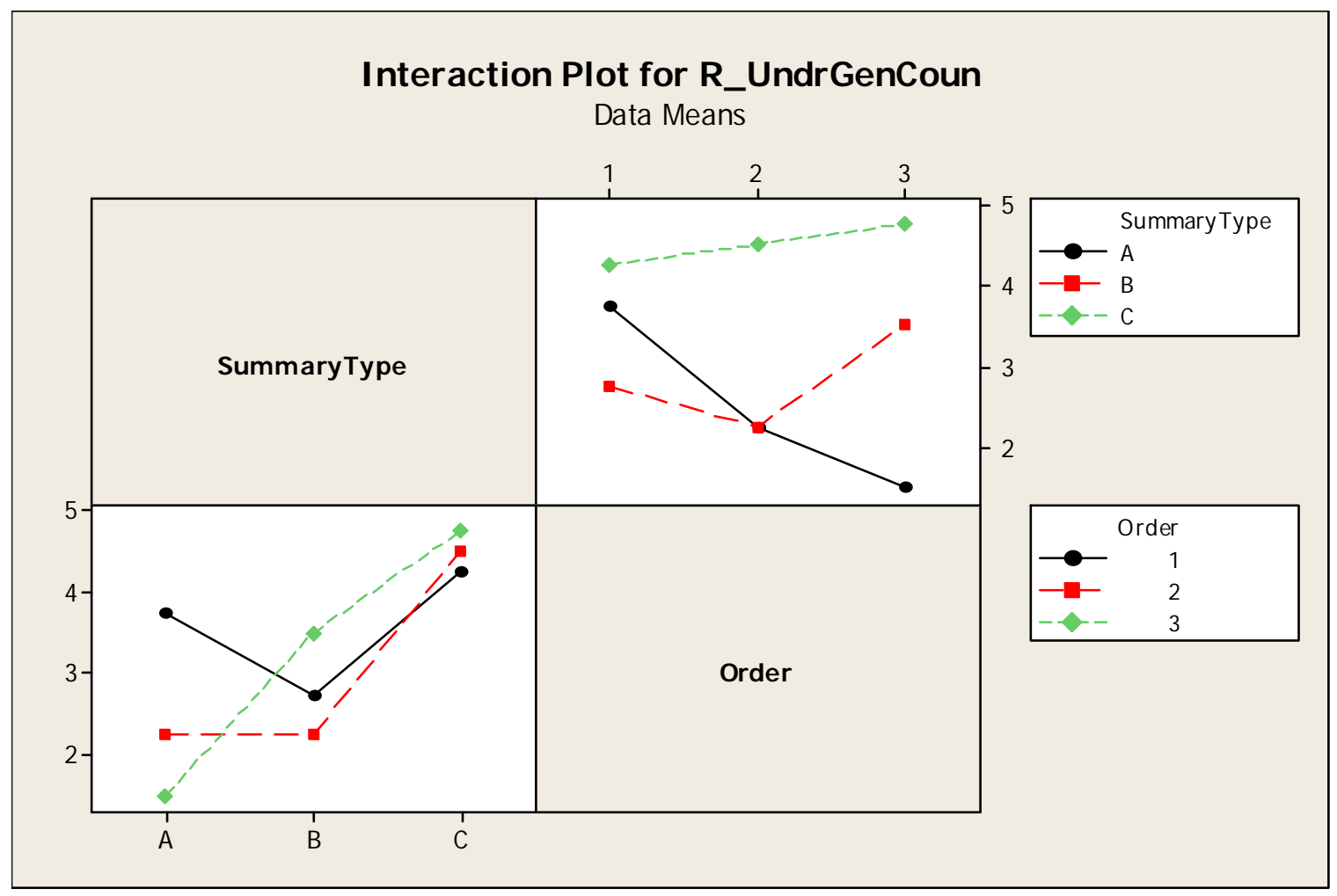




$\begin{array}{lrrrr} & \text { Difference } & \text { SE of } & \text { Adjusted } \\ \text { SummaryType } & \text { of Means } & \text { Difference } & \text { T-Value } & \text { P-Value } \\ \text { C } & 1.667 & 0.2816 & 5.919 & 0.0001\end{array}$

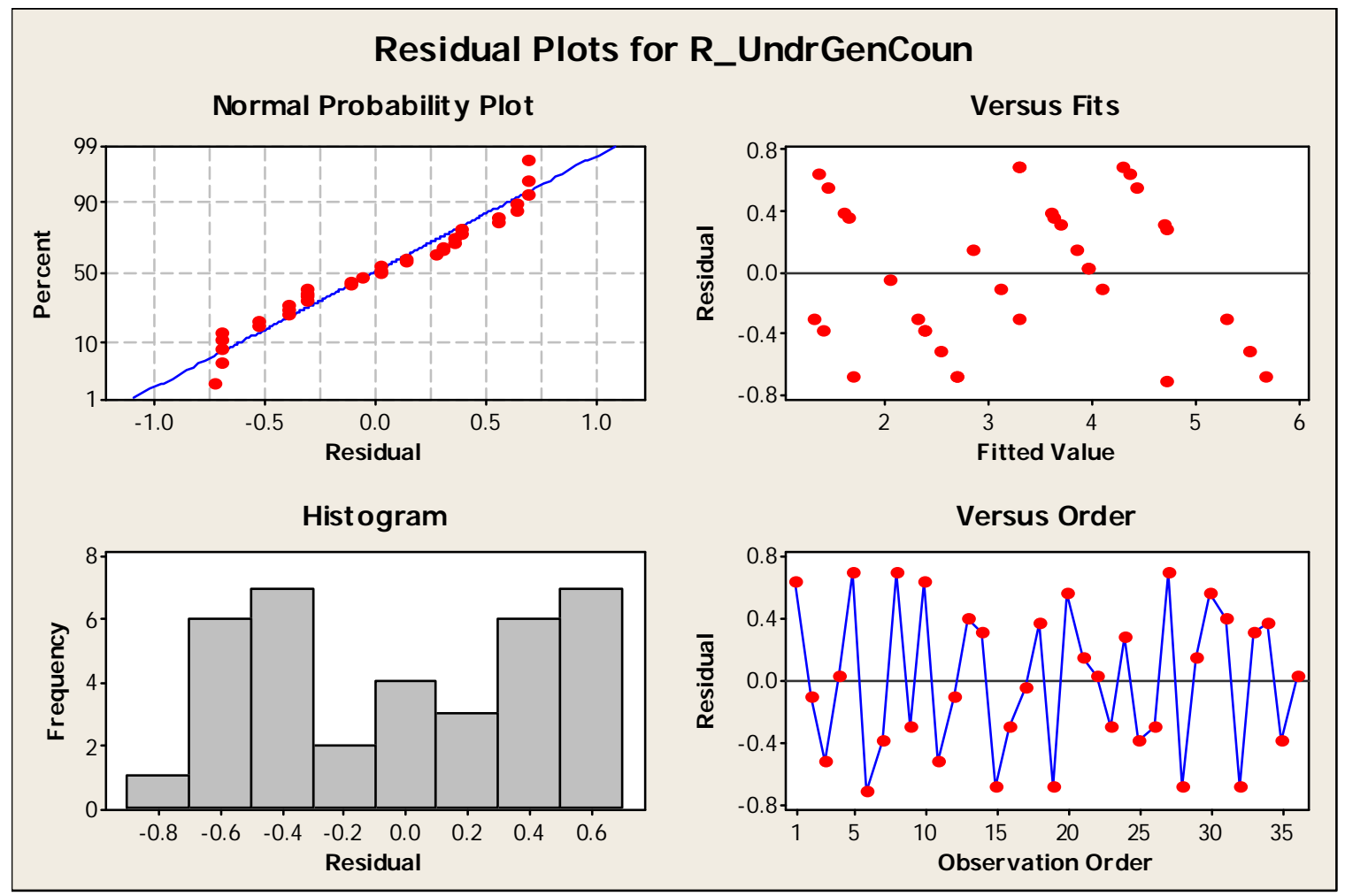

Appendix G.2.3.5 - Understanding Upper Endoscopy High \#9

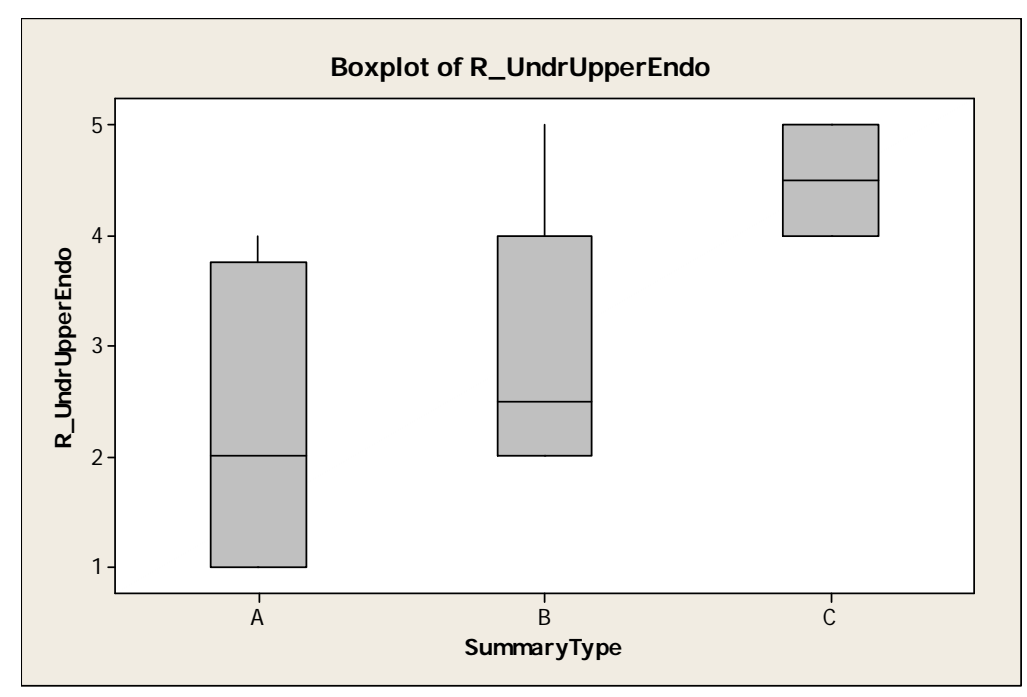



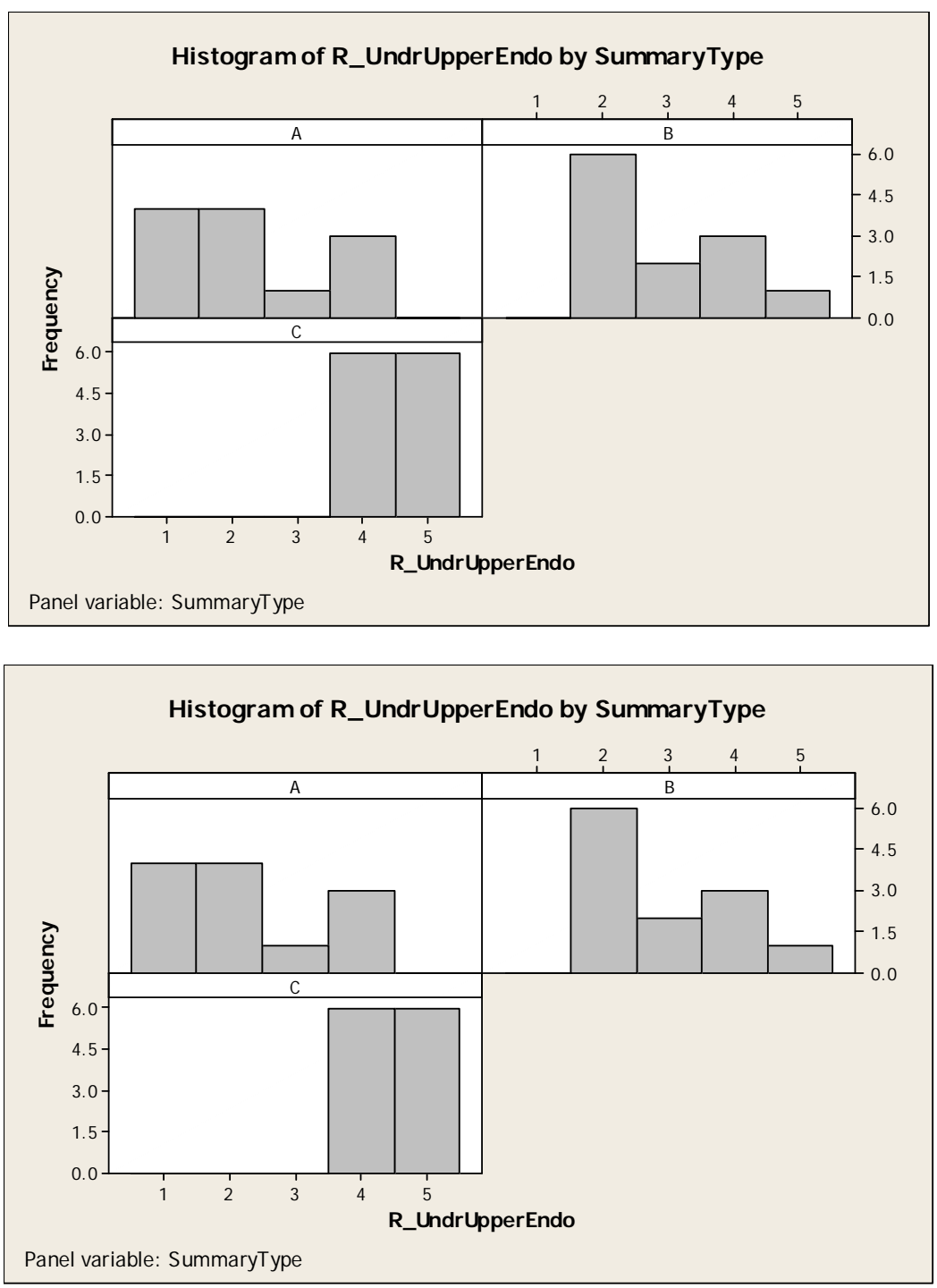

\section{Descriptive Statistics: R_UndrUpperEndo}

$\begin{array}{llrrrrrrr}\text { Variable } & \text { SummaryType } & \mathrm{N} & \mathrm{N}^{*} & \text { Mean } & \text { SE Mean } & \text { StDev } & \text { Minimum } & \text { Q1 } \\ \text { R_UndrUpperEndo } & \text { A } & 12 & 0 & 2.250 & 0.351 & 1.215 & 1.000 & 1.000 \\ & \text { B } & 12 & 0 & 2.917 & 0.313 & 1.084 & 2.000 & 2.000 \\ & \text { C } & 12 & 0 & 4.500 & 0.151 & 0.522 & 4.000 & 4.000 \\ \text { Variable } & \text { SummaryType } & \text { Median } & \text { Q3 } & \text { Maximum } & & \\ \text { R_UndrUpperEndo } & \text { A } & 2.000 & 3.750 & 4.000 & \\ & \text { B } & 2.500 & 4.000 & 5.000 & \\ & \text { C } & 4.500 & 5.000 & 5.000 & \end{array}$




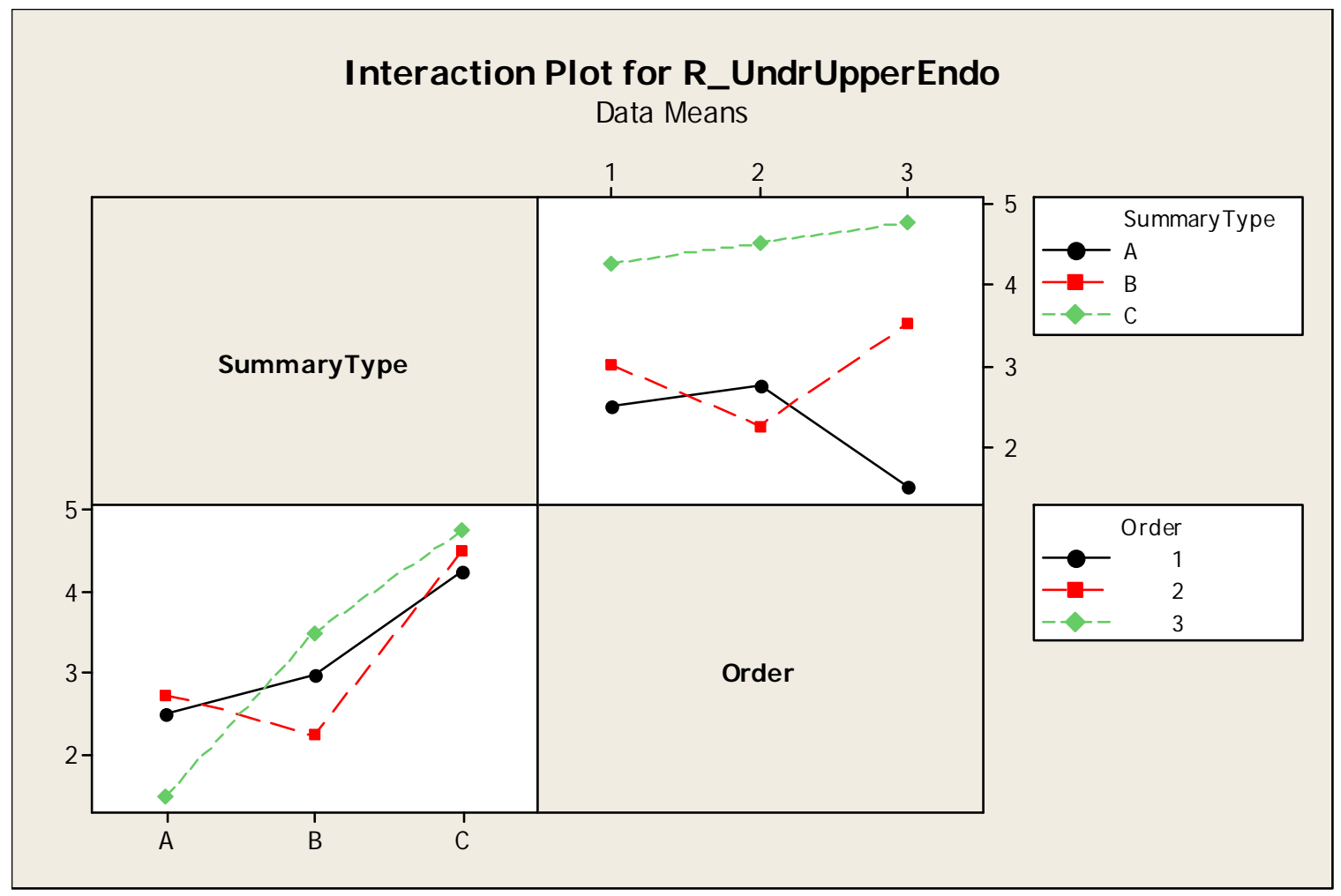

\section{General Linear Model: R_UndrUpperE versus Participant, SummaryType, ...}

$\begin{array}{llrl}\text { Factor } & \text { Type } & \text { Levels } & \text { Values } \\ \text { Participant } & \text { random } & 12 & 1,4,5,6,8,9,10,12,38,39,45,49 \\ \text { SummaryType } & \text { fixed } & 3 \text { A, B, C } \\ \text { Order } & \text { fixed } & 3 \text { 1, 2, 3 }\end{array}$

Analysis of Variance for R_UndrUpperEndo, using Adjusted SS for Tests

\begin{tabular}{|c|c|c|c|c|c|c|}
\hline Source & $\mathrm{DF}$ & Seq SS & Adj $S S$ & Adj $M S$ & $\mathrm{~F}$ & $\mathrm{P}$ \\
\hline Participant & 11 & 15.5556 & 11.6667 & 1.0606 & 1.27 & 0.321 \\
\hline SummaryType & 2 & 32.0556 & 32.0556 & 16.0278 & 19.23 & 0.000 \\
\hline Order & 2 & 0.0556 & 0.0556 & 0.0278 & 0.03 & 0.967 \\
\hline SummaryType*Order & 4 & 3.2222 & 3.2222 & 0.8056 & 0.97 & 0.453 \\
\hline Error & 16 & 13.3333 & 13.3333 & 0.8333 & & \\
\hline Total & 35 & 64.2222 & & & & \\
\hline
\end{tabular}

Unusual Observations for R_UndrUpperEndo

$\begin{array}{rrrrrr}\text { Obs } & \text { R_UndrUpperEndo } & \text { Fit } & \text { SE Fit } & \text { Residual } & \text { St Resid } \\ 31 & 4.00000 & 2.75000 & 0.68041 & 1.25000 & 2.05 \text { R }\end{array}$

$\mathrm{R}$ denotes an observation with a large standardized residual.

Grouping Information Using Tukey Method and 95.0\% Confidence Summarytype N Mean Grouping 


$\begin{array}{llll}\mathrm{C} & 12 & 4.500 & \mathrm{~A} \\ \mathrm{~B} & 12 & 2.917 & \mathrm{~B} \\ \mathrm{~A} & 12 & 2.250 & \mathrm{~B}\end{array}$

Means that do not share a letter are significantly different.

Tukey 95.0\% Simultaneous Confidence Intervals

Response Variable R_UndrUpperEndo

All Pairwise Comparisons among Levels of SummaryType

SummaryType $=\mathrm{A}$ subtracted from:

\begin{tabular}{|c|c|c|c|c|}
\hline $\begin{array}{l}\text { SummaryType } \\
\text { B }\end{array}$ & $\begin{array}{r}\text { Lower } \\
-0.2952\end{array}$ & $\begin{array}{l}\text { Center } \\
0.6667\end{array}$ & $\begin{array}{l}\text { Upper } \\
1.629\end{array}$ & $\begin{array}{c}---+---------+------ \\
(---------\star--------)\end{array}$ \\
\hline C & 1.2881 & 2.2500 & 3.212 & $(---------\star *--------)$ \\
\hline & & & & 2.0 \\
\hline
\end{tabular}

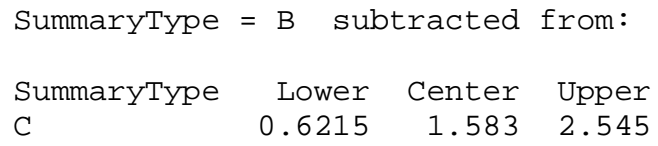

Tukey Simultaneous Tests Response Variable R_UndrUpperEndo

All Pairwise Comparisons among Levels of Summarytype SummaryType $=$ A subtracted from:

$\begin{array}{lrrrr} & \text { Difference } & \text { SE of } & \text { Adjusted } \\ \text { SummaryType } & \text { of Means } & \text { Difference } & \text { T-Value } & \text { P-Value } \\ \text { B } & 0.6667 & 0.3727 & 1.789 & 0.2048 \\ \text { C } & 2.2500 & 0.3727 & 6.037 & 0.0001\end{array}$

$\begin{array}{lrrrr}\text { SummaryType }=\text { B subtracted from: } & \\ & \text { Difference } & \text { SE of } & \text { Adjusted } \\ \text { SummaryType } & \text { of Means } & \text { Difference } & \text { T-Value } & \text { P-Value } \\ \text { C } & 1.583 & 0.3727 & 4.249 & 0.0017\end{array}$




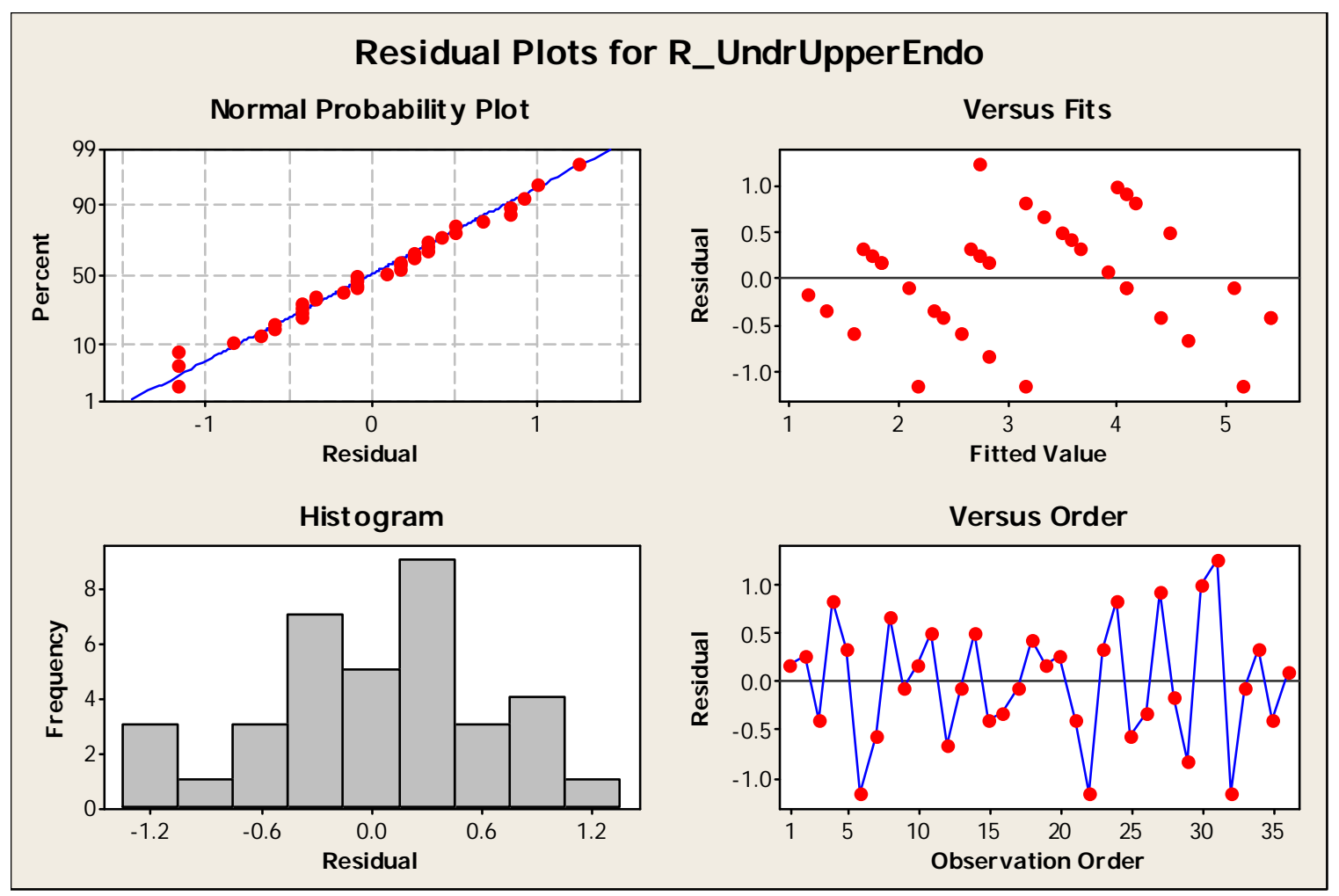

\section{Appendix G.3 - Intent Questions (8)}

Question: If I received these results, I would follow the recommendation and

Response: 1 (Strongly Disagree) to 5 (Strongly Agree)

\section{Appendix G.3.1 - Intent Colonoscopy}

Pop \#9, Mod \#9, High \#11

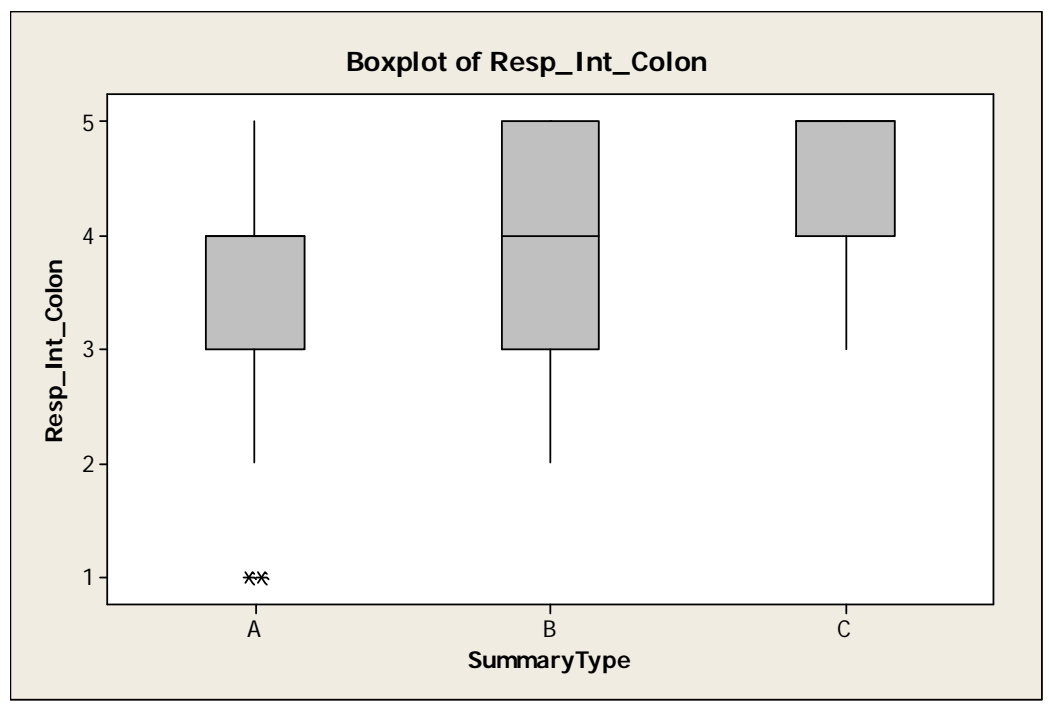




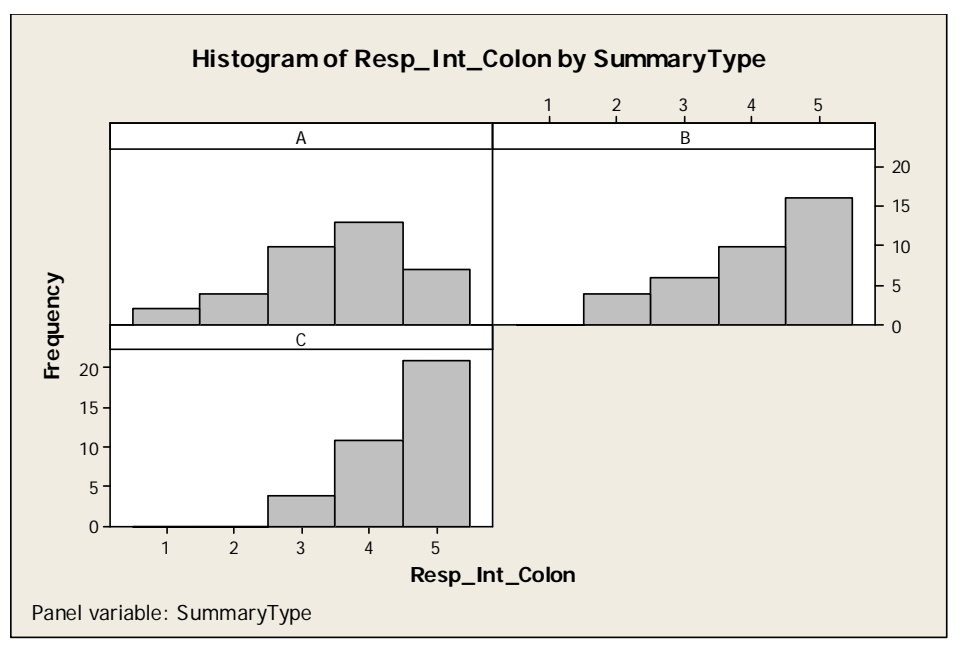

\section{Descriptive Statistics: Resp_Int_Colon}

$\begin{array}{llrrrr}\text { Variable } & \text { Summarytype } & \text { N } & N^{*} & \text { Mean } & \text { SE Mean } \\ \text { Resp_Int_Colon } & \text { A } & 36 & 0 & 3.528 & 0.185 \\ & \text { B } & 36 & 0 & 4.056 & 0.173 \\ & \text { C } & 36 & 0 & 4.472 & 0.116 \\ \text { Variable } & \text { SummaryType } & \text { Median } & \text { Q3 } & \text { Maximum } \\ \text { Resp_Int_Colon } & \text { A } & 4.000 & 4.000 & 5.000 \\ & \text { B } & 4.000 & 5.000 & 5.000 \\ & \text { C } & 5.000 & 5.000 & 5.000\end{array}$

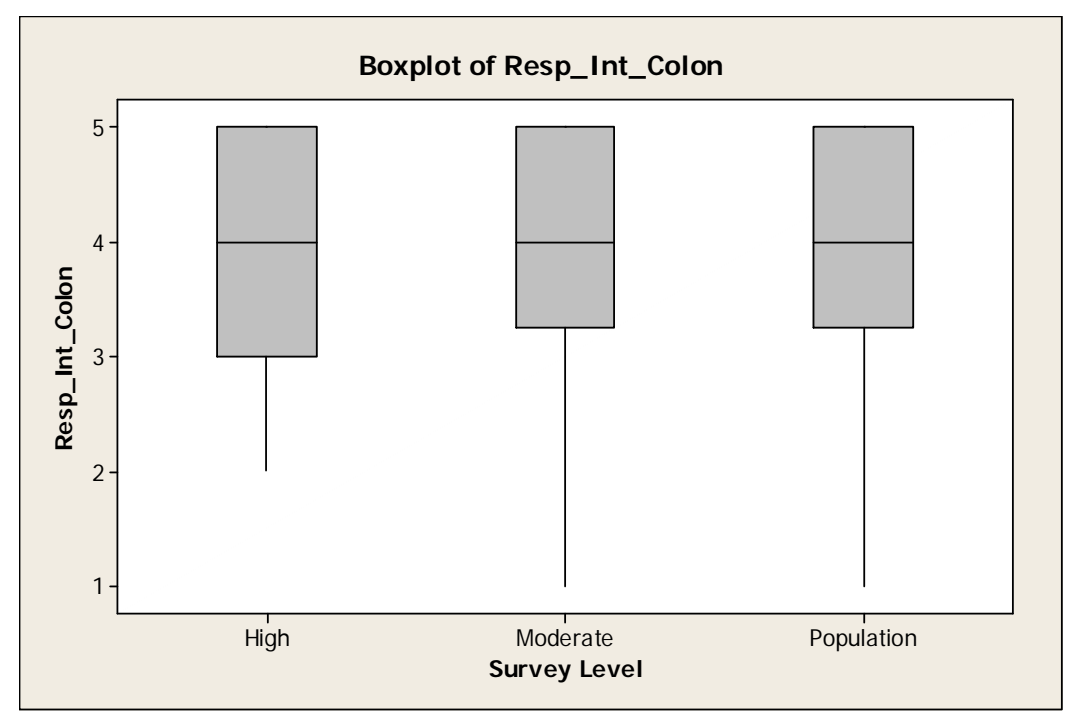




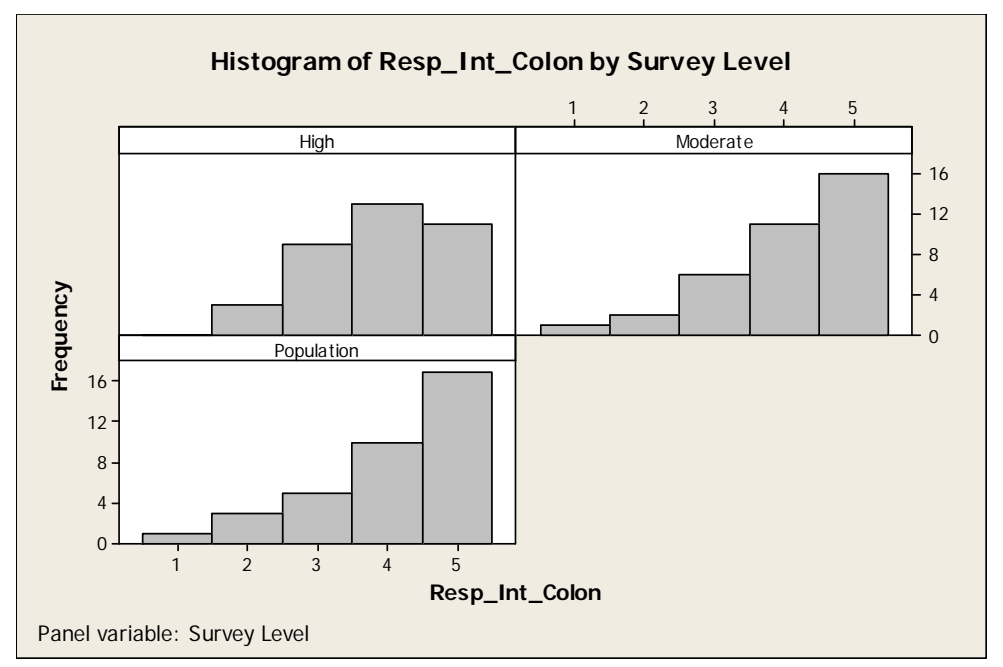

\section{Descriptive Statistics: Resp_Int_Colon}

$\begin{array}{llrrrrrrr}\text { Variable } & \text { Survey Level } & \mathrm{N} & \mathrm{N}^{*} & \text { Mean } & \text { SE Mean } & \text { StDev } & \text { Minimum } & \text { Q1 } \\ \text { Resp_Int_Colon } & \text { High } & 36 & 0 & 3.889 & 0.158 & 0.950 & 2.000 & 3.000 \\ & \text { Moderate } & 36 & 0 & 4.083 & 0.175 & 1.052 & 1.000 & 3.250 \\ & \text { Population } & 36 & 0 & 4.083 & 0.184 & 1.105 & 1.000 & 3.250 \\ \text { Variable } & \text { Survey Level } & \text { Median } & \text { Q3 } & \text { Maximum } & & & \\ \text { Resp_Int_Colon } & \text { High } & 4.000 & 5.000 & 5.000 & \\ & \begin{array}{l}\text { Moderate } \\ \text { Population }\end{array} & 4.000 & 5.000 & 5.000 & \\ & 4.000 & 5.000 & 5.000 & \end{array}$

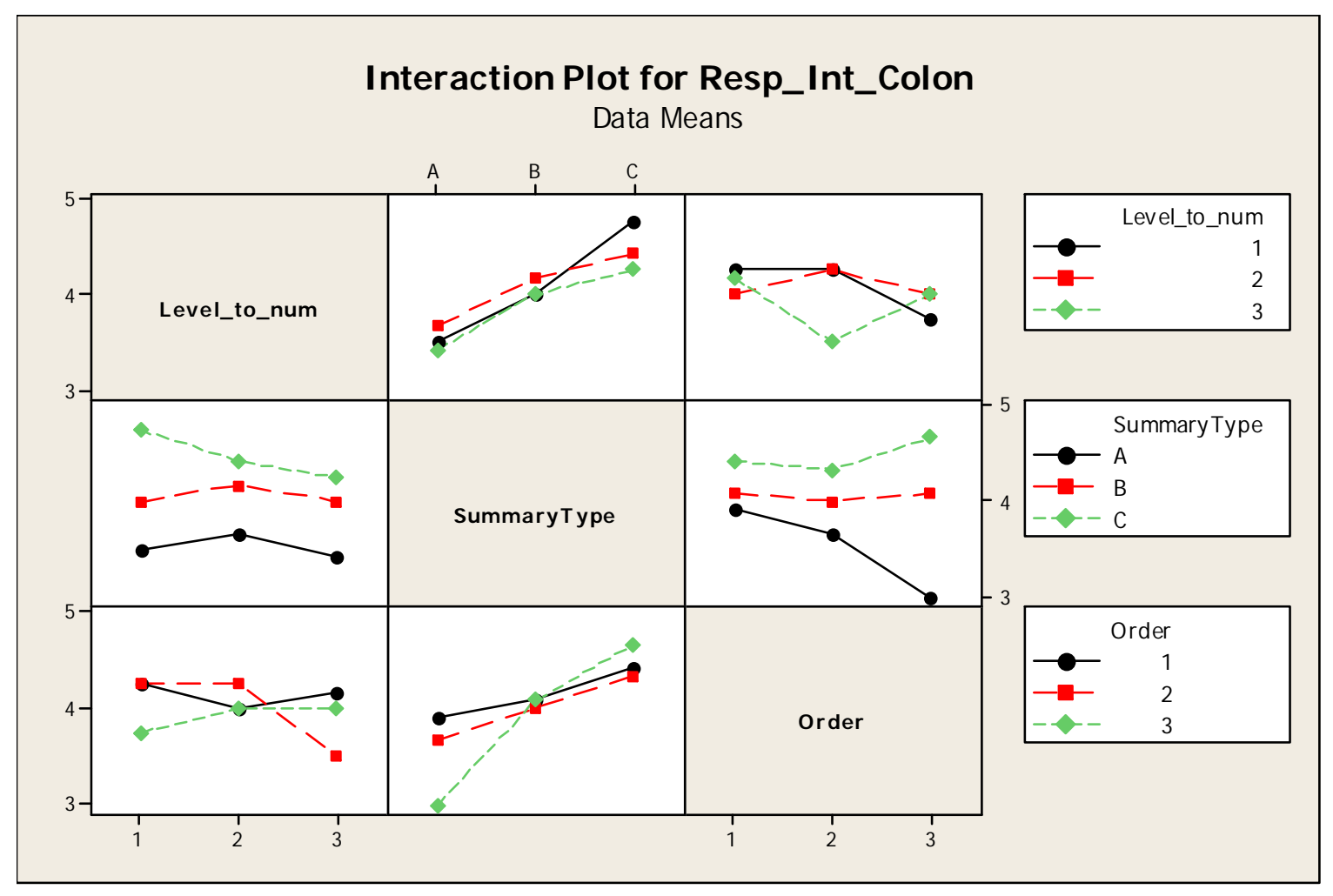




\section{General Linear Model: Resp_Int_Col versus Participant, SummaryType, ...}

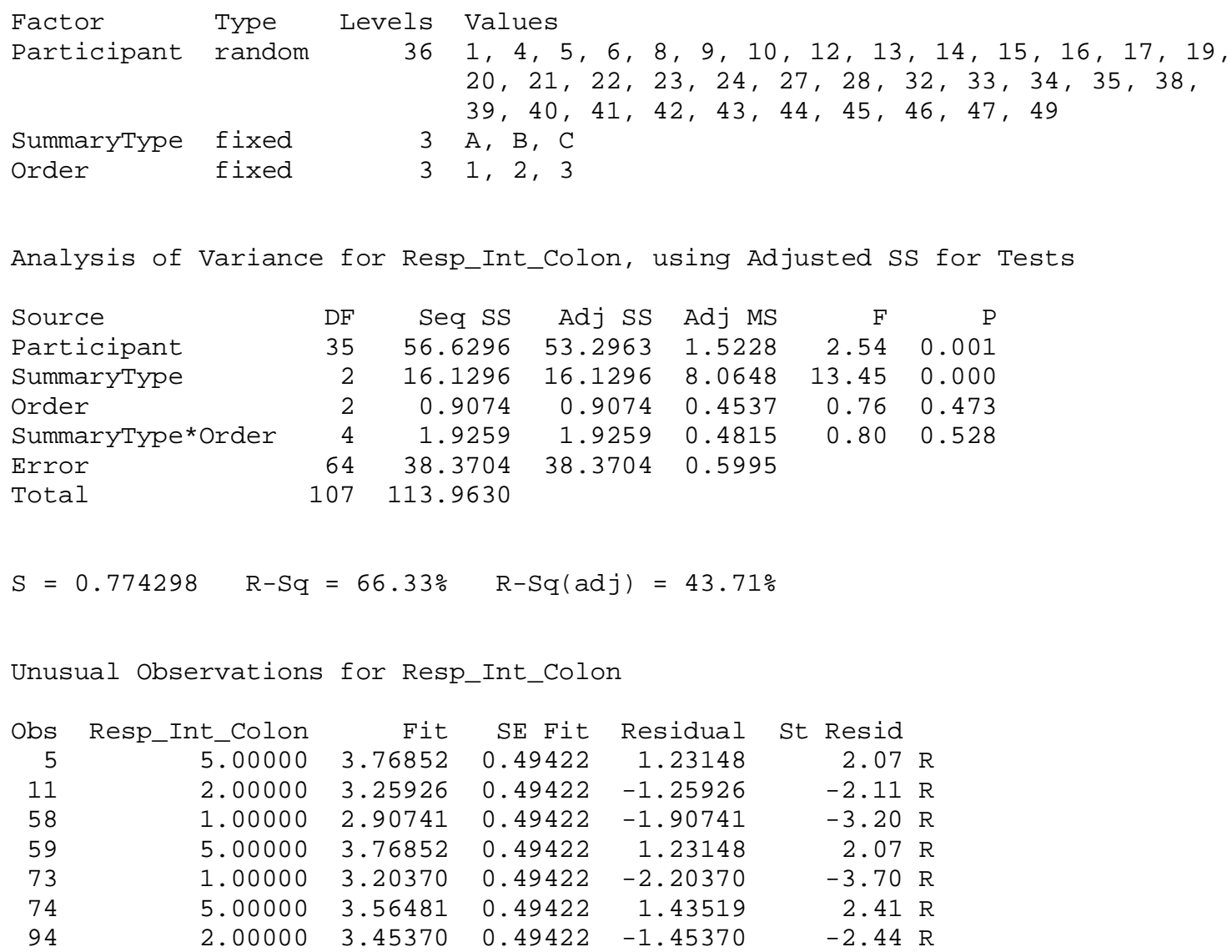

$\mathrm{R}$ denotes an observation with a large standardized residual.

Grouping Information Using Tukey Method and 95.0\% Confidence

$\begin{array}{lrrc}\text { SummaryType } & \text { N } & \text { Mean } & \text { Grouping } \\ \text { C } & 36 & 4.472 & \text { A } \\ \text { B } & 36 & 4.056 & \text { A } \\ \text { A } & 36 & 3.528 & \text { B }\end{array}$

Means that do not share a letter are significantly different.

Tukey 95.0\% Simultaneous Confidence Intervals

Response Variable Resp_Int_Colon

All Pairwise Comparisons among Levels of SummaryType

SummaryType = A subtracted from:

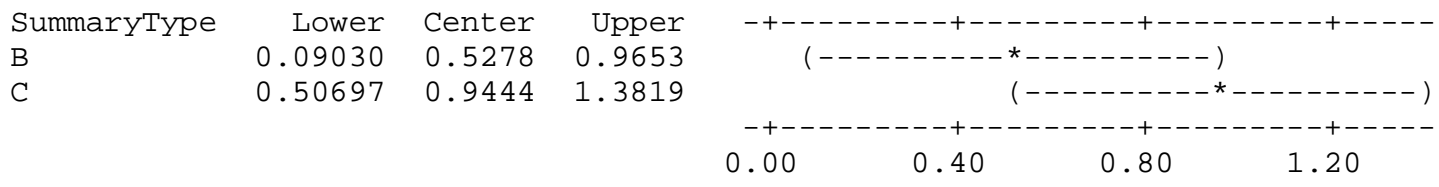

SummaryType $=\mathrm{B}$ subtracted from: 


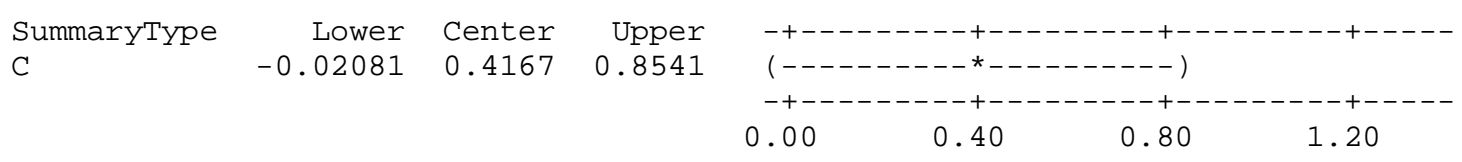

Tukey Simultaneous Tests

Response Variable Resp_Int_Colon

All Pairwise Comparisons among Levels of SummaryType

SummaryType $=$ A subtracted from:

$\begin{array}{lrrrr} & \text { Difference } & \text { SE of } & \text { Adjusted } \\ \text { SummaryType } & \text { of Means } & \text { Difference } & \text { T-Value } & \text { P-Value } \\ \text { B } & 0.5278 & 0.1825 & 2.892 & 0.0143 \\ \text { C } & 0.9444 & 0.1825 & 5.175 & 0.0000\end{array}$
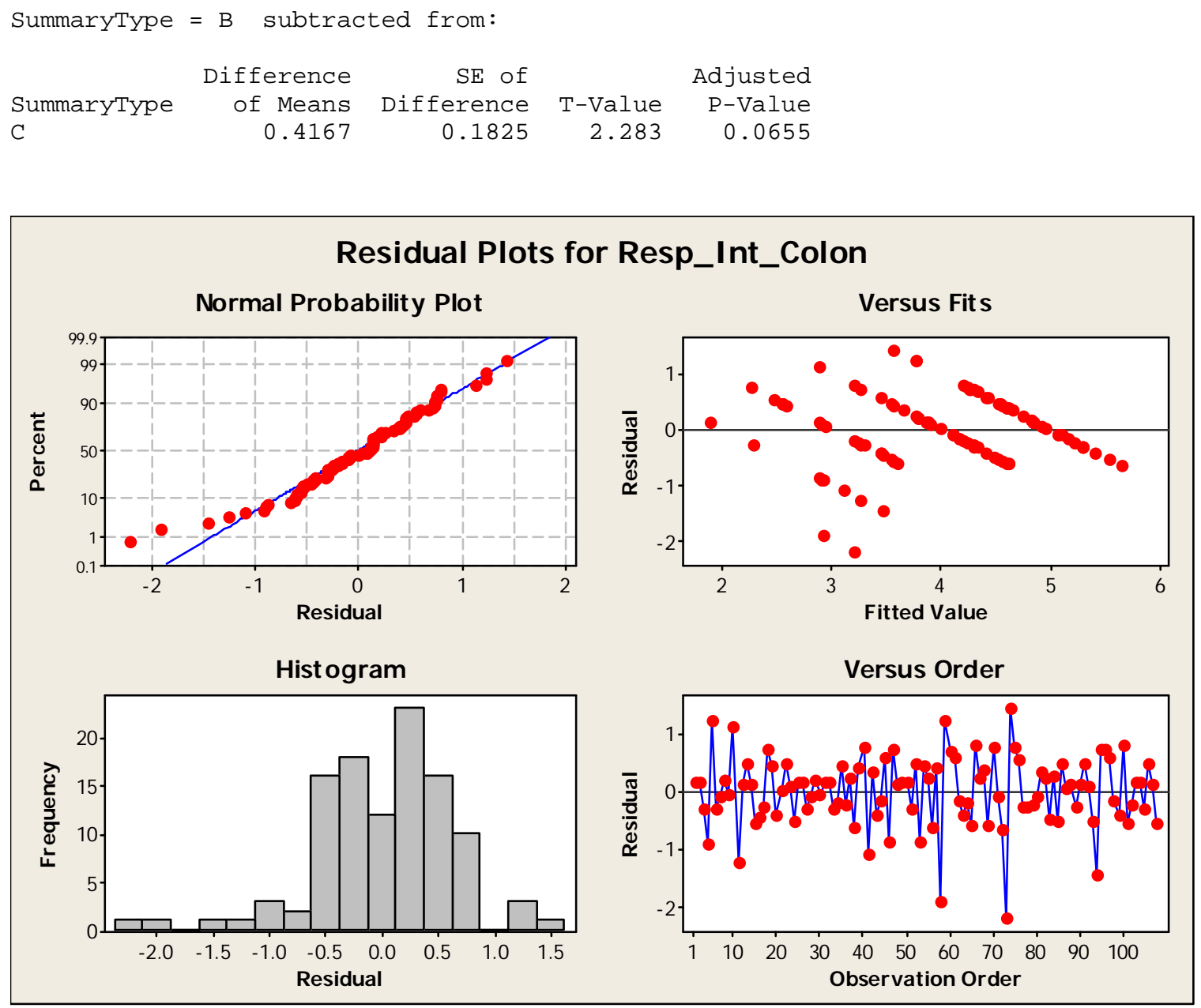

Appendix G.3.2 - Intent Flexible Sigmoidoscopy \#10 Pop 

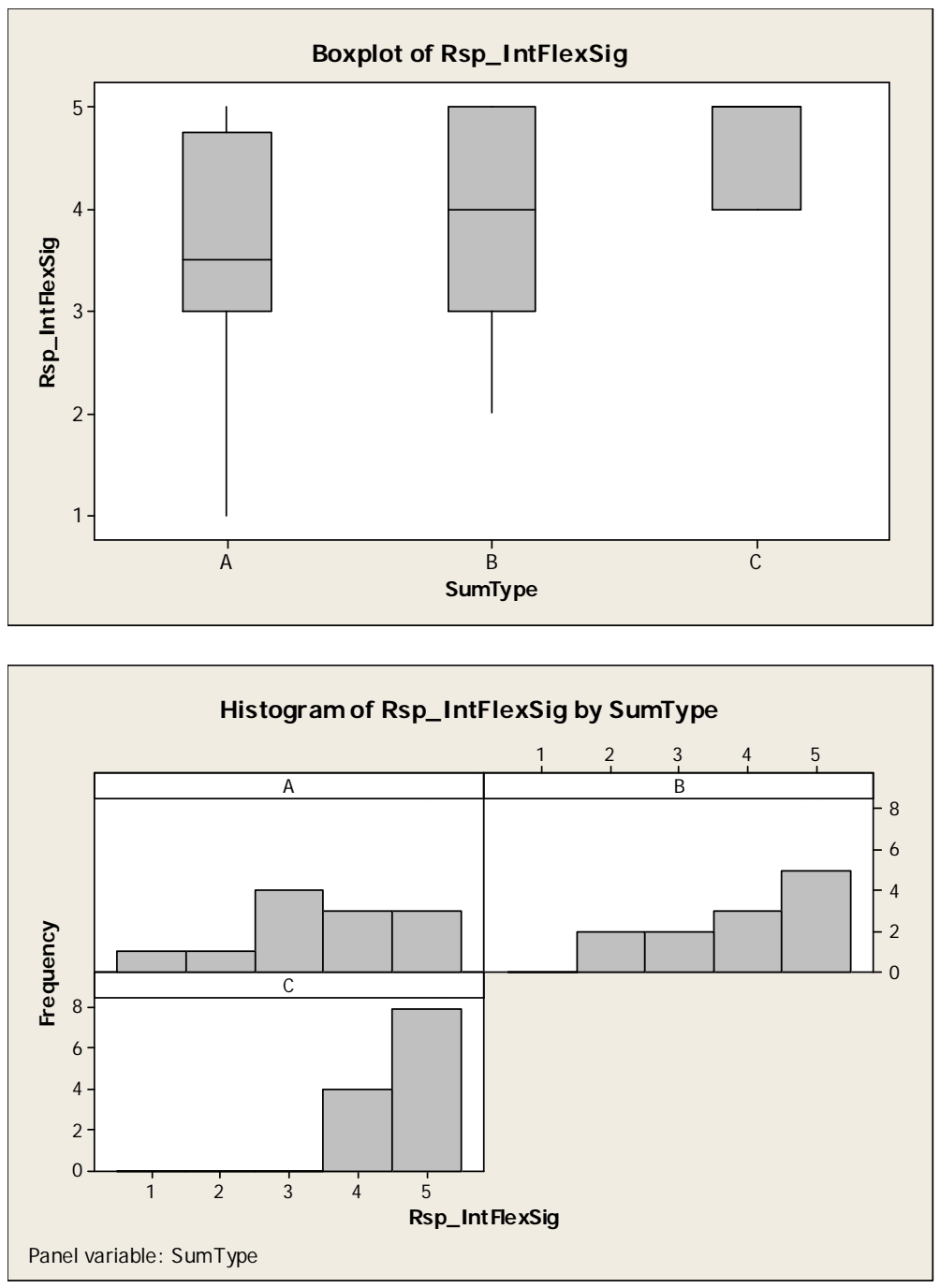

\section{Descriptive Statistics: Rsp_IntFlexSig}

$\begin{array}{llrrr}\text { Variable } & \text { SumType } & \mathrm{N} & \mathrm{N}^{*} & \text { Mean } \\ \text { Rsp_IntFlexSig } & \text { A } & 12 & 0 & 3.500 \\ & \mathrm{~B} & 12 & 0 & 3.917 \\ & \mathrm{C} & 12 & 0 & 4.667 \\ \text { Variable } & \text { SumType } & \text { Q3 } & \text { Maximum } \\ \text { Rsp_IntFlexSig } & \text { A } & 4.750 & 5.000 \\ & \text { B } & 5.000 & 5.000 \\ & \text { C } & 5.000 & 5.000\end{array}$

$\begin{array}{rrrrr}\text { SE Mean } & \text { StDev } & \text { Minimum } & \text { Q1 } & \text { Median } \\ 0.359 & 1.243 & 1.000 & 3.000 & 3.500 \\ 0.336 & 1.165 & 2.000 & 3.000 & 4.000 \\ 0.142 & 0.492 & 4.000 & 4.000 & 5.000\end{array}$




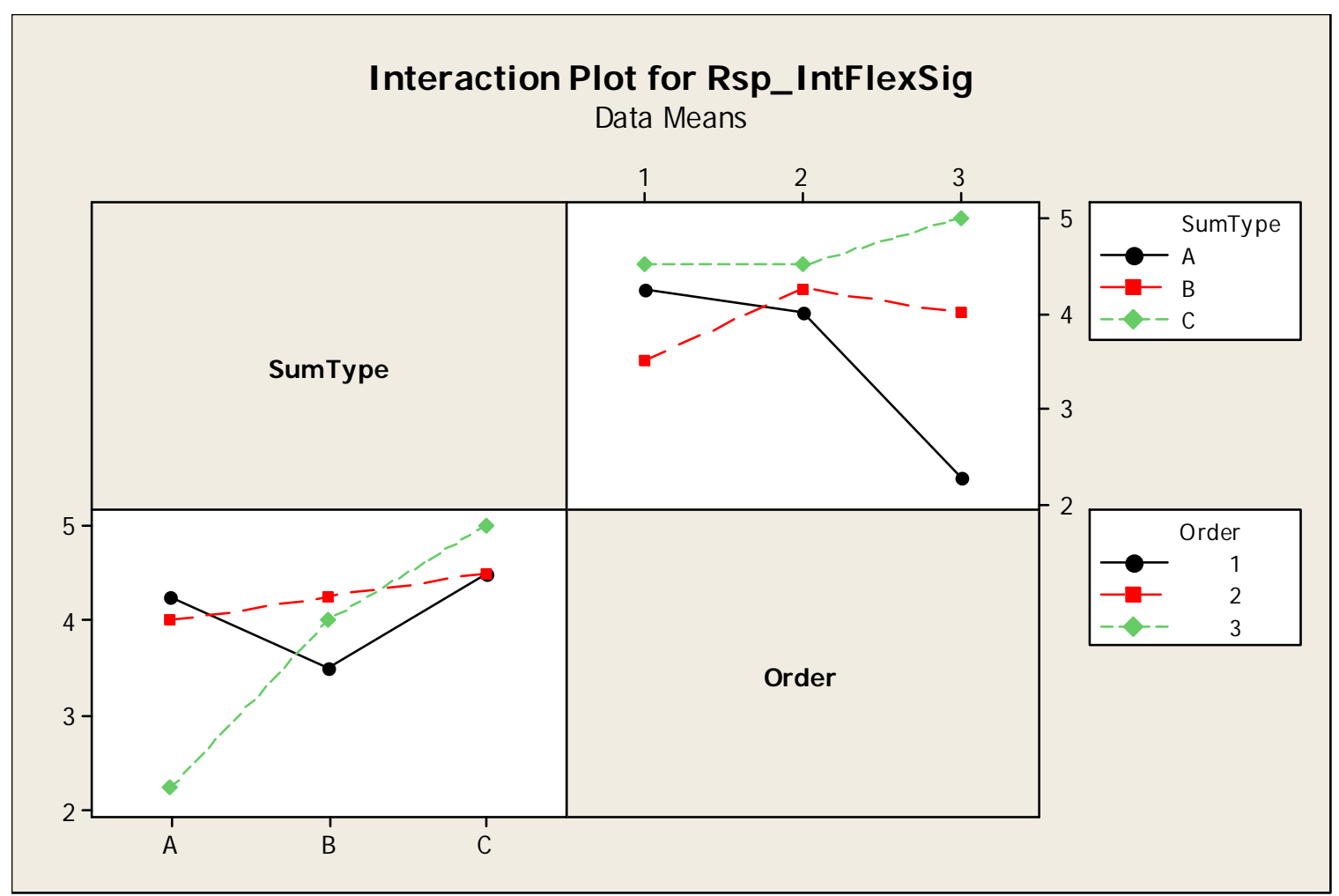

\section{General Linear Model: Rsp_IntFlexS versus Participant, SumType, Order}

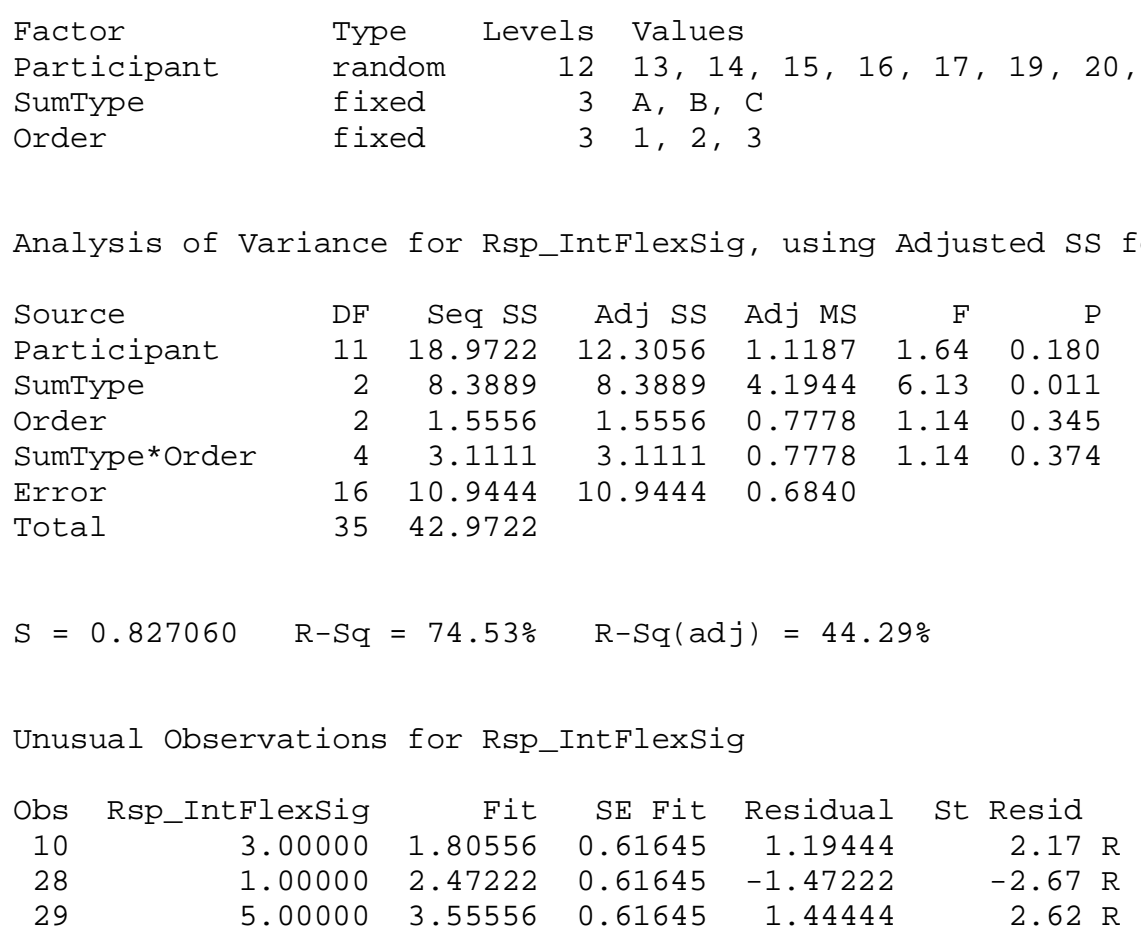

$\mathrm{R}$ denotes an observation with a large standardized residual. 


$\begin{array}{lrrl}\text { SummaryType } & \text { N } & \text { Mean } & \text { Grouping } \\ \text { C } & 12 & 4.7 & \text { A } \\ \text { B } & 12 & 3.9 & \text { A B } \\ \text { A } & 12 & 3.5 & \text { B }\end{array}$

Means that do not share a letter are significantly different.

Tukey 95.0\% Simultaneous Confidence Intervals

Response Variable Rsp_IntFlexSig

All Pairwise Comparisons among Levels of Summarytype

SummaryType $=$ A subtracted from:

SummaryType Lower Center Upper

$\begin{array}{llll}\text { B } & -0.4548 & 0.4167 & 1.288\end{array}$

$\begin{array}{llll}\text { C } & 0.2952 & 1.1667 & 2.038\end{array}$
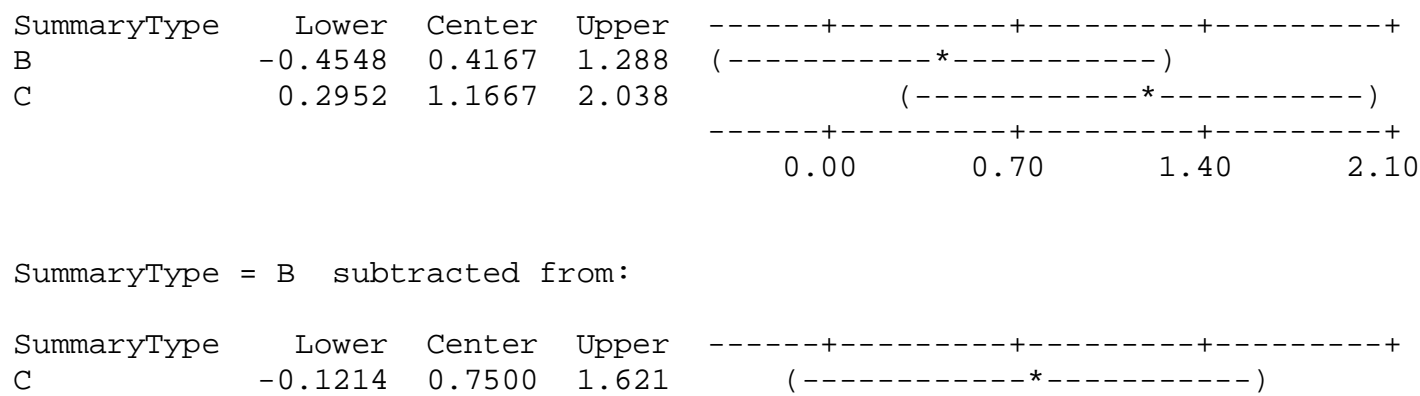

Tukey Simultaneous Tests

Response Variable Rsp_IntFlexSig

All Pairwise Comparisons among Levels of SummaryType

SummaryType $=$ A subtracted from:

$\begin{array}{lrrrr} & \text { Difference } & \text { SE of } & \text { Adjusted } \\ \text { SummaryType } & \text { of Means } & \text { Difference } & \text { T-Value } & \text { P-Value } \\ \text { B } & 0.4167 & 0.3376 & 1.234 & 0.4512 \\ \text { C } & 1.1667 & 0.3376 & 3.455 & 0.0086\end{array}$

\begin{tabular}{lrrrr} 
Summarytype $=\mathrm{B}$ & \multicolumn{2}{c}{ subtracted from: } & \\
& Difference & SE of & Adjusted \\
SummaryType & of Means & Difference & T-Value & P-Value \\
C & 0.7500 & 0.3376 & 2.221 & 0.0978
\end{tabular}




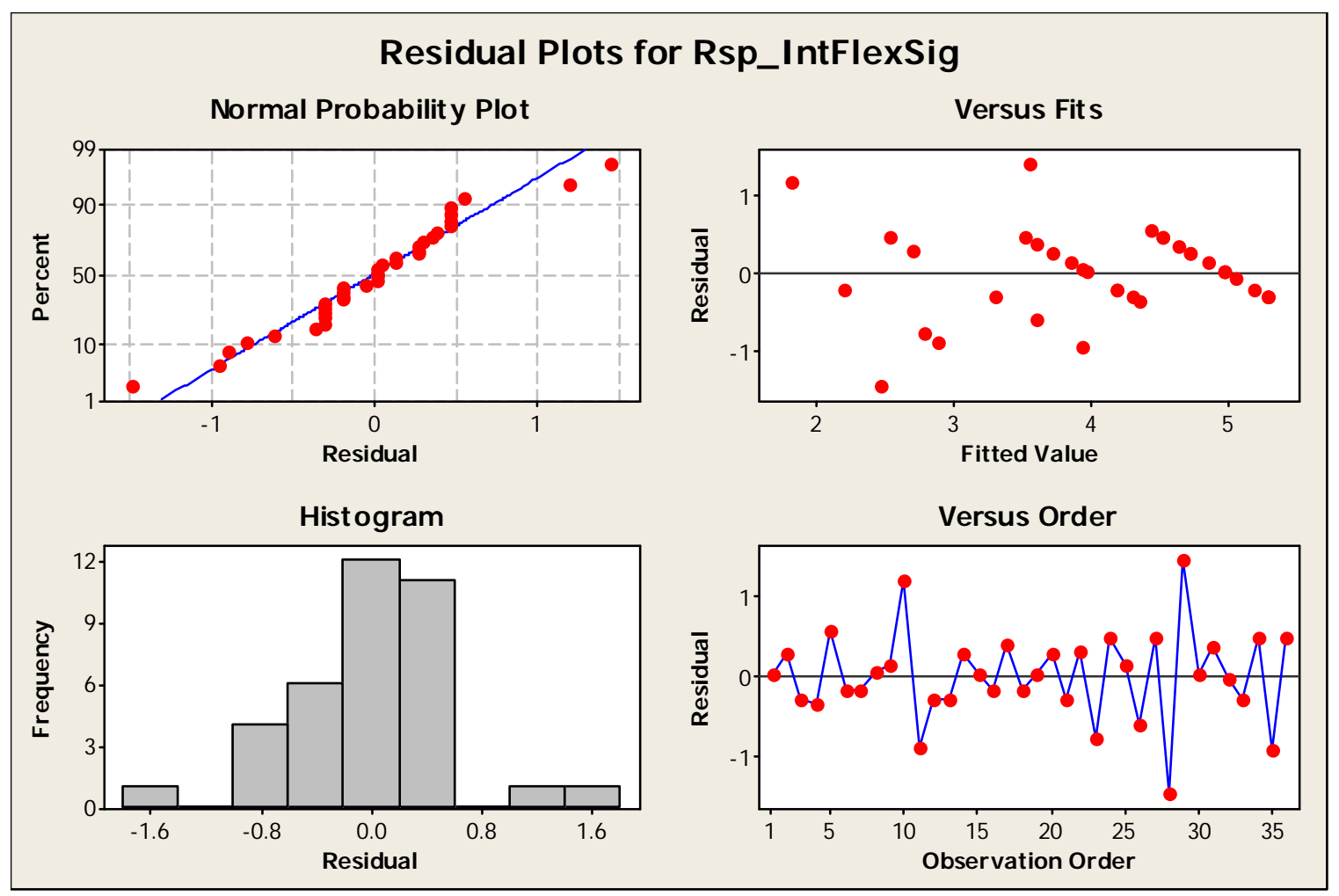

Appendix G.3.3 - Intent MSI

Mod \#10

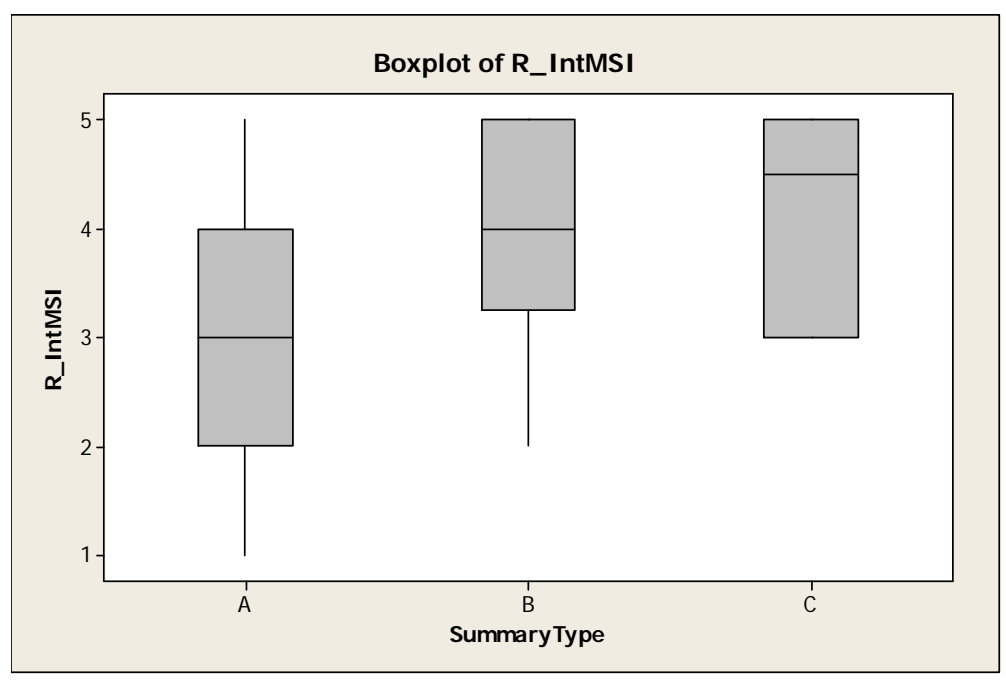




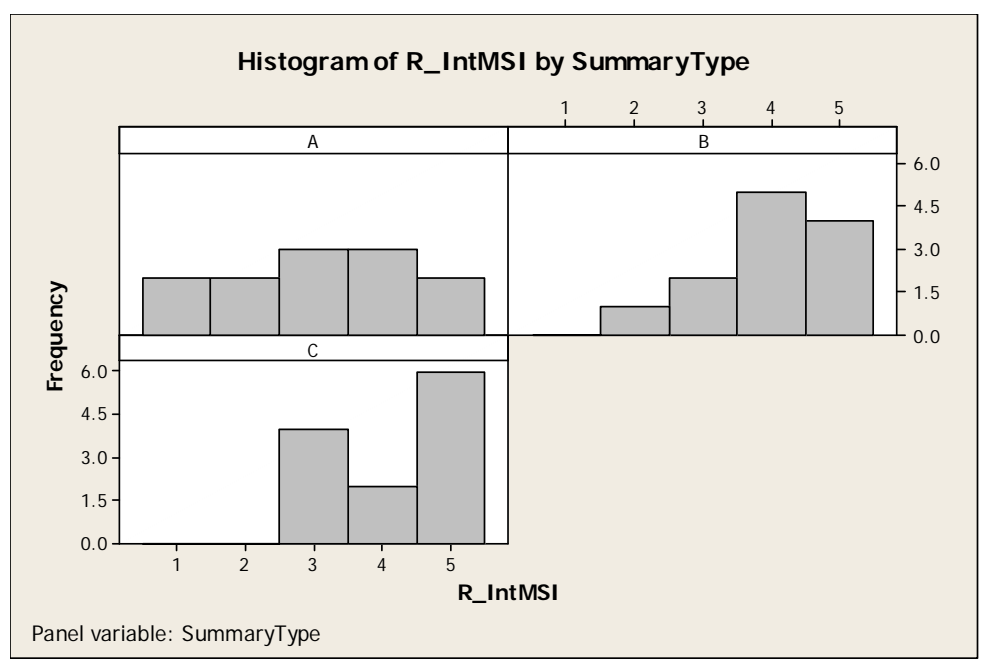

\section{Descriptive Statistics: R_IntMSI}

$\begin{array}{llrrr}\text { Variable } & \text { SummaryType } & \mathrm{N} & \mathrm{N}^{*} & \text { Mean } \\ \text { R_IntMSI } & \text { A } & 12 & 0 & 3.083 \\ & \text { B } & 12 & 0 & 4.000 \\ & \text { C } & 12 & 0 & 4.167 \\ \text { Variable } & \text { SummaryType } & \text { Q3 } & \text { Maximum } \\ \text { R_IntMSI } & \text { A } & 4.000 & 5.000 \\ & \text { B } & 5.000 & 5.000 \\ & \text { C } & 5.000 & 5.000\end{array}$

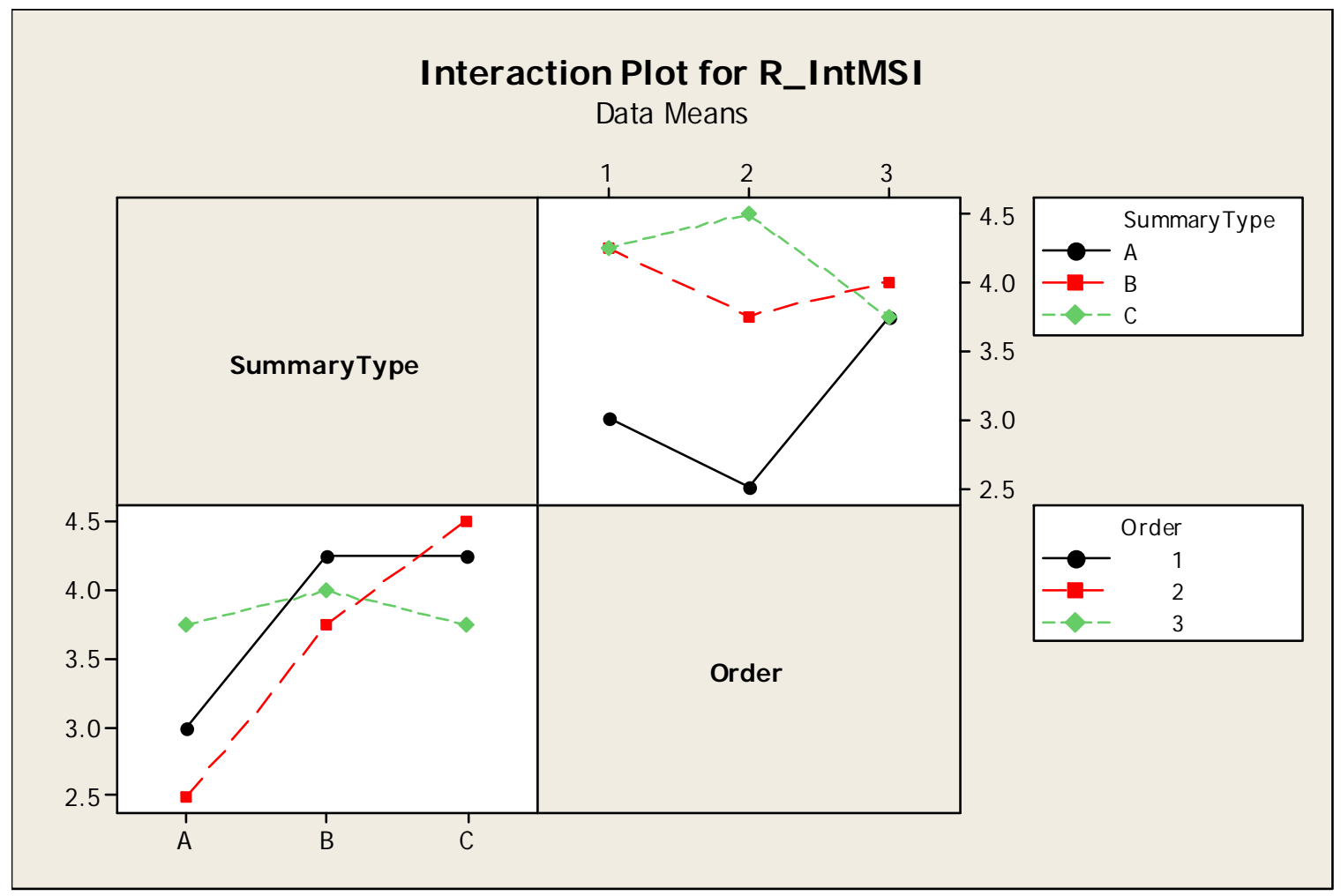


General Linear Model: R_IntMSI versus Participant, SummaryType, Order

$\begin{array}{llrl}\text { Factor } & \text { Type } & \text { Levels } & \text { Values } \\ \text { Participant } & \text { random } & 12 \text { 27, 28, 32, 33, 34, 35, 41, 42, 43, 44, 46, } 47 \\ \text { SummaryType } & \text { fixed } & 3 \text { A, B, C } & \\ \text { Order } & \text { fixed } & 3 \text { 1, 2, 3 }\end{array}$

Analysis of Variance for R_IntMSI, using Adjusted SS for Tests

$\begin{array}{lrrrrrc}\text { Source } & \text { DF } & \text { Seq SS } & \text { Adj SS } & \text { Adj MS } & \text { F } & \text { P } \\ \text { Participant } & 11 & 22.7500 & 20.3056 & 1.8460 & 1.91 & 0.116 t \\ \text { SummaryType } & 2 & 8.1667 & 8.1667 & 4.0833 & 4.23 & 0.034 \\ \text { Order } & 2 & 0.5000 & 0.5000 & 0.2500 & 0.26 & 0.775 \\ \text { SummaryType*Order } & 4 & 1.8889 & 1.8889 & 0.4722 & 0.49 & 0.744 \\ \begin{array}{l}\text { Error } \\ \text { Total }\end{array} & 16 & 15.4444 & 15.4444 & 0.9653 & & \\ & 35 & 48.7500 & & & & \\ \text { S }=0.982486 & R-S q=68.32 \% & \text { R-Sq(adj) } & =30.70 \% & & \end{array}$

Unusual Observations for R_IntMSI

$\begin{array}{rrrrrr}\text { Obs } & \text { R_IntMSI } & \text { Fit } & \text { SE Fit } & \text { Residual } & \text { St Resid } \\ 4 & 4.00000 & 2.47222 & 0.73230 & 1.52778 & 2.33 \mathrm{R} \\ 22 & 1.00000 & 2.80556 & 0.73230 & -1.80556 & -2.76 \mathrm{R}\end{array}$

$\mathrm{R}$ denotes an observation with a large standardized residual.

Grouping Information Using Tukey Method and 95.0\% Confidence

$\begin{array}{lrrl}\text { SummaryType } & \text { N } & \text { Mean } & \text { Grouping } \\ \text { C } & 12 & 4.167 & \text { A } \\ \text { B } & 12 & 4.000 & \text { A B } \\ \text { A } & 12 & 3.083 & \text { B }\end{array}$

Means that do not share a letter are significantly different.

Tukey 95.0\% Simultaneous Confidence Intervals

Response Variable R_IntMSI

All Pairwise Comparisons among Levels of Summarytype

SummaryType $=$ A subtracted from:

$\begin{array}{lrrr}\text { SummaryType } & \text { Lower } & \text { Center } & \text { Upper } \\ \text { B } & -0.1185 & 0.9167 & 1.952 \\ \text { C } & 0.0481 & 1.0833 & 2.119\end{array}$

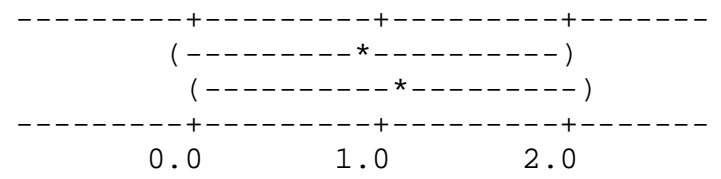

SummaryType $=$ B subtracted from:

SummaryType Lower Center Upper

C

$\begin{array}{lll}-0.8685 & 0.1667 & 1.202\end{array}$

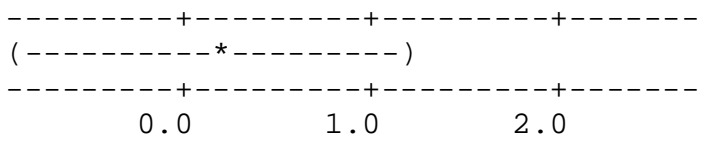

Tukey Simultaneous Tests

Response Variable R_IntMSI 

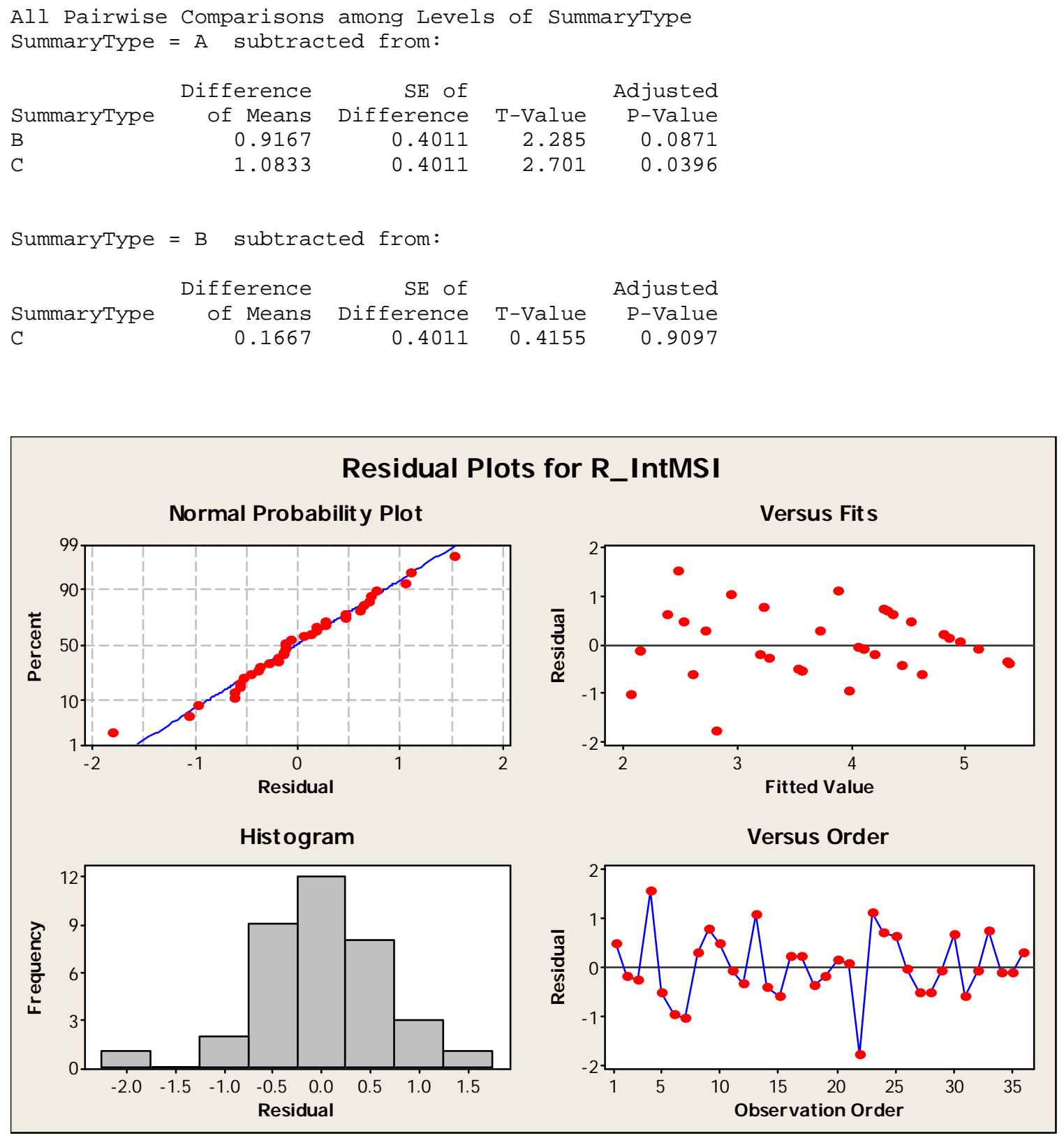

Appendix G.3.4 - Intent Genetic Counselor High \#12 

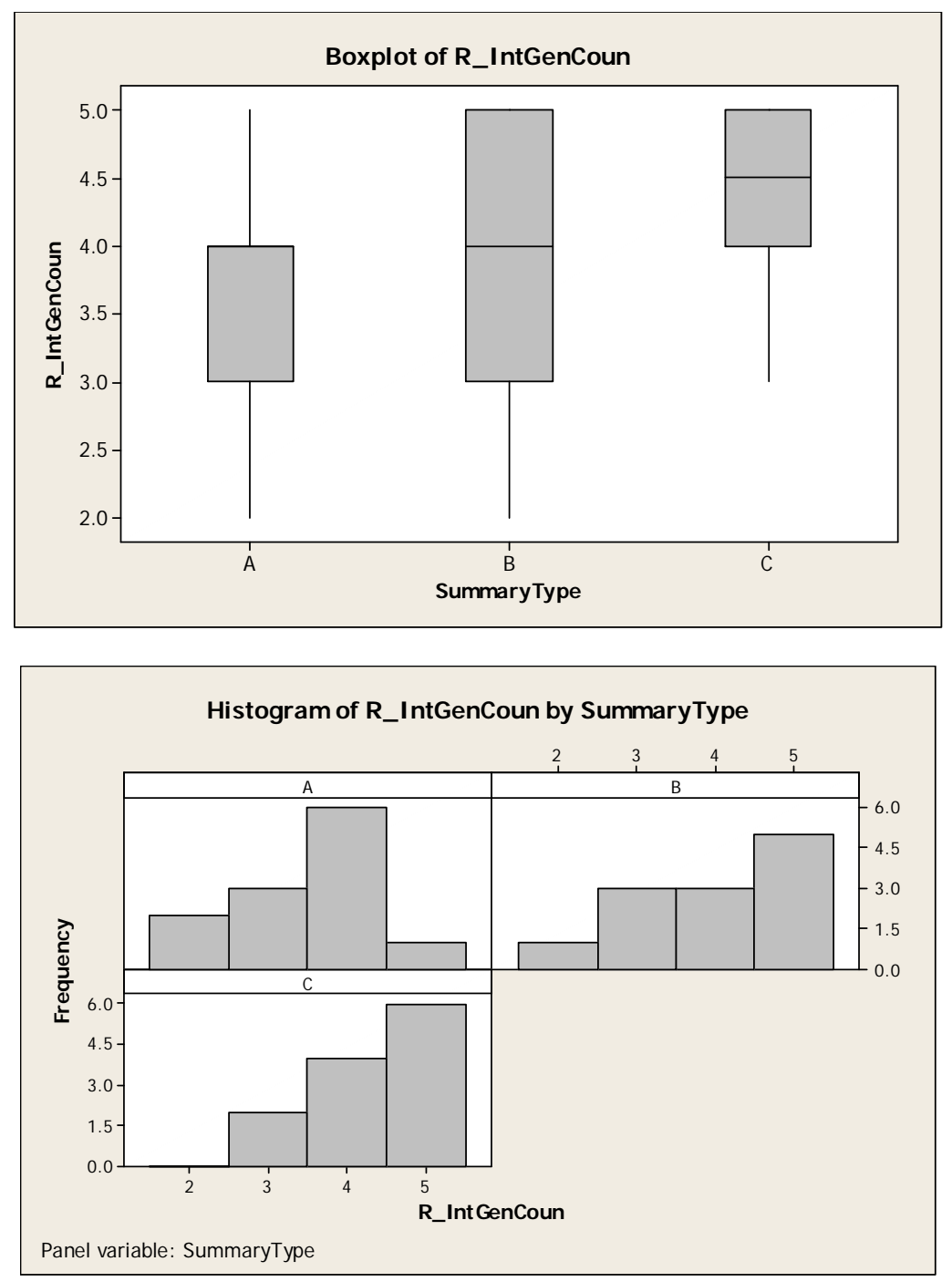

\section{Descriptive Statistics: R_IntGenCoun}

$\begin{array}{llrrrrrrr}\text { Variable } & \text { SummaryType } & \mathrm{N} & \mathrm{N}^{*} & \text { Mean } & \text { SE Mean } & \text { StDev } & \text { Minimum } & \text { Q1 } \\ \text { R_IntGenCoun } & \text { A } & 12 & 0 & 3.500 & 0.261 & 0.905 & 2.000 & 3.000 \\ & \text { B } & 12 & 0 & 4.000 & 0.302 & 1.044 & 2.000 & 3.000 \\ & \text { C } & 12 & 0 & 4.333 & 0.225 & 0.778 & 3.000 & 4.000 \\ \text { Variable } & \text { SummaryType } & \text { Median } & \text { Q3 } & \text { Maximum } & & & \\ \text { R_IntGenCoun } & \text { A } & 4.000 & 4.000 & 5.000 & & \\ & \text { B } & 4.000 & 5.000 & 5.000 & & \\ & \text { C } & 4.500 & 5.000 & 5.000 & & \end{array}$




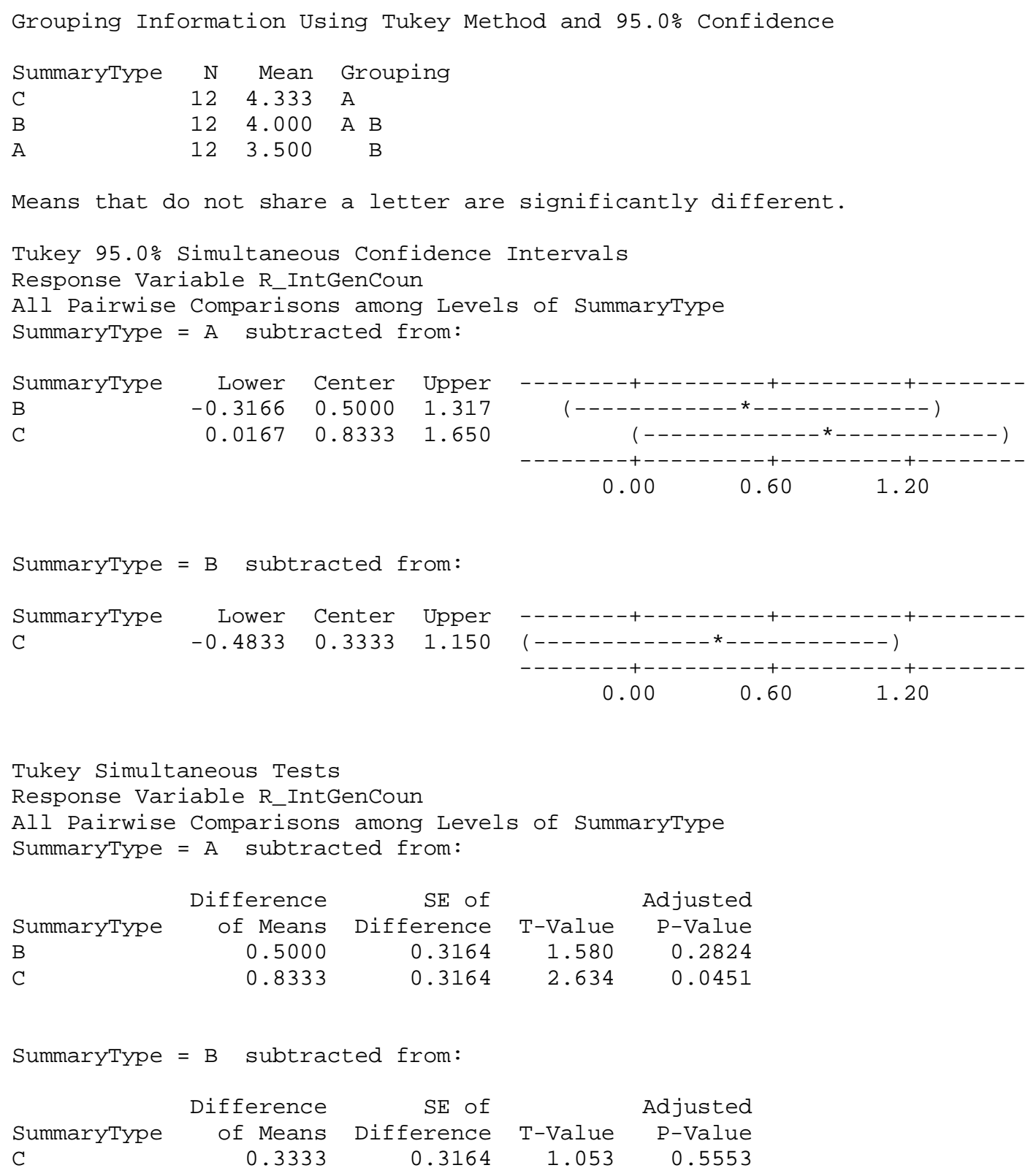




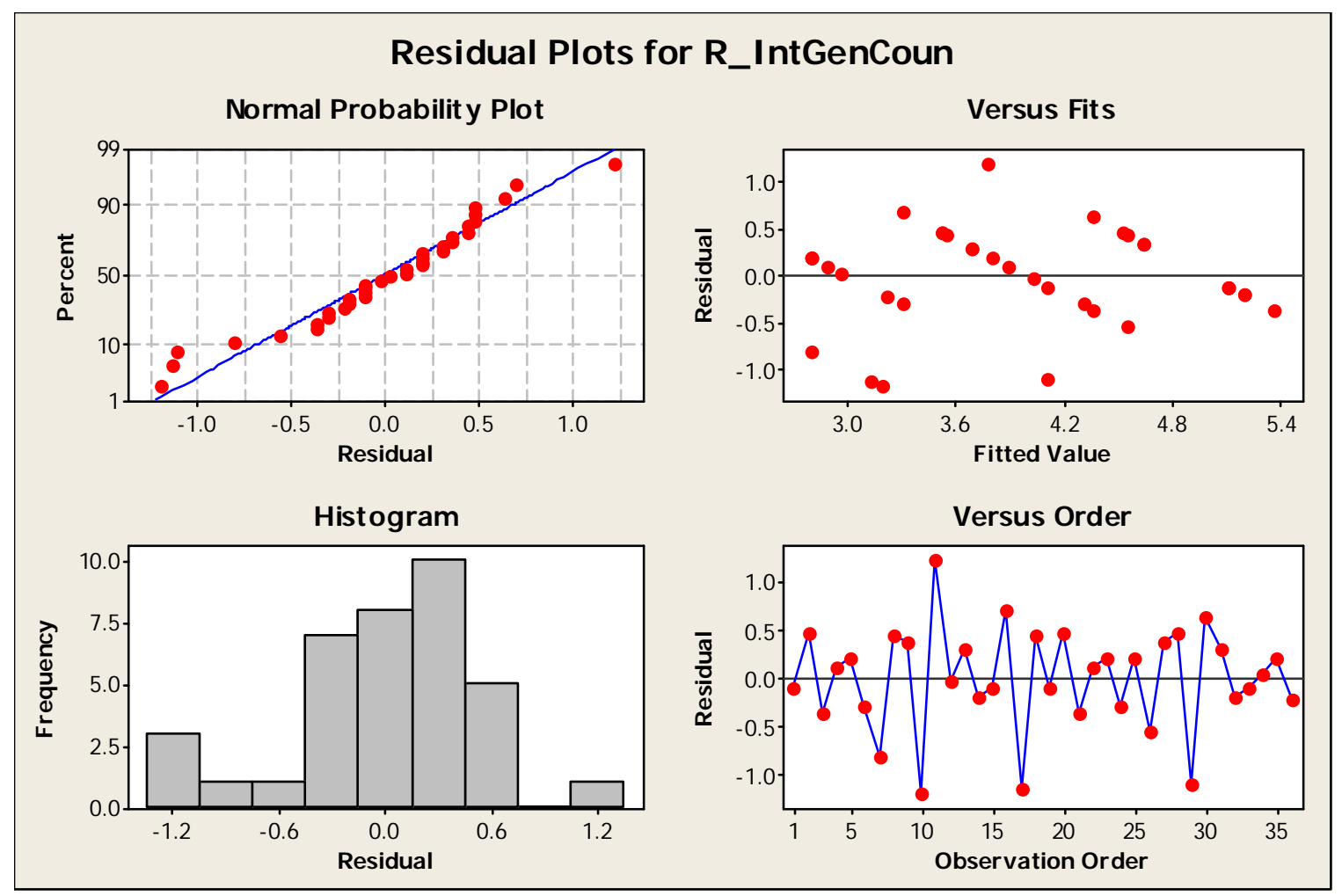

Appendix G.3.5 - Intent Upper Endoscopy

High \#12

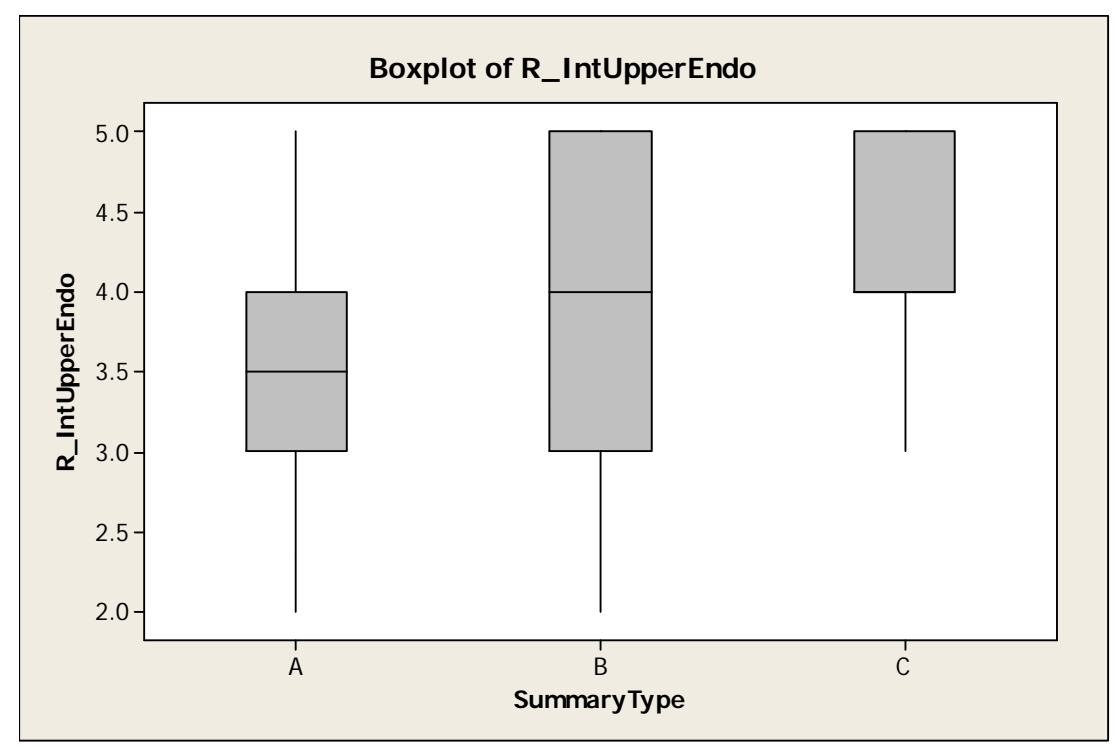




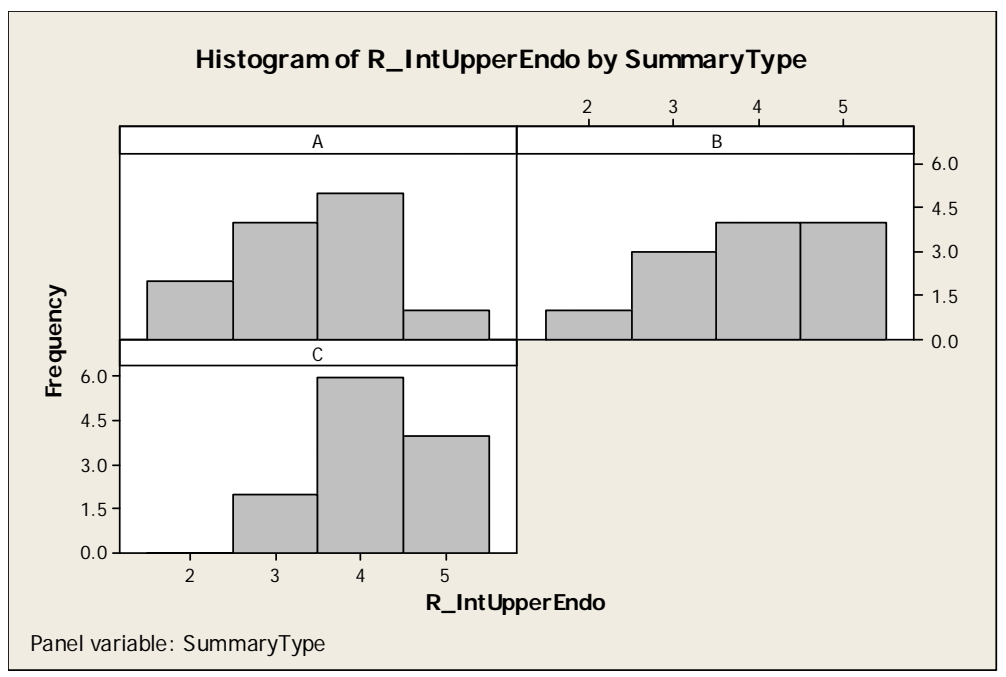

\section{Descriptive Statistics: R_IntUpperEndo}

\begin{tabular}{|c|c|c|c|c|c|c|c|c|}
\hline Variable & SummaryType & $\mathrm{N}$ & $N^{\star}$ & Mean & SE Mean & StDev & Minimum & Q1 \\
\hline \multirow[t]{3}{*}{ R_IntUpperEndo } & A & 12 & 0 & 3.417 & 0.260 & 0.900 & 2.000 & 3.000 \\
\hline & B & 12 & 0 & 3.917 & 0.288 & 0.996 & 2.000 & 3.000 \\
\hline & $\mathrm{C}$ & 12 & 0 & 4.167 & 0.207 & 0.718 & 3.000 & 4.000 \\
\hline Variable & SummaryType & \multicolumn{2}{|c|}{ Median } & Q3 & Maximum & & & \\
\hline \multirow[t]{3}{*}{ R_IntUpperEndo } & A & \multicolumn{2}{|c|}{3.500} & 4.000 & 5.000 & & & \\
\hline & B & \multicolumn{2}{|c|}{4.000} & 5.000 & 5.000 & & & \\
\hline & $\mathrm{C}$ & \multicolumn{2}{|c|}{4.000} & 5.000 & 5.000 & & & \\
\hline
\end{tabular}

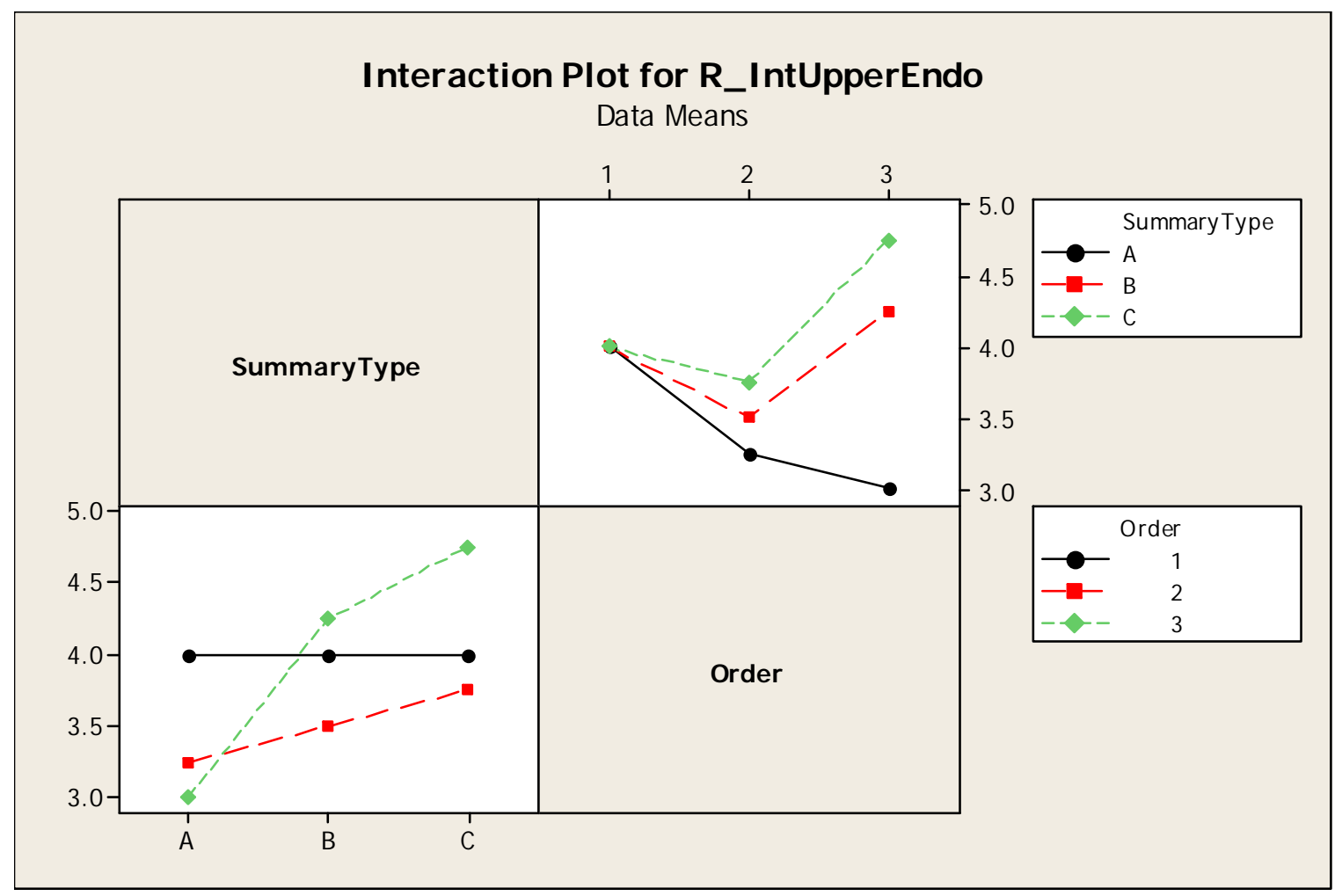




\section{General Linear Model: R_IntUpperEn versus Participant, SummaryType, ...}

$\begin{array}{llrl}\text { Factor } & \text { Type } & \text { Levels Values } \\ \text { Participant } & \text { random } & 12 \text { 1, 4, 5, 6, 8, 9, 10, 12, 38, 39, 45, } 49 \\ \text { SummaryType } & \text { fixed } & 3 \text { A, B, C } \\ \text { Order } & \text { fixed } & 3 \text { 1, 2, 3 }\end{array}$

Analysis of Variance for R_IntUpperEndo, using Adjusted SS for Tests

$\begin{array}{lrrrrrr}\text { Source } & \text { DF } & \text { Seq SS } & \text { Adj SS } & \text { Adj MS } & \text { F } & \text { P } \\ \text { Participant } & 11 & 13.0000 & 11.8333 & 1.0758 & 2.11 & 0.085 \\ \text { SummaryType } & 2 & 3.5000 & 3.5000 & 1.7500 & 3.43 & 0.058 \\ \text { Order } & 2 & 2.0000 & 2.0000 & 1.0000 & 1.96 & 0.173 \\ \text { SummaryType*Order } & 4 & 2.3333 & 2.3333 & 0.5833 & 1.14 & 0.372 \\ \text { Error } & 16 & 8.1667 & 8.1667 & 0.5104 & & \\ \text { Total } & 35 & 29.0000 & & & & \\ & & & & & \\ \text { S }=0.714435 & \text { R-Sq }=71.84 \% & \text { R-Sq(adj) }=38.40 \%\end{array}$

Unusual Observations for R_IntUpperEndo

$\begin{array}{rrrrrr}\text { Obs } & \text { R_IntUpperEndo } & \text { Fit } & \text { SE Fit } & \text { Residual } & \text { St Resid } \\ 10 & 2.00000 & 3.08333 & 0.53251 & -1.08333 & -2.27 \mathrm{R} \\ 11 & 5.00000 & 3.91667 & 0.53251 & 1.08333 & 2.27 \mathrm{R} \\ 17 & 2.00000 & 3.25000 & 0.53251 & -1.25000 & -2.62 \mathrm{R}\end{array}$

$\mathrm{R}$ denotes an observation with a large standardized residual.

Grouping Information Using Tukey Method and 95.0\% Confidence

$\begin{array}{lrrl}\text { SummaryType } & \text { N } & \text { Mean } & \text { Grouping } \\ \text { C } & 12 & 4.167 & \text { A } \\ \text { B } & 12 & 3.917 & \text { A } \\ \text { A } & 12 & 3.417 & \text { A }\end{array}$

Means that do not share a letter are significantly different.

Tukey 95.0\% Simultaneous Confidence Intervals

Response Variable R_IntUpperEndo

All Pairwise Comparisons among Levels of SummaryType

SummaryType $=$ A subtracted from:

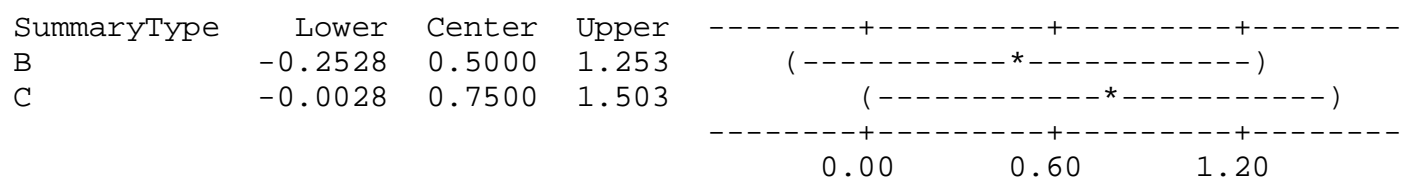

SummaryType $=$ B subtracted from:

Summarytype Lower Center Upper

$\begin{array}{llll}\text { C } & -0.5028 & 0.2500 & 1.003\end{array}$

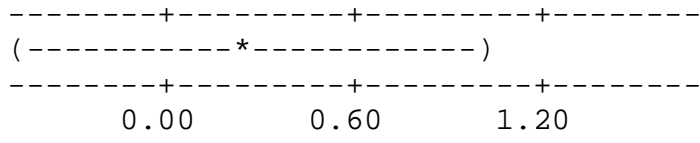

Tukey Simultaneous Tests

Response Variable R_IntUpperEndo 

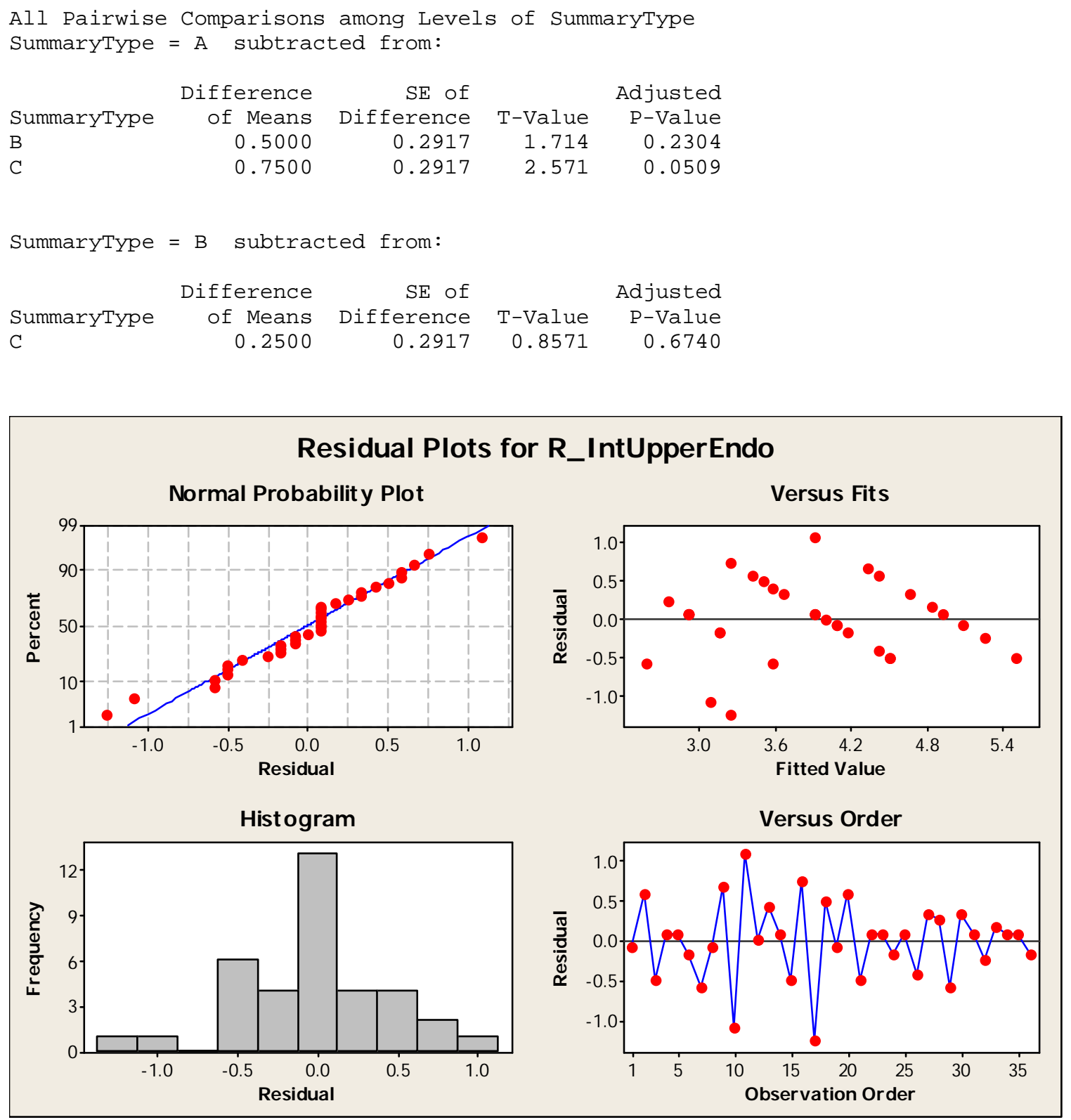

\section{Appendix G.4 - Usefulness Questions (9-10)}

Appendix G.4.1 - Reduce

Question: If I received these results, I would feel confident that the recommendations would help reduce my colorectal cancer risk.

Response: 1 (Strongly Disagree) to 5 (Strongly Agree)

Pop -12, Mod - 12, High - 14 

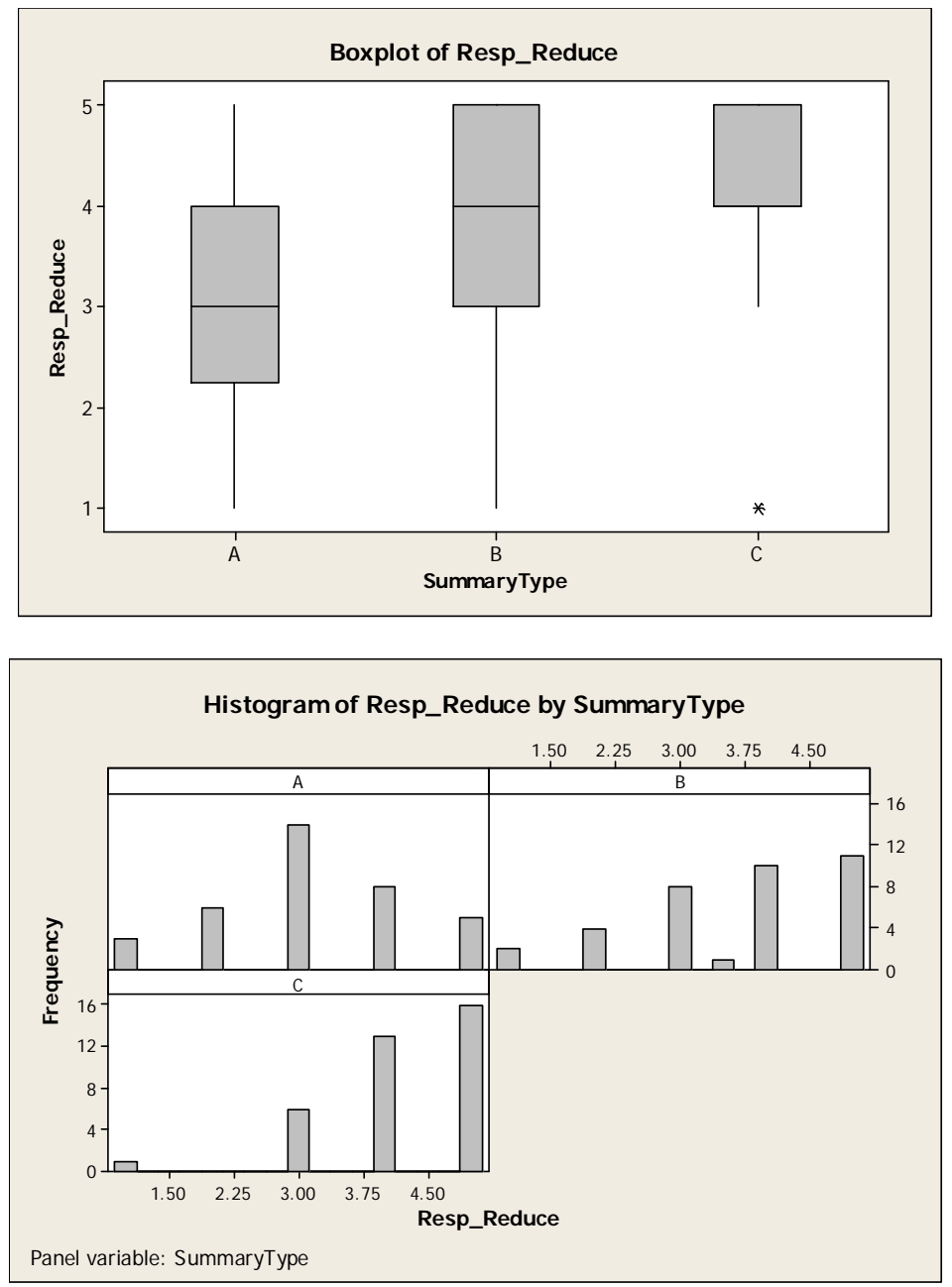

\section{Descriptive Statistics: Resp_Reduce}

\begin{tabular}{|c|c|c|c|c|c|c|c|c|c|}
\hline Variable & SummaryType & $\mathrm{N}$ & $\mathrm{N}^{*}$ & Mean & SE Mean & StDev & Minimum & Q1 & Median \\
\hline \multirow[t]{3}{*}{ Resp_Reduce } & A & 36 & 0 & 3.167 & 0.189 & 1.134 & 1.000 & 2.250 & 3.000 \\
\hline & B & 36 & 0 & 3.683 & 0.198 & 1.190 & 1.000 & 3.000 & 4.000 \\
\hline & $\mathrm{C}$ & 36 & 0 & 4.194 & 0.153 & 0.920 & 1.000 & 4.000 & 4.000 \\
\hline Variable & SummaryType & & 23 & Maximum & & & & & \\
\hline \multirow[t]{3}{*}{ Resp_Reduce } & $\mathrm{A}$ & 4.0 & & 5.000 & & & & & \\
\hline & B & 5.0 & & 5.000 & & & & & \\
\hline & $\mathrm{C}$ & 5.0 & & 5.000 & & & & & \\
\hline
\end{tabular}



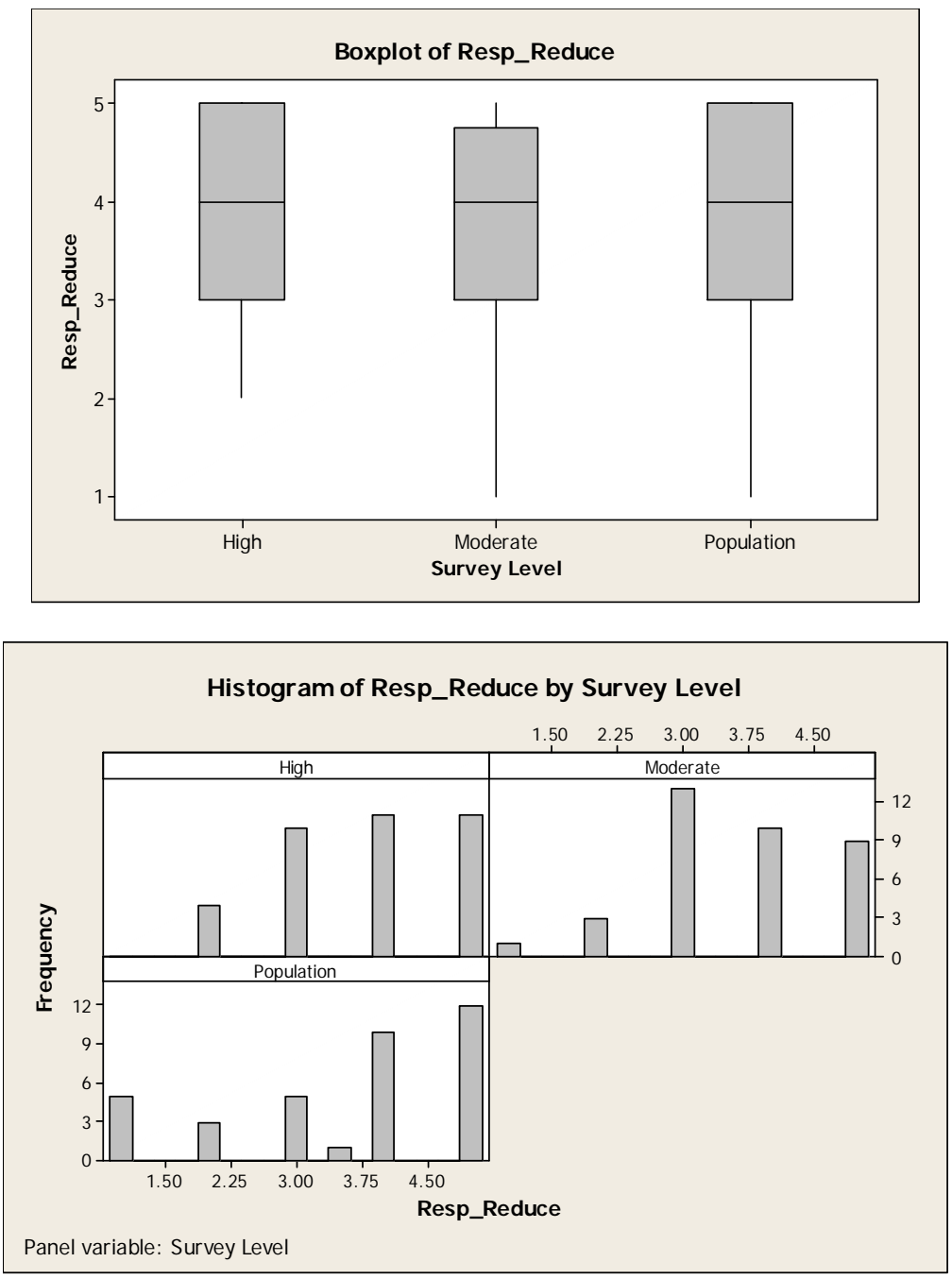

\section{Descriptive Statistics: Resp_Reduce}

$\begin{array}{llrrrrrrr}\text { Variable } & \text { Survey Level } & \mathrm{N} & \mathrm{N}^{*} & \text { Mean } & \text { SE Mean } & \text { StDev } & \text { Minimum } & \mathbf{Q} 1 \\ \text { Resp_Reduce } & \text { High } & 36 & 0 & 3.806 & 0.168 & 1.009 & 2.000 & 3.000 \\ & \begin{array}{l}\text { Moderate } \\ \text { Population }\end{array} & 36 & 0 & 3.639 & 0.174 & 1.046 & 1.000 & 3.000 \\ & & 0 & 3.600 & 0.233 & 1.398 & 1.000 & 3.000 \\ \text { Variable } & \text { Survey Level } & \text { Median } & \text { Q3 } & \text { Maximum } & & & \\ \text { Resp_Reduce } & \text { High } & 4.000 & 5.000 & 5.000 & & \\ & \text { Moderate } & 4.000 & 4.750 & 5.000 & & \\ & \text { Population } & 4.000 & 5.000 & 5.000 & & \end{array}$




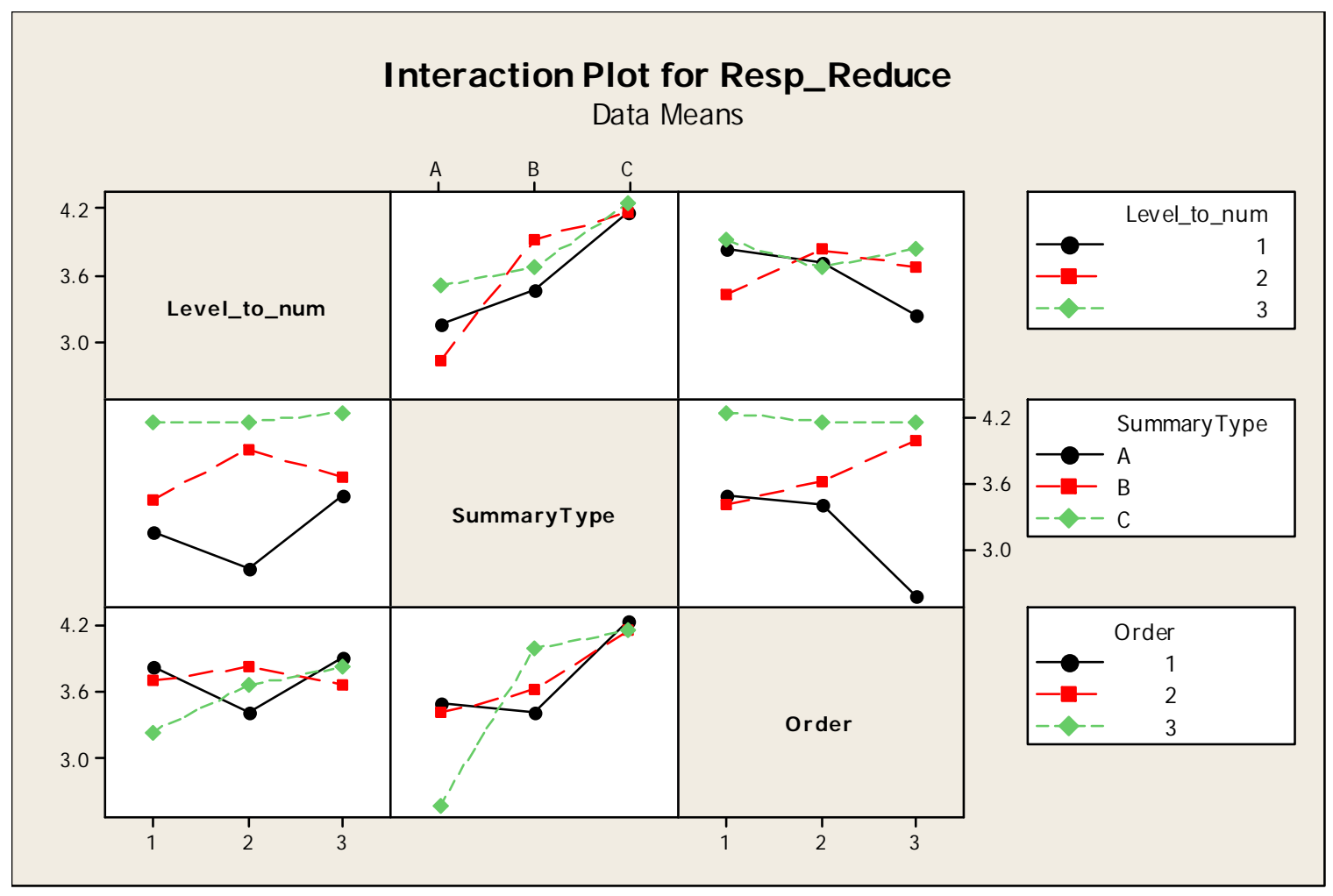

\section{General Linear Model: Resp_Reduce versus SummaryType, SurveyLevel, ...}

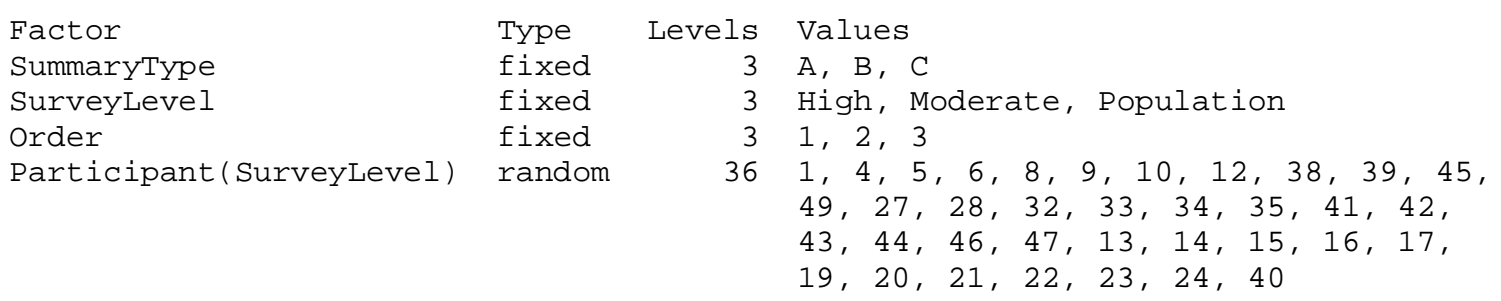

$x$ Not an exact F-test.

$S=0.816766 \quad R-S q=70.19 \% \quad R-S q(\operatorname{adj})=50.15 \%$

Unusual Observations for Resp_Reduce

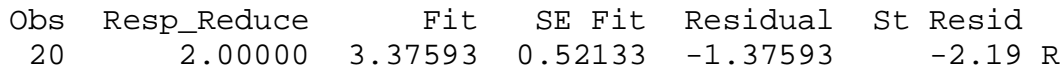




$\begin{array}{llllrrr}38 & 1.00000 & 2.34630 & 0.52133 & -1.34630 & -2.14 & R \\ 58 & 1.00000 & 2.77593 & 0.52133 & -1.77593 & -2.82 & R \\ 59 & 5.00000 & 3.70926 & 0.52133 & 1.29074 & 2.05 & R \\ 73 & 1.00000 & 3.08519 & 0.52133 & -2.08519 & -3.32 & R \\ 74 & 5.00000 & 3.70741 & 0.52133 & 1.29259 & 2.06 & R \\ 94 & 2.00000 & 3.67963 & 0.52133 & -1.67963 & -2.67 & R\end{array}$

$\mathrm{R}$ denotes an observation with a large standardized residual.

Grouping Information Using Tukey Method and 95.0\% Confidence

\begin{tabular}{lrrrr} 
SummaryType & N & Mean & Grouping \\
C & 36 & 4.2 & A & \\
B & 36 & 3.7 & \multicolumn{2}{c}{ B } \\
A & 36 & 3.2 & \multicolumn{2}{c}{ C }
\end{tabular}

Means that do not share a letter are significantly different.

Tukey 95.0\% Simultaneous Confidence Intervals

Response Variable Resp_Reduce

All Pairwise Comparisons among Levels of SummaryType

SummaryType $=$ A subtracted from:

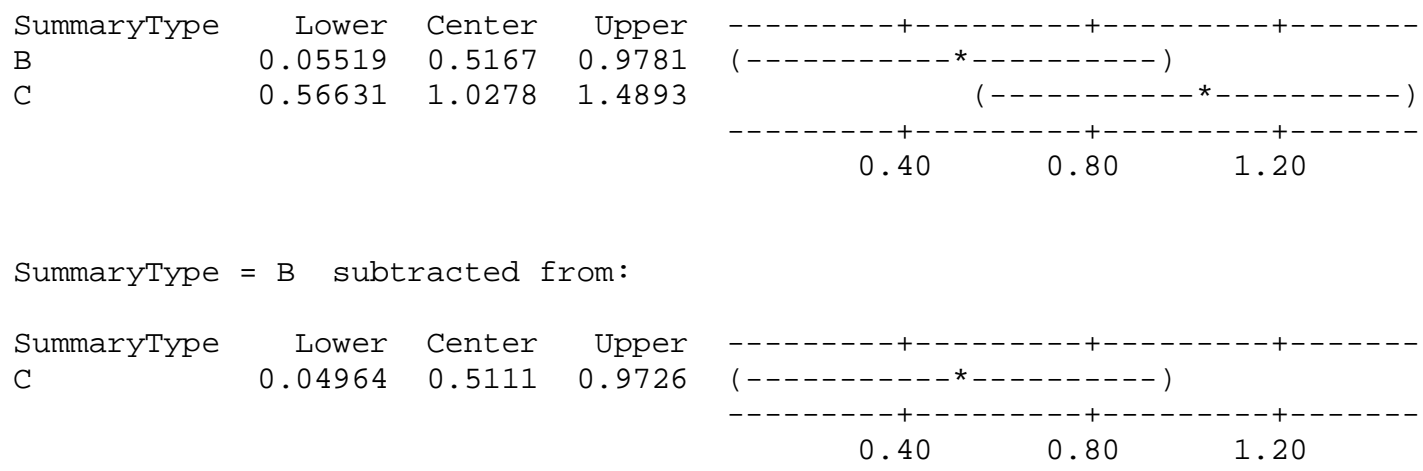

Tukey Simultaneous Tests

Response Variable Resp_Reduce

All Pairwise Comparisons among Levels of SummaryType

SummaryType $=$ A subtracted from:

$\begin{array}{lrrrr} & \text { Difference } & \text { SE of } & \text { Adjusted } \\ \text { SummaryType } & \text { of Means } & \text { Difference } & \text { T-Value } & \text { P-Value } \\ \text { B } & 0.5167 & 0.1925 & 2.684 & 0.0248 \\ \text { C } & 1.0278 & 0.1925 & 5.339 & 0.0000\end{array}$

\begin{tabular}{lrrrr} 
SummaryType $=\mathrm{B}$ & \multicolumn{2}{c}{ subtracted from: } \\
& Difference & SE of & \\
SummaryType & of Means & Difference & T-Value & P-Value \\
C & 0.5111 & 0.1925 & 2.655 & 0.0267
\end{tabular}




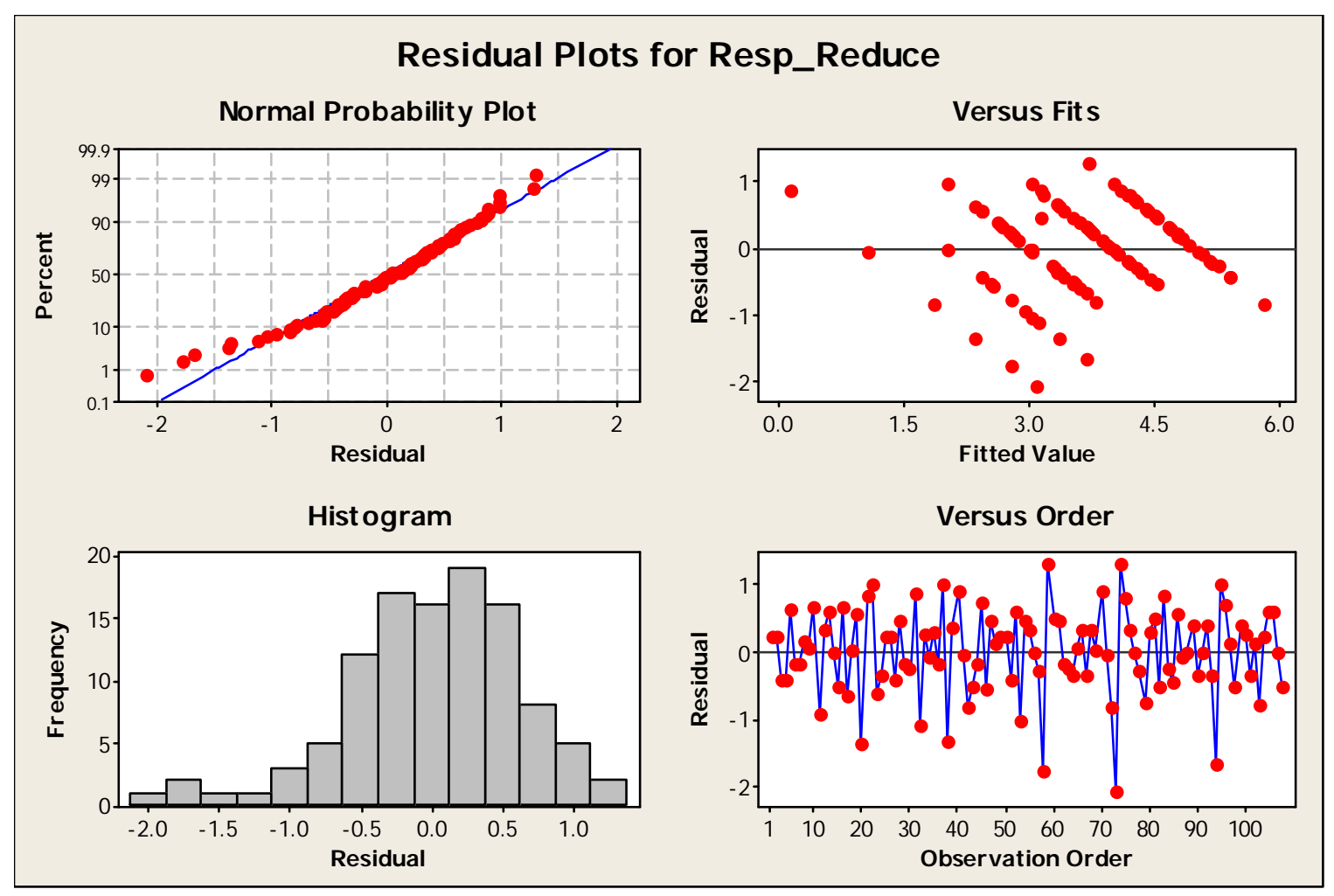

\section{Appendix G.4.2 - Helpful}

Question: I would find it helpful to receive this type of personalized summary report page for my individual colorectal cancer risk level.

Response: 1 (Strongly Disagree) to 5 (Strongly Agree)

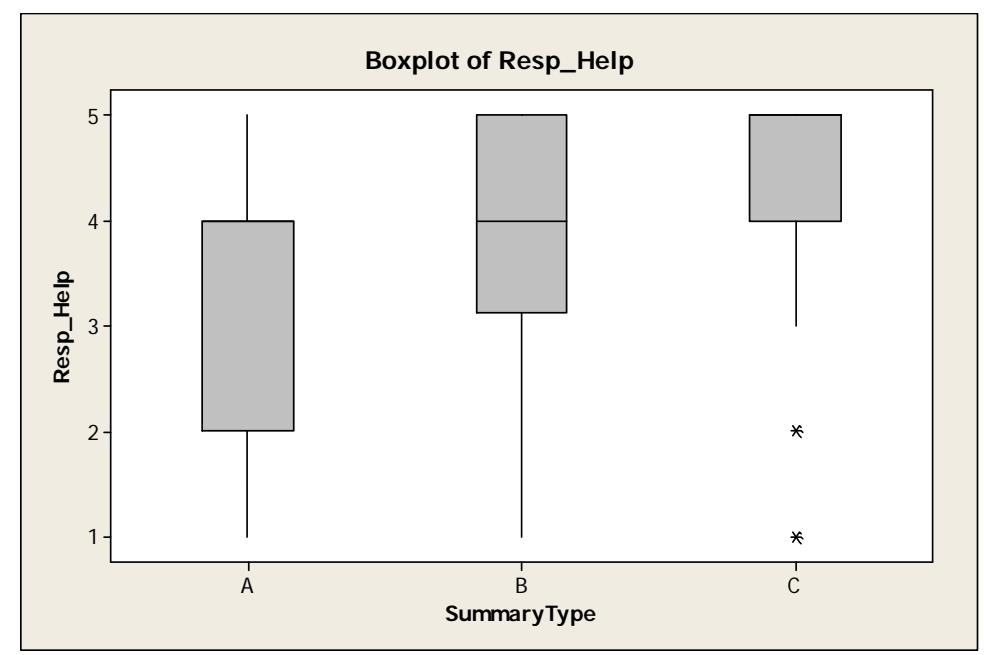




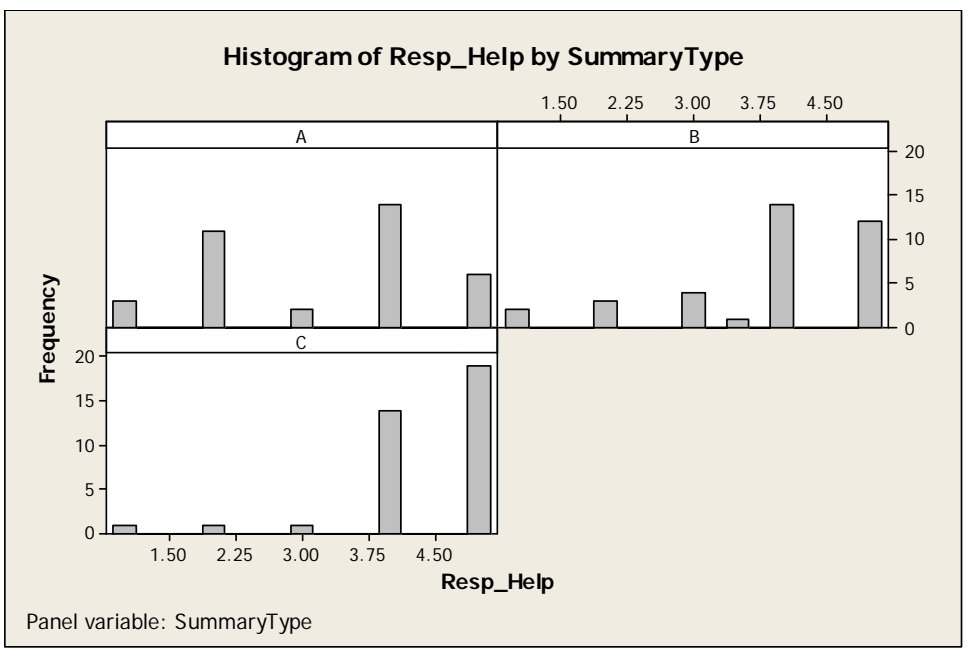

\section{Descriptive Statistics: Resp_Help}

\begin{tabular}{|c|c|c|c|c|c|c|c|c|c|}
\hline Variable & SummaryType & $\mathrm{N}$ & $\mathrm{N}^{*}$ & Mean & SE Mean & StDev & Minimum & Q1 & Median \\
\hline \multirow[t]{3}{*}{ Resp_Help } & $\mathrm{A}$ & 36 & 0 & 3.250 & 0.216 & 1.296 & 1.000 & 2.000 & 4.000 \\
\hline & B & 36 & 0 & 3.875 & 0.190 & 1.142 & 1.000 & 3.128 & 4.000 \\
\hline & C & 36 & 0 & 4.361 & 0.150 & 0.899 & 1.000 & 4.000 & 5.000 \\
\hline Variable & SummaryType & & Q3 & Maximum & & & & & \\
\hline \multirow[t]{3}{*}{ Resp_Help } & A & 4. & & 5.000 & & & & & \\
\hline & B & 5. & & 5.000 & & & & & \\
\hline & $\mathrm{C}$ & 5. & & 5.000 & & & & & \\
\hline
\end{tabular}

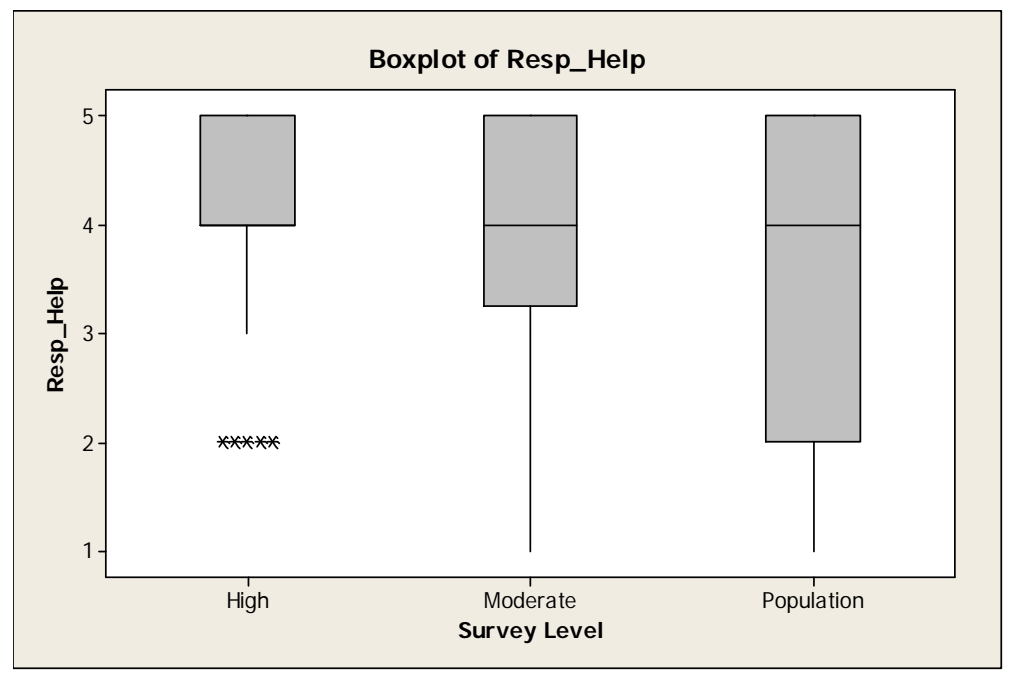




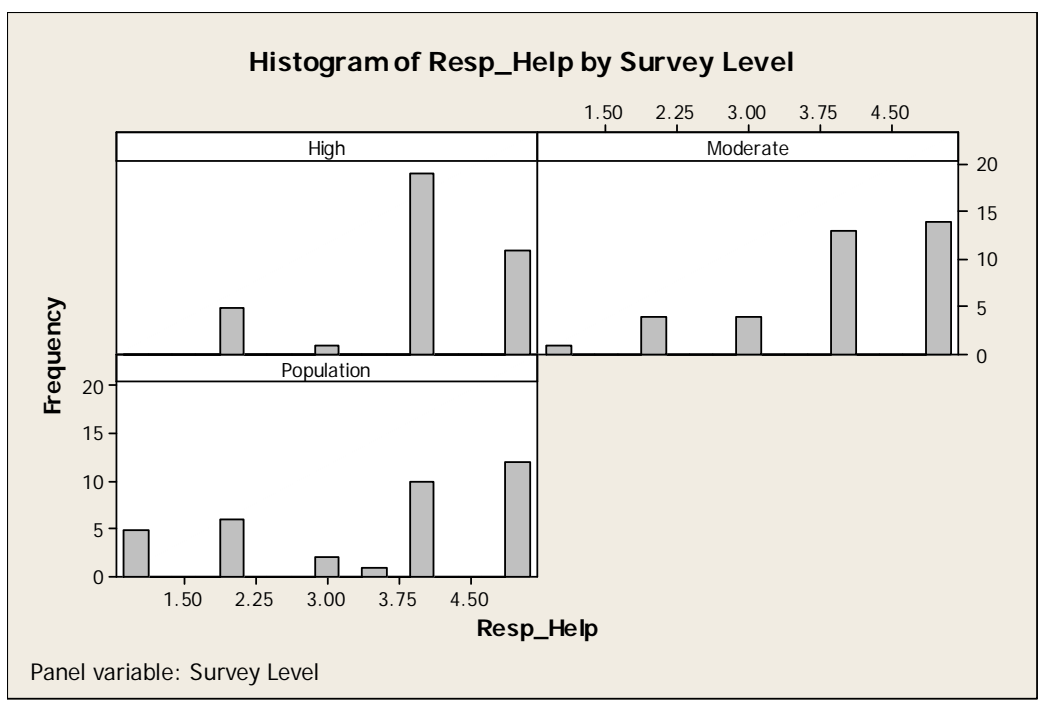

\section{Descriptive Statistics: Resp_Help}

$\begin{array}{llrrr}\text { Variable } & \text { Survey Level } & \mathrm{N} & \mathrm{N}^{*} & \text { Mean } \\ \text { Resp_Help } & \text { High } & 36 & 0 & 4.000 \\ & \begin{array}{l}\text { Moderate } \\ \text { Population }\end{array} & 36 & 0 & 3.972 \\ & & 0 & 3.514 \\ \text { Variable } & \text { Survey Level } & \text { Q3 } & \text { Maximum } \\ \text { Resp_Help } & \text { High } & 5.000 & 5.000 \\ & \text { Moderate } & 5.000 & 5.000 \\ & \text { Population } & 5.000 & 5.000\end{array}$

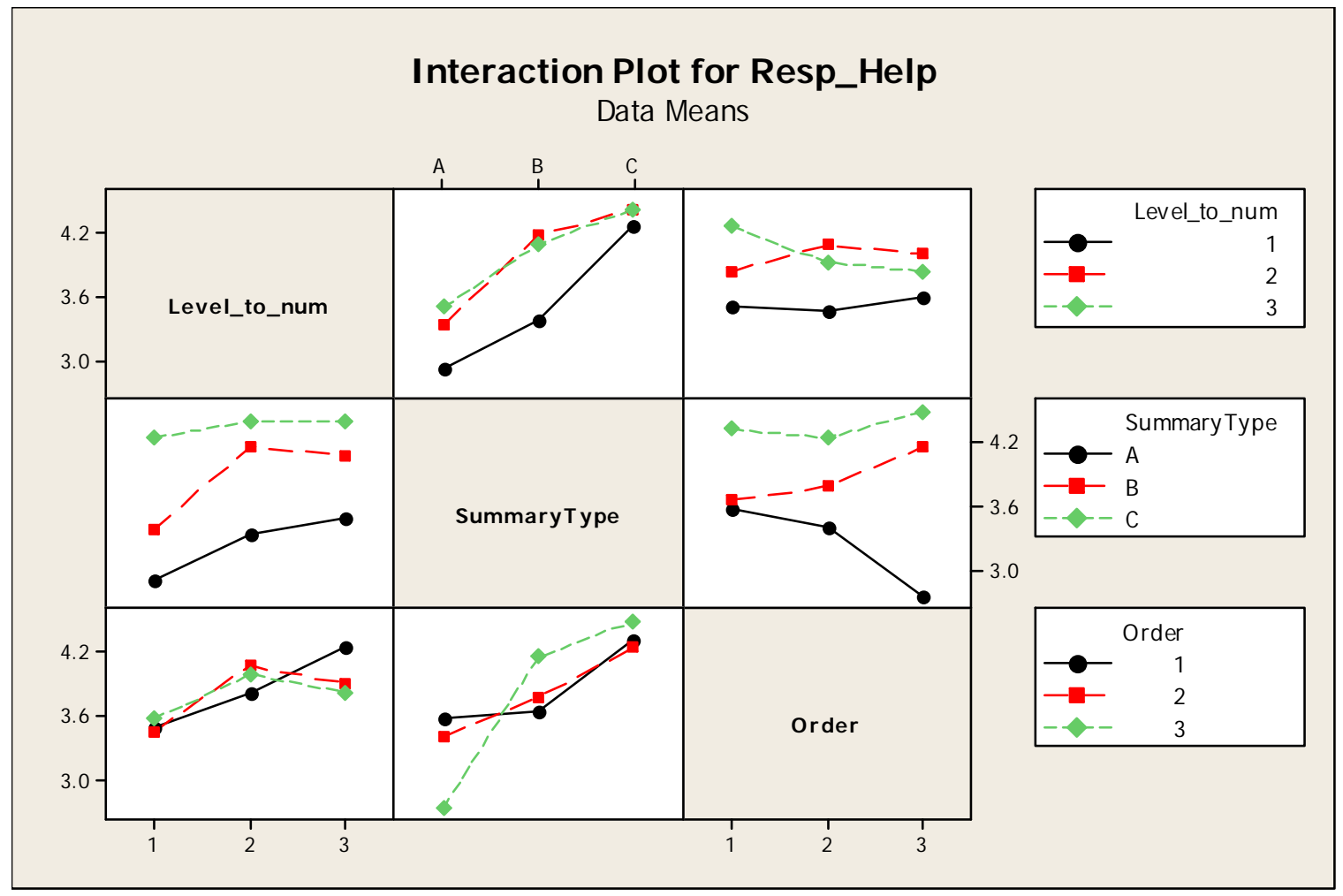




\section{General Linear Model: Resp_Help versus SummaryType, SurveyLevel, ...}

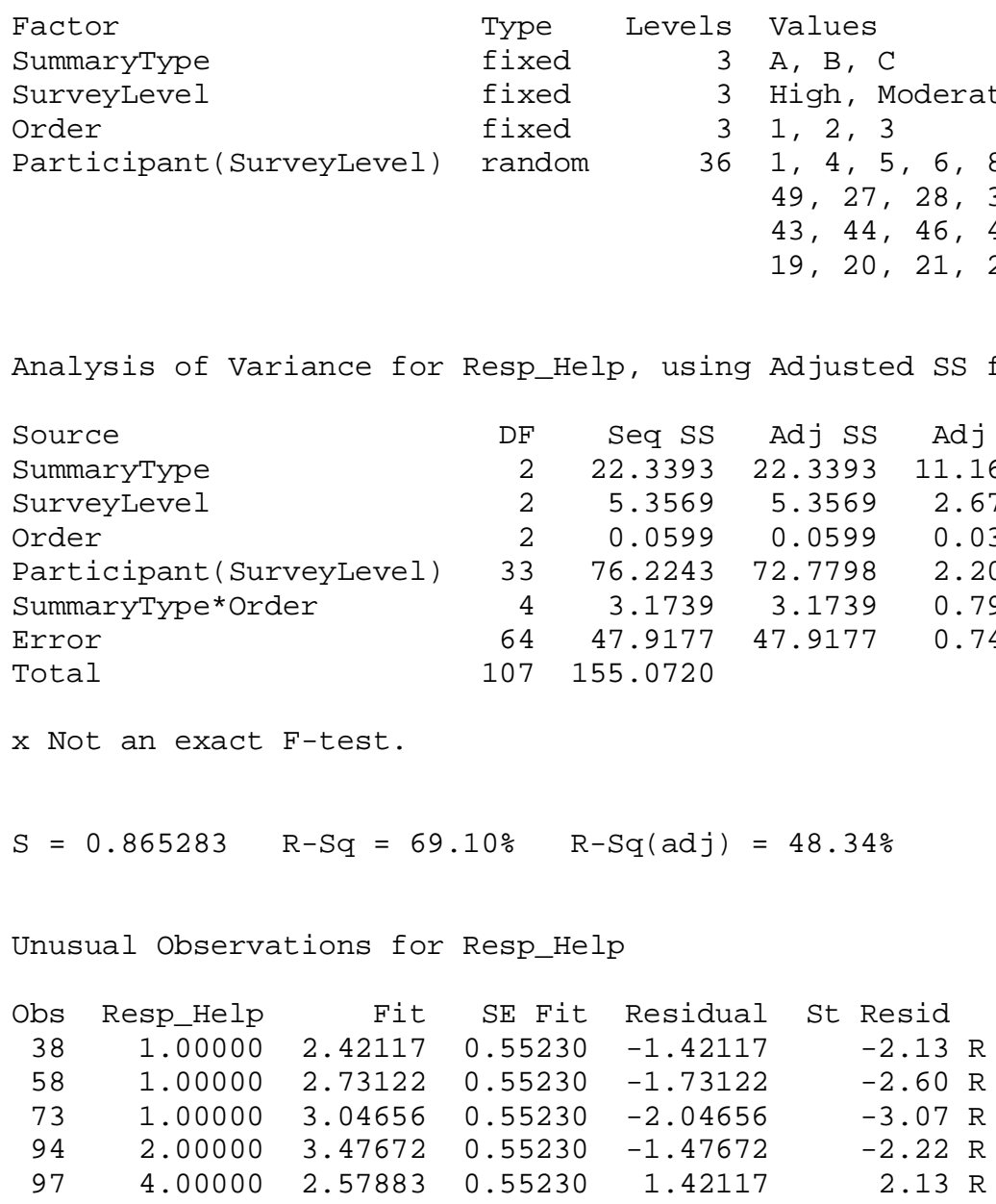

$\mathrm{R}$ denotes an observation with a large standardized residual.

Grouping Information Using Tukey Method and 95.0\% Confidence

$\begin{array}{lrrl}\text { SummaryType } & \text { N } & \text { Mean } & \text { Grouping } \\ \text { C } & 36 & 4.4 & \text { A } \\ \text { B } & 36 & 3.9 & \text { A } \\ \text { A } & 36 & 3.3 & \text { B }\end{array}$

Means that do not share a letter are significantly different.

Tukey 95.0\% Simultaneous Confidence Intervals

Response Variable Resp_Help

All Pairwise Comparisons among Levels of SummaryType

SummaryType $=$ A subtracted from:

$\begin{array}{lrrr}\text { SummaryType } & \text { Lower } & \text { Center } & \text { Upper } \\ \text { B } & 0.1365 & 0.6254 & 1.114 \\ \text { C } & 0.6222 & 1.1111 & 1.600\end{array}$

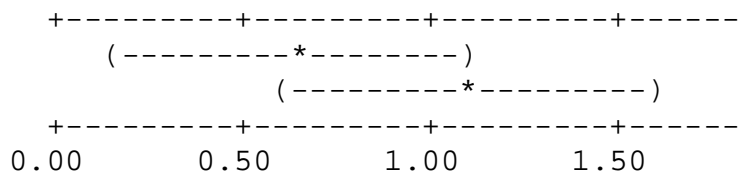




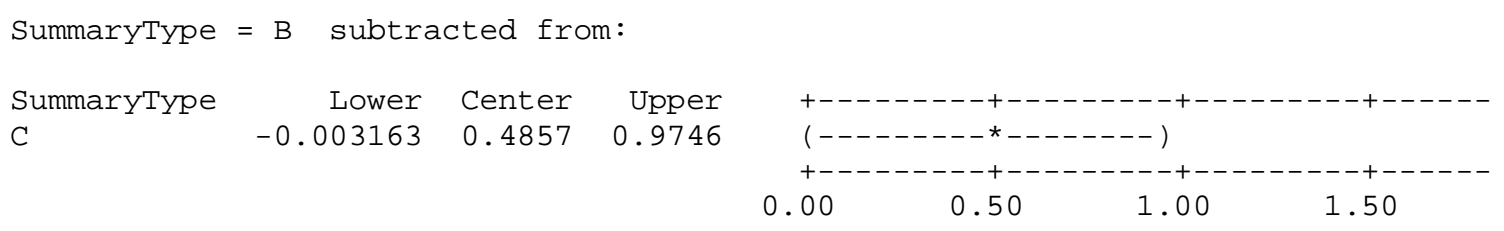

Tukey Simultaneous Tests

Response Variable Resp_Help

All Pairwise Comparisons among Levels of SummaryType

SummaryType $=$ A subtracted from:

$\begin{array}{lrrrr} & \text { Difference } & \text { SE of } & \text { Adjusted } \\ \text { SummaryType } & \text { of Means } & \text { Difference } & \text { T-Value } & \text { P-Value } \\ \text { B } & 0.6254 & 0.2039 & 3.066 & 0.0088 \\ \text { C } & 1.1111 & 0.2039 & 5.448 & 0.0000\end{array}$
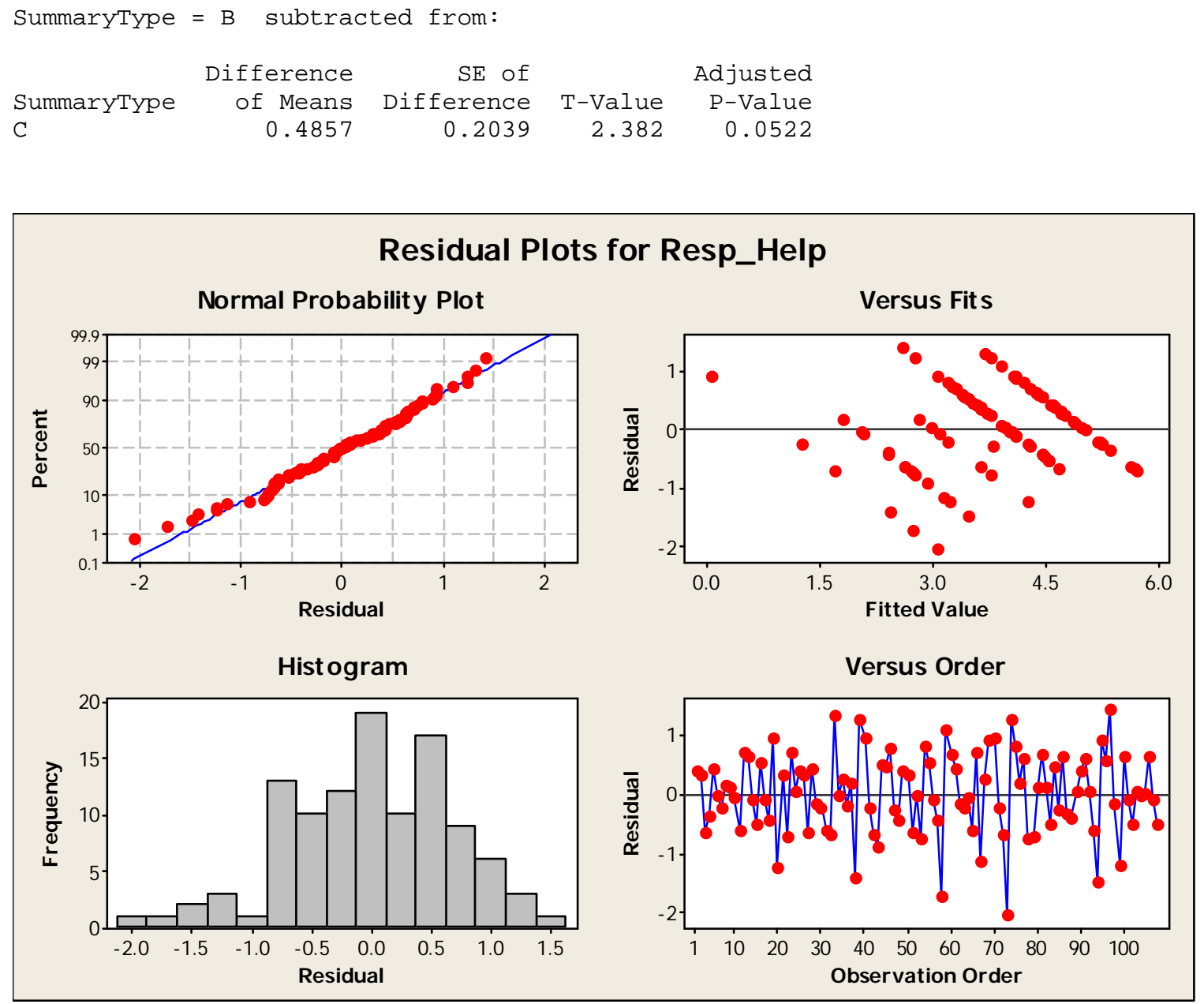

Appendix G.5 - Overall Opinion (11-12)

There were two ranking questions used in this study. One in the third survey to rank from 1-3

the three various summary type pages, and then a question in the fourth study to include the 
ranking of the full report (with no cover page) against the previous three summary page types including the full report.

\section{Appendix G.5.1 - KW analysis}

Appendix G.5.1.1 - KW analysis Ranking 1 to 3

Analysis using the KW test showed there was no relationship found in risk level versus summary type. The stacked data showed significant difference between rank and summary. This indicates that there is a strong preference for Summary Type C over both Summary Type B and A.

Response versus Summary Type ( 1 =high/favorite, 3 =low/least favorite)

\section{Kruskal-Wallis Test: Response versus Treatment}

\begin{tabular}{|c|c|c|c|c|c|}
\hline Treatment & $\mathrm{N}$ & Median & Ave & Rank & Z \\
\hline Summary A & 34 & 3.000 & & 75.5 & 5.79 \\
\hline Summary B & 34 & 2.000 & & 52.5 & 0.24 \\
\hline Summary C & 34 & 1.000 & & 26.5 & -6.03 \\
\hline Overall & 102 & & & 51.5 & \\
\hline$=46.68$ & $\mathrm{DF}$ & $\mathrm{P}$ & 0.000 & & \\
\hline $\mathrm{H}=52.51$ & $\mathrm{DF}=$ & $\mathrm{P}=$ & 0.000 & & usted for ties) \\
\hline
\end{tabular}

$\underline{\text { Response versus Risk Level }}$

\section{Kruskal-Wallis Test: Response versus $\mathbf{R}$ _Level}

\begin{tabular}{|c|c|c|c|c|}
\hline R_Level & $\mathrm{N}$ & Median Ave & Rank & Z \\
\hline $\mathrm{High}$ & 36 & 2.000 & 51.5 & 0.00 \\
\hline Moderate & 30 & 2.000 & 51.5 & 0.00 \\
\hline Population & 36 & 2.000 & 51.5 & 0.00 \\
\hline Overall & 102 & & 51.5 & \\
\hline $\mathrm{H}=0.00$ & $\mathrm{DF}=2$ & $P=1.000$ & & \\
\hline $\mathrm{H}=0.00$ & $\mathrm{DF}=2$ & $P=1.000$ & ( adj & sted for ties) \\
\hline
\end{tabular}

Appendix G.5.1.2 - KW analysis Ranking 1 to 4

Similar to the 1 to 3 rankings, summary type is shown to be significantly different within the rankings. Risk Level is not significant.

Response versus Summary Type ( 1 =high/favorite, $4=$ low/least fav) 


Kruskal-Wallis Test on Response
$\begin{array}{lrrrr}\text { Treatment } & \text { N } & \text { Median } & \text { Ave Rank } & \mathrm{Z} \\ \text { No Summary } & 31 & 3.000 & 70.1 & 1.36 \\ \text { Summary A } & 31 & 3.000 & 85.3 & 4.08 \\ \text { Summary B } & 31 & 2.000 & 61.4 & -0.19 \\ \text { Summary C } & 31 & 1.000 & 33.1 & -5.25 \\ \text { Overall } & 124 & & 62.5 & \\ & \\ \mathrm{H}=34.62 & \mathrm{DF}=3 & \mathrm{P}=0.000 & \\ \mathrm{H}=36.95 & \mathrm{DF}=3 & \mathrm{P}=0.000 & \text { (adjusted for ties) }\end{array}$

Response versus Risk Level ( $1=$ high/favorite, $4=$ low/least fav)

Kruskal-Wallis Test: Response versus R_Level

$\begin{array}{lrrrr}\text { Kruskal-Wallis } & \text { Test on Response } \\ \text { R_Level } & \mathrm{N} & \text { Median } & \text { Ave Rank } & \mathrm{Z} \\ \text { High } & 40 & 2.500 & 63.8 & 0.27 \\ \text { Moderate } & 44 & 2.000 & 60.2 & -0.52 \\ \text { Population } & 40 & 2.500 & 63.8 & 0.27 \\ \begin{array}{l}\text { Overall } \\ \text { M }\end{array} & 124 & & 62.5 & \\ \mathrm{H}=0.27 & \mathrm{DF}=2 & \mathrm{P}=0.873 & \\ \mathrm{H}=0.29 & \mathrm{DF}=2 & \mathrm{P}=0.865 & \text { (adjusted for ties) }\end{array}$

Appendix G.5.2 - Friedman Test

The Friedman Test confirmed the results of the Kruskal-Wallis test and showed significant difference between the three summary types for both sets of ranking.

Appendix G.5.2.1 - Friedman Test for Ranking 1 to 3

Friedman Test: Response versus Treatment blocked by Participant_Num

$\begin{array}{lrrr}\text { S }=35.35 & \text { DF }=2 \quad P=0.000 \\ & & \begin{array}{r}\text { Est } \\ \text { Treatment }\end{array} \text { Sum of } \\ \text { Summary A } & 34 & 3.000 & 92.0 \\ \text { Summary B } & 34 & 2.000 & 69.0 \\ \text { Summary C } & 34 & 1.000 & 43.0 \\ \text { Grand median }=2.000\end{array}$

Appendix G.5.2.2 - Friedman Test for Ranking 1 to 4

Friedman Test: Response versus Treatment blocked by Participant_Num

$$
\begin{aligned}
& S=28.19 \quad D F=3 \quad P=0.000 \\
& \mathrm{~S}=28.47 \mathrm{DF}=3 \mathrm{P}=0.000 \text { (adjusted for ties) } \\
& \text { Treatment } \mathrm{N} \text { Est Sum of } \\
& \text { No Summary } 313.000 \text { Ranks }
\end{aligned}
$$


Summary A $31 \quad 3.000$

100.5

Summary B $31 \quad 2.000$

76.5

Summary C $31 \quad 1.000$

48.0

Grand median $=2.250$ 